\title{
The Impact of Driving, Non-Driving Work, and Rest Breaks on Driving Performance in Commercial Motor Vehicle Operations
}

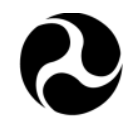

U.S. Department of Transportation

Federal Motor Carrier Safety Administration 


\section{FOREWORD}

The work performed under this project included a literature review of topics related to commercial motor vehicle driver fatigue (including topics of work hours, driving time, duty periods, and restart/recovery periods) published between 2006 and July 2010. The research also included an assessment of the tasks drivers perform in a typical workday. In addition, analyses were conducted to determine the impact of driving hours, work hours, and breaks on driving performance.

\section{NOTICE}

This document is disseminated under the sponsorship of the U.S. Department of Transportation in the interest of information exchange. The United States Government assumes no liability for its contents or the use thereof.

The contents of this Report reflect the views of the contractor, who is responsible for the accuracy of the data presented herein. The contents do not necessarily reflect the official policy of the Department of Transportation.

This Report does not constitute a standard, specification, or regulation.

The United States Government does not endorse products or manufacturers named herein. Trade or manufacturers' names appear herein only because they are considered essential to the objective of this document. 
TECHNICAL REPORT DOCUMENTATION PAGE

\begin{tabular}{|c|c|c|}
\hline $\begin{array}{l}\text { 1. Report No. } \\
\text { FMCSA-RRR-11-017 }\end{array}$ & 2. Government Accession No. & 3. Recipient's Catalog No. \\
\hline \multirow{2}{*}{\multicolumn{2}{|c|}{$\begin{array}{l}\text { 4. Title and Subtitle } \\
\text { The Impact of Driving, Non-Driving Work, and Rest Breaks on Driving } \\
\text { Performance in Commercial Motor Vehicle Operations }\end{array}$}} & $\begin{array}{l}\text { 5. Report Date } \\
\text { May } 2011\end{array}$ \\
\hline & & 6. Performing Organization Code \\
\hline \multicolumn{2}{|c|}{$\begin{array}{l}\text { 7. Author(s) } \\
\text { Myra Blanco, Richard J. Hanowski, Rebecca L. Olson, Justin F. Morgan, } \\
\text { Susan A. Soccolich, Shih-Ching Wu, Feng Guo }\end{array}$} & 8. Performing Organization Report No. \\
\hline \multirow{2}{*}{\multicolumn{2}{|c|}{$\begin{array}{l}\text { 9. Performing Organization Name and Address } \\
\text { The Center for Truck and Bus Safety } \\
\text { Virginia Tech Transportation Institute } \\
\text { 3500 Transportation Research Plaza (0536) } \\
\text { Blacksburg, VA 24061 }\end{array}$}} & 10. Work Unit No. (TRAIS) \\
\hline & & 11. Contract or Grant No. \\
\hline \multirow{3}{*}{\multicolumn{2}{|c|}{$\begin{array}{l}\text { 12. Sponsoring Agency Name and Address } \\
\text { U.S. Department of Transportation } \\
\text { Federal Motor Carrier Safety Administration } \\
\text { Office of Analysis, Research, and Technology } \\
1200 \text { New Jersey Ave. SE } \\
\text { Washington, DC } 20590\end{array}$}} & $\begin{array}{l}\text { 13. Type of Report and Period Covered } \\
\text { Final Report: June 2010-March } 2011\end{array}$ \\
\hline & & \\
\hline & & $\begin{array}{l}\text { 14. Sponsoring Agency Code } \\
\text { FMCSA }\end{array}$ \\
\hline
\end{tabular}

15. Supplementary Notes

Contracting Officer's Technical Representatives: Martin Walker and Theresa Hallquist

16. Abstract

Current hours-of-service (HOS) regulations prescribe limits to commercial motor vehicle (CMV) drivers' operating hours. Besides assessing activities performed in the 14-hour workday, the relationship between safety-critical events (SCEs) and driving hours, work hours, and breaks was investigated. The data used in the analyses were collected in the Naturalistic Truck Driving Study and included 97 drivers and about 735,000 miles of continuous driving data.

The assessment of the drivers' workday determined that, on average, drivers spent 66 percent of their shift driving, 23 percent in non-driving work, and 11 percent resting. Analyses on driving hours (i.e., driving only) and SCE risk found a time-on-task effect across hours. Analyses on work hours (i.e., driving in addition to non-driving work) found that risk of being involved in an SCE increased as work hours increased. This suggests that time-on-task effects may not be related to driving hours alone, but implies an interaction between driving hours and work hours: if a driver begins the day with several hours of non-driving work, followed by driving that goes deep into the 14hour workday, SCE risk was found to increase. The finding from the workday characterization that drivers spent approximately 23 percent of their workday performing non-driving work provides a possible explanation for this time-on-task effect across work hours. Breaks from driving were found to be beneficial in reducing SCEs (during 1hour window after a break) and were effective to counteract the negative effects of time-on-task.

\begin{tabular}{|c|c|c|c|c|}
\hline \multicolumn{2}{|c|}{$\begin{array}{l}\text { 17. Key Words } \\
\text { CMV, commercial motor vehicle, driving hours, } \\
\text { drowsiness, drowsy driving, fatigue, HOS, hours-of- } \\
\text { service, safety, work hours }\end{array}$} & \multicolumn{3}{|c|}{$\begin{array}{l}\text { 18. Distribution Statement } \\
\text { No restrictions }\end{array}$} \\
\hline $\begin{array}{l}\text { 19. Security Classif. (of this report) } \\
\text { Unclassified }\end{array}$ & $\begin{array}{l}\text { 20. Security } \mathrm{Cl} \\
\text { Unclassified }\end{array}$ & of this page) & \begin{tabular}{|c|} 
21. No. of Pages \\
$\mathbf{1 2 4}$
\end{tabular} & 22. Price \\
\hline
\end{tabular}

Form DOT F 1700.7 (8-72)

Reproduction of completed page authorized. 


\section{SI* (MODERN METRIC) CONVERSION FACTORS}

Table of APPROXIMATE CONVERSIONS TO SI UNITS

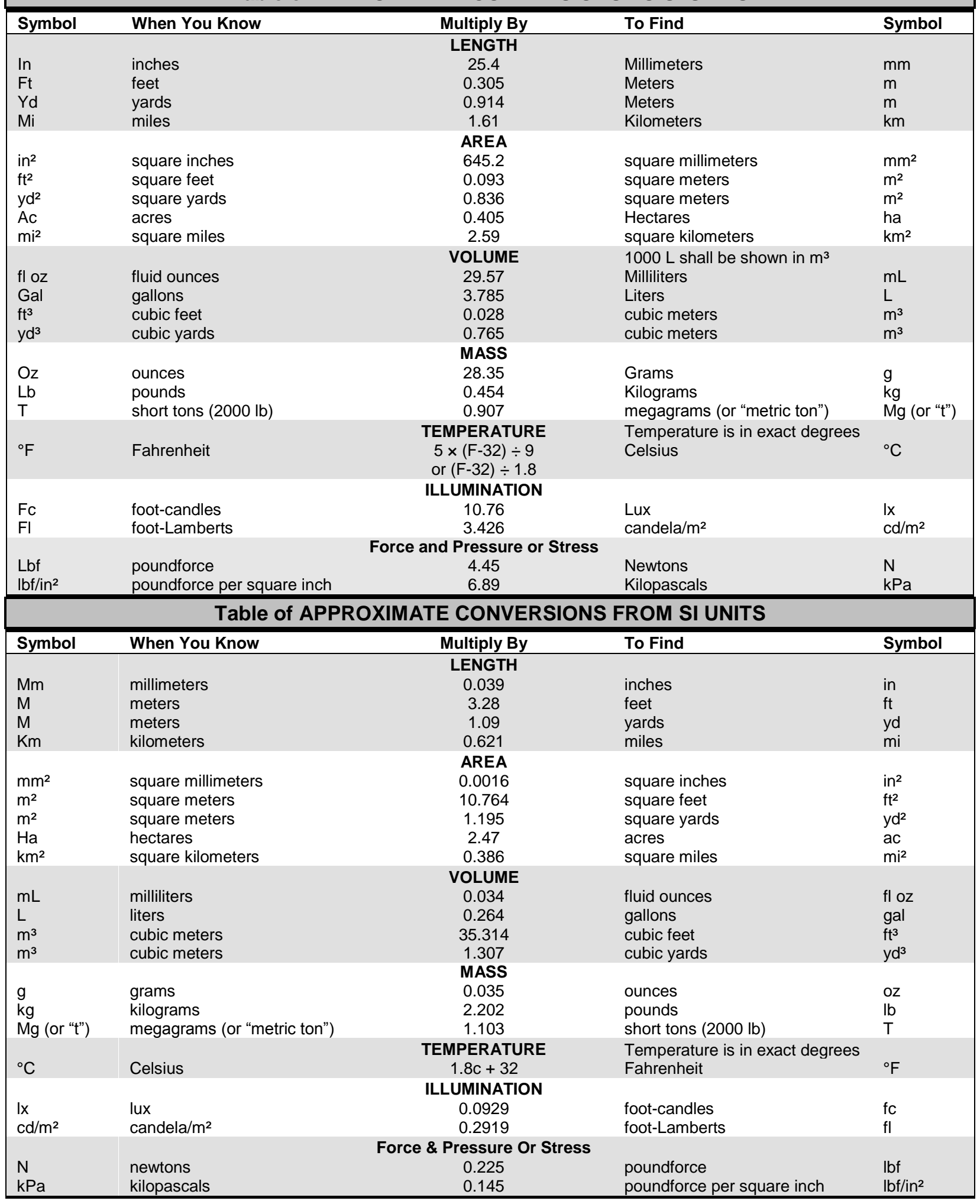

* $\mathrm{SI}$ is the symbol for the International System of Units. Appropriate rounding should be made to comply with Section 4 of ASTM E380. (Revised March 2003, Section 508-accessible version September 2009) 


\section{TABLE OF CONTENTS}

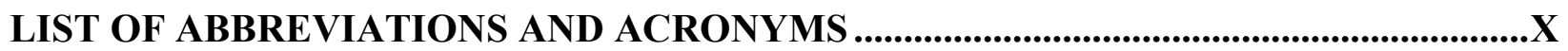

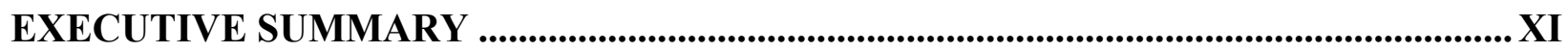

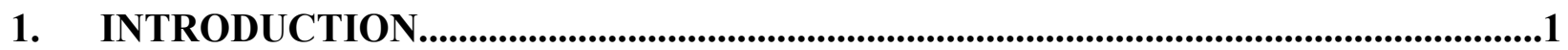

1.1 DEFINING THE PROBLEM .........................................................................

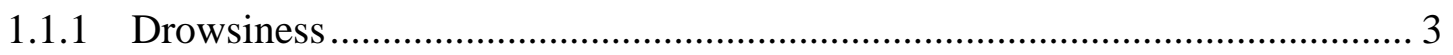

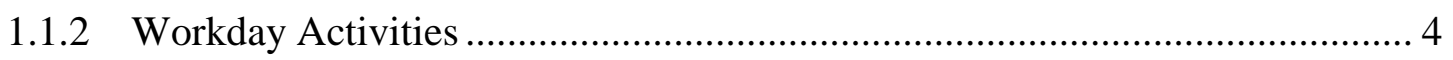

1.1.3 Driving Hour and Time-on-Task ........................................................... 5

1.1.4 Working Hours and Time-on-Task Findings From Other Domains ................. 8

1.2 PURPOSE OF THE CURRENT STUDY .........................................................

1.3 OVERVIEW OF THE CURRENT STUDY …................................................... 10

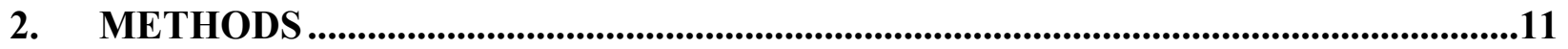

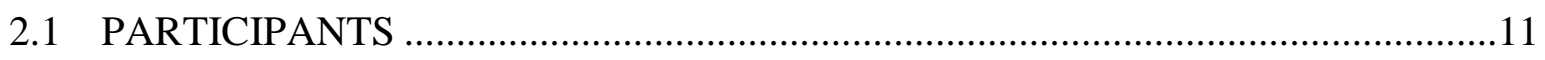

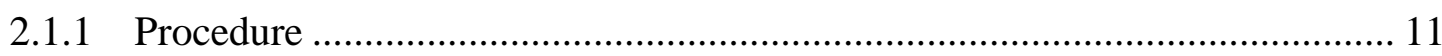

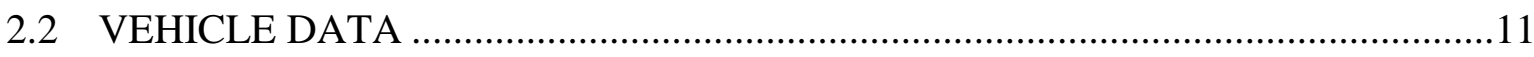

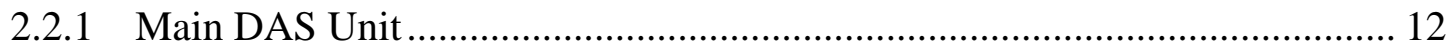

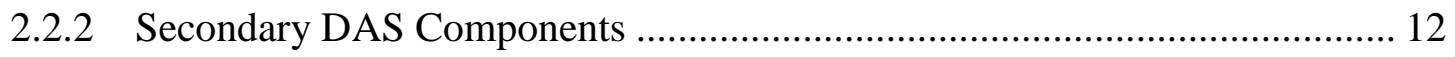

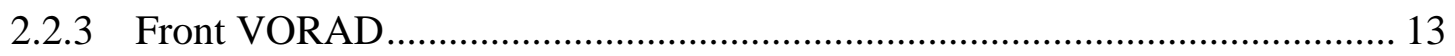

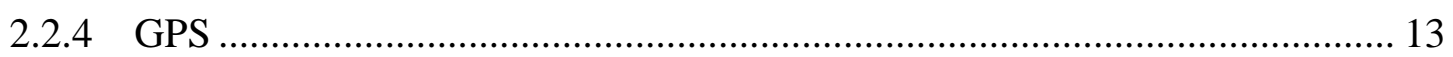

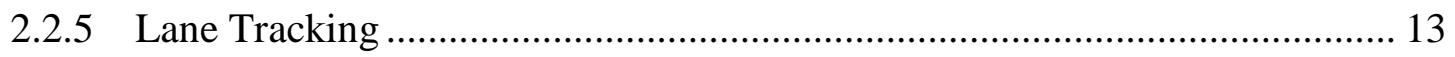

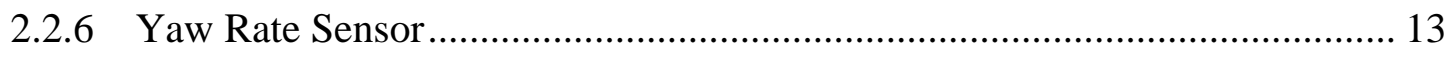

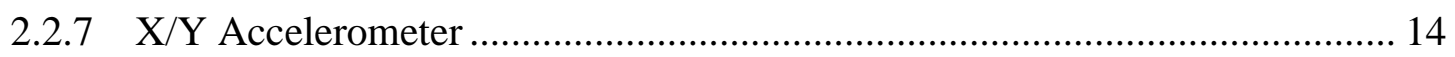

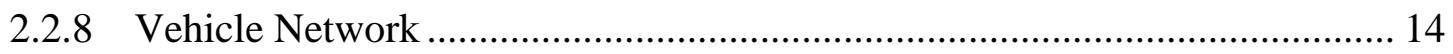

2.3 DRIVER PERFORMANCE MEASURES ...........................................................14

2.4 ACTIVITY REGISTER .............................................................................. 15

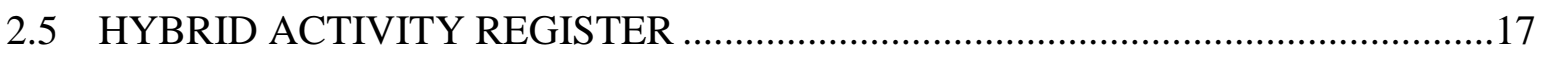

2.5.1 Generate Hybrid Activity Register Data ................................................... 17

2.5.2 Adjusting Activity Code for Time Periods Left Blank ................................. 19

2.5.3 Calculating Breaks from Driving and a Shift ........................................... 20

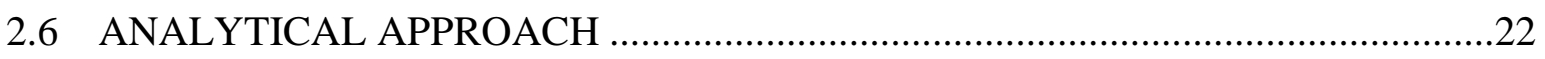

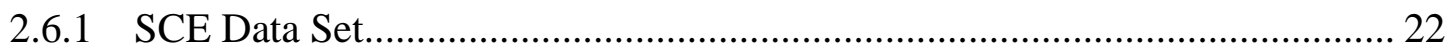

2.6.2 SCE as a Function of Driving Hour ........................................................ 22

2.6.3 SCE as a Function of Work Hour ........................................................... 23 
2.6.4 Safety Impact of Breaks from Driving................................................ 24

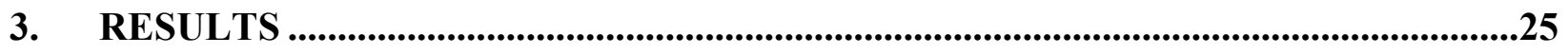

3.1 THE AVERAGE CMV DRIVER WORKDAY ................................................25

3.2 SAFETY-CRITICAL EVENTS AS A FUNCTION OF DRIVING HOUR ..............28

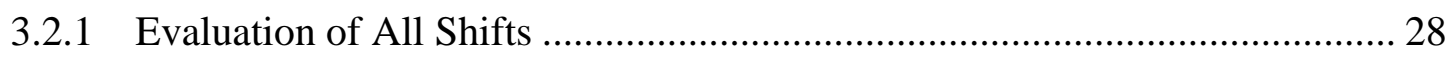

3.2.2 Evaluation of Only Shifts with 11 Driving Hours ...................................... 35

3.3 SAFETY-CRITICAL EVENTS AS A FUNCTION OF WORK HOUR .................42

3.3.1 Evaluation of All Shifts ......................................................................... 42

3.3.2 Evaluation of Only Shifts with 14 Working Hours ..................................... 54

3.4 SAFETY IMPACTS OF BREAKS FROM DRIVING …...................................64

3.4.1 Total Breaks Taken from Driving During a Shift ........................................ 65

3.4.2 Type of Break Taken from Driving During a Shift ...................................... 67

3.4.3 SCE Rate One Hour Before/After Breaks ............................................... 71

4. SUMMARY AND CONCLUSIONS .......................................................................75

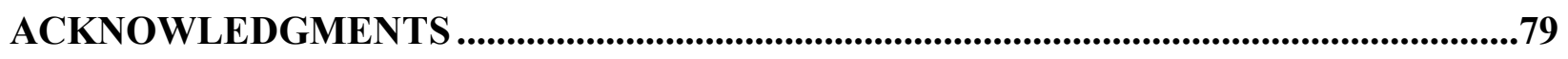

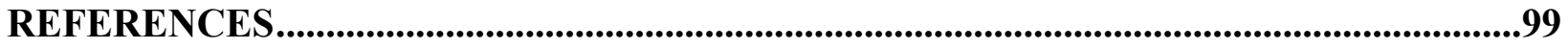




\section{LIST OF APPENDICES}

APPENDIX A—DRIVING HOUR ODDS RATIO TABLES ................................................81

APPENDIX B-DRIVING HOUR-WORK HOUR COMBINATION ODDS RATIOS

TABLES.................................................................................................................................... 


\section{LIST OF FIGURES AND FORMULAS}

Figure 1. Illustration. Daily Activity Register Used to Record Activities................................... xii

Figure 2. Bar Graph. Rate of SCE Occurrence as a Function of Driving Hour (Dichotomous Approach).....

Figure 3. Data Plot. Rate of SCE Occurrence as a Function of Work Hour Category for Shifts That Went Into the 14th Work Hour …………………........................................... xvi

Figure 4. Illustration. Line Graph Shows an Alertness Circadian Rhythm .....................................

Figure 5. Bar Graph. Reportable Crashes by Driving Hour ...........................................................6

Figure 6. Bar Graph. Use of Driving Hours 9-11 and the 34-Hour Restart ..................................

Figure 7. Photo. Five Camera Images Multiplexed Into a Single Image........................................12

Figure 8. Illustration. Daily Activity Register Sheet Used to Record Activities ............................16

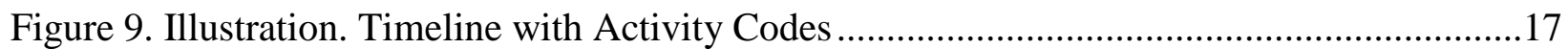

Figure 10. Flowchart. A Model of Current U.S. HOS Regulations.............................................21

Figure 11. Equation. Formula Used to Assess Probability of Having an SCE by Odds Ratio......23

Figure 12. Pie Chart. Proportion of Tasks Performed During an Average Workday for Local/Short Haul Drivers. (Adapted from Hanowski et al. 2000) ${ }^{(29)}$.............................25

Figure 13. Pie Chart. Proportion of Tasks Performed During an Average Workday, for All

Drivers in the Current Study …………………………..........................................26

Figure 14. Pie Chart. Proportion of Tasks Performed During an Average Workday, for Line-Haul

Drivers in the Current Study ......................................................................................2

Figure 15. Pie Chart. Proportion of Tasks Performed During an Average Workday, for Long-

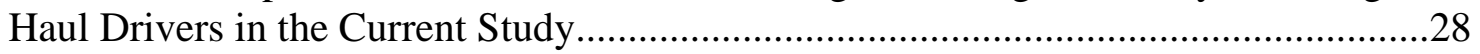

Figure 16. Bar Graph. Total Opportunities for Driving Hours 1-11 ……..................................30

Figure 17. Bar Graph. Rate of SCE Occurrence as a Function of Driving Hour............................30

Figure 18. Line Graph. Rate of SCE Occurrence as a Function of Driving Hour ...........................32

Figure 19. Rate of SCE Occurrence as a Function of Driving Hour, with Multiple Within-Hour

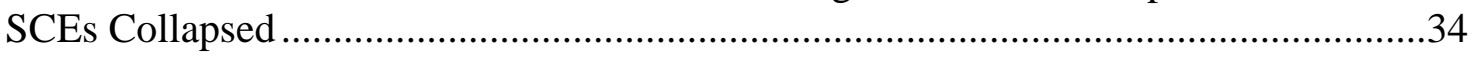

Figure 20. Bar Graph. Rate of SCE Occurrence as a Function of Driving Hour for Shifts That

Went Into the 11th Driving Hour ....................................................................................

Figure 21. Bar Graph. Rate of SCE Occurrence as a Function of Driving Hour for Shifts That Went Into the 11th Driving hour. Four Driver Outliers Have Been Removed from the

Data Set.....

Figure 22. Bar Graph. Rate of SCE Occurrence as a Function of Driving Hour, with Multiple Within-Hour SCEs Collapsed, for Shifts That Went Into the 11th Driving Hour ..........39

Figure 23. Scatter Plot. Rate of SCE Occurrence as a Function of Driving Hour, with Multiple

Within-Hour SCEs Collapsed, for Shifts That Went Into the 11th Driving Hour .........40

Figure 24. Scatter Plot. Rate of SCE Occurrence as a Function of Driving Hour for Shifts That

Went Into the 11th Driving Hour................................................................................. 41

Figure 25. Bar Graph. Total Opportunities as a Function of Driving Hour and Work Hour. .......44

Figure 26. Bar Graph. Rate of SCE Occurrence as a Function of Driving Hour and Beginning

Work Hours (Hours 1-5)..........................................................................................45 
Figure 27. Bar Graph. Rate of SCE Occurrence as a Function of Driving Hour and Middle Work Hours (Hours 6-9)

Figure 28. Bar Graph. Rate of SCE Occurrence as a Function of Driving Hour and End Work

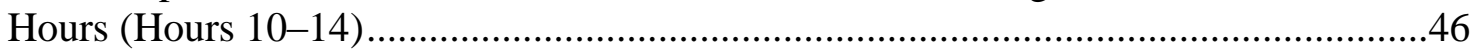

Figure 29. Bar Graph. Rate of SCE Occurrence as a Function of Driving Hour and Work Hour 47

Figure 30. Bar Graph. Rate of SCE Occurrence as a Function of Driving Hour and Beginning

Work Hours (Hours 1-5), with Multiple Within-Hour SCEs Collapsed ........................49

Figure 31. Bar Graph. Rate of SCE Occurrence as a Function of Driving Hour and Middle Work

Hours (Hours 6-9), with Multiple Within-Hour SCEs collapsed

Figure 32. Bar Graph. Rate of SCE Occurrence as a Function of Driving Hour and End Work

Hours (Hours 10-14), with Multiple Within-Hour SCEs Collapsed .50

Figure 33. Bar Graph. Rate of SCE Occurrence as a Function of Driving Hour and Work Hour, with Multiple Within-Hour SCEs Collapsed

Figure 34. Bar Graph. Rate of SCE Occurrence as a Function of Driving Hour and Beginning Work Hours (Hours 1-5), for Shifts That Went Into the 14th Work Hour ....................56

Figure 35. Bar Graph. Rate of SCE Occurrence as a Function of Driving Hour and Middle Work Hours (Hours 6-9), for Shifts That Went Into the 14th Work Hour .56

Figure 36. Bar Graph. Rate of SCE Occurrence as a Function of Driving Hour and End Work Hours (Hours 10-14), for Shifts That Went Into the 14th Work Hour.

Figure 37. Bar Graph. Rate of SCE Occurrence as a Function of Driving Hour and Work Hour, for Shifts That Went Into the 14th Work Hour .58

Figure 38. Bar Graph. Rate of SCE Occurrence as a Function of Driving Hour and Beginning Work Hours (Hours 1-5) (Dichotomous Approach), with Multiple Within-Hour SCEs Collapsed, for Shifts That Went Into the 14th Work Hour....

Figure 39. Bar Graph. Rate of SCE Occurrence as a function of Driving Hour and Middle Work Hours (Hours 6-9) (Dichotomous Approach), with Multiple Within-Hour SCEs Collapsed, for Shifts That Went Into the 14th Work Hour... .60

Figure 40. Bar Graph. Rate of SCE Occurrence as a Function of Driving Hour and End Work Hours (Hours 10-14) (Dichotomous Approach), with Multiple Within-Hour SCEs Collapsed, for Shifts That Went Into the 14th Work Hour ...

Figure 41. Bar Graph. Rate of SCE Occurrence as a Function of Driving Hour and Work Hour (Dichotomous Approach), with Multiple Within-Hour SCEs Collapsed, for Shifts That

Went Into the 14th Work Hour .62

Figure 42. Data Plot. Rate of SCE Occurrence as a Function of Work Hour Category for Shifts

That Went Into the 14th Work Hour .63

Figure 43. Bar Graph. Number of Shifts That Included Breaks From Driving ............................68

Figure 44. Bar Graph. Driving Hour in Which Break Begins ........................................................68

Figure 45. Box Plot. Total Duration of Breaks by Break Type 


\section{LIST OF TABLES}

Table 1. Comparing Individual Driving Hours for Differences in SCE Rates ........................ xiv

Table 2. Taxonomy of Break-From-Driving Types.......................................................... xvii

Table 3. Distribution of Drivers and Shifts by Break Duration .............................................. xvii

Table 4. SCE Rate Before/After: All Break Types................................................................ xviii

Table 5. Summary of the HOS Regulations from 1940 to the Present .........................................

Table 6. HOS Regulations in Major Industrialized Nations ......................................................... 3

Table 7. Trigger Types Used to Identify SCEs ................................................................. 15

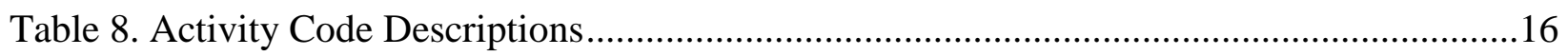

Table 9. Explanation of Time, Duration, and Activities in Figure 7 ........................................17

Table 10. $2 \times 2$ Contingency Table Used to Calculate Odds Ratio .............................................22

Table 11. SCEs and Total Opportunities by Driving Hour for Hours 1-11 ..............................29

Table 12. SCE Rate as a Function of Driving Hour as a Continuous Variable, using Total Opportunities for Driving Hours 1-11 .................................................................31

Table 13. SCE Rate as a Function of Driving Hour as a Discrete Variable, using Total Opportunities for Driving Hours $1-11$................................................................ 31

Table 14. Comparing Individual Driving Hours for Differences in SCE Rates ...........................32

Table 15. SCEs and Total Opportunities by Driving Hour for Hours 1-11, with Multiple Within-

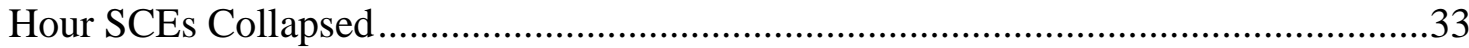

Table 16. SCEs and Total Shifts by Driving Hour for Hours 1-11, with Multiple Within-Hour SCEs Collapsed —-Data Used to Calculate Odds Ratios ............................................34

Table 17. Results from the Odds Ratio Analyses ...................................................................35

Table 18. SCEs and Total Opportunities by Driving Hour for Hours 1-11, for Shifts That Went

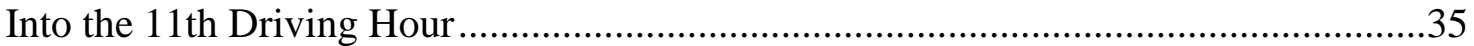

Table 19. NB Model: Pair-Wise SCE Rate Comparison of Driving Hour 11 to Hours 8, 9, and 1036

Table 20. SCEs and Total Opportunities by Driving Hour for Hours 1-11, for Shifts That Went Into the 11th Driving Hour; Four Driver Outliers were Removed from the Data Set ...37

Table 21. SCEs and Total Opportunities by Driving Hour for Hours 1-11, with Multiple WithinHour SCEs Collapsed, for Shifts that Went into the 11th Driving Hour ......................38

Table 22. SCEs and Total Shifts by Driving Hour for Hours 1-11, with Multiple Within-Hour SCEs Collapsed, for Shifts That Went Into the 11th Driving Hour-Data Used to Calculate Odds Ratios .39

Table 23. Results from the Odds Ratio Analyses .40

Table 24. Linear Regression Model for Rate of SCE Occurrence as a Function of Driving Hour, with Multiple Within-Hour SCEs Collapsed, for Shifts That Went Into the 11th Driving Hour.

Table 25. Linear Regression Model for Rate of SCE Occurrence as a Function of Driving Hour for Shifts That Went Into the 11th Driving Hour ................................................... 41

Table 26. SCEs and Total Opportunities for Driving Hours 1-11 and Work Hours 1-14...........43 
Table 27. SCEs and Total Opportunities for Driving Hours 1-11 and Work Hours 1-14, with Multiple Within-Hour SCEs Collapsed.....

Table 28. SCEs and Total Shifts for Driving Hours 1-11 and Work Hours 1-14, with Multiple Within-Hour SCEs Collapsed-Data Used to Calculate Odds Ratios. .52

Table 29. Significant Results from the Odds Ratio Analysis with Multiple Within-Hour SCEs Collapsed.

Table 30. SCEs and Total Opportunities for Driving Hours 1-11 and Work Hour Categories Beginning, Middle, and End, for Shifts That Went Into the 14th Work Hour... .55

Table 31. SCEs and Total Opportunities for Driving Hours 1-11 and Work Hours 1-14, with Multiple Within-Hour SCEs Collapsed (Dichotomous Approach), for Shifts That Went Into the 14th Work Hour .... .59

Table 32. Significant Results from the Odds Ratio Analysis with Multiple Within-Hour SCEs Collapsed (Dichotomous Approach), for Shifts That Went Into the 14th Working Hour64

Table 33. Taxonomy of Break-From-Driving Types .65

Table 34. Mean SCE Rate by Number of Breaks from Driving. .65

Table 35. Safety Impact of Number of Breaks from Driving, Working Hours, and Driving Hours66

Table 36. Safety Impact of Total Number of Breaks from Driving: NB Model Results. .67

Table 37. Distribution of Drivers and Shifts by Break Duration ................................................70

Table 38. Distribution of Drivers and Shifts by Break Duration, Alternative Bin Sizes..............70

Table 39. Safety Impacts of Number of Breaks by Type: NB Model Results............................71

Table 40. SCE Rate Before/After: All Break Types..............................................................72

Table 41. NB Model: Change (Before-After) by Break Types ..............................................73

Table 42. Results from the Odds Ratio Analysis with Multiple Within-Hour SCEs Collapsed (Dichotomous Approach), for All Shifts.

Table 43. Results from the Odds Ratio Analysis with Multiple Within-Hour SCEs Collapsed (Dichotomous Approach), for Shifts That Went Into the 11th Driving Hour....

Table 44. Results from the Odds Ratio Analysis for the Beginning Work Hours (Hours 1-5) with Multiple Within-Hour SCEs Collapsed (Dichotomous Approach), for All Shifts ........85

Table 45. Results from the Odds Ratio Analysis for the Middle Work Hours (Hours 6-9) with Multiple Within-Hour SCEs Collapsed (Dichotomous Approach), for All Shifts .......86

Table 46. Results from the Odds Ratio Analysis for the End Work Hours (Hours 10-14) with Multiple Within-Hour SCEs Collapsed (Dichotomous Approach), for All Shifts ........88

Table 47. Results from the Odds Ratio Analysis for the Beginning Work Hours (Hours 1-5) with Multiple Within-Hour SCEs Collapsed (Dichotomous Approach), for Shifts That Went Into the 14th Working Hour

Table 48. Results from the Odds Ratio Analysis for the Middle Work Hours (Hours 6-9) with Multiple Within-Hour SCEs Collapsed (Dichotomous Approach), for Shifts That Went Into the 14th Working Hour

Table 49. Results from the Odds Ratio Analysis for the End Work Hours (Hours 10-14) with Multiple Within-Hour SCEs (Dichotomous Approach), for Shifts That Went Into the 14th Working Hour 


\section{LIST OF ABBREVIATIONS AND ACRONYMS}

$\begin{array}{ll}\text { ATRI } & \text { American Transportation Research Institute } \\ \text { CMV } & \text { commercial motor vehicle } \\ \text { DAS } & \text { data acquisition system } \\ \text { EU } & \text { European Union } \\ \text { FMCSA } & \text { Federal Motor Carrier Safety Administration } \\ \text { HOS } & \text { hours of service } \\ \text { LCL } & \text { lower confidence limit } \\ \text { L/SH } & \text { local/short haul } \\ \text { LTCCS } & \text { Large Truck Crash Causation Study } \\ \text { LTL } & \text { less than truckload } \\ \text { NB } & \text { negative binomial } \\ \text { NSF } & \text { National Sleep Foundation } \\ \text { NTDS } & \text { Naturalistic Truck Driving Study } \\ \text { PC } & \text { personal computer } \\ \text { SCE } & \text { safety-critical event } \\ \text { TL } & \text { truckload } \\ \text { UCL } & \text { upper confidence limit } \\ \text { USDOT } & \text { United States Department of Transportation } \\ \text { VMT } & \text { vehicle miles of travel } \\ \text { VTTI } & \text { Virginia Tech Transportation Institute } \\ & \end{array}$




\section{EXECUTIVE SUMMARY}

This study, sponsored by the Federal Motor Carrier Safety Administration (FMCSA), was directed at analyzing several issues regarding the commercial motor vehicle (CMV) hours-ofservice (HOS) regulations. Topics including driving hours, work hours, and breaks as a function of time-on-task have not been well explored in the published literature. The present study focused on four key issues relevant to the HOS regulations:

- Workday Characterization: What activities comprise an average workday for long-haul and line-haul drivers?

- Driving Hour: What is the impact of time-on-task on the risk of safety-critical events (SCEs) as a function of driving hour? Specifically, and critical to increasing the knowledge base on the HOS regulations, is there a significant increase in risk associated with the 11th hour of driving?

- Work Hour: What is the impact of time-on-task on the risk of SCEs as a function of work hour? This is a topic that has not been previously studied.

- Breaks: What is the impact of time-on-task on the risk of SCEs as a function of breaks from the driving task? Are breaks from driving used to perform other work-related tasks impacting SCEs in a similar manner as breaks to rest?

\section{METHODS}

\section{Participants}

Data collection took place from November 2005 to March 2007. A total of 100 drivers were involved in the study. However, 3 drivers were removed due to missing data that were necessary for analyses (e.g., activity register data, to be described later). This left 97 drivers for analyses. Of these 97 drivers, 96 provided demographic information. Of the 96 drivers that provided demographic information, 91 were male and 5 were female. The average age was 44 years old (range: 21-73 years), and the drivers had an average of 9.13 years' experience driving CMVs (range: 4 weeks to 54 years). Four for-hire trucking companies participated in the study. Longhaul and line-haul operations were both represented-75 drivers were primarily long-haul and 21 drivers were primarily line-haul. Presently, as well as at the time of data collection, two of the carriers were ranked in the 'Top 100 For-Hire Carriers. ${ }^{(1)}$ The two smaller companies had a total of approximately 180 employed drivers. As with any study that uses volunteers, the drivers may not be representative of the entire population of commercial drivers.

\section{Procedure}

A naturalistic-data-collection approach was used (i.e., data were collected as study participants drove instrumented company trucks during their normal revenue-producing runs). Each driver drove an instrumented truck for approximately 4 weeks. The final project data set consisted of approximately 735,000 miles of driving data. 
Nine trucks were fitted with unobtrusive data-collection equipment consisting of a data acquisition system (DAS), sensors to measure driver performance, and video cameras that recorded the driver's face, steering wheel, and three views outside of the truck.

\section{Driver Performance Measures}

Driver performance was assessed through the occurrence of SCEs: crashes, near-crashes, and crash-relevant conflicts, as well as unintentional lane deviations. In any examination of transportation safety, the most important variables are crashes and similar serious events such as near-crashes. However, less severe events, such as crash-relevant conflicts and unintentional lane deviations, also present important information for analyses. For example, lane deviations have been used in previous HOS research and have been shown to be a valid measure of performance degradation and fatigue. ${ }^{(2)}$ Additionally, unintentional lane deviations represent "driver errors." While much less serious than crashes, these may reflect potential time-on-task issues. It should be noted that unintentional lane deviations were not used in the previous Hanowski et al., ${ }^{(3)}$ data set. Therefore, the data set used in the current study had a larger number of SCEs available for analysis.

\section{Activity Register}

In addition to vehicle data, each participant was asked to fill out a daily activity register (including both on-duty and off-duty periods) for the entire 4 weeks he or she participated in the study. A sample page of the activity register is shown in Figure 1.

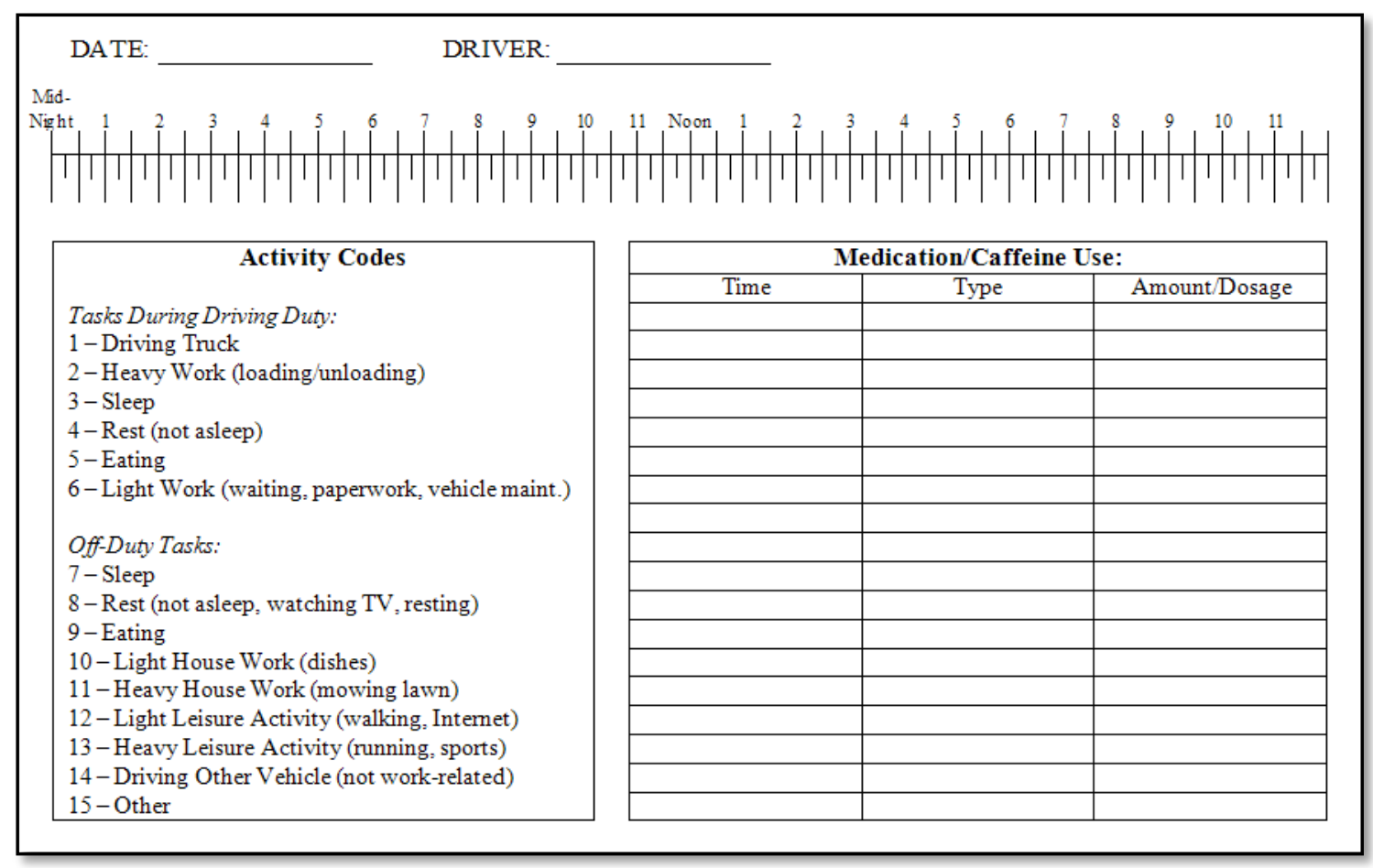

Figure 1. Illustration. Daily Activity Register Used to Record Activities

The top of the daily activity register included a 24-hour timeline which began at midnight and ended at 11:59 p.m., with 15-minute increments. Participants were instructed to choose one of 
the 15 activity codes listed on the left side of the register and write down the chosen code on the timeline.

\section{Hybrid Activity Register}

In order to calculate the drivers' work hours for a shift, it was necessary to use the data from the activity register to determine what the drivers were doing when they were not driving the truck. Therefore, the activity register data and the vehicle's time-stamped data were combined to form a single data set that included both driving and non-driving activities. An exposure measure using each driver's participation time was also calculated for the analysis. The combined data set was used for all of the analyses described in this report.

\section{KEY RESULTS}

The four main topics examined were:

- Assessment of CMV drivers' workday.

- SCEs as a function of driving hour.

- SCEs as a function of work hour.

- Safety impact of breaks from driving.

Descriptive statistics, odds ratios, and negative binomial (NB) regression models were the statistical techniques used to analyze the data.

\section{Driver Workday}

The activity register data provided a detailed account of the tasks that CMV drivers performed during their workday. Using the activity data from the current study, for all drivers, the makeup of an "average" workday was determined.

The long-haul and line-haul drivers spent most of their workday driving, (65.7 percent). The drivers spent another 22.8 percent of their day performing non-driving work activities, such as paperwork or loading/unloading. The remaining 11.5 percent of the drivers workday was spent resting, eating, or sleeping. It may be somewhat surprising that the CMV drivers' workday efforts were much more diverse than simply driving.

\section{Driving Hours}

In the current U.S. regulations, drivers are restricted to 11 driving hours during a 14-hour workday. The focus of this analysis was on the driving-hour component of the HOS regulations. The purpose of the first analysis was to investigate if there were significant differences in the rate of being involved in an SCE, as a function of driving hour. That is, does the 11th hour of driving present a higher rate of SCEs compared to the 10th hour or any other driving hour?

Several subanalyses were conducted to investigate the safety impact associated with driving hours. The primary analysis treated driving hour as a continuous variable, and used a mixedeffect NB regression model to assess the impact of driving hour on SCE rate. The results of the 
NB model show a statistically significant effect for driving hour ( $\left.p_{\text {Driving Hour }}=0.0014\right)$. Though this significant result indicates a difference across hours, it does not indicate which specific hours are different. As such, follow-up pair-wise analyses were conducted to determine which specific hours were significantly different. The focus of the pair-wise comparisons were on the 11th driving hour to driving hours 1-10; the analyses used a mixed-effect NB regression model and treated driving hour as a discrete variable (Table 1).

Table 1. Comparing Individual Driving Hours for Differences in SCE Rates

\begin{tabular}{|c|c|c|c|c|c|}
\hline Contrast Between Driving Hours & Estimate & $\boldsymbol{P}$ & $\boldsymbol{\alpha}$ & LCL & UCL \\
\hline 11 versus 1 & 0.4684 & 0.0202 & 0.05 & 0.0730 & 0.8638 \\
\hline 11 versus 2 & 0.4839 & 0.0162 & 0.05 & 0.0896 & 0.8782 \\
\hline 11 versus 3 & 0.3912 & 0.0515 & 0.05 & -0.0026 & 0.7851 \\
\hline 11 versus 4 & 0.3367 & 0.0932 & 0.05 & -0.0564 & 0.7298 \\
\hline 11 versus 5 & 0.3050 & 0.1313 & 0.05 & -0.0912 & 0.7012 \\
\hline 11 versus 6 & 0.1831 & 0.3635 & 0.05 & -0.2119 & 0.5781 \\
\hline 11 versus 7 & 0.0459 & 0.8213 & 0.05 & -0.3524 & 0.4442 \\
\hline 11 versus 8 & 0.2619 & 0.2149 & 0.05 & -0.1520 & 0.6757 \\
\hline 11 versus 9 & 0.4221 & 0.0550 & 0.05 & -0.0091 & 0.8533 \\
\hline 11 versus 10 & 0.2378 & 0.3005 & 0.05 & -0.2124 & 0.6881 \\
\hline
\end{tabular}

The results from this analysis showed a statistically significant increase in SCE rate when comparing the 11th driving hour to the $1 \mathrm{st}(p=0.020)$ and 2 nd $(p=0.016)$ driving hours, but not when comparing to the 11 th driving hour to the 10th driving hour $(p=0.300)$. The significant effect for the comparison of the 11th driving hour to the 1st and 2nd driving hours is different than found previously by Hanowski et al., ${ }^{(3)}$ which found that the 1 st driving hour had a significantly higher SCE rate when compared to driving hours 2-10. However, the non-effect of the comparison between the 10th driving hour and the 11th driving hour is consistent with the previous Hanowski et al., study.

A second analysis examined every shift, regardless of shift duration, and accounted for shift duration in the analysis. In this analysis, a dichotomous approach was taken: for each driving hour for a given driver and shift, it was determined if an SCE occurred. If multiple SCEs occurred within a single hour for a given driver on a given shift, it was considered to be one SCE for that hour. While other methods of analysis were conducted (discussed in detail later in the report), this method provides a controlled approach for assessing the impact of driving hour across all hours of a shift, thereby identifying effects specific to driving hour. Figure 2 shows the plot of the SCE rate data. 


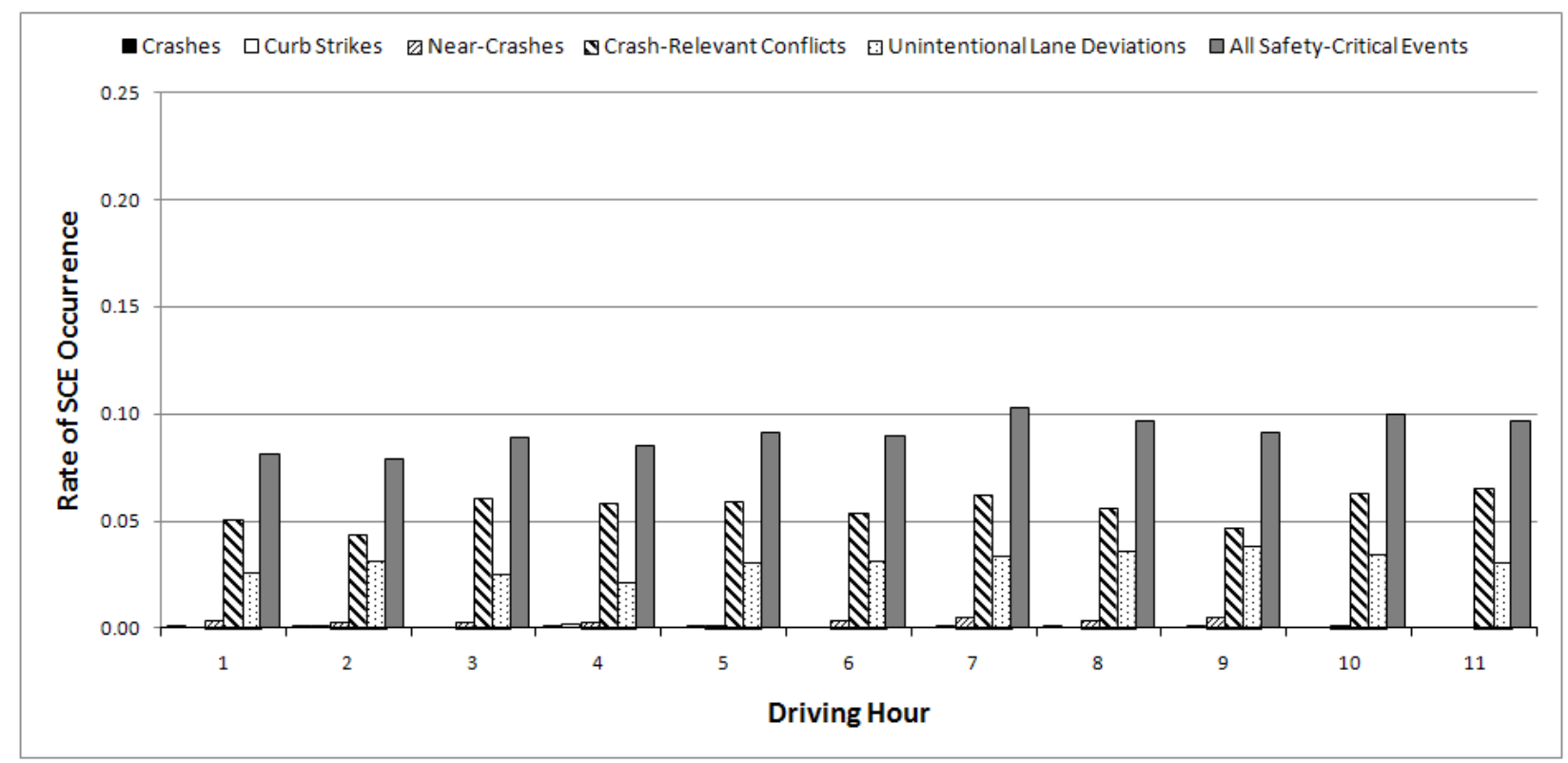

Figure 2. Bar Graph. Rate of SCE Occurrence as a Function of Driving Hour (Dichotomous Approach)

The results of this analysis found no statistically significant effect for the 11th driving hour. In particular, and of primary interest for this study, the 11th driving hour did not present an increase in risk of SCE occurrence as compared to the 8th, 9th, or 10th driving hours.

\section{Work Hours}

Following a similar method to the one used to analyze driving hours, a dichotomous approach was used to analyze work hours. For this analysis, SCEs were grouped by driving hour (similar to the previous analysis) and each driving hour was classified based on when it occurred during the 14-hour workday. For example, consider a driver who performs 2 hours of non-driving work (e.g., paperwork) at the start of a shift, followed by 3 hours of driving (i.e., the 1st driving hour began in the 3rd working hour, the 2 nd driving hour began in the 4th working hour, and the 3rd driving hour began in the 5 th working hour). Consider a second driver who starts his shift by driving for 3 hours, followed by a 2-hour break to eat (i.e., the 1st driving hour coincided with the 1st working hour, and so on). After his 2-hour break is finished, this driver, like the driver in the first example, would be 5 hours into his 14-hour workday. In both examples, the drivers have completed 3 hours of driving within 5 hours of the workday. However the driving hour-work hour combinations are different. For the driver in the first example, the driving hour-work hour combinations are: 1-3, 2-4, and 3-5 while the combinations for the second driver are: 1-1, 2-2, and 3-3.

There were 99 different driving hour-work hour combinations in the current data set, many of which had a very small sample size such that it was not possible to analyze every combination independently. Therefore, the 14-hour workday was divided into three categories: Beginning (work hours 1-5), Middle (work hours 6-9), and End (work hours 10-14). Translating this work hour grouping strategy from individual work hours, the combination 'driving hour 1/work hour 1' (i.e., a driver started the workday by driving 1 hour) would be 'driving hour 1/work hour Beginning.' The combination 'driving hour 1/work hour 10' (i.e., the driver did not start driving 
until the 10th hour of his shift) would be 'driving hour 1/work hour End.' Therefore, the work hour categories Beginning, Middle, and End can be thought of as intervals within the 14-hour workday that the driver was driving. The three work hour categories reduced the number of driving hour-work hour combinations. This resulted in a larger sample size for each driving hour-work hour combination and provided the opportunity to analyze whether the SCE rate per driving hour changed depending on which segment of the workday the driving hour occurred.

An analysis was conducted to compare the three work-hour categories, independent of driving hour. The rate of SCE occurrence is plotted in Figure 3 solely as a function of the work hour category (collapsing over driving hour). Each point on the plot represents a driving hour/workhour SCE rate. The results of a simple linear regression analysis indicated that as the work hour increases from Beginning to End, the SCE rate increases, demonstrated by the trend line shown in Figure 3 (Pearson correlation coefficient of 0.41). A positive Pearson correlation coefficient indicates that the $\mathrm{x}$-axis and $\mathrm{y}$-axis variables grow together.

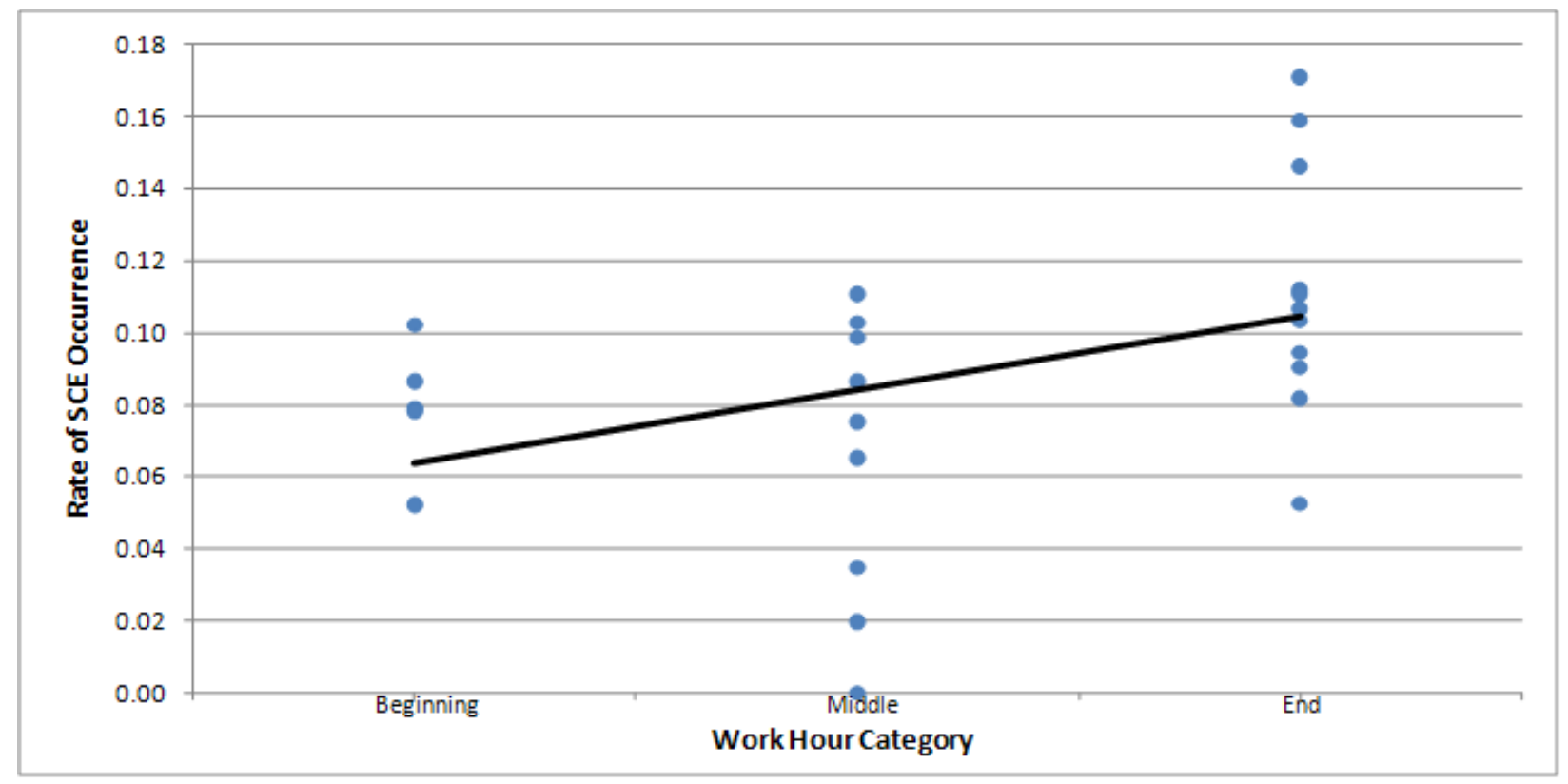

Figure 3. Data Plot. Rate of SCE Occurrence as a Function of Work Hour Category for Shifts That

A key take-away from the above analyses, as well as other analyses discussed in the report, is that the risk of being involved in an SCE generally increases as the work hour increases. That is, driving time occurring later in the driver's workday due to performing non-driving tasks earlier in the workday, has a negative safety effect. Therefore, though driving hour, in and of itself, may not show an increase in risk when comparing the 10th and 11th driving hours, the combination of driving hour/work hour does show negative time-on-task effects for late driving hours. These results suggest that perhaps the important question is not whether drivers should be allowed to drive 10 or 11 hours, but rather: what are the safety implications of a 14-hour workday? That is, though driving for 11 hours was not shown to increase the risk of an SCE as compared to the 10th driving hour, if drivers drove deep into their 14-hour shift, SCE risk increased. 


\section{Breaks from Driving}

The results from the work hour analysis suggest that performing non-driving tasks prior to the start of driving (at the beginning of a driver's shift), which leads to driving late into the 14-hour shift, may have an adverse effect on the driving task. Breaks may be considered a countermeasure for the negative time-on-task effects observed in the work-hour analysis.

Not all breaks from driving are similar. As noted in the workday characterization, drivers performed other tasks in addition to the driving task (i.e., light/heavy work, and rest). Breaks were grouped into four categories: rest during duty period, work during duty period, rest during duty period/off duty, and off duty (Table 2). Note that breaks analyzed were those that occurred during the workday and not shift (e.g., 10 hours) or restart (e.g., 34 hours) breaks.

Table 2. Taxonomy of Break-From-Driving Types

\begin{tabular}{|l|l|}
\hline Break Type & \multicolumn{1}{|c|}{ Description } \\
\hline $\begin{array}{l}\text { Type 1-Rest During Duty } \\
\text { Period. }\end{array}$ & $\begin{array}{l}\text { Any consecutive duration of rest activities during the duty } \\
\text { period (e.g., sleep, eat). }\end{array}$ \\
\hline $\begin{array}{l}\text { Type 2-Work During Duty } \\
\text { Period. }\end{array}$ & $\begin{array}{l}\text { Any consecutive duration of work (e.g., light work, heavy } \\
\text { work). }\end{array}$ \\
\hline $\begin{array}{l}\text { Type 3-Rest During Duty } \\
\text { Period/Off Duty. }\end{array}$ & $\begin{array}{l}\text { Any combination of consecutive duration of rest activities } \\
\text { during a duty period (Break 1) and off-duty activity (Break 4). }\end{array}$ \\
\hline Type 4-Off Duty. & $\begin{array}{l}\text { Any consecutive duration of off-duty activity (e.g., leisure- } \\
\text { related activities). }\end{array}$ \\
\hline
\end{tabular}

Table 3 details the distribution of drivers and shifts across various break durations: 5 minutes or longer, 30 minutes or longer, and 1 hour or longer. "All Breaks" refers to any of the four break types shown in the table above, while "Rest Breaks" refers to break types 1, 3, and 4. Each driver had at least one break of 5 minutes or longer, with nearly 85 percent of shifts including a break of 5 minutes or longer. Although this very brief break duration was not further analyzed, it does demonstrate that many drivers are, in fact, pulling off the road for non-driving breaks at some point during their workday. Every driver also took a break of 30 minutes or longer at some point during their study participation, with almost 80 percent of shifts including a 30 minute or longer break. In general, rest breaks were far less common. Most drivers took rest breaks as part of the sleeper berth provision or in a 10-hour rest period to be able to start a new working window.

Table 3. Distribution of Drivers and Shifts by Break Duration

\begin{tabular}{|l|r|r|r|r|}
\hline Break Duration & $\begin{array}{c}\text { All Breaks, } \\
\text { Drivers }(\boldsymbol{n}, \%)\end{array}$ & $\begin{array}{c}\text { All Breaks, } \\
\text { Shifts }(\boldsymbol{n}, \%)\end{array}$ & $\begin{array}{c}\text { Rest Breaks, } \\
\text { Drivers }(\boldsymbol{n}, \%)\end{array}$ & $\begin{array}{c}\text { Rest Breaks, } \\
\text { Shifts }(\boldsymbol{n}, \%)\end{array}$ \\
\hline 5 min or longer & $97(100)$ & $1,594(84.7)$ & $89(91.8)$ & $801(42.6)$ \\
\hline 30 min or longer & $97(100)$ & $1,476(78.5)$ & $84(86.6)$ & $699(37.2)$ \\
\hline 1 hour or longer & $96(99)$ & $984(52.3)$ & $76(78.4)$ & $406(21.6)$ \\
\hline
\end{tabular}

The next analysis examined the rate of SCE occurrence during the time period of 1 hour before and 1 hour after a break from driving. The safety benefit of breaks was evaluated by comparing 
the SCE rate between these two time periods. The relationship between various break types and the SCE rates was thus explored in this analysis. Because the before period was used as a baseline, potential confounding factors associated with driver or shift characteristics-including environmental factors (e.g., road type, weather) and driver factors (e.g., previous night's sleep, previous shift work) - were somewhat controlled. Therefore, while not a direct cause-and-effect examination, the effects from this analysis could be attributed more directly to driving breaks. The analysis was performed considering all breaks as well as individual break types.

There were 3,171 breaks (of 30 minutes or longer) in the data used for this analysis.

Table 4 presents a comparison of SCE rates during the 1-hour window occurring both before and after a break. It should be noted that because multiple break types could make up a single break, the summation of break frequency by types can be more than the total number of breaks. As shown in Table 4, the SCE rate for the 1-hour window after a break is consistently lower than the before period, regardless of the break type.

The magnitude of the decrease in SCE rate ranges from 30 percent to more than 50 percent. The break-level analysis indicates a 29-percent reduction in SCE rate in the 1-hour window after a break compared to the 1-hour window before a break for All Break types. The largest reduction in SCE rate was observed after Break Type 4 (Off Duty). The SCE rate after the break is half that of before the break (a reduction of more than 51 percent). Break Type 2 (Work During Duty Period) shows the smallest reduction in SCE rate, where a 28-percent reduction was observed.

Table 4. SCE Rate Before/After: All Break Types

\begin{tabular}{|l|l|r|r|r|r|}
\hline \multicolumn{1}{|c|}{ Break Type } & \multicolumn{1}{|c|}{ Metric } & \multicolumn{1}{|c|}{$\begin{array}{c}\text { Before } \\
\text { Break }\end{array}$} & \multicolumn{1}{|c|}{$\begin{array}{c}\text { After } \\
\text { Break }\end{array}$} & $\begin{array}{c}\text { SCE Ratio } \\
\text { (Before/ } \\
\text { After) }\end{array}$ & $\begin{array}{l}\text { Magnitude } \\
\text { of } \\
\text { Reduction }\end{array}$ \\
\hline All Break Types & SCE Frequency & 429 & 305 & - & - \\
\hline All Break Types & Opportunities & 3,171 & 3,171 & - & - \\
\hline All Break Types & SCE Rate & 0.135 & 0.096 & 1.406 & 28.889 \\
\hline Type 1: Rest During Duty Period & SCE Frequency & 118 & 85 & - & - \\
\hline Type 1: Rest During Duty Period & Opportunities & 789 & 789 & - & - \\
\hline Type 1: Rest During Duty Period & SCE Rate & 0.150 & 0.108 & 1.389 & 28.000 \\
\hline Type 2: Work During Duty Period & SCE Frequency & 339 & 237 & - & - \\
\hline Type 2: Work During Duty Period & Opportunities & 2,518 & 2,518 & - & - \\
\hline Type 2: Work During Duty Period & SCE Rate & 0.135 & 0.094 & 1.436 & 30.370 \\
\hline Type 3: Rest During Duty/Off Duty & SCE Frequency & 3 & 2 & - & - \\
\hline Type 3: Rest During Duty/Off Duty & Opportunities & 15 & 15 & - & - \\
\hline Type 3: Rest During Duty/Off Duty & SCE Rate & 0.200 & 0.133 & 1.504 & 33.500 \\
\hline Type 4: Off Duty & SCE Frequency & 35 & 17 & - & - \\
\hline Type 4: Off Duty & Opportunities & 211 & 211 & - & - \\
\hline Type 4: Off Duty & SCE Rate & 0.166 & 0.081 & 2.049 & 51.205 \\
\hline
\end{tabular}

A key take-away from the break analyses is that the 1-hour window after a break from driving is associated with a significant reduction in SCE rate compared to the 1-hour window before a break. The magnitude of this reduction in risk ranges between about 30 to 50 percent, with the 
greatest reductions in risk observed for break types classified as Type 4 (Off Duty) with an SCE rate reduction of 51 percent. These results suggest that there was a reduction in SCE rate after breaks were taken, whether the break consisted of work activities or restful activities. Put another way, any break was better than no break, though an Off-Duty break provided the most benefit.

\section{SUMMARY AND CONCLUSIONS}

This study provides information on many aspects of the drivers' daily operations, including daily workday activities, driving hours, work hours, and breaks. The key findings include:

- Workday Characterization: Most of the drivers' workday was spent driving (66 percent) or performing other work-related activities (23 percent), while 11 percent of the workday was classified as "Rest."

- Driving Hour: One of the analyses conducted identified a significant time-on-task effect across all driving hours. Follow-up hour-by-hour comparison analyses failed to find a statistically significant difference between the 10th and 11th driving hours.

- Work Hours: The risk of SCE involvement increased when non-driving activities pushed driving hours towards the end of the 14 hour shift. This significant time-on-task effect may be the result of the inclusion of the non-driving work (in addition to the driving work) which represented a considerable portion of the CMV drivers' workday (i.e., 23 percent).

- Breaks from Driving: When non-driving activities (both work- and rest-related) were introduced during the driver's shift—creating a break from the driving task— these breaks significantly reduced the risk of being involved in an SCE during the 1-hour window after the break.

The results from this study provide information not available from previous research. By combining driving data from the Naturalistic Truck Driving Study (NTDS) with an activity register of non-driving tasks (off-duty and during-duty-period activities), a more complete picture of the driver's workday was obtained. In addition, several key findings relevant to HOS were obtained from this study. These results include information on the potential for an increase in risk in the 11th driving hour, the impact of work hour on SCEs, and the impact that breaks can have on safety.

The results from this study with regard to driving hour concurs with the findings of Hanowski et al., ${ }^{(3)}$ with respect to non-significant differences when comparing the 10th and 11th driving hours. In the Hanowski study, which also used naturalistic data, no statistically significant increase in risk was found for the 11th driving hour when compared to the 10th driving hour.

The algorithm used to assess the risk of driving hour in the previous Hanowski et al., ${ }^{(3)}$ study was based solely on driving and, because the data were not available, could not account for the impact of non-driving work on driving risk. The results from the current study regarding work hour indicate that time-on-task across 14 hours of work impacts risk. When drivers drove deep into their 14-hour shift due, perhaps, to non-driving work conducted, there was an increase in the rate of SCEs. That is, the risk of being involved in an SCE generally increased as work hour increased. When controlling for driving hour, the results found that the risk of an SCE was 
reduced when driving was completed earlier in the shift as compared to late in the shift. This suggests that time-on-task effects may not be related to driving hours alone, but implies that there may be an interaction between driving hours and work hours: if a driver drives deep into the 14 hour workday, driving-related SCE risk increased. The significant time-on-task results from this study are not surprising and are consistent with findings from time-on-task research in other domains. ${ }^{(3,4,5)}$

The potential influence that non-driving work has on time-on-task effects and driving-related SCEs makes intuitive sense, based on the results of the breakdown of the drivers' workday. Though driving comprised the bulk of the workday - at 66 percent - non-driving work also was a factor at 23 percent. Therefore, focusing solely on driving hours (unless it represents 100 percent of a driver's workday) does not account for the variety of work that drivers actually perform. This finding may raise other issues beyond the scope of this research, including pay approaches (i.e., pay-per-mile), that do not account for the substantial amount of daily, nondriving work that truck drivers routinely perform. This is the first study of which the authors are aware that has investigated work hours in combination with, and independent of, driving hours. Therefore, additional research is suggested to further evaluate this issue.

Breaks were found to be a successful countermeasure to address the negative time-on-task effects. The results from the break analyses indicated that significant safety benefits can be realized when drivers take breaks from driving. The benefits of breaks from driving ranged from a 30 to 50-percent reduction in risk of SCEs (depending on the type of break from driving), with the most benefit occurring for Off-Duty (non-working) breaks.

While the primary focus areas that were investigated in the current study (i.e., workday characterization, driving, non-driving work, and breaks from driving) have provided important information to explain some of the parameters that may impact SCEs due to time-on-task, there are other factors, not investigated in the current effort, that must also be considered. Although outside the scope of this study, other factors that may impact SCE occurrence include, but are not limited to, sleep hygiene and off-duty activities. It must be noted that a drivers' activities during off-duty time cannot be controlled in a naturalistic study such as this. Previous research by Hanowski et al., ${ }^{(3)}$ suggested that providing more time to rest under the current HOS regulations allowed drivers to increase the amount of sleep they obtained, and that drivers usually received less than their own average amount of sleep in the time prior to an SCE. Therefore, there are key issues that bear addressing in addition to those investigated in this study. For example, educating drivers on the importance of sleep hygiene, company policies that allow drivers to rest when needed, and the implementation of a safety culture within fleets, as well as other countermeasures to address behind-the-wheel drowsiness, are additional critical components that would be important issues to consider for reducing risk in CMV operations. 


\section{INTRODUCTION}

\subsection{DEFINING THE PROBLEM}

In 2000, the National Sleep Foundation (NSF) called for new hours-of-service (HOS) regulations based on current scientific research concerning sleep. At that time, the current HOS regulations had been in effect since 1938, with the last revision occurring in 1962. The rationale behind the call for revised regulations was to synchronize the regulations to a 24-hour schedule - a schedule more consistent with the human body's natural circadian rhythm. This would allow commercial motor vehicle (CMV) drivers to follow a more natural sleep schedule and to obtain a better quality of sleep each night. This is a critical issue since, under the old HOS regulations, CMV drivers were only getting between $4.8^{(6)}$ and 5.18 hours $^{(7)}$ of sleep per night (approximately 3 hours less than is typically suggested). ${ }^{(8)}$ There have been two revisions to the HOS regulations since the original proposal for change in 2000, and there are currently (as of this report's writing) efforts underway to revise current HOS regulations. ${ }^{(9)}$ The history of the HOS regulations is summarized in Table 5 below. ${ }^{(10)}$ 
Table 5. Summary of the HOS Regulations from 1940 to the Present

\begin{tabular}{|c|c|c|c|c|}
\hline Provision & $\begin{array}{c}1940 \text { Regulations } \\
\text { (1940-1962) }\end{array}$ & $\begin{array}{c}1962 \\
\text { Regulations } \\
(1962-2004)\end{array}$ & $\begin{array}{l}2003 \text { Regulations } \\
\text { (2004-2005) }\end{array}$ & $\begin{array}{c}2005 \text { Regulations } \\
\text { (2005-Present) }\end{array}$ \\
\hline $\begin{array}{l}\text { Maximum } \\
\text { Daily Drive } \\
\text { Time }\end{array}$ & $\begin{array}{l}\text { CMV driver may drive } \\
\text { a total of } 10 \text { hours in } \\
\text { a } 24 \text {-hour period. }\end{array}$ & $\begin{array}{l}\text { CMV driver may } \\
\text { drive } 8 \text { consecutive } \\
\text { hours after } 8 \\
\text { consecutive hours } \\
\text { off duty. }\end{array}$ & $\begin{array}{l}\text { CMV driver may drive } 11 \\
\text { hours after } 10 \text { hours off } \\
\text { duty. }\end{array}$ & No change. \\
\hline $\begin{array}{l}\text { Workday } \\
\text { Hours }\end{array}$ & $\begin{array}{l}\text { CMV driver must take } \\
\text { at least } 8 \text { consecutive } \\
\text { hours off duty during } \\
\text { each } 24 \text {-hour period. }\end{array}$ & $\begin{array}{l}\text { CMV driver may not } \\
\text { drive after } 15 \text { hours } \\
\text { on duty, following } 8 \\
\text { consecutive hours } \\
\text { off duty, but off-duty } \\
\text { time does not count } \\
\text { against the } 15 \text {-hour } \\
\text { limit. }\end{array}$ & $\begin{array}{l}\text { CMV driver may not drive } \\
\text { beyond the } 14 \text { th hour after } \\
\text { coming on duty, following } \\
10 \text { hours off duty. }\end{array}$ & No change. \\
\hline $\begin{array}{l}\text { Total Driving } \\
\text { Time per } \\
\text { Period }\end{array}$ & $\begin{array}{l}\text { CMV driver may not } \\
\text { remain on duty for a } \\
\text { total of more than } \\
60 / 70 \text { hours in } 7 / 8 \\
\text { consecutive days. }\end{array}$ & $\begin{array}{l}\text { CMV driver may not } \\
\text { drive after } 60 / 70 \\
\text { hours on duty in } 7 / 8 \\
\text { consecutive days. }\end{array}$ & $\begin{array}{l}\text { CMV driver may not drive } \\
\text { after } 60 / 70 \text { hours on duty in } \\
7 / 8 \text { consecutive days. } \\
\text { A driver may restart a } 7 / 8 \\
\text { consecutive day period } \\
\text { after taking } 34 \text { or more } \\
\text { consecutive hours off duty. }\end{array}$ & No change. \\
\hline $\begin{array}{l}\text { Minimum Duty } \\
\text { Cycle }\end{array}$ & 24 hours. & 18 hours. & 21 hours. & 21 hours. \\
\hline Sleeper Berth & $\begin{array}{l}\text { CMV drivers using a } \\
\text { sleeper berth must } \\
\text { take } 8 \text { hours off duty, } \\
\text { but may plit that time } \\
\text { into two periods. }\end{array}$ & $\begin{array}{l}\text { CMV drivers using } \\
\text { a sleeper berth } \\
\text { must take } 8 \text { hours } \\
\text { off duty, but may } \\
\text { split that time into } \\
\text { two periods } \\
\text { provided neither is } \\
\text { less than } 2 \text { hours } \\
\text { long. }\end{array}$ & $\begin{array}{l}\text { CMV drivers using a } \\
\text { sleeper berth must take } 10 \\
\text { hours off duty, but may split } \\
\text { sleeper-berth time into two } \\
\text { periods provided neither is } \\
\text { less than } 2 \text { hours. }\end{array}$ & $\begin{array}{l}\text { CMV drivers using a } \\
\text { sleeper berth must } \\
\text { take at least } 8 \\
\text { consecutive hours in } \\
\text { the sleeper berth, } \\
\text { plus } 2 \text { consecutive } \\
\text { hours either in the } \\
\text { sleeper berth, off } \\
\text { duty, or any } \\
\text { combination of the } \\
\text { two. }\end{array}$ \\
\hline
\end{tabular}

The major changes between the old HOS regulations and the 2003 HOS regulations included an increase in driving time from 10 hours to 11 hours and an increase in off-duty time from 8 hours to 10 hours. There was also a decrease in workday hours from 15 hours to 14 hours and the addition of a 34-hour restart period, which allowed drivers to restart their workweek after 34 hours off duty. Also, the revised 2003 regulations included the addition of the sleeper berth provision which allowed drivers to extend their workday by taking rest periods in the sleeper berth. The only change between the 2003 HOS regulations and the 2005 HOS regulations was the modification of the sleeper berth provision. The 2005 HOS regulations now requires drivers to take at least one break in the sleeper berth of at least 8 hours in addition to a second break of at least 2 hours. These changes leave U.S. HOS regulations in general agreement with those of other major industrialized nations. Table 6 compares the U.S. HOS regulations with the HOS regulations in other major industrialized countries. 
Table 6. HOS Regulations in Major Industrialized Nations

\begin{tabular}{|c|c|c|c|c|}
\hline Regulation & Australia & Canada & European Union & United States \\
\hline $\begin{array}{l}\text { Maximum On-Duty } \\
\text { Time. }\end{array}$ & 14 hours. & 14 hours. & - . & $\begin{array}{l}\text { None, provided the } \\
60 / 70 \text { hours in } 7 / 8 \\
\text { day schedule is met. }\end{array}$ \\
\hline $\begin{array}{l}\text { Maximum Daily } \\
\text { Driving Time. }\end{array}$ & $\begin{array}{l}12 \text { hours in a } 24- \\
\text { hour period. }\end{array}$ & $\begin{array}{l}13 \text { hours in a } 24 \\
\text { hour period. }\end{array}$ & $\begin{array}{l}9 \text { hours (10 hours } \\
\text { max. } 2 \text { times } \\
\text { weekly). }\end{array}$ & $\begin{array}{l}11 \text { hours in a } 14- \\
\text { hour period. }\end{array}$ \\
\hline $\begin{array}{l}\text { Maximum } \\
\text { Continuous Driving } \\
\text { Time. }\end{array}$ & 5 hours. & Not Specified. & 4.5 hours. & 11 hours. \\
\hline $\begin{array}{l}\text { Minimum Mandatory } \\
\text { Break Time. }\end{array}$ & $\begin{array}{l}0.5 \text { hours for every } 5 \\
\text { hours driving time. }\end{array}$ & $\begin{array}{l}2 \text { breaks consisting } \\
\text { of } 15 \mathrm{~min} .\end{array}$ & $\begin{array}{l}0.75 \text { hour (can be } \\
\text { split into } 15 \text { and } 30 \\
\text { min breaks). }\end{array}$ & $\begin{array}{l}\text { None specified } \\
\text { during shift. }\end{array}$ \\
\hline $\begin{array}{l}\text { Minimum Daily } \\
\text { Continuous Rest. }\end{array}$ & 6 hours. & $\begin{array}{l}10 \text { hours, or } 8 \text { hours } \\
\text { and } 2 \text { hours using } \\
\text { the sleeper berth } \\
\text { provision. }\end{array}$ & $\begin{array}{l}11 \text { hours, } 9 \text { hours } \\
\text { max. } 3 \text { times weekly. }\end{array}$ & $\begin{array}{l}10 \text { hours, or } 8 \text { hours } \\
\text { and } 2 \text { hours using } \\
\text { the sleeper berth } \\
\text { provision. }\end{array}$ \\
\hline Daily Cycle. & 24 hours. & 24 hours. & $\begin{array}{l}20.75 \text { hours }(\min . \\
18.75 \text { hours, } \max \\
21.75 \text { hours). }\end{array}$ & $\begin{array}{l}24-\text { hour goal ( } 14 \\
\text { hours during driving } \\
\text { duty and } 10 \text { hours } \\
\text { rest; including meals } \\
\text { and fuel stops). }\end{array}$ \\
\hline $\begin{array}{l}\text { Time Off After Days } \\
\text { of Driving. }\end{array}$ & $\begin{array}{l}24 \text { hours after } 72 \\
\text { hours working. }\end{array}$ & $\begin{array}{l}24 \text { hours every } 14 \\
\text { days. }\end{array}$ & $\begin{array}{l}45 \text { hours after } 6 \text { days } \\
\text { of driving. }\end{array}$ & $\begin{array}{l}10 \text { hours off, } \\
\text { provided the } 60 / 70 \\
\text { hours in } 7 / 8 \text { day } \\
\text { schedule is met, or a } \\
\text { 34-hour restart. }\end{array}$ \\
\hline $\begin{array}{l}\text { Total Driving Time } \\
\text { per Period. }\end{array}$ & 72 hours in 7 days. & $\begin{array}{l}70 / 120 \text { hours in } 7 / 14 \\
\text { days. }\end{array}$ & 56 hours in 7 days. & $\begin{array}{l}60 / 70 \text { hours in } 7 / 8 \\
\text { days moving } \\
\text { window. }\end{array}$ \\
\hline
\end{tabular}

Note. Information for Australia is given for all areas except Western Australia and the Northern Territory. Information for Canada is given for areas south of $60^{\circ}$ North latitude. Information for the United States is given for all areas except Alaska and Hawaii. Adapted from Jensen \& Dahl.(11)

Table 6 shows some interesting contrasts between the U.S. HOS regulations and those of other countries. For example, the European Union has the most restrictive HOS regulations in terms of driving hours (10 hours), while Canada has the least restrictive (13 hours). It can also be seen that the United States is the only country without a mandatory break time.

\subsubsection{Drowsiness}

When discussing CMV drivers and HOS regulations, an important aspect to consider is driver drowsiness. Drowsiness, which may also be referred to as "sleepiness," is the "inclination to sleep. ${ }^{,(12)}$ Drowsiness, and its impact on CMV drivers, is discussed in more detail below.

Drowsiness occurs naturally in every healthy person. Each person's body functions on an approximately 24-hour circadian rhythm, based on whether it is light or dark outside (along with other measures such as body temperature, melatonin levels, etc.). This causes two circadian lows (periods with a higher inclination to sleep) during a 24-hour period: one during the middle of the night (between approximately midnight and 6 a.m.) and a second that occurs between 2 p.m. and 4 p.m. ${ }^{(13)}$ Because of this, drowsiness is something that all people will invariably experience. 
Prior research has found that driver drowsiness increases during the hours of midnight to 6 a.m. ${ }^{(13,14)}$ Figure 4 shows a graph of alertness over a 24 -hour time period, illustrating the circadian rhythm. It can be seen that the low points occur between 1 p.m. and 3 p.m. and again from about midnight to 6 a.m.

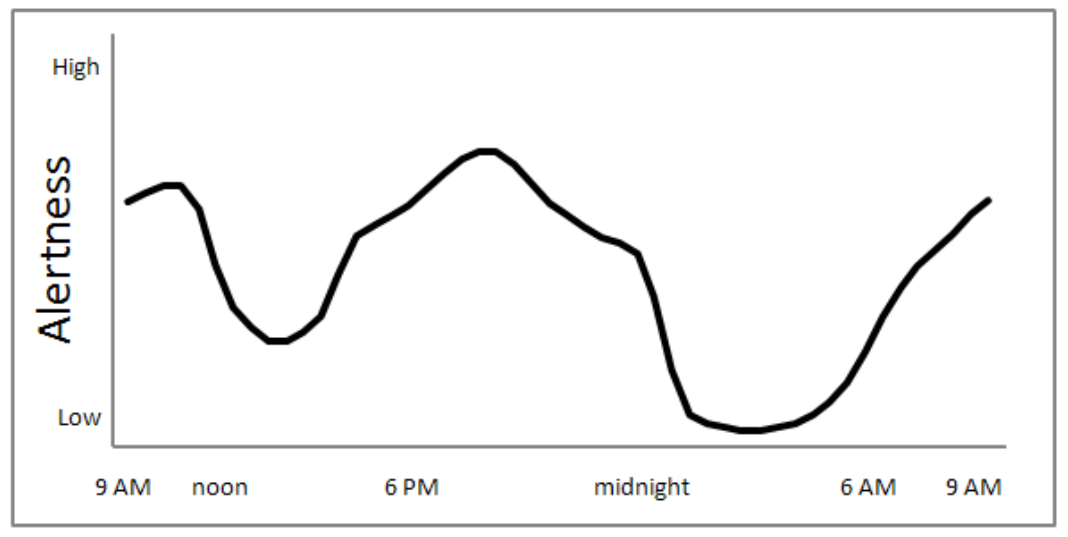

Adapted from www.sleepfoundation.org.

Figure 4. Illustration. Line Graph Shows an Alertness Circadian Rhythm

Driver drowsiness is an important issue for CMV drivers for several reasons. First, CMV drivers can work long shifts (up to 11 hours driving in a 14-hour total shift) with no mandatory break time. Some CMV drivers also keep irregular schedules, including waking very early in the morning or driving throughout the night. Both are natural circadian lows. In addition, CMV drivers may drive long hours on mundane interstates and highways that provide little stimulation to help keep the driver alert. This can create a state where drivers' alertness, and therefore levels of drowsiness, is affected by the lack of stimulation. Because of these and other factors, including the high mileage exposure that CMV drivers face, drowsiness is a critical issue in CMV safety.

\subsubsection{Workday Activities}

A CMV driver's workday involves more than simply driving the truck. Drivers can also be responsible for "heavy work," such as loading or unloading their trailers, as well as "light work," such as filling out paperwork related to a delivery. In addition to work activities, drivers may also take breaks to eat, sleep, and relax. According to the revised 2003/2005 HOS regulations discussed above, drivers may drive up to 11 hours within a 14-hour workday, but there are many combinations of activities that drivers may use to meet these regulations. Three different examples of how a driver may split up the workday:

\section{- Workday example 1.}

- 7 a.m. -8 a.m.: Paperwork; Work total: 1 hour; Driving total: 0 hours.

- 8 a.m.-noon.: Driving; Work total: 5 hours; Driving total: 4 hours.

- Noon-1 p.m.: Lunch; Work total: 6 hours; Driving total: 4 hours.

- 1 p.m.-4 p.m.: Driving; Work total: 9 hours; Driving total: 7 hours.

- 4 p.m.-4:30 p.m.: Unloading; Work total: 9.5 hours; Driving total 7 hours. 
- 4:30 p.m.-6:30 p.m.: Driving; Work total: 11.5 hours; Driving total: 9 hours.

- 6:30 p.m.-7 p.m.: Dinner; Work total: 12 hours; Driving total: 9 hours.

- 7 p.m.-9 p.m.: Driving; Work total: 14 hours; Driving total: 11 hours.

\section{- Workday example 2.}

- 6 p.m.-8 p.m.: Unloading; Work total: 2 hours; Driving total: 0 hours.

- 8 p.m.-1 a.m.: Driving; Work total: 7 hours; Driving total: 5 hours.

- 1 a.m.-2 a.m.: Sleep; Work total: 8 hours; Driving total 5 hours.

- 2 a.m.-8 a.m.: Driving; Work total: 14 hours; Driving total: 11 hours.

\section{- Workday Example 3.}

- 11 a.m.-3 p.m.: Driving; Work total: 4 hours; Driving total: 4 hours.

- 3 p.m.-6 p.m.: Eating/Rest; Work total: 7 hours; Driving total: 4 hours.

- 6 p.m.-1 a.m.: Driving; Work total: 14 hours; Driving total: 11 hours.

Each example is in compliance with the HOS regulations (assuming that the driver had taken at least 10 hours off duty prior to starting the workday), yet each example is made up of different activities occurring for different durations of time and during different times of their workday. A driver who starts the workday with 2 hours of heavy work may have different levels of risk for being involved in a safety-critical event (SCE - such as a crash or near-crash - to be defined in more detail below) than a driver who starts the day by doing paperwork or driving. Each of these workday factors (e.g., type of activity, time of day, when activity occurs during shift, time-ontask) may influence a driver's level of fatigue and risk of being involved in an SCE.

\subsubsection{Driving Hour and Time-on-Task}

The majority of the research dealing with crash risk and HOS regulations has examined time-ontask. In 2006, the American Transportation Research Institute (ATRI) conducted an evaluation of the safety impacts of the then-recent 2003 HOS regulations. This study compared incidents occurring in 2003 and 2004 (per vehicle mile of travel [VMT]) as reported by the fleets surveyed. ${ }^{(15,16)}$ Reportable crashes were collected and analyzed. (A reportable crash involves a fatality, an injury requiring medical treatment away from the scene of the crash, or a towaway). The analysis indicated that miles logged under the 2003 HOS regulations were associated with significant decreases in crashes per million VMT. Overall, crashes per million VMT dropped by 3.7 percent. Preventable crashes and non-preventable crashes showed a 4.8 - and 0.8-percent reduction, respectively. In addition, driver injuries under the 2003 HOS regulations were reduced. Overall driver injuries dropped by 12.6 percent, and crash-related and non-crash-related injuries dropped by 7.6 and 13.7 percent, respectively.

These findings were largely replicated in a 2010 follow-up analysis. ${ }^{(17)}$ Data for the 2010 study were collected in 2009 using the same data collection instrument (fleet-reported incidents and mileage) as the 2006 study, with the addition of questions specifically directed to the 11th driving hour and the 34-hour restart provisions. These data were compared to the 2004 data in terms of reportable crash, preventable crash, and driver injury rates. The frequency of reportable crashes by driving hour and the use frequency of 9th-10th, and 10th-11th driving hour, and the 
34-hour restart were also examined. Results indicated that total crashes per million VMT (11.7percent reduction), preventable crashes per million VMT (30.6-percent reduction), and driver injuries per million VMT (1.6-percent reduction) all experienced a significant reduction in 2009 as compared to 2004. The individual carrier types—-Less Than Truckload (LTL), and Truckload (TL) - did not typically show any significant changes (the change was only significant at the overall level), with the exception of TL operations, which showed a significant drop of total driver injuries per million VMT by 23 percent from 2004 to 2009. Reportable crashes by driving hour largely agreed with the findings of other researchers. ${ }^{(3,18)}$

The ATRI-conducted analysis of crashes per driving hour used data collected in October 2009 and January 2010. These results indicate that the majority (approximately 87 percent) of reportable crashes occurred in the first 8 driving hours. Fewer events occurred beyond the 9th hour (Figure 5) ${ }^{(18)}$ While this analysis did not account for driving exposure, it does provide a useful overview of crash frequency per hour.

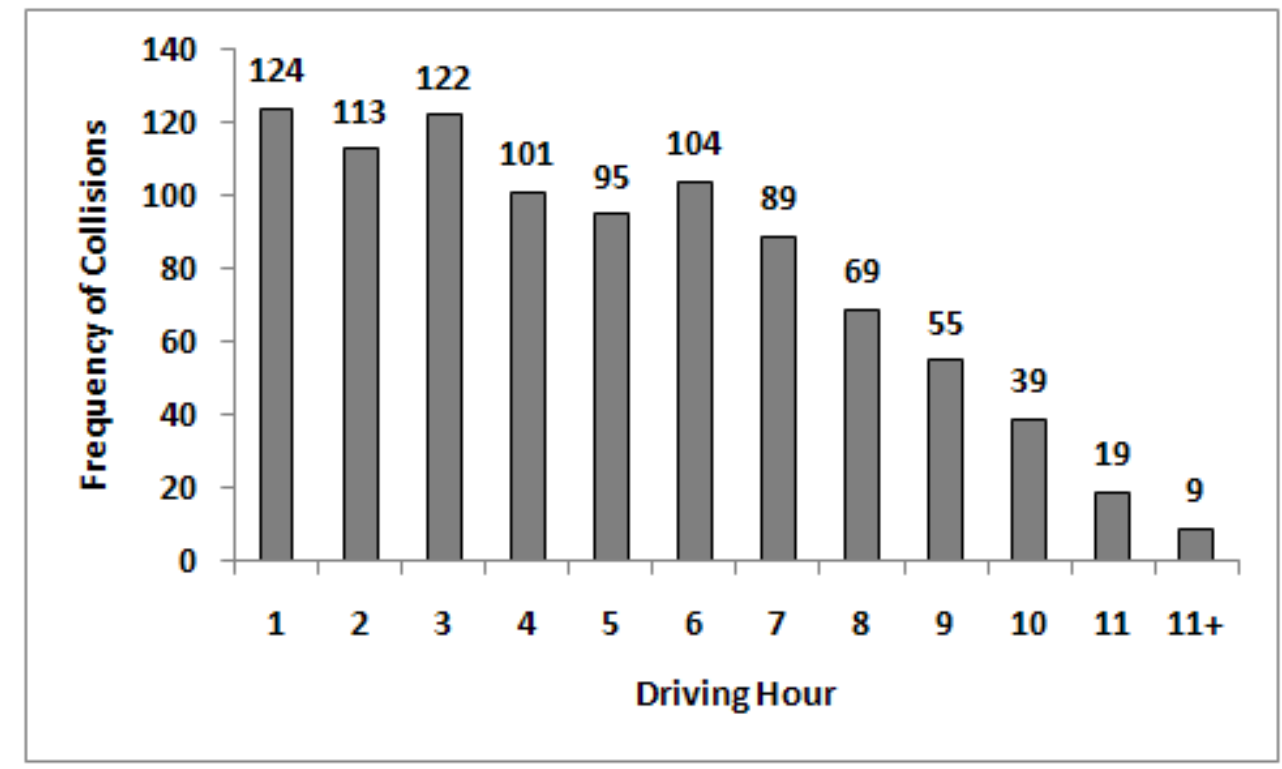

(Source: ATRI, 2010)

Figure 5. Bar Graph. Reportable Crashes by Driving Hour

The ATRI study also examined the use of driving hours 9-11 and the 34-hour restart provision. The findings of this suggested a fairly consistent use pattern. ${ }^{(18)}$ The majority (more than 60 percent) of drivers used the 9-10 driving hour and 10-11 driving hour epochs. Slightly more than 50 percent of drivers used the entire 10-11 driving hour, and almost 80 percent used the 34hour restart provision at least once in the month (Figure 6). The 34-hour restart provision was typically used three or fewer times per month, and 79 percent used the 34-hour restart provision at least once in the month. 


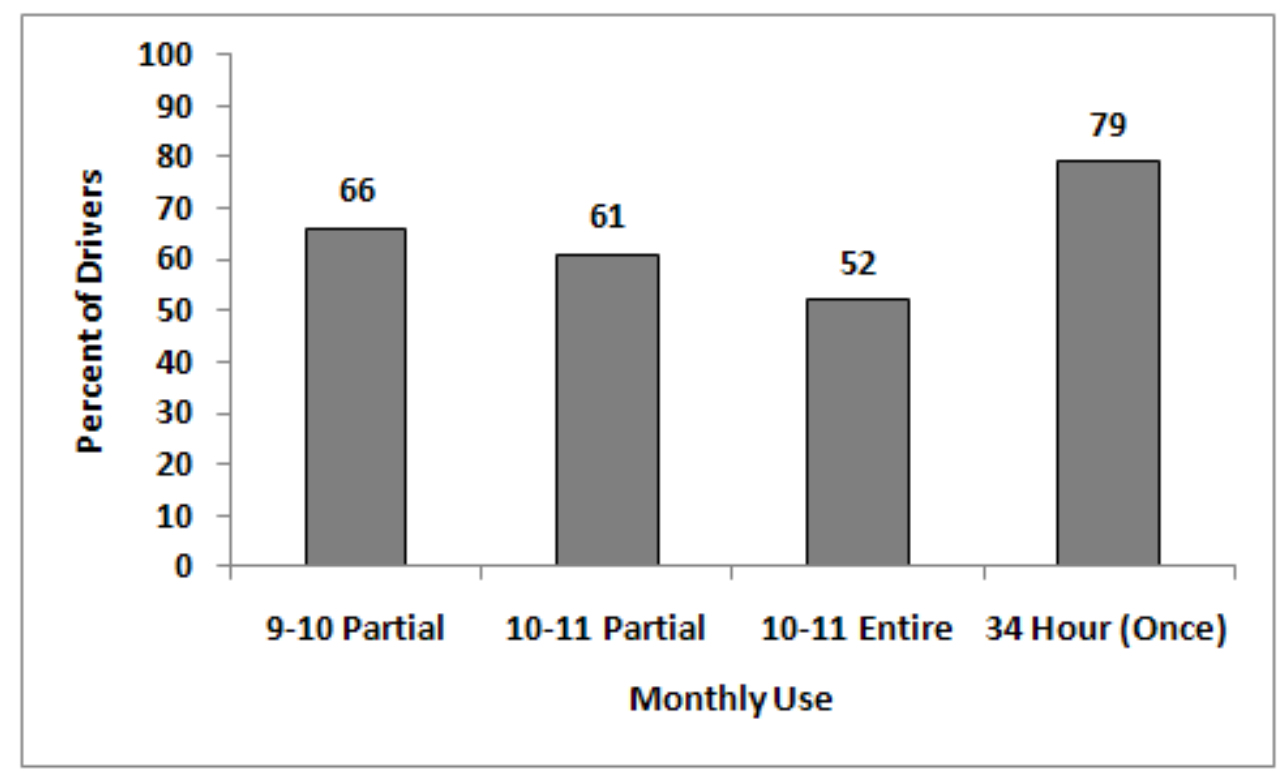

(Source: ATRI, 2010)

Figure 6. Bar Graph. Use of Driving Hours 9-11 and the 34-Hour Restart

In another study, the Virginia Tech Transportation Institute (VTTI) collected and analyzed more than 14,500 hours of naturalistically collected CMV driving data (more than 2,200 shifts). ${ }^{(19)}$ The data set contained 2,899 SCEs, consisting of 13 crashes ( 8 of which were tire strikes) and 61 near-crashes, as well as a number of crash-relevant conflicts, lane departures, and illegal maneuvers. In addition, the study drivers wore actigraphy devices, allowing for a determination of sleep/wake cycles to be made. Analysis of the duration of the restart period indicated that the average restart period preceding an SCE was 53 hours every 5 days (as compared to baseline events' average restart period of 58 hours). Long-haul drivers had a briefer duration restart (48 hours) as compared to medium-haul (53 hours) or short-haul drivers (63 hours). These results indicate that all three driver types took more than the 34-hour minimum restart provision. However, the duration of the restart period was not found to be related to SCEs.

A second study by VTTI evaluated the effect of time-on-task on SCE risk. ${ }^{(20)}$ This research utilized naturalistically collected driving data gathered from 103 drivers (102 males, 1 female) between May 2004 and September 2005. Key safety analyses conducted included examining SCEs as a function of driving hours, SCEs as a function of driving hour for drivers who drove into the 11th hour, and SCEs as a function of time of day. Results indicated that there were significantly more SCEs during the first driving hour as compared to all other driving hours. However, comparisons of all other driving hours failed to reach statistical significance. Similar findings were present for the analysis of SCEs as a function of driving hour for drivers who drove into the 11th hour. The first driving hour represented an increase in SCE risk, but the comparison of all other driving hours (including the 11th hour) did not reach significance. The time-of-day analysis suggested there was a significant time-of-day effect on SCE risk. However, Hanowski and colleagues note that other explanatory factors (primarily traffic density) may have influenced the findings. 
In a 2009 paper, Knipling examined the Large Truck Crash Causation Study (LTCCS) database and compared different types of large-truck crash involvement (single vehicle, multivehicle with the CMV at fault, and multivehicle with another vehicle at fault). ${ }^{(21)}$ The critical reason of being "asleep at the wheel" was associated with 13 percent of single vehicle, 1 percent of multivehicle with the CMV at fault, and 9 percent of multivehicle with another vehicle at fault crashes.

Knipling reported that factors associated with single-vehicle crashes included: not wearing safety belts, driving on unfamiliar roadways, vehicle failures, lack of prior sleep, being awake more than 16 hours, and driving in the early morning. However, dense traffic situations were more likely to be associated with multivehicle/CMV-at-fault crashes. For crashes with fatigue involvement, those related to sleep and alertness were typically linked to the single-vehicle crashes.

\subsubsection{Working Hours and Time-on-Task Findings From Other Domains}

Research from non-driving domains indicate that time-on-task is highly associated with fatigue. ${ }^{(22)}$ The topic of time-on-task is also highly related to shift duration, which has been widely studied in both medical and industrial domains. Therefore, it may be of use to provide a brief summary of the findings from these fields in order to provide context for the current study.

Research in the medical domain has indicated that longer shifts are associated with greater numbers of errors. One study of nurses and extended work shifts found that all adverse events and errors identified were associated with working more than 40 hours in a week. ${ }^{(4)}$ For shifts longer than 12.5 hours, self-reported frequency of errors is three times greater than for shorter shift durations, and working more than 40 hours per week is associated with a significant increase in self-reported errors among nurses. ${ }^{(5)}$ When these extended schedules lead medical personnel into working during nighttime shifts, errors can become more frequent. One study of trainee physicians found that lapses in attention (a precursor to errors) occur between 1.5 times (during the day) and twice as often (during the night) under a 30-hour physician trainee duty schedule as opposed to a 16-hour duty schedule. ${ }^{(23)}$

Industrial research has found that working more than 60 hours per week is associated with a 23percent higher injury hazard rate, and working in a job with overtime is associated with a 61percent higher injury hazard rate. ${ }^{(6)}$ These schedules can lead to sleep problems. Industrial workers on a rotating shift (12 hours in a 16-day rotation period) got less sleep during the initial days of the shift. During the night-shift period, workers reported lower perceived alertness levels and increased difficulty working. ${ }^{(24)}$ This is an important finding, as other research has indicated that sleep debts (including self-perceived sleep debts) are associated with both driving and nondriving accidents. ${ }^{(25)}$ Furthermore, impaired or shortened sleep is noted as a major cause of workplace accidents in industrial settings. ${ }^{(26)}$ These extended shifts can also lead to other health problems. Musculoskeletal disorders are associated with increased hours of work per day and week. (27)

\subsection{PURPOSE OF THE CURRENT STUDY}

Despite the studies highlighted previously, topics including driving hours, work hours, and breaks as a function of time-on-task have not been well explored in the published literature. As 
such, the current study provides data on these under-researched topics. The present study focuses on four key issues relevant to the HOS regulations:

- Workday Characterization: What activities comprise an average workday for long-haul and line-haul drivers?

- Driving Hour: What is the impact of time-on-task on the risk of SCEs as a function of driving hour? Specifically, and critical to increasing the knowledge base on the HOS regulations, is there a significant increase in risk associated with the 11th hour of driving?

- Work Hour: What is the impact of time-on-task on the risk of SCEs as a function of work hour? This is a topic that has not been previously studied.

- Breaks: What is the impact of time-on-task on the risk of SCEs as a function of breaks from the driving task? Are breaks from driving used to perform other work-related tasks impacting SCEs in a similar manner as breaks to rest?

It must be noted that it is not possible for a single study to answer all questions of interest related to HOS. For example, although important, the current study does not explicitly assess fatigue (or drowsiness) as a function of crash risk, the sleep quality/quantity of study drivers, or individual differences in drowsiness and sleep response. Additional research may be required, and existing research should be considered, to address these areas. Considering the primary research areas outlined for this study, there are a few clues from previous studies for what might be the expected results from the current study.

When considering the potential for an increase in risk of SCEs as a function of driving hour, there are two contrasting possibilities indicated from previous research. First, there is a possibility of an increase in crash risk for the 11th hour of driving as compared to other driving hours. ${ }^{(19)}$ Using a time-dependent logistic regression modeling approach, Jovanis and colleagues found that the risk of a crash increased in the 8th, 9th, 10th, and11th driving hours for sleeper operations and in the $2 \mathrm{nd}, 3 \mathrm{rd}$, 5th , 7th, and 9th hours for non-sleeper operations. ${ }^{(28)}$ An alternative hypothesis, based on research conducted by Hanowski et al., is that risk does not increase in the 11th driving hour as compared to other driving hours. ${ }^{(3)}$

The research team has not been able to identify prior research that has examined the impact of time-on-task on risk as a function of work hour (work hours ranging from 1 to 14). As noted, previous studies ${ }^{(3)}$ considered all hours within a driver's workday as equal; that is, "driving" was treated as equivalent to "work." However, based on research from subgroups of the trucking industry, such as Local/Short Haul (L/SH), we know that driving is not typically the only "work" that drivers engage in as part of their duty day. ${ }^{(29)}$ As such, the current study provides new insight into an important but understudied topic.

The effect of breaks from the driving task and their potential risk mitigation benefits for CMV drivers has not been extensively examined in the literature. There is evidence from non-driving research to suggest that breaks from a primary task (i.e., driving) are needed to help reduce the effects of vigilance lapses or fatigue. ${ }^{(30,31)}$ These studies indicate that breaks may lead to increased performance on the primary task. Therefore, the current study and its focus on driving 
hour, work hour, and breaks provide key information on issues pertinent to the HOS regulatory efforts.

\subsection{OVERVIEW OF THE CURRENT STUDY}

The current study involved specific analyses using data from the Naturalistic Truck Driving Study (NTDS). The analyses include examinations of:

- Assessment of CMV drivers' workday.

- Safety-critical events as a function of driving hour.

- Safety-critical events as a function of work hour.

- Safety impact of breaks from driving.

Exposure was calculated for each analysis, allowing for rates to be generated for each longitudinal variable. Likewise, odds ratios were calculated allowing for estimates of the rate of SCE occurrence from driving hours and work hours. The method used in these calculations, the results of the respective analyses, and discussion of the findings are in the next section. 


\section{METHODS}

Data for these analyses were collected during the FMCSA-funded NTDS. A description of the methodology used in the NTDS can be found in Blanco et al. ${ }^{(18)}$ A total of 100 drivers, from 4 different fleet companies, participated in the NTDS. Three of the fleet companies were line-haul operations (out-and-back), while the fourth fleet was a long-haul operation (typically out for 1 week at a time). Two of the companies had terminals in Virginia, while the other two were based in North Carolina.

\subsection{PARTICIPANTS}

Data collection for the NTDS took place from November 2005 to March 2007. A total of 100 drivers were involved in the study. However, three drivers were removed due to missing data that were necessary for analyses (e.g., activity register data, described later). This left 97 drivers for analyses. Of these 97 drivers, 96 provided demographic information. Of the 96 drivers that provided demographic information, 91 were male and 5 were female. The average age was 44 years old (range: $21-73$ years), and the drivers had an average of 9.13 years experience driving CMVs (range: 4 weeks to 54 years). Nine drivers did not complete high school, 41 drivers had a high-school degree, 31 drivers had taken some college classes, 5 drivers had a 2-year college degree, 9 drivers had a 4-year college degree, and 1 driver had a professional degree. Long-haul and line-haul operations were both represented in the study: 75 drivers were primarily long-haul and 21 drivers were primarily involved in line-haul. Four for-hire trucking companies participated in the study. Long-haul and line-haul operations were both represented in the study: 75 drivers were primarily long-haul and 21 drivers were primarily line-haul. Presently, as well as at the time of data collection, two of the carriers were ranked in the 'Top 100 For-Hire Carriers. ${ }^{(1)}$ The two smaller companies had a total of approximately 180 employed. All drivers and companies were volunteers and recruited for the study. Virginia Tech served as the Institutional Review Board of record. Drivers signed an Informed Consent prior to participation, and a Certificate of Confidentiality (from the National Institutes of Health) was in place. As with any study that uses volunteers the drivers may not be representative of the general population of commercial drivers.

\subsubsection{Procedure}

A naturalistic-data-collection approach was used where data were collected as study participants drove instrumented company trucks during their normal revenue-producing runs. Typically, once a driver had completed his or her participation in the study, a different driver would be assigned to the instrumented truck. Each driver drove an instrumented truck for approximately 4 weeks. The final project data set consisted of approximately 735,000 miles of driving data and 6.2 terabytes of video and dynamic sensor data.

\subsection{VEHICLE DATA}

The data acquisition system (DAS) was comprised of five main components, including an encased unit that housed the computer and external hard drive, dynamic sensors, vehicle network, incident box, and five video cameras. Unobtrusive data-collection equipment consisting 
of a DAS, sensors, and cameras were installed in nine trucks. The data-collection equipment included sensors to measure driver performance and video that recorded the driver's face, steering wheel, and three views outside of the truck (Figure 7). The individual components of the DAS are described in more detail below.

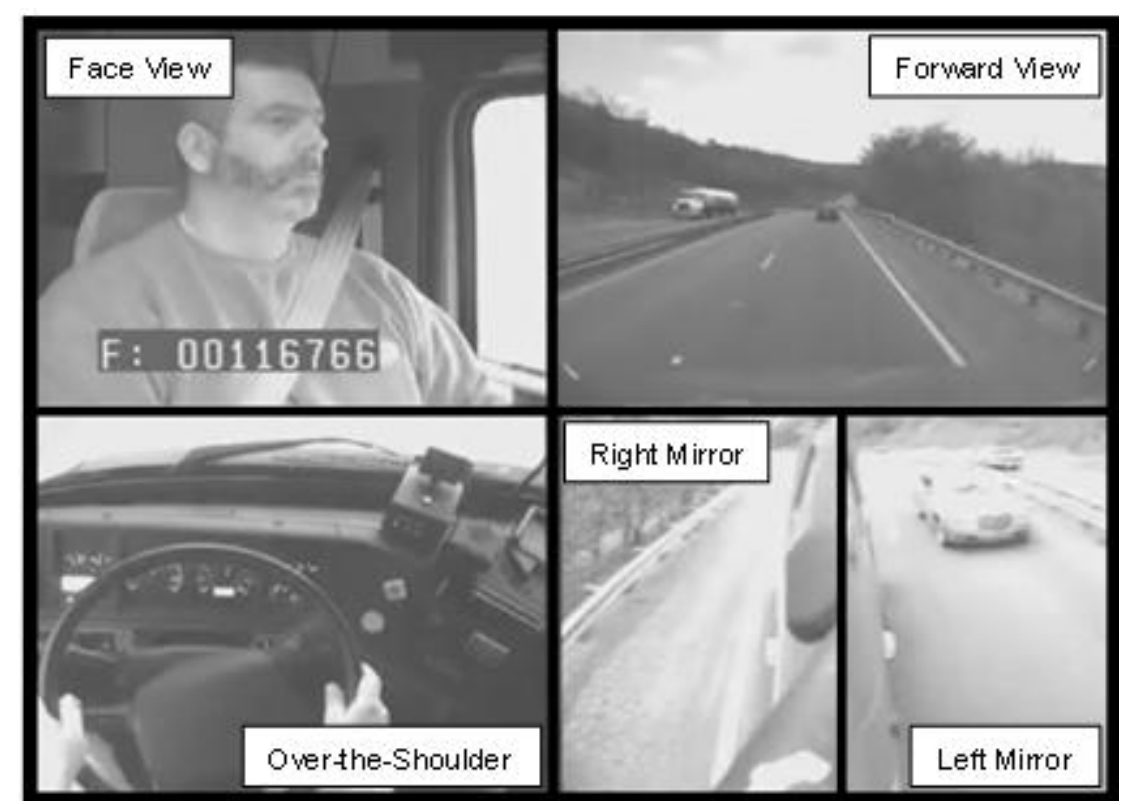

Figure 7. Photo. Five Camera Images Multiplexed Into a Single Image

\subsubsection{Main DAS Unit}

The main DAS unit was mounted under the passenger seat for trucks without a sleeper berth and for trucks with sleeper berths but without an air-ride-equipped seat or an air-conditioning unit under the seat. For trucks with sleeper berths or limited room under the passenger seat, the main DAS unit was mounted in the driver's side rear compartment.

\subsubsection{Secondary DAS Components}

\subsubsection{Video Cameras/Incident Button}

Digital video cameras were used to record continuous video of the driver and driving environment. The face video camera and incident button were combined into a single unit. A microphone was also instrumented as part of the incident box. In addition to inserting a flag in the data stream, pressing the incident button opened an audio channel for 60 seconds and allowed the driver to record a verbal comment about the event.

The face camera/incident box device was mounted in one of two locations in the truck. The first location was at the top, and near the center, of the inside of the windshield. This location was selected to minimize obstruction of the driver's forward view by the device. The second location was mounted in the upper center of the windshield on the far left side in a vertical position. In some of the trucks used in the study, the sun visors were large enough in the down position so as to obstruct the view of the driver by the face camera. These visors were replaced with modified 
visors with a section of the visor cut out to ensure a clear view of the driver by the face camera, even with the visor in the down position.

The five camera images were multiplexed into a single image (Figure 7). The top left frame shows the driver's face camera view, the top right shows the forward camera view, the bottom right shows the left/right rear camera views in a split-quadrant format, and the bottom left shows the over-the-shoulder view from the dome camera. A timestamp (frame number) was included in the video data. The frame number was used to time-synchronize the video with the truck/performance data. The digital video files did not contain continuous audio.

\subsubsection{Front VORAD}

A radar-based Eaton VORAD unit was installed on the front bumper of the truck to provide a measure of range to lead vehicles and objects. From the range measure, range rate, and time-tocrash can also be derived.

\subsubsection{GPS}

A global positioning system (GPS) device was mounted on top of each truck to provide data on truck location. Data output included measures of latitude, longitude, altitude, horizontal and vertical velocity, heading, and status/strength of satellite signal acquisition, as well as time and date data.

\subsubsection{Lane Tracking}

A custom-developed lane tracking system was included in the DAS. The lane tracking system consisted of a single analog black-and-white camera, a personal computer (PC) with a frame grabber card, and an interface-to-vehicle network for obtaining ground speed (note that the video frames were not stored; instead these files were processed in real time to calculate the vehicle position relative to road lane markings). Once installed, the lane tracking system automatically calibrated based on camera position. The following variables were reported by the system:

- Distance from center of truck to left and right lane markings (estimated maximum error less than 6 inches, average error less than 2 inches).

- Angular offset between truck centerline and road centerline (estimated maximum error less than 1 degree).

- Approximate road curvature.

- Confidence in reported values for each marking found.

- Marking characteristics, such as dashed versus solid and double versus single.

- Status information, such as in-lane or solid line crossed.

\subsubsection{Yaw Rate Sensor}

A yaw rate (gyro) sensor was installed in the main DAS unit to provide a measure of steering instability (jerky steering movements). 


\subsection{7 $\mathrm{X} / \mathrm{Y}$ Accelerometer}

Accelerometers instrumented in the truck were used to measure longitudinal (x) and lateral (y) accelerations.

\subsubsection{Vehicle Network}

The vehicle network refers to a from-the-factory onboard data collection system. The format of messages and data were collected by onboard microprocessors (defined by SAE J1587) ${ }^{(32)}$ and were installed on the vehicle at the truck manufacturing facility and not by the research team. Depending on the truck model, year, and manufacturer, there were several data network protocols or standards that were used, including those defined by SAE J1708, ${ }^{(33)}$ SAE J1939, ${ }^{(34)}$ and SAE J1587. ${ }^{(33)}$ After assessing the data requirements associated with the current study, it was decided that the data defined by $\mathrm{J} 1708$ would be accessed. An interface was developed by the research team to access the data and bring it into the DAS data set. Some of the measures accessed from the truck's vehicle network were dependent on the make, model, and year of the vehicle.

It must be noted that because the data collection instrumentation resides on the subject vehicle, SCEs that are captured record the event from the subject vehicle driver's perspective only. As such, the behaviors of non-subject vehicle drivers involved in an SCE with the subject vehicle are generally unknown. For example, analysts would not know if a non-subject vehicle driver was distracted at the time of the event and that non-subject driver's distraction may have precipitated the SCE. As such, though the subject vehicle driver's perspective can be generally determined through the data collected, there may be events where relevant factors for nonsubject vehicle drivers are unknown.

\subsection{DRIVER PERFORMANCE MEASURES}

Driver performance was assessed through the occurrence of SCEs: crashes, near-crashes, crashrelevant conflicts, and unintentional lane deviations. Each is defined as:

- Crash: Any contact with an object, either moving or fixed, at any speed, including another vehicle, roadside barrier, object on or off of the roadway, pedestrian, pedalcyclist, or animal.

- Near-crash: Any circumstance that required a rapid, evasive maneuver (e.g., hard braking, steering) by the subject vehicle or any other vehicle, pedestrian, pedalcyclist, or animal, in order to avoid a crash.

- Crash-relevant conflict: Any circumstance that required a crash-avoidance response on the part of the subject vehicle, any other vehicle, pedestrian, pedalcyclist, or animal that is less severe than a rapid evasive maneuver (as defined above), but greater in severity than a normal maneuver. A crash-avoidance response can include braking, steering, accelerating, or any combination of control inputs.

- Unintentional lane deviation: Any circumstance where the subject vehicle crosses over a solid lane line (e.g., onto the shoulder) where no hazard (e.g., guardrail, ditch, vehicle, etc.) is present. 
SCEs were identified using a software program to search through all data files for spikes in sensors. For example, the program searched for all occurrences of longitudinal accelerations of equal to or greater than $-0.20 \mathrm{~g}$ to locate instances of hard braking. Once potential SCEs had been identified by the software program, researchers viewed the video and other corresponding data to determine whether the trigger was a valid SCE. Table 7 outlines the trigger types and thresholds used to identify SCEs.

Table 7. Trigger Types Used to Identify SCEs

\begin{tabular}{|l|l|}
\hline \multicolumn{1}{|c|}{ Trigger Type } & \multicolumn{1}{c|}{ Description } \\
\hline $\begin{array}{l}\text { Longitudinal } \\
\text { Acceleration. }\end{array}$ & $\begin{array}{l}\text { Deceleration equal to or greater than }-0.20 \mathrm{~g} \text {. Speed equal to or greater } \\
\text { than } 1 \mathrm{mi} / \mathrm{h} .\end{array}$ \\
\hline Time-to-Crash. & $\begin{array}{l}\text { A forward time-to-crash value of less than or equal to } 2 \text { seconds }(\mathrm{s}) \text {, } \\
\text { coupled with a range of less than or equal to } 250 \mathrm{ft} \text {, a target speed of equal } \\
\text { to or greater than } 5 \mathrm{mi} / \mathrm{h} \text {, a gyro rate of less than or equal to }|6 \% \mathrm{~s}| \text {, and an } \\
\text { azimuth of less than or equal to }\left|0.12^{\circ}\right| .\end{array}$ \\
\hline Swerve. & $\begin{array}{l}\text { Swerve value of equal to or greater than } 2 \mathrm{rad} / \mathrm{s}^{2} \text {. Speed greater than or } \\
\text { equal to } 5 \mathrm{mi} / \mathrm{h} .\end{array}$ \\
\hline $\begin{array}{l}\text { Lane Deviation. } \\
\text { Button. }\end{array}$ & $\begin{array}{l}\text { Lane tracker status }=\text { abort. Distance from center of lane to outside of lane } \\
\text { line less than } 44 \text { inches. }\end{array}$ \\
\hline Analyst-Identified. & $\begin{array}{l}\text { Activated by the driver upon pressing a button, located by the driver's visor, } \\
\text { when an incident occurred that he/she deemed critical. }\end{array}$ \\
\hline $\begin{array}{l}\text { Event that was identified by a data reductionist viewing video footage; no } \\
\text { other trigger listed above identified the event (Longitudinal Acceleration, } \\
\text { time-to-crash, etc.). }\end{array}$ \\
\hline
\end{tabular}

Although crashes and near-crashes are the typical variables of interest in a safety evaluation such as the present study, less severe events can also provide valuable information. For example, unintentional lane deviations present additional safety concerns and have been shown to be a valid measure of performance decrement in prior research on HOS regulations and fatigue. ${ }^{(2)}$ Additionally, unintentional lane deviations represent "driver errors." While much less serious than crashes, these may reflect potential time-on-task issues. Previous research has suggested that there are no differences in safety events across driving hours. ${ }^{(2)}$ If similar findings are present in this analysis, which includes minor events that are sensitive to time-on-task, then this would provide strong evidence for the veracity of previous findings.

\subsection{ACTIVITY REGISTER}

In addition to the vehicle data described above, each participant was asked to fill out an activity register for the entire 4 weeks he or she participated in the study. Participants were asked to fill out their daily activities for both during-duty periods and off-duty periods. There were 15 possible activity codes, with the first 6 classified as tasks during driving duty and the last 9 classified as off-duty activities. Each activity code, as well as its classification and description, are provided in Table 8 . A sample page of the activity register is shown below in Figure 8 . 
Table 8. Activity Code Descriptions

\begin{tabular}{|l|l|}
\hline \multicolumn{1}{|c|}{ Activity Code } & \multicolumn{1}{c|}{ Description } \\
\hline 1/Tasks During Driving Duty. & Driving Truck. \\
\hline 2/Tasks During Driving Duty. & Heavy Work (Loading/Unloading). \\
\hline 3/Tasks During Driving Duty. & Sleep. \\
\hline 4/Tasks During Driving Duty. & Rest. \\
\hline 5/Tasks During Driving Duty. & Eating. \\
\hline 6/Tasks During Driving Duty. & Light Work. \\
\hline 7/Off Duty. & Sleep. \\
\hline 8/Off Duty. & Rest (Not Asleep, Watching TV, Resting). \\
\hline 9/Off Duty. & Eating. \\
\hline 10/Off Duty. & Light House Work (Dishes). \\
\hline 11/Off Duty. & Heavy House Work (Mowing Lawn). \\
\hline 12/Off Duty. & Light Leisure Activity (Walking, Internet). \\
\hline 13/Off Duty. & Heavy Leisure Activity (Running, Sports). \\
\hline 14/Off Duty. & Driving Other Vehicle (Not Work-Related). \\
\hline 15/Off Duty. & Other. \\
\hline
\end{tabular}

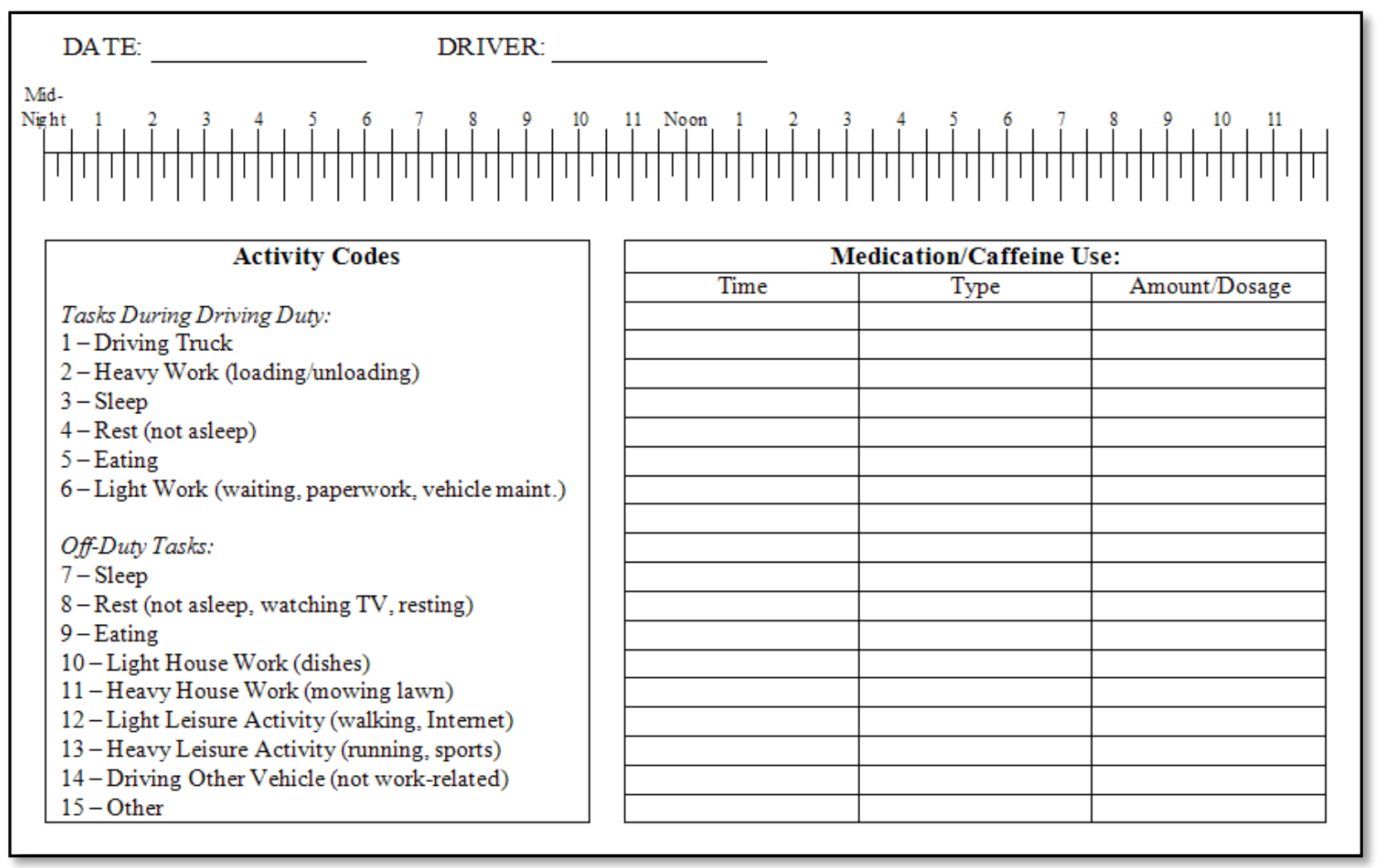

Figure 8. Illustration. Daily Activity Register Sheet Used to Record Activities

The top part of the daily activity register was a 24-hour timeline, which began at midnight and ended at 11:59 p.m., scaled with 15-minute increments (see Figure 8). Participants were instructed to choose 1 of the 15 activity codes from the left side of the form and write down the chosen code on the timeline. The tasks during driving duty included codes $1-6$, while the off- 
duty activities were coded as 7-15. Figure 9 displays an example of a completed day in the activity register's timeline.

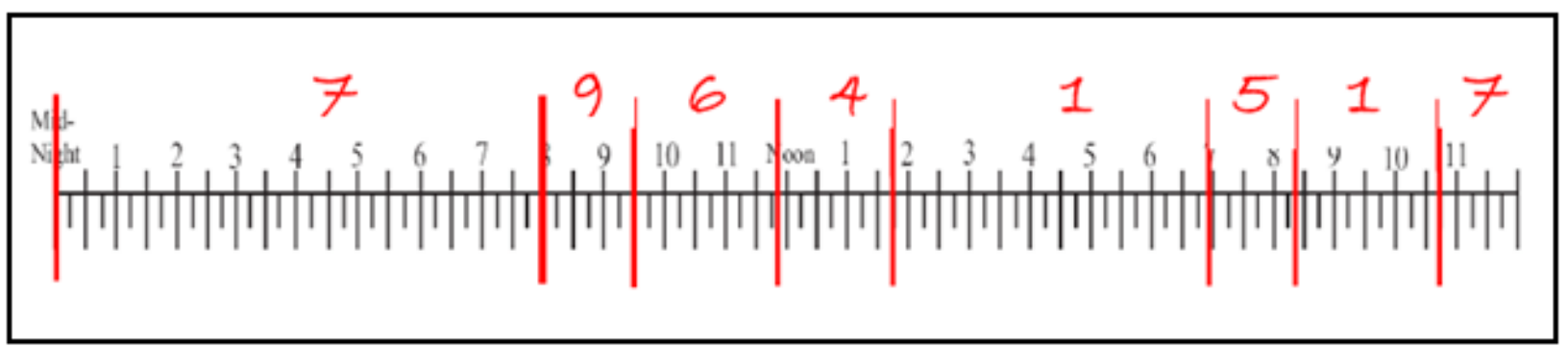

Figure 9. Illustration. Timeline with Activity Codes

Table 9 provides an explanation of the activities shown in the timeline (Figure 9). Note that the activities of Sleep, Rest, and Eating were included under both sets of activity codes. For example, participants were instructed to record code 5 "Eating" in their daily register when during a duty period they took time to eat (e.g., dinner break while waiting for load), whereas they were instructed to write down code 9 "Eating" if the same activity occurred during their offduty periods (e.g., dinner at home).

Table 9. Explanation of Time, Duration, and Activities in Figure 7

\begin{tabular}{|l|l|}
\hline \multicolumn{1}{|c|}{ Time Period } & \multicolumn{1}{c|}{ Activity Code } \\
\hline Midnight-8 a.m. & 7 (Off Duty Sleep). \\
\hline 8 a.m.-9:30 a.m. & 9 (Off Duty Eating). \\
\hline 9:30 a.m.-11:45 a.m. & 6 (Light Work During Driving Duty). \\
\hline 11:45 a.m.-1:45 p.m. & 4 (Rest During Driving Duty). \\
\hline 1:45 p.m.-7 p.m. & 1 (Driving). \\
\hline 7 p.m.-8:15 p.m. & 5 (Eating During Driving Duty). \\
\hline 8:15 p.m.-10:45 p.m. & 1 (Driving). \\
\hline 10:45 p.m.-midnight & 7 (Off Duty Sleep). \\
\hline
\end{tabular}

\subsection{HYBRID ACTIVITY REGISTER}

In order to calculate the drivers' work hours for a shift, it was necessary to use the data from the activity register to determine what the drivers were doing when they were not driving the truck. Therefore, the activity register data and the vehicle data were combined to form a single data set that included both driving and non-driving activities. An exposure measure using each driver's participation time was also calculated to be used during the analysis. The steps taken within this process are described herein.

\subsubsection{Generate Hybrid Activity Register Data}

Once the blank activity codes were adjusted, the following steps were taken to generate the hybrid activity code data: 
1. Combine video files - Since video files were originally collected from the truck in segments no longer than 1 hour, the individual video files were combined (provided that the time between adjacent video files was less than 15 minutes) into a video file representing one driving file. If the time between adjacent video files was greater than 15 minutes, the following file was considered to be the beginning of a new driving file and a new file was created.

2. Trim start/end time of video files - Once the video files were combined, the start and end of each new file was scanned for a 30-second consecutive time period where the truck speed was continuously greater than $5 \mathrm{mi} / \mathrm{h}$. The first occurrence of such a 30 -second consecutive time period (within a newly combined file) was denoted as the new start of a driving time. The last occurrence of another 30-second consecutive time period was the new end of a driving time.

3. Separate files - Once all files were scanned and new start/end times were determined, each combined video file was separated into one of two groups: less than 15 minutes, or equal to or greater than 15 minutes.

After the combined video files were separated, all combined video files that were less than 15 minutes in duration were verified to meet the driving criteria outlined below. If these criteria were met, the combined video file was kept. Otherwise, it was not included in the hybrid activity register. Files used to verify the participant's activity register entries were required to meet the following criteria:

- $\quad$ Truck speed was greater than $5 \mathrm{mi} / \mathrm{h}$ for more than 80 percent of the combined file.

- The combined file has at least a consecutive 30 seconds where the truck speed was equal to or greater than $30 \mathrm{mi} / \mathrm{h}$.

- The length of the combined video file was longer than 5 minutes.

If the above criteria were met, then the date and time of the combined video files were used to check against the activity register entries. If a combined driving video file occurred simultaneously with a non-driving activity register entry, then the corresponding time in the activity register was changed to reflect driving (activity code 1). Approximately 50 percent of shifts required an adjustment of the addition of at least 30 minutes of driving time. The average amount of time adjusted, per shift, was 106 minutes. As noted, the reasons for these required time adjustments included drivers not accurately filling out the activity register and the fact that the vehicle data were recorded in 1/10-second intervals while the activity register values were in 15-minute intervals.

The hybrid activity register was created based on files that met the criteria to verify activity registers, with the following additional criteria:

- Truck speed was greater than $5 \mathrm{mi} / \mathrm{h}$ for at least 20 percent of the file.

- Duration of the combined video file was equal to or greater than 15 minutes. 
Files failing to meet these criteria were not included in the hybrid activity register. The date and time of the combined video files was used to check against the activity register entries. If the file matched to a non-driving entry, and the overlapping time was greater than or equal to 15 minutes, then the entry of the overlapping time was changed to driving (activity code 1).

Once the above criteria were applied and the hybrid activity register data was generated, there were approximately 93 SCEs that occurred during a non-driving activity register code. Using the date and time of video files that contained those SCEs, an exception to the previous inclusion criteria was made (for combined files greater than or equal to 15 minutes) and all overlapping times were changed to "driving" for these files.

\subsubsection{Adjusting Activity Code for Time Periods Left Blank}

There were some time periods left blank in the driver activity register. There are a couple of possible explanations for this. One potential reason could be that the driver activity register was not always filled out immediately after the activity was performed (e.g., drivers may not have been able to fill out the activity register until the end of their day and then may have forgotten certain activities). Another potential explanation is that because the DAS has a $10 \mathrm{~Hz}$ resolution and the activity register was in 15-minute increments, there was a potential for mismatched driving codes (activity code $=1$ ). Both of these explanations may have caused some activity codes to not line up perfectly with the vehicle data. Therefore, a hybrid activity register was created that combined the vehicle data (driving data) and the activity register data into one data set.

There were 246 periods of time that were left blank by the driver (activity code 16-left blank/off duty). The following rules were used to update the blank activity codes to activity codes that involve activities during the duty period (activity code 17-left blank/potential work during duty period or 19-left blank/potential rest during duty period):

- If the duration of a time period left blank (activity code 16) is less than 6 hours and fell between:

- Two work during duty period activities that were part of the tasks during a duty period (activity code 1,2, or 6), the period was re-coded as activity code 17-left blank/potential work during duty period.

- Two rest during duty period activities that were part of the tasks during a duty period (activity codes 3, 4, or 5), the blank period was recorded as activity code 19-left blank/potential rest during duty period.

- A work during duty period activity (activity code 1, 2, or 6) and a rest during duty period activity (activity codes 3,4 , or 5 ), the blank period was recorded as activity code 19/left blank/potential rest during duty period.

- A work during duty period activity (activity code 1, 2, or 6) and an off-duty activity (activity codes 7-15), the blank period was recorded as activity code 19-left blank/potential rest during duty period.

- Two off-duty activities (activity codes 7-15), then the time period was left as blank (activity code 16). 
- If the duration of a time period left blank (activity code 16) was greater than 6 hours, then the time period was left as blank (activity code 16).

\subsubsection{Calculating Breaks from Driving and a Shift}

Once the blank activity codes were adjusted and the activity register entries were adjusted based on the above criteria, driver breaks and the start and end times of each shift were calculated. For the purpose of this study, four different types of breaks from driving were identified:

- $\quad$ Break 1-Rest During Duty Period: Any consecutive duration of rest activities (activity codes: 3-sleep, 4-rest, 5-eating, or 19-rest during duty period) during the duty period.

- Break 2-Work During Duty Period: Any consecutive duration of work (activity codes: 2-heavy work, or 6-light work, or 17-work during duty period).

- $\quad$ Break 3-Rest During Duty Period /Off Duty: Any consecutive duration of rest activities during a duty period (activity codes: 3-sleep, 4-rest, 5-eating, or 19-rest during duty period), off-duty activity (activity codes: 7-sleep, 8-rest, 9-eating, 10-light house work, 11-heavy house work, 12-light leisure activity, 13-heavy leisure activity, 14-driving other vehicle, 15-other, 16-left blank/off duty) or any combination of these activities.

- Break 4-Off Duty: Any consecutive duration of off-duty activity (activity codes: 7sleep, 8-rest, 9-eating, 10-light house work, 11-heavy house work, 12-light leisure activity, 13-heavy leisure activity, 14-driving other vehicle, 15-other, 16-left blank/off duty).

A shift was defined as the duration of time from the start of a duty period activity (driving or non-driving work-related activity) to the end of another duty period activity. For example, shift 1 will start at the beginning of a driver's study participation time, and will increase in duration until the end of a driver's study participation time (e.g., approximately 4 weeks). The beginning of a shift was determined with the following criteria:

- At the end of any occurrence of break types 1,3 , or 4 that was greater than or equal to 10 hours in duration.

- If, during a 14-hour time period, the driver takes a Break 1 of greater than or equal to 8 hours but less than 10 hours AND either a Break 1, Break 3, or Break 4 of greater than or equal to 2 hours but less than 10 hours (in any order), then the start of the next shift was moved to the end of the first break period.

The HOS flowchart (Figure 10) was used to assist in the shift calculation, as well. Once the hybrid activity register was generated, it was necessary to calculate the exposure needed for the analyses of interest. During this process, cumulative driving hours and cumulative work hours were computed for each shift. This allowed the research team to determine how long the driver had been driving and working at the time of an SCE. 


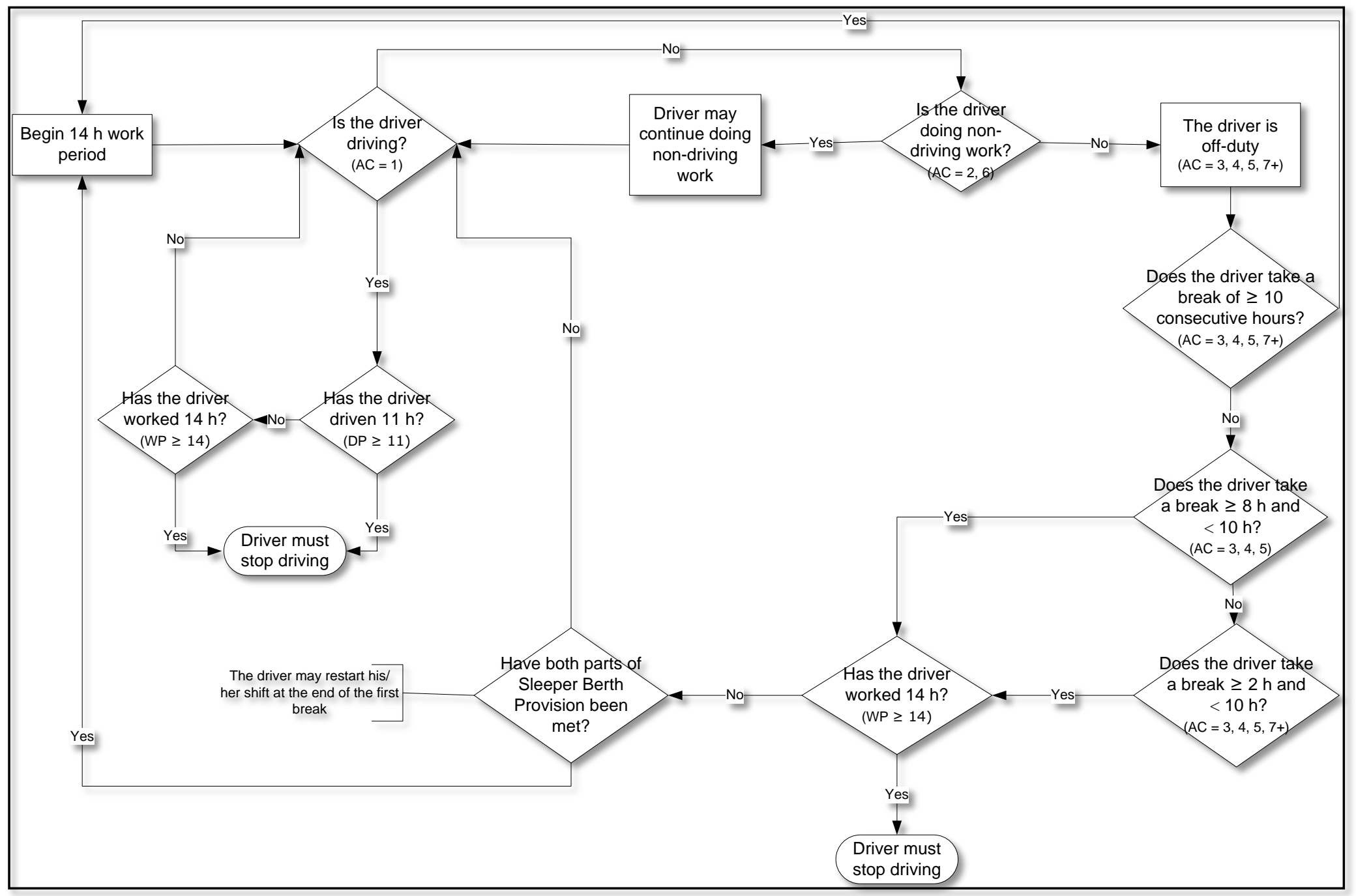

Figure 10. Flowchart. A Model of Current U.S. HOS Regulations 


\subsection{ANALYTICAL APPROACH}

\subsubsection{SCE Data Set}

A total of 2,197 SCEs from 97 drivers were included in the analyses. Data for 3 drivers from the original 100 drivers were removed, as 2 drivers did not complete an activity register during the study and 1 driver did not have valid vehicle data (video files were corrupt and unusable).

\subsubsection{SCE as a Function of Driving Hour}

This analysis considered how many hours the driver had been driving at the time of an SCE occurring. The rate of occurrence, for all SCEs as a function of driving hour, was calculated using data on how long a driver had been driving at the time of an SCE along with the exposure data. The data for this analysis were parsed and analyzed two ways:

- All Shifts: This included the entire data set, with the exception of information outlined above. This provided the largest data set available.

- All Shifts with Multiple Within-Hour SCE Collapsed: There were cases in which a given driving hour (for the same driver and the same shift) had multiple SCEs recorded. This analysis removed these multiples and treated SCEs as a Bernoulli random variable. Thus, for each hour there are two possible outcomes: either an SCE occurred in the hour or no SCE occurred in the hour. Only the most severe SCE was retained for this analysis; the SCE with the less severe classification was removed (e.g., in an hour with both a crash and a near-crash, the near-crash would be removed instead of the crash).

Each grouping of data was graphed to show the rate of SCE occurrence as a function of driving hour. The driving hour data for all shifts (non-dichotomous SCE counts) was analyzed with two mixed-effect negative binomial (NB) models. In the first model, the driving hour was considered continuous and in the second model, the driving hour was considered discrete. In addition, odds ratios were calculated to determine whether the rate of SCE occurrence was statistically different across driving hours. Under the assumption that the occurrence of SCEs was rare, the retrospective odds ratios provide an estimate of the prospective rate of SCE occurrence; therefore, the rate of SCE occurrence of driving in hour "I" versus hour "J" can be assessed with an odds ratio. This method was used in previous studies of SCE occurrence as a function of driving hour. ${ }^{(3)}$

To provide some background on this statistical technique, an odds ratio is a measure of association commonly employed in the analysis of $2 \times 2$ contingency tables. ${ }^{(35)}$ The data for this analysis can be displayed as a $2 \times 2$ contingency table, as shown in Table 10 .

Table 10. $2 \times 2$ Contingency Table Used to Calculate Odds Ratio

\begin{tabular}{|l|c|c|c|}
\hline \multicolumn{1}{|c|}{ Shift Hour } & $\begin{array}{c}\text { Incident } \\
\text { Occurrence }\end{array}$ & $\begin{array}{c}\text { No Incident } \\
\text { Occurrence }\end{array}$ & $\begin{array}{c}\text { Total Opportunity for } \\
\text { Incident Occurrence }\end{array}$ \\
\hline Hour "l" of Shift & $\mathrm{n}_{11}$ & $\mathrm{n}_{12}$ & $\mathrm{n}_{1 .}$ \\
\hline Hour "J" of Shift & $\mathrm{n}_{21}$ & $\mathrm{n}_{22}$ & $\mathrm{n}_{2 .}$ \\
\hline Total & $\mathrm{n}_{.1}$ & $\mathrm{n}_{.2}$ & $\mathrm{n}_{. .}$ \\
\hline
\end{tabular}


Odds of occurrence were defined as the probability of event occurrence divided by the probability of non-occurrence. Figure 11 was used to perform the calculation to determine the odds ratio in order to assess the increase in probability of having an SCE in hour "I" versus hour "J":

$$
\text { Odds Ratio }=\left(n_{11}\right)\left(n_{22}\right) /\left(n_{21}\right)\left(n_{12}\right)
$$

Figure 11. Equation. Formula Used to Assess Probability of Having an SCE by Odds Ratio

A second analysis was conducted to examine the relationship between SCE rate and driving hour at the individual shift level. For shifts that went into the 11th driving hours, the SCE rate was calculated for the 8th, 9th, 10th, and 11th driving hours. The 11th hour was then compared to the 8th, 9th, and 10th hours using a mixed-effect NB regression model with logarithm link. Using this model allowed for comparisons to be made at the individual shift level, to determine if an increase in driving hours was associated with an increase in SCE rate. This analysis was important because each driver's "normal driving" might be characterized by a different SCE rate, and each driver's rate could be high or low for all driving hours. This allowed for an examination of whether or not SCE rates are higher than expected for that particular shift in the 8th, 9th, and 10th hours.

\subsubsection{SCE as a Function of Work Hour}

For this analysis, SCEs were grouped by driving hour (similar to the previous analysis) and each driving hour was classified based on when it occurred during the 14-hour workday. An example is used to illustrate the analysis approach. Consider a driver who performs 2 hours of non-driving work (e.g., paper work) at the start of a shift, followed by 3 hours of driving. In this example, the driver has accumulated 3 hours of driving time, but 5 hours of work time. Additionally, the 1st driving hour began in the 3rd working hour, the 2nd driving hour began in the 4th working hour, and the 3rd driving hour began in the 5 th working hour. At this point in time, the driver would be 5 hours into his 14-hour workday. Consider a second driver who starts his shift by driving for 3 hours, followed by a 2-hour break to eat. In this example, the 1st driving hour coincided with the 1st working hour, and so on. After his 2-hour break is finished, this driver, like the driver in the first example, would be 5 hours into his 14-hour workday. In both examples, the drivers have completed 3 hours of driving within 5 hours of the workday. However the driving hour-work hour combinations are different. For the driver in the first example, the driving hour-work hour combinations are: 1-3, 2-4, and 3-5 while the driving hour-work hour combinations for the second driver are: 1-1, 2-2, and 3-3.

There were 99 different driving hour-work hour combinations in the current data set, many of which had a very small sample size such that it was not possible to analyze every combination independently. Therefore, the 14-hour workday was divided into three categories: Beginning (work hours 1-5), Middle (work hours 6-9), and End (work hours 10-14). Translating this work hour grouping strategy from individual work hours, the combination "driving hour 1-work hour 1 " (a driver started the workday by driving 1 hour) would be "driving hour 1-work hour Beginning." The combination "driving hour 1-work hour 10" (the driver did not start driving until he had been on duty for 10 hours) would be "driving hour 1-work hour End." Therefore, the work hour categories Beginning, Middle, and End can be thought of as intervals within the 14hour workday that the driver was driving. The three work hour categories reduced the number of 
driving hour-work hour combinations. This resulted in a larger sample size for each driving hour-work hour combination and provided the opportunity to analyze whether the SCE rate per driving hour changed depending on when during the workday (Beginning, Middle, or End) the driving hour occurred.

The data for this analysis were parsed and analyzed in the same two categories as in the analysis of SCEs as a function of driving hour: All Shifts and All Shifts with Multiple Within-Hour SCEs Collapsed. Each grouping of data was plotted to show the rate of SCE occurrence as a function of the driving hour-work hour combination. Odds ratios were also calculated to determine whether the rate of SCE occurrence was statistically different across each driving hour and work hour combination.

\subsubsection{Safety Impact of Breaks from Driving}

This analysis considered both driving and non-driving activities as predictors in modeling risk of an SCE. Breaks, as defined previously, consisted of all non-driving activities marked in the activity register. Note that breaks analyzed were those that occurred during the workday and not shift (e.g., 10 hours) or restart (e.g., 34 hours) "breaks." In this analysis, only breaks from driving that were at least 30 minutes in duration and did not start a new shift were included in the analyses, and a single break from driving could be made up of successive breaks of different types, as long as the total break from driving was at least 30 minutes.

A mixed-effect NB model with logarithm link function was used to model SCE rate at the shift level. The NB model allows for the assumptions that the number of SCEs for a shift was generated from a stochastic process (e.g., random) and that the expected event rate is a function of various predictors. Factors included in the model included the number of breaks over shift, working hours, and exposure. This analysis was first conducted using all breaks. A follow-up model of the same type was created using frequency of breaks for each break type as predictor variables.

Follow-up analyses were conducted and breaks were characterized by the number of breaks per shift, type of break per shift, and driving hour when the break starts. Further analysis examined whether there were more SCEs immediately before or after a break. To conduct this analysis, the number of SCEs in a 1-hour window before and after a break was determined. A mixed-effect NB regression model with logarithm link was again used to determine if there was a meaningful relationship between the 1-hour window before a break and the 1-hour window after a break as the predictor, and SCE rate as the response variable. This analysis was conducted for breaks overall and for each individual break type. 


\section{RESULTS}

\subsection{THE AVERAGE CMV DRIVER WORKDAY}

Drivers are restricted to 11 driving hours during a 14-hour workday, and the breakdown of activities during a CMV driver's workday has not been extensively studied in the literature. This study opens a window into the driver's workday that was not available before, as the activity register provided a detailed account of the tasks that CMV drivers performed while they were not driving. Until now, the most detailed knowledge available for a CMV driver's workday was for L/SH operations (Figure 12). ${ }^{(30)}$

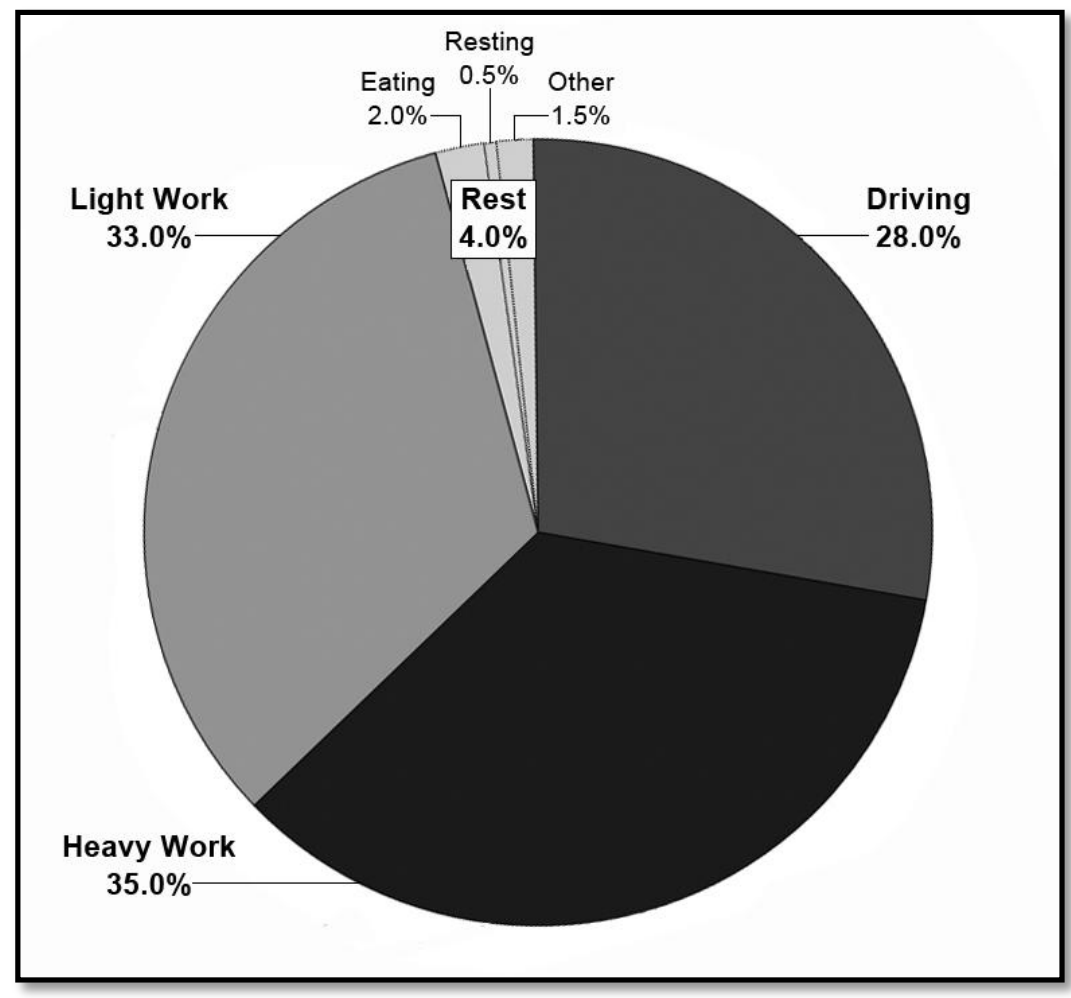

Figure 12. Pie Chart. Proportion of Tasks Performed During an Average Workday for Local/Short Haul Drivers. (Adapted from Hanowski et al. 2000) ${ }^{(29)}$

From Hanowski et al., ${ }^{(30)}$ it can be seen that $\mathrm{L} / \mathrm{SH}$ drivers drive, on average, for 28 percent of their workday. The majority of their workday, 68 percent, is comprised of non-driving work activities. For L/SH operations, loading/unloading (i.e., heavy work) accounted for 35 percent, which was the largest proportion of the drivers' workday. In addition, drivers spent 4 percent of their workday resting (e.g., 2 percent was spent eating, 0.5 percent was spent resting, and 1.5 percent was spent doing other, non-driving activities).

The activity register data used in the current study provided a detailed account of the tasks that CMV drivers performed during their workday. Figure 13 shows the data from the current study, for all drivers, across an average workday. The majority of their day, 65.7 percent, was spent driving while 4.1 percent was spent doing heavy work (e.g., loading/unloading), 18.7 percent 
was spent doing light work (e.g., paperwork), and 11.5 percent was spent resting (e.g., 4.4 percent spent sleeping, 4.7 percent spent resting, and 2.4 percent spent eating). These last three categories were considered "breaks from driving." However, it should be noted that some of these breaks from driving were taken to perform additional work-related tasks and others were taken to rest.

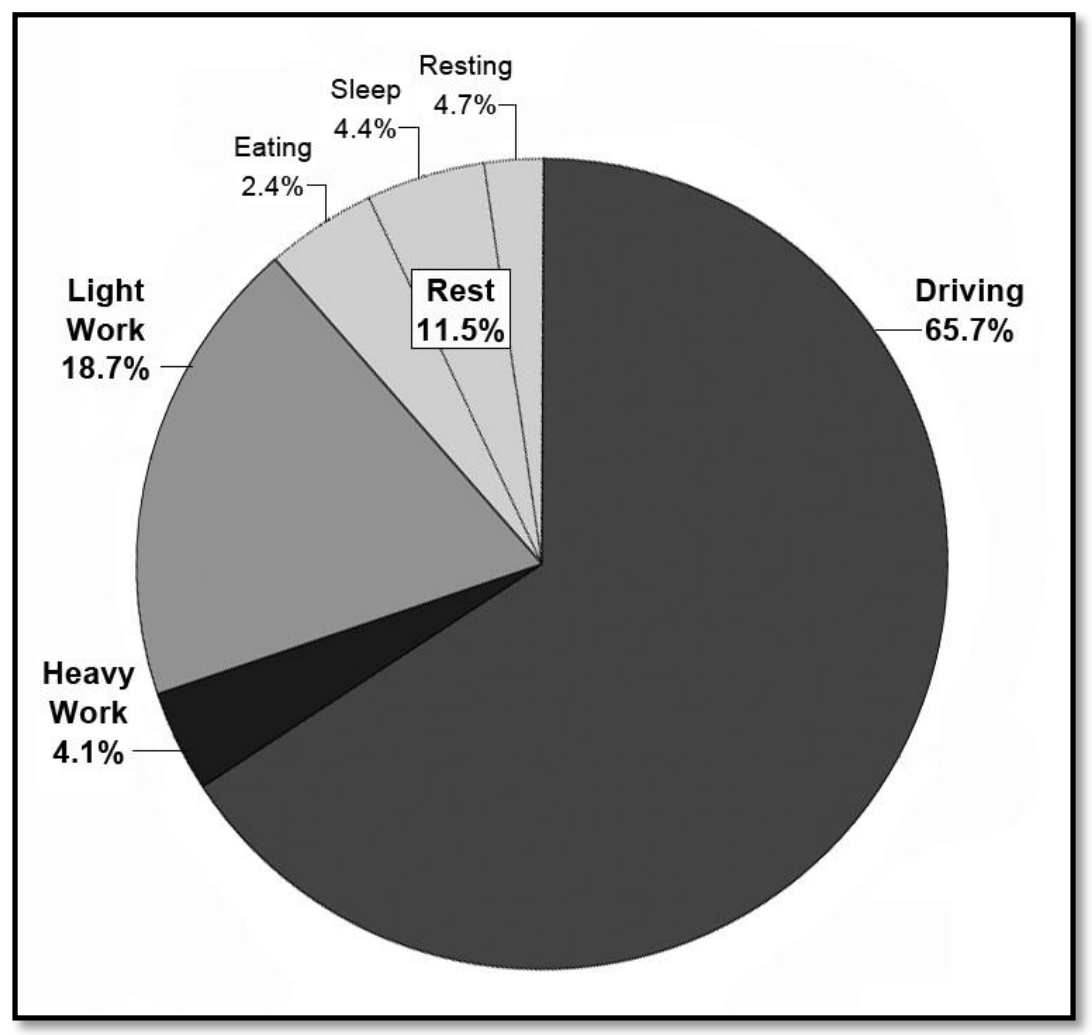

Figure 13. Pie Chart. Proportion of Tasks Performed During an Average Workday, for All Drivers in the Current Study

The data from the current study were also segmented by line-haul and long-haul drivers to see how their average workday may differ across operation types. Figure 14 shows the data for linehaul drivers, across an average workday. The majority of their day, 59.9 percent, was spent driving, while 12 percent was spent doing heavy work (e.g., loading/unloading), 25.4 percent was spent doing light work (e.g., paperwork), and only 2.6 percent was spent resting (e.g., 1.1 percent spent eating, 0.5 percent spent sleeping, and 1.0 percent spent resting). 


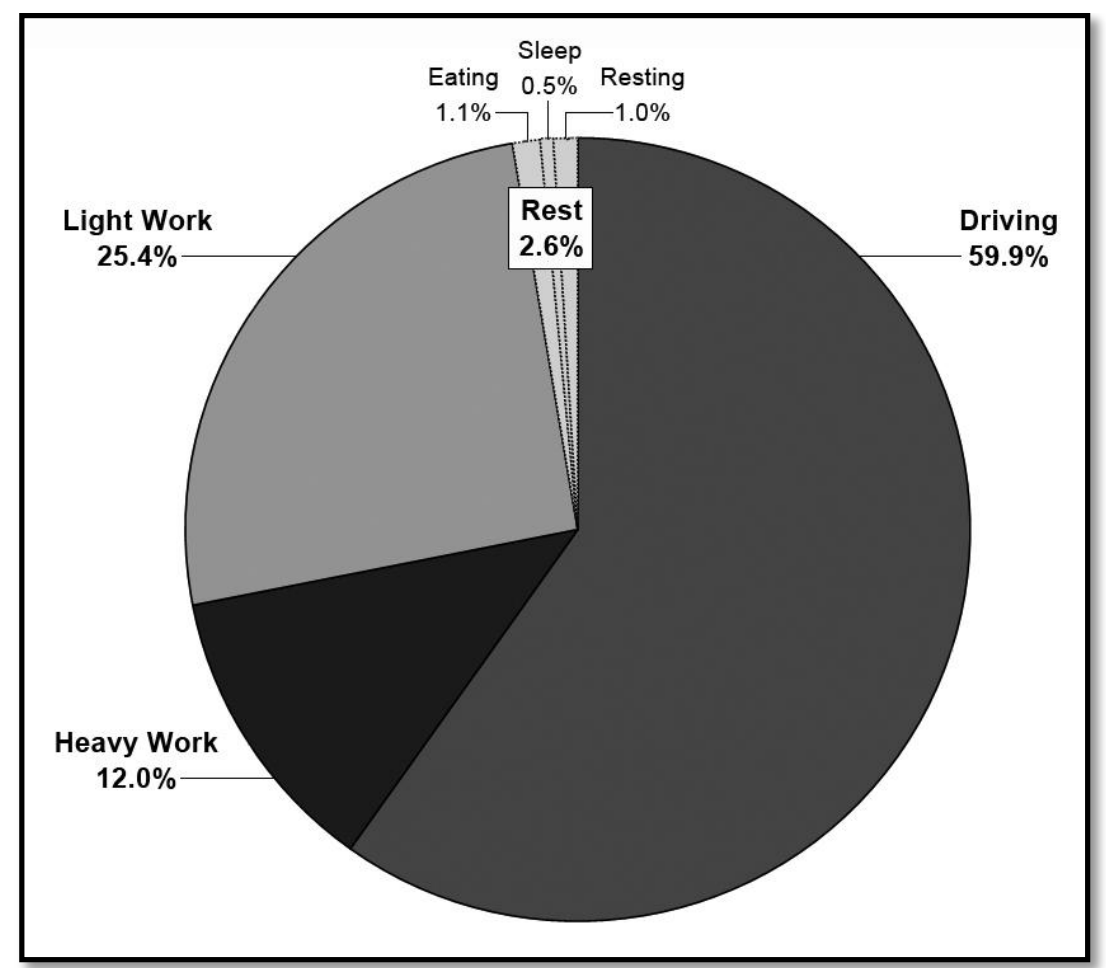

Figure 14. Pie Chart. Proportion of Tasks Performed During an Average Workday, for Line-Haul Drivers in the Current Study

Figure 15 shows the data for long-haul drivers, across an average workday. The majority of their day, 67.7 percent, was spent driving while 2 percent was spent doing heavy work (e.g., loading/unloading), 17.4 percent was spent doing light work (e.g., paperwork), and 12.8 percent was spent resting (e.g., 2.3 percent spent eating, 5.1 percent spent sleeping, and 5.4 percent spent resting). 


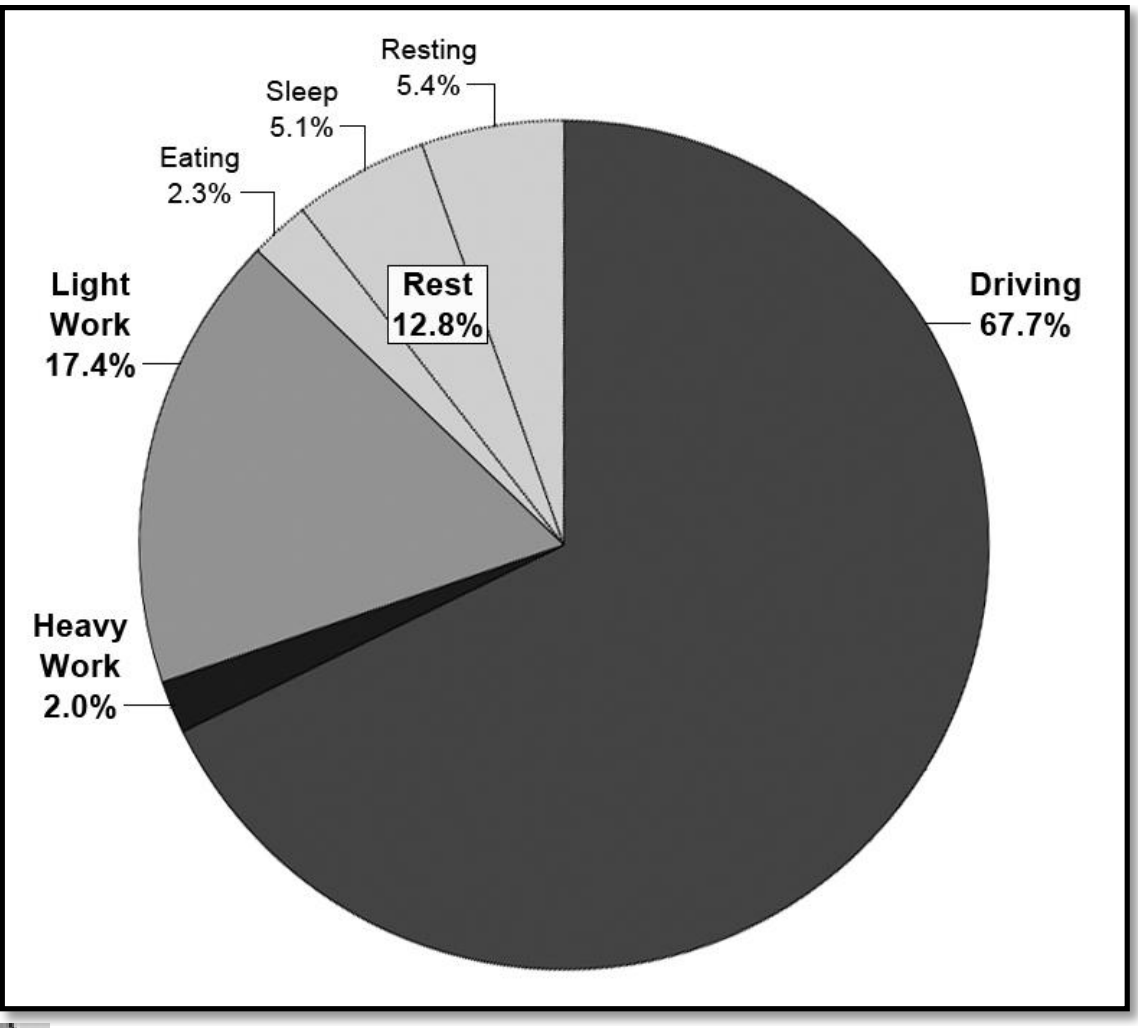

Figure 15. Pie Chart. Proportion of Tasks Performed During an Average Workday, for Long-Haul Drivers in the Current Study

Comparing the average workdays of line-haul and long-haul drivers, it can be seen that long-haul drivers spent relatively more time driving (68 percent) as compared to line-haul drivers (60 percent). For long-haul drivers, given that a larger proportion of their workday was spent driving, their non-driving work (19 percent) was much less than that of the line-haul drivers (37 percent). Finally, line-haul drivers spent proportionally less time resting ( 3 percent) as compared to longhaul drivers (13 percent).

\subsection{SAFETY-CRITICAL EVENTS AS A FUNCTION OF DRIVING HOUR}

\subsubsection{Evaluation of All Shifts}

The data set used in this analysis included all data that occurred in driving hours 1-11. However, drivers did not necessarily always reach the 11th driving hour. This included 2,197 SCEs: 4 crashes, 7 curb strikes, 46 near-crashes, 1,022 crash-relevant conflicts, and 1,118 unintentional lane deviations recorded over 1,881 shifts. The frequencies of crashes, curb strikes, and nearcrashes were too small to conduct any meaningful analyses independent of the crash-relevant conflicts and the unintentional lane deviations. Decades of previous research have suggested that unintentional lane deviations provide a reliable indicator of fatigue. (See references 36, 37, 38, and 39.) Thus, these two, less-severe, measures were also included in the analyses. As illustrated in the previous section, drivers typically performed non-driving activities during a shift; therefore, for 1,452 shifts (approximately 77 percent of all shifts) drivers drove into the 10th 
hour or less. Analyses were also conducted that included only the 429 shifts (approximately 23 percent of all shifts) where drivers drove into the 11th hour.

Table 11 shows the data set for the first analysis, which included all SCEs, and all driving opportunities (shifts), that occurred in the 1st-11th driving hours. Each driving hour has a different number of opportunities to be involved in an SCE. For example, a driver may have driven into the 10th hour but not into the 11th hour; as a result, there were fewer opportunities to be involved in an SCE in the 11th hour. To adjust and account for the differences in opportunities across driving hour, a rate was calculated. This rate was calculated as the frequency of SCEs, in any given driving hour, divided by the total opportunities for that hour. As noted previously, it is important to point out that the data in Table 11 includes cases where multiple SCEs were recorded in the same driving hour; a follow-up analysis, presented later, removed the multiple cases to set up a dichotomous variable providing a more direct analysis of the effects of driving hour.

Table 11. SCEs and Total Opportunities by Driving Hour for Hours 1-11

\begin{tabular}{|c|c|c|c|}
\hline $\begin{array}{c}\text { Driving } \\
\text { Hour }\end{array}$ & $\begin{array}{c}\text { SCEs Per } \\
\text { Driving Hour }\end{array}$ & $\begin{array}{c}\text { Total Opportunities Per } \\
\text { Driving Hour }\end{array}$ & $\begin{array}{c}\text { Rate of SCE/Total } \\
\text { Opportunities }\end{array}$ \\
\hline 1 & 218 & $1,864.60$ & 0.117 \\
\hline 2 & 230 & $1,826.97$ & 0.126 \\
\hline 3 & 235 & $1,786.90$ & 0.132 \\
\hline 4 & 285 & $1,715.56$ & 0.166 \\
\hline 5 & 263 & $1,612.94$ & 0.163 \\
\hline 6 & 265 & $1,477.66$ & 0.179 \\
\hline 7 & 248 & $1,261.41$ & 0.197 \\
\hline 8 & 154 & $1,021.06$ & 0.151 \\
\hline 9 & 125 & 808.78 & 0.155 \\
\hline 10 & 98 & 553.16 & 0.177 \\
\hline 11 & 76 & 321.48 & 0.236 \\
\hline
\end{tabular}

Figure 16 plots the number of opportunities for each driving hour. The opportunities represent the shifts that included that driving hour and are calculated using the exact amount of time that the driver drove into that shift. For example, if the driver drove 8.5 hours, there would be one opportunity each in hours 1-8 and 0.5 in hour 9 . Not surprisingly, the number of opportunities drops off as the number of driving hours increases. Thus, by the time drivers reach the 11th hour, many of the shifts had concluded. This suggests that drivers in the current study did not always drive 11 hours, but rather stopped their shifts short of the 11th hour. 


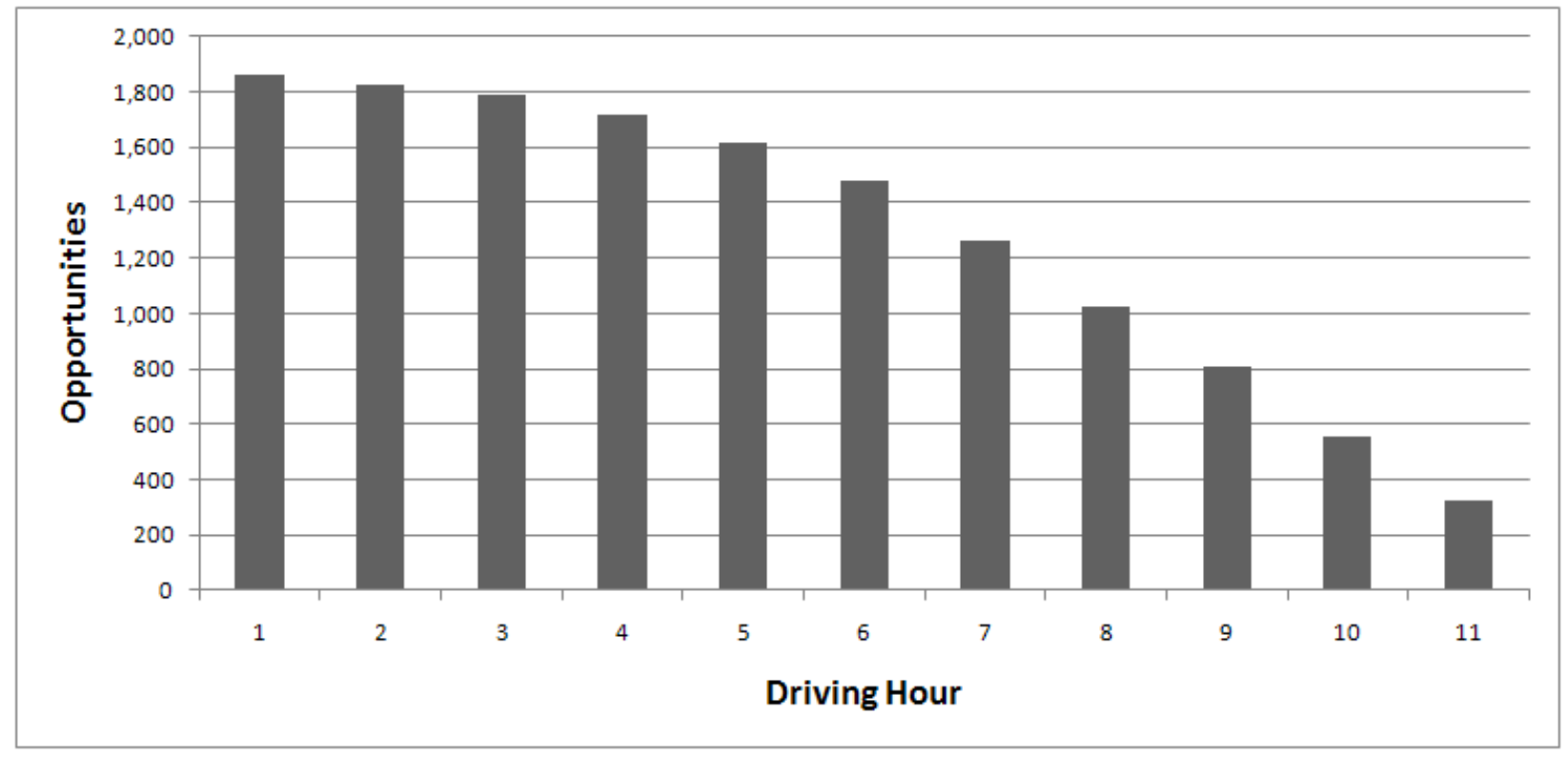

Figure 16. Bar Graph. Total Opportunities for Driving Hours 1-11

Figure 17 shows the rate of SCE occurrence as a function of driving hour for hours $1-11$. A breakdown by frequency for each type of SCE is shown, including crashes, curb strikes, nearcrashes, crash-relevant conflicts, unintentional lane deviations, and all SCEs.

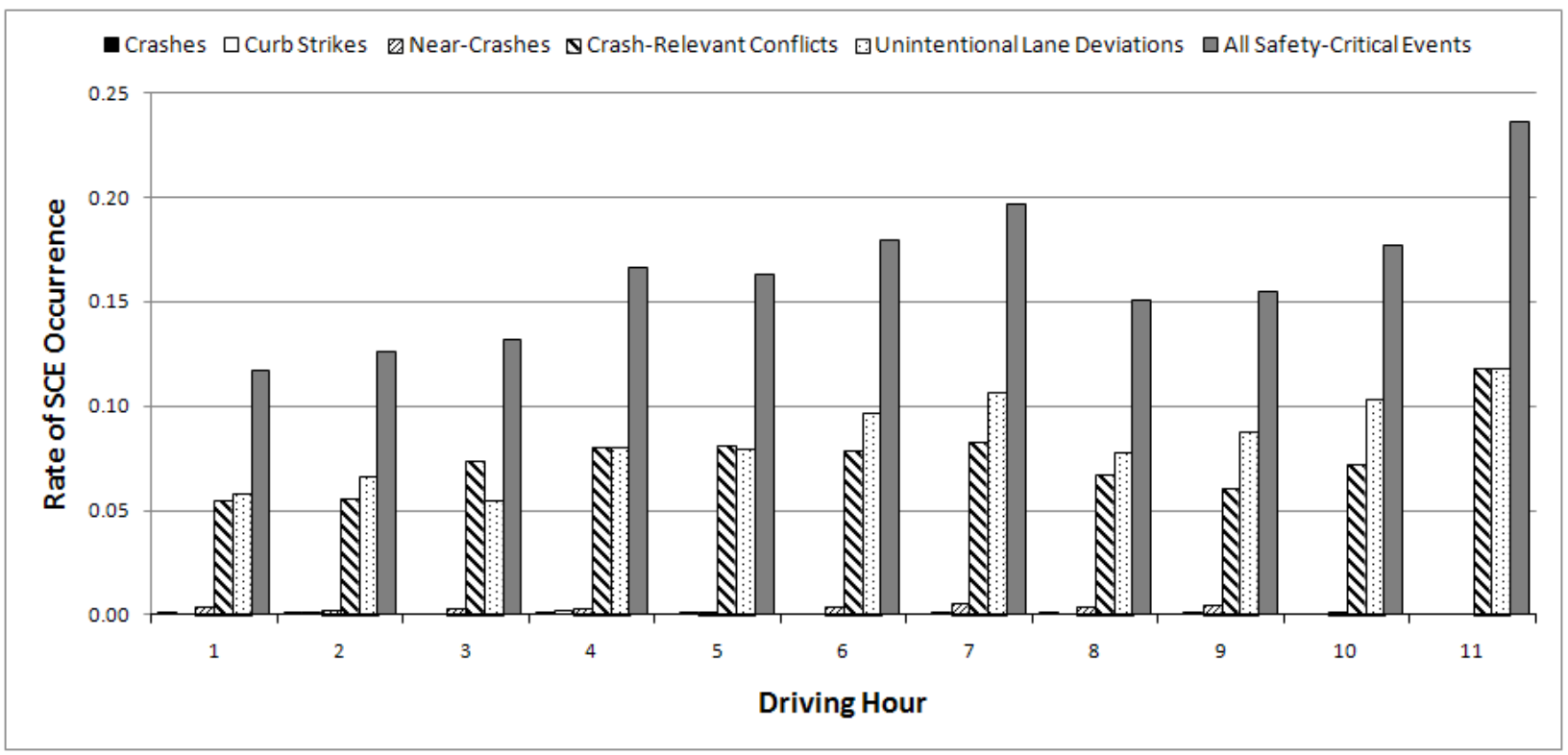

Figure 17. Bar Graph. Rate of SCE Occurrence as a Function of Driving Hour

In the first analysis, using the data presented in Table 11, driving hour was treated as a continuous variable. A mixed-effect NB regression model was used to assess the impact of driving hour on SCE rate. The data were stratified by subject, shift, and driving hour. The number of SCEs and exact driving time was calculated for each stratum. The model assumes the number of SCEs is from an NB distribution, whose rate is a function of driving hour. The exact 
driving time was treated as an offset. Since each driver has multiple shifts, a driver's specific random intercept was used to account for this effect.

The results of the NB model are shown in Table 12. The driving hour effect was statistically significant $\left(p_{\text {Driving Hour }}=0.0014\right.$ ). The point estimate of the effect of the driving hour is positive $(0.03625)$ - this result implies that as the driving hour increases, the SCE rate will also increase.

Table 12. SCE Rate as a Function of Driving Hour as a Continuous Variable, using Total Opportunities for Driving Hours 1-11

\begin{tabular}{|c|c|c|c|c|c|}
\hline Effect & Estimate & SE & df & $\boldsymbol{t}$ & $\boldsymbol{p}$ \\
\hline Intercept & -2.8581 & 0.1506 & 96 & -18.98 & $<0.0001$ \\
\hline Driving Hour & 0.0363 & 0.0113 & 14841 & 3.20 & 0.0014 \\
\hline
\end{tabular}

This result indicates only that there is a significant different across hours, but does not provide the power to determine which specific driving hours have significantly different SCE rates. In addition, this model assumes that there is one constant rate of increase between each adjacent hour; that is, the increase in SCE rate from the 1st hour to the 2nd hour is exactly the same as the increase in SCE rate from the 10th hour to the 11th hour. A follow-up analysis that addressed these concerns is shown below.

A second analysis, using the data presented in Table 11, used a mixed-effect NB regression model and treated driving hour as a discrete variable. This model, using driving hour as a discrete variable, does not rely on the assumption of one constant increase in SCE rate across driving hours. This second analysis provided an opportunity to examine the difference between the 11th driving hour and all other driving hours. The results of the model are shown in Table 13. The overall effect of driving hours was still significant $(p=0.02)$, indicating an impact on SCE rate. However, when examining the differences between the 11th driving hour and all other driving hours (Table 14), the only significant results were between the 11th driving hour and the 1 st and 2 nd driving hours. The SCE rate in the 11th driving hour was not significantly different from the SCE rate in the 3rd through 10th driving hours (all $p$ 's $>0.05$ ).

Table 13. SCE Rate as a Function of Driving Hour as a Discrete Variable, using Total Opportunities for Driving Hours 1-11

\begin{tabular}{|c|c|c|c|c|}
\hline Effect & Numerator df & Denominator df & $\boldsymbol{F}$ & $\boldsymbol{p}$ \\
\hline Driving Hour & 10 & 14832 & 2.08 & 0.0225 \\
\hline
\end{tabular}


Table 14. Comparing Individual Driving Hours for Differences in SCE Rates

\begin{tabular}{|c|c|c|c|c|c|}
\hline Contrast Between Driving Hours & Estimate & $\boldsymbol{P}$ & $\boldsymbol{\alpha}$ & LCL & UCL \\
\hline 11 versus 1 & 0.4684 & 0.0202 & 0.05 & 0.0730 & 0.8638 \\
\hline 11 versus 2 & 0.4839 & 0.0162 & 0.05 & 0.0896 & 0.8782 \\
\hline 11 versus 3 & 0.3912 & 0.0515 & 0.05 & -0.0026 & 0.7851 \\
\hline 11 versus 4 & 0.3367 & 0.0932 & 0.05 & -0.0564 & 0.7298 \\
\hline 11 versus 5 & 0.3050 & 0.1313 & 0.05 & -0.0912 & 0.7012 \\
\hline 11 versus 6 & 0.1831 & 0.3635 & 0.05 & -0.2119 & 0.5781 \\
\hline 11 versus 7 & 0.0459 & 0.8213 & 0.05 & -0.3524 & 0.4442 \\
\hline 11 versus 8 & 0.2619 & 0.2149 & 0.05 & -0.1520 & 0.6757 \\
\hline 11 versus 9 & 0.4221 & 0.0550 & 0.05 & -0.0091 & 0.8533 \\
\hline & 0.2378 & 0.3005 & 0.05 & -0.2124 & 0.6881 \\
\hline
\end{tabular}

As can be seen in Table 14, though there was an effect of driving hour as determined in the NB model (Table 12), the effect as a function of the 11th driving hour was significant only for the early driving hours and not for the 10th driving hour $(p=0.3)$. The data from Table 11 can also be represented as a line plot (Figure 18). Though this approach visually demonstrates the overall statistically significant finding across all hours (as determine by the NB model), it is important to note that the key pair-wise comparison of 10th versus 11th driving hour, failed to reach statistical significance $(p=0.3)$.

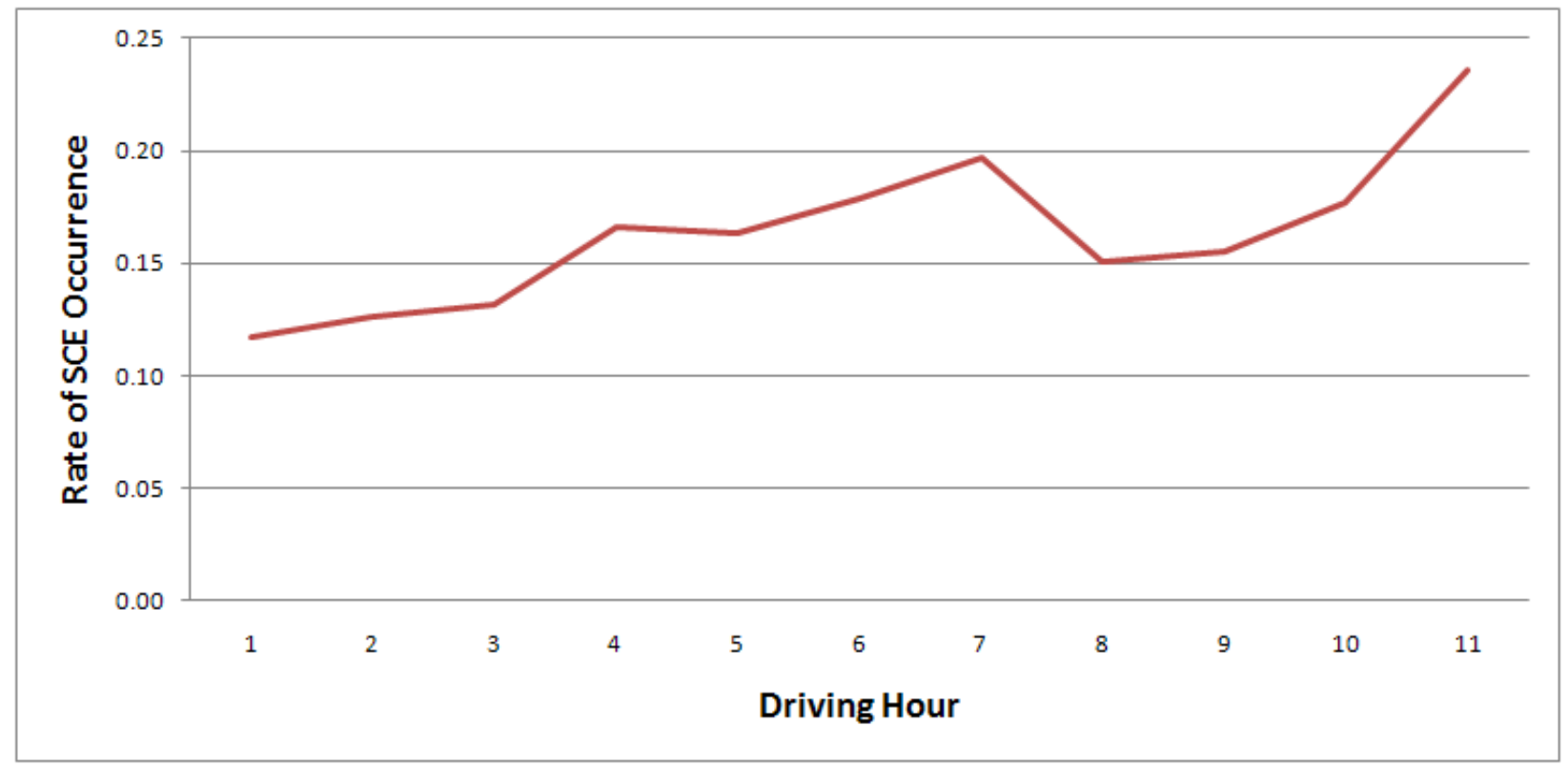

Figure 18. Line Graph. Rate of SCE Occurrence as a Function of Driving Hour

In assessing the safety impact of driving hour, the results from this analysis suggest that though there is an overall time-on-task effect across hours, there was no statistically significant difference in the SCE rate between the 10th and 11th driving hour. To further investigate 
potential time-on-task effects as a function of driving hour, odds ratios were calculated in a follow-on analysis that collapsed over SCEs per driving hour (shown next).

\subsubsection{Evaluation of All Shifts with Multiple Within-Hour SCEs Collapsed}

As noted, the larger data set included multiple SCEs that may have been recorded in the same hour of the same shift, and for the same driver. There are several approaches in which these data can be analyzed. One approach is to include every SCE for each participant on a given hour, with the assumption that this is a better representation of the risk associated with the given hour (this is the approach used in the previous analysis). An alternative method is to evaluate solely the presence or absence of an SCE within a given hour in order to prevent a minority of participants with high SCE rates (outliers) from artificially inflating the overall SCE rate. ${ }^{(40)}$ This latter method was used for this analysis and results in a dichotomous variable, with either the occurrence or non-occurrence of an SCE for each driving hour. Note that this analysis includes all available data, and treats SCE as a dichotomous variable within each driving hour. Table 15 shows the data set where multiple SCEs (same hour, during the same shift), were collapsed and Figure 19 shows the data plotted.

Table 15. SCEs and Total Opportunities by Driving Hour for Hours 1-11, with Multiple Within-Hour SCEs Collapsed

\begin{tabular}{|c|c|c|c|}
\hline $\begin{array}{c}\text { Driving } \\
\text { Hour }\end{array}$ & $\begin{array}{c}\text { SCEs Per } \\
\text { Driving Hour }\end{array}$ & $\begin{array}{c}\text { Total Opportunities } \\
\text { Per Driving Hour }\end{array}$ & $\begin{array}{c}\text { Rate of SCE/Total } \\
\text { Opportunities }\end{array}$ \\
\hline 1 & 151 & $1,864.60$ & 0.081 \\
\hline 2 & 144 & $1,826.97$ & 0.079 \\
\hline 3 & 159 & $1,786.90$ & 0.089 \\
\hline 4 & 146 & $1,715.56$ & 0.085 \\
\hline 5 & 147 & $1,612.94$ & 0.091 \\
\hline 6 & 133 & $1,477.66$ & 0.090 \\
\hline 7 & 130 & $1,261.41$ & 0.103 \\
\hline 8 & 99 & $1,021.06$ & 0.097 \\
\hline 9 & 74 & 808.78 & 0.091 \\
\hline 10 & 55 & 553.16 & 0.099 \\
\hline 11 & 31 & 321.48 & 0.096 \\
\hline
\end{tabular}




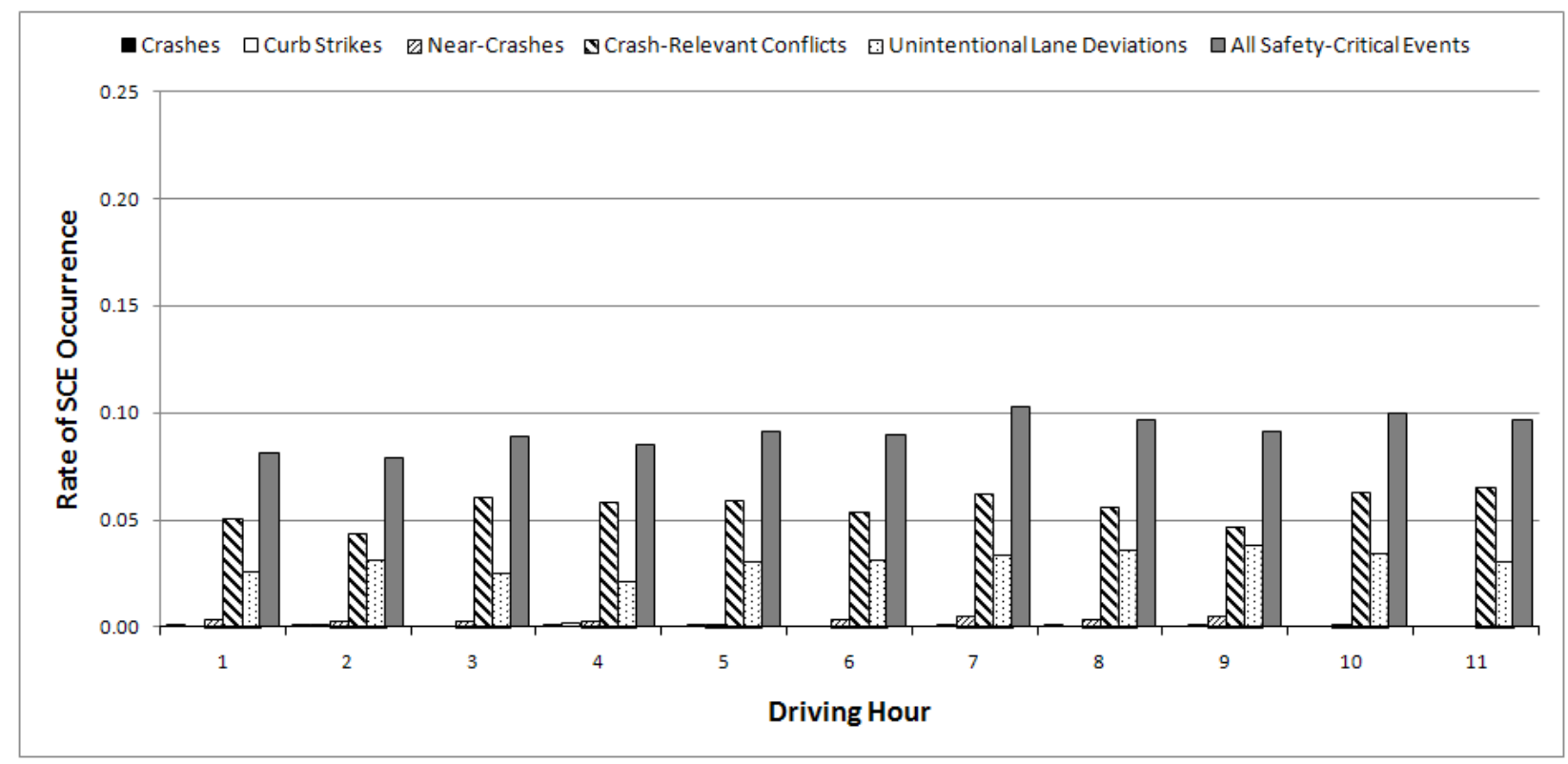

Figure 19. Rate of SCE Occurrence as a Function of Driving Hour, with Multiple Within-Hour SCEs Collapsed

Table 16. SCEs and Total Shifts by Driving Hour for Hours 1-11, with Multiple Within-Hour SCEs Collapsed-Data Used to Calculate Odds Ratios

\begin{tabular}{|c|c|c|c|}
\hline $\begin{array}{c}\text { Driving } \\
\text { Hour }\end{array}$ & $\begin{array}{c}\text { SCEs Per } \\
\text { Driving Hour }\end{array}$ & $\begin{array}{c}\text { Total Number of Shifts } \\
\text { per Driving Hour }\end{array}$ & $\begin{array}{c}\text { Rate of SCE/Total } \\
\text { Shifts }\end{array}$ \\
\hline 1 & 151 & 1,881 & 0.080 \\
\hline 2 & 144 & 1,845 & 0.078 \\
\hline 3 & 159 & 1,809 & 0.088 \\
\hline 4 & 146 & 1,761 & 0.083 \\
\hline 5 & 147 & 1,669 & 0.088 \\
\hline 6 & 133 & 1,557 & 0.085 \\
\hline 7 & 130 & 1,395 & 0.093 \\
\hline 8 & 99 & 1,128 & 0.088 \\
\hline 9 & 74 & 923 & 0.080 \\
\hline 10 & 55 & 698 & 0.079 \\
\hline 11 & 31 & 429 & 0.072 \\
\hline
\end{tabular}

Odds ratios were calculated and analyzed using the data shown in Table 16. Table 17 shows the results of the odds ratio analysis for the 11th driving hour compared to the 8th, 9th, and 10th driving hours, along with the lower (LCL) and upper (UCL) confidence limits. No statistically significant results were found among any of the driving hours. ( $p>0.05$ for all comparisons) (see appendix A for all odds ratios calculated as part of this analysis). 
Table 17. Results from the Odds Ratio Analyses

\begin{tabular}{|c|c|c|c|}
\hline $\begin{array}{c}\text { Comparison of } \\
\text { Driving Hours }\end{array}$ & Odds Ratio & LCL & UCL \\
\hline 11 versus 8 & 0.81 & 0.53 & 1.23 \\
\hline 11 versus 9 & 0.89 & 0.58 & 1.38 \\
\hline 11 versus 10 & 0.91 & 0.58 & 1.44 \\
\hline
\end{tabular}

\subsubsection{Evaluation of Only Shifts with 11 Driving Hours}

In the current U.S. regulations, drivers are restricted to 11 driving hours during a 14-hour workday. The focus of these analyses was on the driving hour component of the HOS regulations. The purpose of the analysis was to investigate if there were significant differences in the rate of being involved in an SCE, as a function of driving hour; that is, does the 11th hour of driving presenting a higher rate of SCEs over the 10th hour or any of the other driving hours?

Several subanalyses were conducted. First, all shifts where drivers drove into the 11th hour were examined. In order to compare a driver's performance in each of the 11 driving hours, only data where drivers drove into each of the hours were included. This data set included drivers who had a full opportunity (drove throughout the entire driving hour) to drive into hours 1 through 10 and a partial to full opportunity to drive into the 11th hour. Table 18 shows the data used for this analysis.

Table 18. SCEs and Total Opportunities by Driving Hour for Hours 1-11, for Shifts That Went Into the 11th Driving Hour

\begin{tabular}{|c|c|c|c|}
\hline $\begin{array}{c}\text { Driving } \\
\text { Hour }\end{array}$ & $\begin{array}{c}\text { SCEs Per Driving Hour } \\
\text { for 11th Driving Hour } \\
\text { Shifts }\end{array}$ & $\begin{array}{c}\text { Total Opportunities Per } \\
\text { Driving Hour for 11th } \\
\text { Driving Hour Shifts }\end{array}$ & $\begin{array}{c}\text { Rate of SCE/Total } \\
\text { Opportunities }\end{array}$ \\
\hline 1 & 53 & 429 & 0.124 \\
\hline 2 & 71 & 429 & 0.166 \\
\hline 3 & 63 & 429 & 0.147 \\
\hline 4 & 67 & 429 & 0.156 \\
\hline 5 & 72 & 429 & 0.168 \\
\hline 6 & 82 & 429 & 0.191 \\
\hline 7 & 86 & 429 & 0.200 \\
\hline 8 & 75 & 429 & 0.175 \\
\hline 9 & 62 & 429 & 0.145 \\
\hline 10 & 66 & 429 & 0.154 \\
\hline 11 & 76 & 321.48 & 0.236 \\
\hline
\end{tabular}

As shown in Table 18, there were 429 shifts in which the driver drove a full 10 hours. However, not all drivers drove a full 11 hours and this is reflected in the 321.48 number shown in the Opportunities column. The 321.48 represents the partial amount of time that drivers drove into the 11th hour. To explain by example, if one driver drove 10.5 hours and a second driver drove 10.2 hours, that would be a total of 0.7 hours of driving into the 11 th hour for these two drivers. For this analysis, all SCEs within a driving hour (for the same driver and the same shift) were 
included. The overall rate of SCE occurrence, presented by SCE type, is shown plotted in Figure 20.

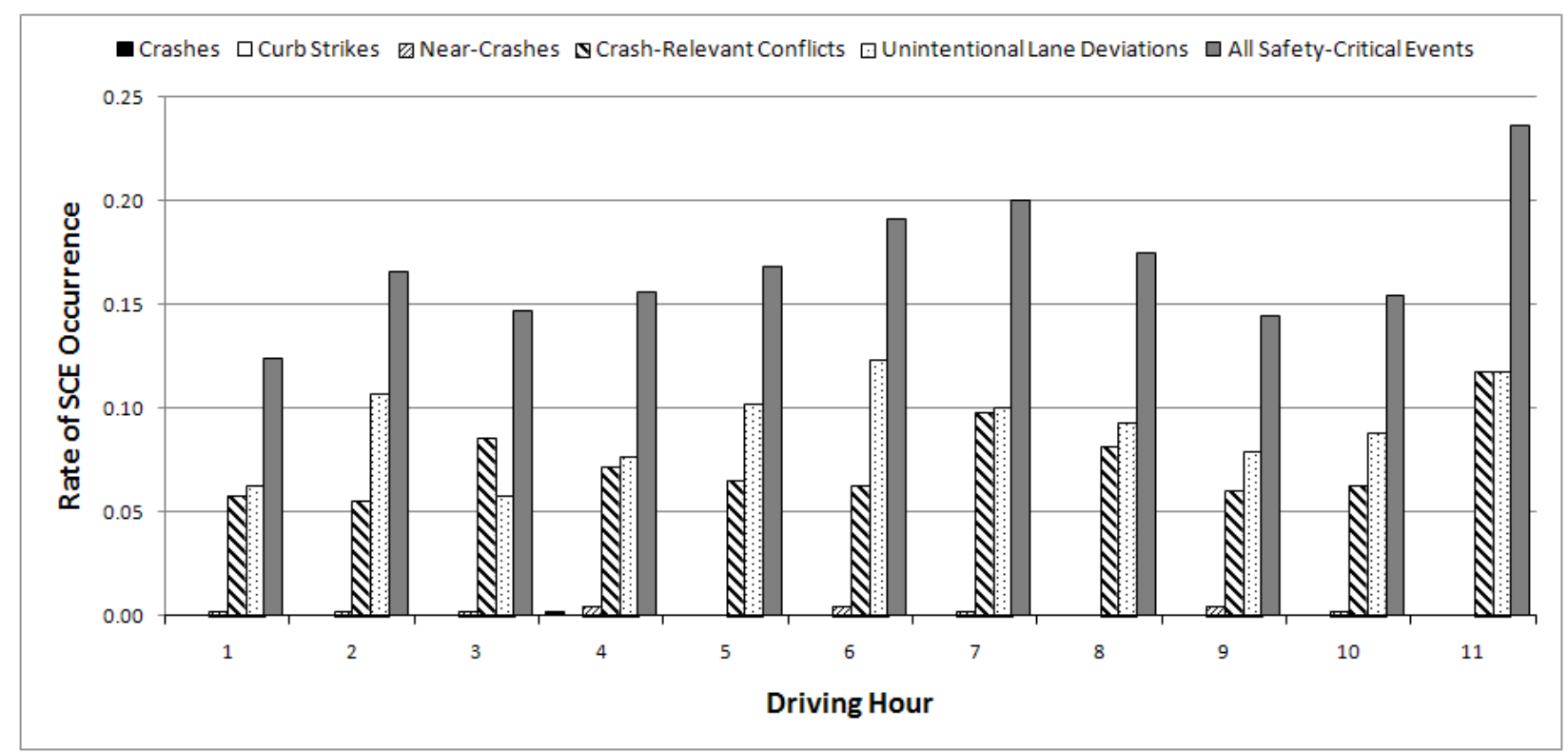

Figure 20. Bar Graph. Rate of SCE Occurrence as a Function of Driving Hour for Shifts That Went Into the 11th Driving Hour

The data from Table 18 were analyzed using a mixed-effect NB regression model with logarithm link, to compare the rate of SCE occurrence across the driving hours. The number of SCEs in each shift was assumed to be generated from a stochastic process and the expected event rate may be a function of the driving hour (assumptions that also contributed to the use of an NB model). For each shift included in the analysis, the SCE rate was calculated for driving hours 811 using the exact opportunities shown above in Table 18. The focus was on driving hours 8-11, given that the "normal" duration of a workday for a full-time employee is commonly known as an 8-hour day and it would be unlikely that anyone would suggest that truck operations drive less than 8 hours. By using only the shifts that went into the 11th driving hour, a statistical comparison could be made between the 11th driving hour and the 8th, 9th, and 10th driving hours. In the NB analysis, the SCE rate using exact opportunities was compared in hours 8, 9, and 10 versus 11 across each shift. In this method, the shift is a constant, which allows for control of individual driver behaviors as well as factors like time-of-day and location.

Table 19 shows the results of the NB analysis. The results indicate that the rate of SCE occurrence for the 11th driving hour was not statistically different from the rate of SCE occurrence for driving hours 8,9 , or 10 ( $\left.p_{8 \text { th hour }}=0.7689, p_{9 \text { th hour }}=0.4079, p_{10 \text { th hour }}=0.4221\right)$.

Table 19. NB Model: Pair-Wise SCE Rate Comparison of Driving Hour 11 to Hours 8, 9, and 10

\begin{tabular}{|c|c|c|c|c|c|}
\hline $\begin{array}{c}\text { Comparison of } \\
\text { Driving Hours }\end{array}$ & Estimate & SE & df & $\boldsymbol{t}$ & $\boldsymbol{p}$ \\
\hline $\mathbf{1 1}$ versus 8 & 0.0840 & 0.2858 & 428 & 0.29 & 0.7689 \\
\hline $\mathbf{1 1}$ versus 9 & 0.2323 & 0.2804 & 428 & 0.83 & 0.4079 \\
\hline $\mathbf{1 1}$ versus 10 & 0.2038 & 0.2536 & 428 & 0.80 & 0.4221 \\
\hline
\end{tabular}


Based on inspection of the data, four drivers were identified as outliers that had many more SCEs than the average driver. This finding is not surprising as other research has found that a few drivers tend to account for a disproportionate number of SCEs. ${ }^{(41,41,42)}$ The four drivers from the current study who were identified as outliers each accounted for more than 100 SCEs, representing 36 percent of the entire data set of SCEs. Table 20 shows the data and Figure 21 shows the data plotted with the outliers removed.

Table 20. SCEs and Total Opportunities by Driving Hour for Hours 1-11, for Shifts That Went Into the 11th Driving Hour; Four Driver Outliers were Removed from the Data Set

\begin{tabular}{|c|c|c|c|}
\hline $\begin{array}{c}\text { Driving } \\
\text { Hour }\end{array}$ & $\begin{array}{c}\text { SCEs Per Driving Hour } \\
\text { for 11th Driving Hour } \\
\text { Shifts }\end{array}$ & $\begin{array}{c}\text { Total Opportunities Per } \\
\text { Driving Hour for 11th } \\
\text { Driving Hour Shifts }\end{array}$ & $\begin{array}{c}\text { Rate: SCEs/Total } \\
\text { Opportunities }\end{array}$ \\
\hline 1 & 41 & 402 & 0.102 \\
\hline 2 & 36 & 402 & 0.090 \\
\hline 3 & 34 & 402 & 0.085 \\
\hline 4 & 33 & 402 & 0.082 \\
\hline 5 & 41 & 402 & 0.102 \\
\hline 6 & 43 & 402 & 0.107 \\
\hline 7 & 54 & 402 & 0.134 \\
\hline 8 & 53 & 402 & 0.132 \\
\hline 9 & 38 & 402 & 0.095 \\
\hline 10 & 47 & 402 & 0.117 \\
\hline 11 & 37 & 298.52 & 0.124 \\
\hline
\end{tabular}

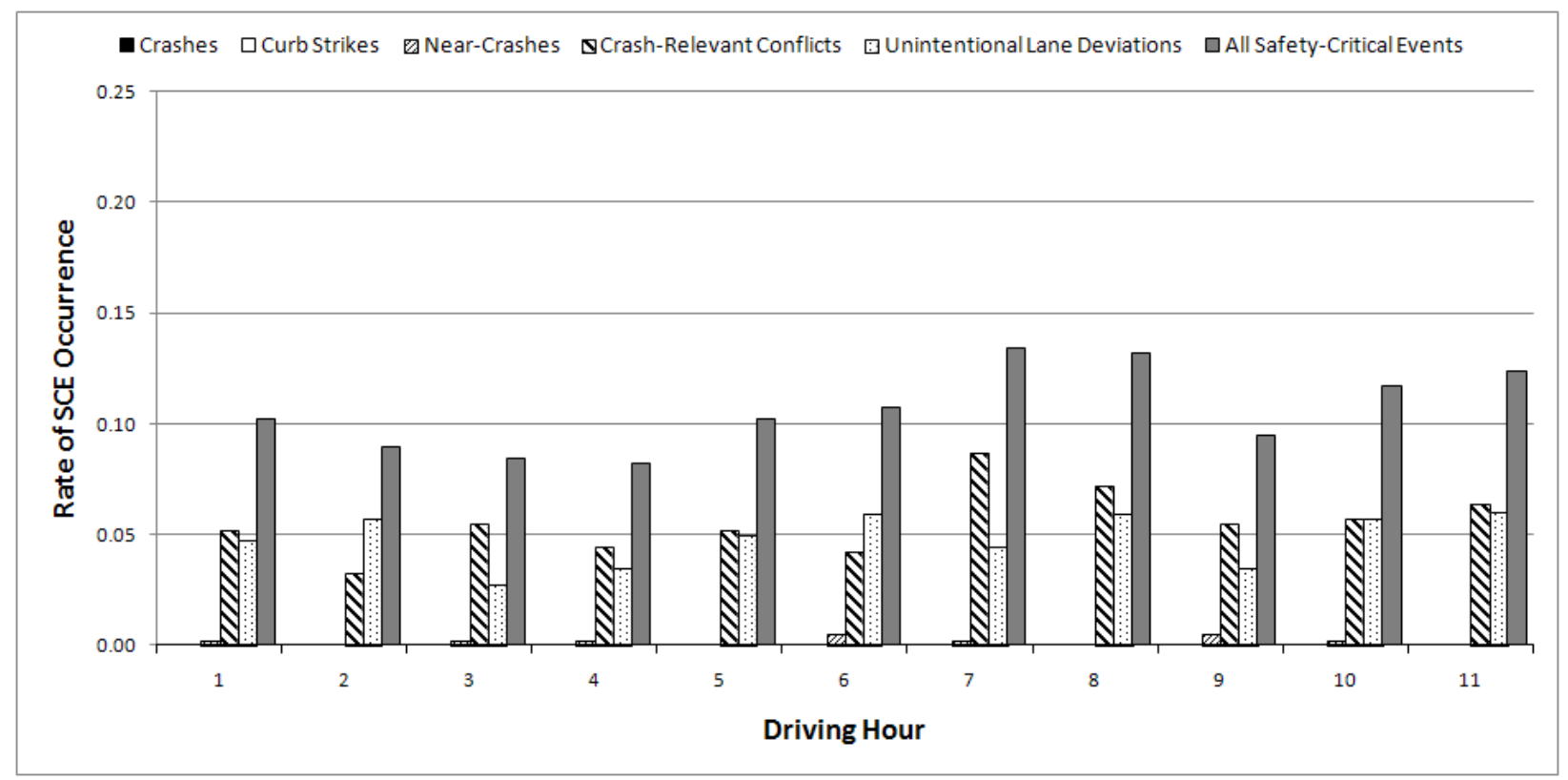

Figure 21. Bar Graph. Rate of SCE Occurrence as a Function of Driving Hour for Shifts That Went Into the 11th Driving hour. Four Driver Outliers Have Been Removed from the Data Set

From a visual inspection and comparison of Figure 20 and Figure 21, two things are striking. First, the rate of SCE occurrence drops markedly when the four outliers are removed. For example, the rate for the 11th hour drops in half from 0.236 to 0.124 . Second, the ratio of SCE 
rates for the 11th and 10th hours shown in Figure 20 (0.236: 0.154) is substantially reduced when the outliers are removed (0.124: 0.117$)$ and statistical tests indicate no difference between the 10th and 11th hours. Although these four drivers with large SCE counts were uncharacteristic of the participants in general, the drivers were included in the analysis. It was decided these four drivers represented a type of driver in the CMV driver population and should be included in the analysis.

\subsubsection{Evaluation of All Shifts with Multiple Within-Hour SCE Collapsed}

With the goal of being comprehensive in the analysis approaches used, an alternative analysis technique was conducted which examined every shift, regardless of the shift duration, and accounted for the shift duration in the analysis. In order to focus the analysis on "driving hour," a dichotomous approach was taken: if multiple SCEs occurred within a single hour for a given driver on a given shift, it was considered to be one SCE for that hour. Table 21 shows the data set for this dichotomous approach, while Figure 22 shows the rate of SCE occurrence plotted.

Table 21. SCEs and Total Opportunities by Driving Hour for Hours 1-11, with Multiple Within-Hour SCEs Collapsed, for Shifts that Went into the 11th Driving Hour

\begin{tabular}{|c|c|c|c|}
\hline $\begin{array}{c}\text { Driving } \\
\text { Hour }\end{array}$ & $\begin{array}{c}\text { SCEs Per } \\
\text { Driving Hour }\end{array}$ & $\begin{array}{c}\text { Total Opportunities per } \\
\text { Driving Hour }\end{array}$ & $\begin{array}{c}\text { Rate of SCE/Total } \\
\text { Opportunities }\end{array}$ \\
\hline 1 & 39 & 429 & 0.091 \\
\hline 2 & 38 & 429 & 0.089 \\
\hline 3 & 38 & 429 & 0.089 \\
\hline 4 & 40 & 429 & 0.093 \\
\hline 5 & 40 & 429 & 0.093 \\
\hline 6 & 46 & 429 & 0.107 \\
\hline 7 & 50 & 429 & 0.117 \\
\hline 8 & 43 & 429 & 0.100 \\
\hline 9 & 36 & 429 & 0.084 \\
\hline 10 & 38 & 429 & 0.089 \\
\hline 11 & 31 & 321.48 & 0.096 \\
\hline
\end{tabular}




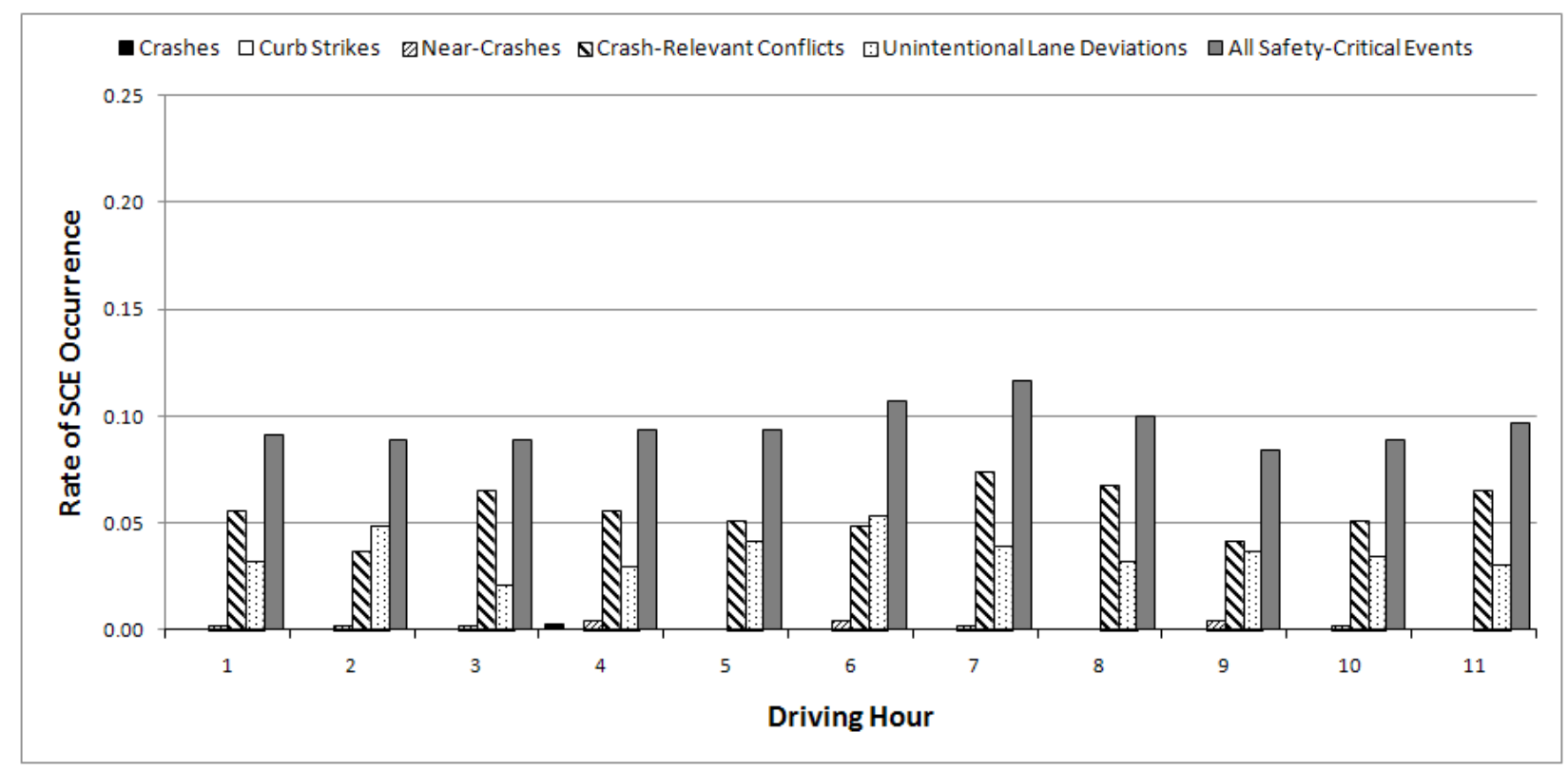

Figure 22. Bar Graph. Rate of SCE Occurrence as a Function of Driving Hour, with Multiple WithinHour SCEs Collapsed, for Shifts That Went Into the 11th Driving Hour

Table 22. SCEs and Total Shifts by Driving Hour for Hours 1-11, with Multiple Within-Hour SCEs Collapsed, for Shifts That Went Into the 11th Driving Hour-Data Used to Calculate Odds Ratios

\begin{tabular}{|c|c|c|c|}
\hline $\begin{array}{c}\text { Driving } \\
\text { Hour }\end{array}$ & $\begin{array}{c}\text { SCEs Per } \\
\text { Driving Hour }\end{array}$ & $\begin{array}{c}\text { Total Number of Shifts } \\
\text { per Driving Hour }\end{array}$ & $\begin{array}{c}\text { Rate of SCE/Total } \\
\text { Shifts }\end{array}$ \\
\hline 1 & 39 & 429 & 0.091 \\
\hline 2 & 38 & 429 & 0.089 \\
\hline 3 & 38 & 429 & 0.089 \\
\hline 4 & 40 & 429 & 0.093 \\
\hline 5 & 40 & 429 & 0.093 \\
\hline 6 & 46 & 429 & 0.107 \\
\hline 7 & 50 & 429 & 0.117 \\
\hline 8 & 43 & 429 & 0.100 \\
\hline 9 & 36 & 429 & 0.084 \\
\hline 10 & 38 & 429 & 0.089 \\
\hline 11 & 31 & 429 & 0.072 \\
\hline
\end{tabular}

Odds ratios were calculated and analyzed. Table 22 shows the data used to calculate the odds ratios. The results of this analysis were similar to the previous analysis in that no statistically significant results were found for the 11th driving hour (Table 23) when compared to the 10th driving hour. The only hour that reached significance was the 7 th hour when compared to the 11 th hour (SCE rate was greater for the 7 th hour as compared to the 11 th hour). Of primary interest for this study, the 11th driving hour did not present an increase in risk of SCE occurrence as compared to the 8 th, 9 th, or 10 th driving hour. 
Table 23. Results from the Odds Ratio Analyses

\begin{tabular}{|c|c|c|c|}
\hline $\begin{array}{c}\text { Comparison of } \\
\text { Driving Hours }\end{array}$ & Odds Ratio & LCL & UCL \\
\hline 7 versus 11 & 1.69 & 1.06 & 2.71 \\
\hline 11 versus 8 & 0.70 & 0.43 & 1.13 \\
\hline 11 versus 9 & 0.85 & 0.52 & 1.40 \\
\hline 11 versus 10 & 0.80 & 0.49 & 1.31 \\
\hline
\end{tabular}

As an alternative to the bar chart, a scatter plot of rate of SCE occurrence by driving hour was created to visually inspect the data for trends. Figure 23 shows the data plotted from shifts that went into the 11th driving hour with multiple within-hour SCEs collapsed. The rate of SCE occurrence appears nearly constant, near 0.09 , for all driving hours except driving hours 6 and 7 , where the rate rises above 0.1 . To examine if a linear trend exists, a linear regression model was fitted to the data (Table 24). The linear regression model, however, had a $p$-value of $p=0.6554$, which is larger than $\alpha=0.05$, indicating the slope is not statistically significantly different from zero. This finding is further supported by the coefficient of determination $\mathrm{R}^{2}=0.023$.

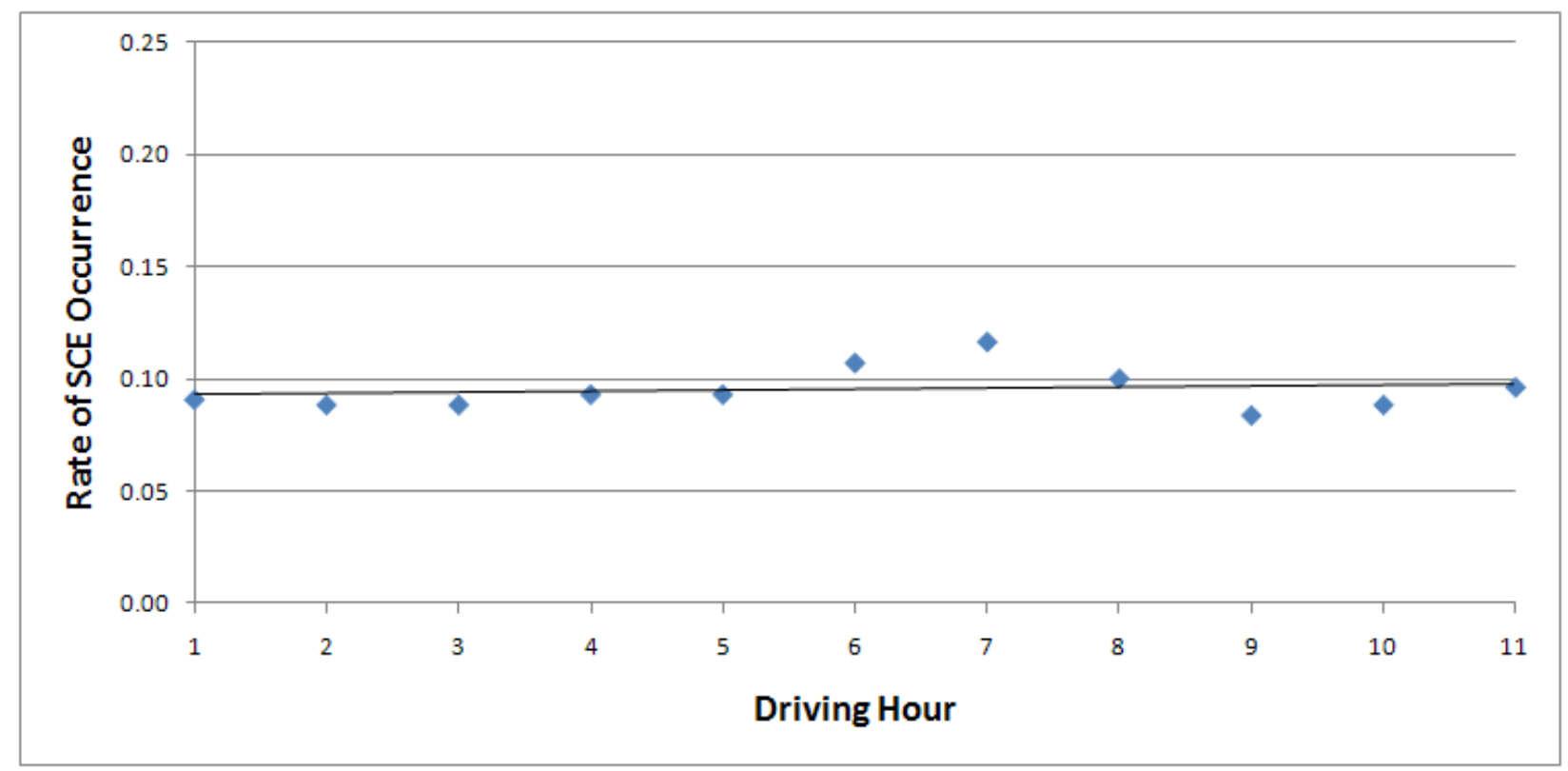

Figure 23. Scatter Plot. Rate of SCE Occurrence as a Function of Driving Hour, with Multiple Within-Hour SCEs Collapsed, for Shifts That Went Into the 11th Driving Hour

Table 24. Linear Regression Model for Rate of SCE Occurrence as a Function of Driving Hour, with Multiple Within-Hour SCEs Collapsed, for Shifts That Went Into the 11th Driving Hour

\begin{tabular}{|c|c|c|c|c|}
\hline Parameter & Estimate & $\begin{array}{c}\text { Standard } \\
\text { Error }\end{array}$ & $\mathbf{t}$ Value & $\operatorname{Pr}>|\mathbf{t}|$ \\
\hline Intercept & 0.0927 & 0.0064 & 14.45 & $<.0001$ \\
\hline Driving Hour & 0.0004 & 0.0009 & 0.46 & 0.6554 \\
\hline
\end{tabular}


The data for shifts that went into the 11th driving hour with multiple within-hour SCEs included were plotted in a scatter plot as well (Figure 24). As seen in the plot, the rates of SCE occurrence rise and fall between 0.12 and 0.24 across the 11 driving hours. Although the data does not appear to be strictly linear, a linear regression model was used to see if a general trend existed of increasing rate of SCE occurrence over driving hours (Table 25). This model was not statistically significant $(p=0.070)$. The $\mathrm{R}^{2}=0.319$ and positive driving hour coefficient $(0.0052)$ also indicate a weak positive relationship between driving hour and rate of SCE occurrence. A positive trend is what one would expect if indeed a relationship were to exist between rate of SCE occurrence and time on task.

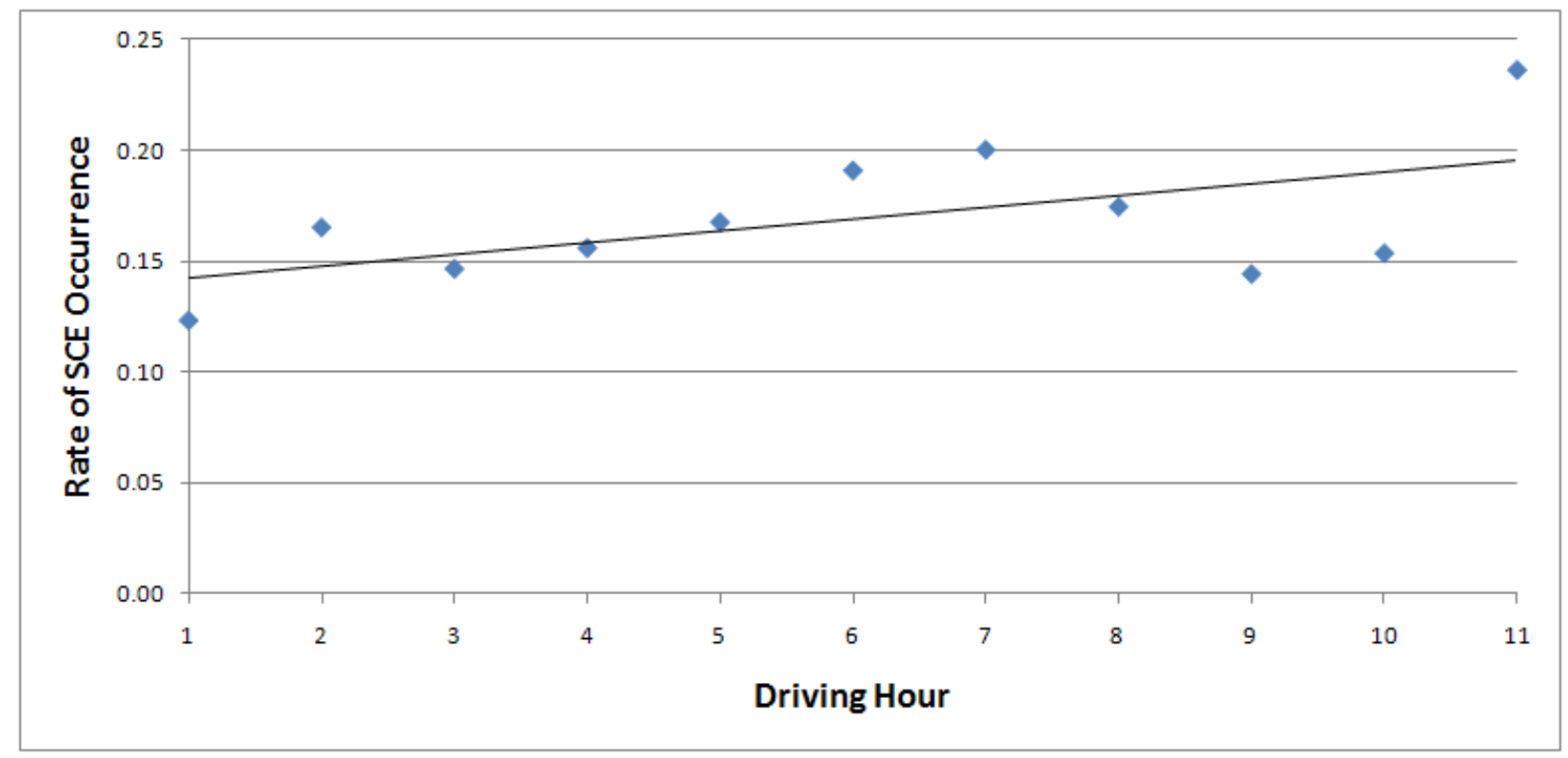

Figure 24. Scatter Plot. Rate of SCE Occurrence as a Function of Driving Hour for Shifts That Went Into the 11th Driving Hour

Table 25. Linear Regression Model for Rate of SCE Occurrence as a Function of Driving Hour for Shifts That Went Into the 11th Driving Hour

\begin{tabular}{|c|c|c|c|c|}
\hline Parameter & Estimate & $\begin{array}{c}\text { Standard } \\
\text { Error }\end{array}$ & $\mathbf{t}$ Value & $\operatorname{Pr}>|\mathbf{t}|$ \\
\hline Intercept & 0.1379 & 0.0173 & 7.97 & $<.0001$ \\
\hline Driving Hour & 0.0052 & 0.0026 & 2.05 & 0.0703 \\
\hline
\end{tabular}

A key take-away from the set of various analyses on driving hours was a lack of statistical significance for an increase in SCE rate for the 11th driving hour, except when compared to the 1st and 2nd driving hour for one analysis that included the outlier data and multiple SCEs per hour and treated driving hour as a continuous variable. Therefore, separate analyses came to the same result; no statistically significant increase in risk for the 11th hour of driving when compared to the 10th driving hour. Nonetheless, results from one analysis did show a statistically significant time-on-task effect for driving hour which suggests that perhaps another variable (in addition to driving hours) may provide a more complete explanation for the increasing SCE rate 
over time. This idea was examined in the next section, which investigated the entire driver workday and the rate of SCE occurrence.

\subsection{SAFETY-CRITICAL EVENTS AS A FUNCTION OF WORK HOUR}

The second set of analyses considered the full work shift, including driving and non-driving activities. The following analyses looked at each of the 14 work hours which have been grouped by Beginning of shift (work hours 1-5), Middle of shift (work hours 6-9) and End of shift (work hours 10-14). Following this, a subset of the data with only those drivers who reached a full 14 work hours was examined.

\subsubsection{Evaluation of All Shifts}

Table 26 shows the data set for the first analysis, which included all SCEs, and all driving opportunities (shifts), that occurred in the 1st through 11th driving hours divided as Beginning, Middle, or End of the work hours in a shift. As shown in Table 26, each combination of driving hour and work hour has a different number of opportunities to be involved in an SCE. For example, a driver may have driven into the 6th hour at the Middle of his/her work hours but not into the 7th hour at the Middle of the work hours due to a rest break or a work-related break from driving to do other tasks; as a result, there were fewer opportunities to be involved in an SCE in the 7th hour during the Middle of the work hours. To adjust for the differences in opportunities across driving hour-work hour combinations, rates were calculated which, in effect, normalized the data; that is, the frequency of SCEs, in any given driving hour-work hour combination, was divided by the total opportunities for that combination. This provided a rate of SCE occurrence for any given driving hour-work hour combination. As noted previously, it is important to point out that the data in Table 26 include cases where multiple SCEs were recorded in the same driving hour; a follow-up analysis, presented later, removed the multiple cases to set up a dichotomous variable. A few cells have a low occurrence count; the reader is cautioned about making any inferences based on those cells. 
Table 26. SCEs and Total Opportunities for Driving Hours 1-11 and Work Hours 1-14

\begin{tabular}{|c|c|c|c|c|}
\hline $\begin{array}{l}\text { Driving } \\
\text { Hour }\end{array}$ & $\begin{array}{l}\text { Work Hour } \\
\text { Category }\end{array}$ & $\begin{array}{l}\text { SCEs Per Driving } \\
\text { Hour-Work Hour }\end{array}$ & $\begin{array}{c}\text { Total } \\
\text { Opportunities Per } \\
\text { Driving Hour-Work } \\
\text { Hour }\end{array}$ & $\begin{array}{c}\text { Rate of SCE/Total } \\
\text { Opportunities }\end{array}$ \\
\hline 1 & Beginning & 217 & $1,824.97$ & 0.119 \\
\hline 1 & Middle & 0 & 29.26 & 0.000 \\
\hline 1 & End & 1 & 10.37 & 0.096 \\
\hline 2 & Beginning & 216 & $1,733.69$ & 0.125 \\
\hline 2 & Middle & 9 & 80.12 & 0.112 \\
\hline 2 & End & 5 & 13.16 & 0.380 \\
\hline 3 & Beginning & 199 & $1,565.25$ & 0.127 \\
\hline 3 & Middle & 34 & 199.49 & 0.170 \\
\hline 3 & End & 2 & 22.17 & 0.090 \\
\hline 4 & Beginning & 209 & $1,206.41$ & 0.173 \\
\hline 4 & Middle & 67 & 468.20 & 0.143 \\
\hline 4 & End & 9 & 40.96 & 0.220 \\
\hline 5 & Beginning & 77 & 688.87 & 0.112 \\
\hline 5 & Middle & 166 & 828.99 & 0.200 \\
\hline 5 & End & 20 & 95.08 & 0.210 \\
\hline 6 & Middle & 242 & $1,285.18$ & 0.188 \\
\hline 6 & End & 23 & 192.47 & 0.119 \\
\hline 7 & Middle & 185 & 920.65 & 0.201 \\
\hline 7 & End & 63 & 340.76 & 0.185 \\
\hline 8 & Middle & 50 & 553.96 & 0.090 \\
\hline 8 & End & 104 & 467.10 & 0.223 \\
\hline 9 & Middle & 24 & 241.29 & 0.099 \\
\hline 9 & End & 101 & 567.49 & 0.178 \\
\hline 10 & End & 98 & 553.16 & 0.177 \\
\hline 11 & End & 76 & 321.48 & 0.236 \\
\hline
\end{tabular}

Figure 25 plots the number of opportunities (also considered "shifts") for each work hour. As expected, most of the first few hours of driving occurred during the Beginning of the shift, although there were instances where the first few hours of driving happened during the End of the shift because the driver performed non-driving tasks (e.g., paperwork, loading/unloading) prior to driving. Similarly to the driving-hour analysis, there were 321.48 opportunities for drivers to drive into the 11th hour. As noted previously, the opportunities represent the shifts that included the driving hour and work hour combination and are calculated using the exact amount of time that the driver drove into that shift. For example, if the driver drove 8.5 hours, there would be one opportunity each in driving hours $1-8$ and 0.5 in the 9 th hour. 


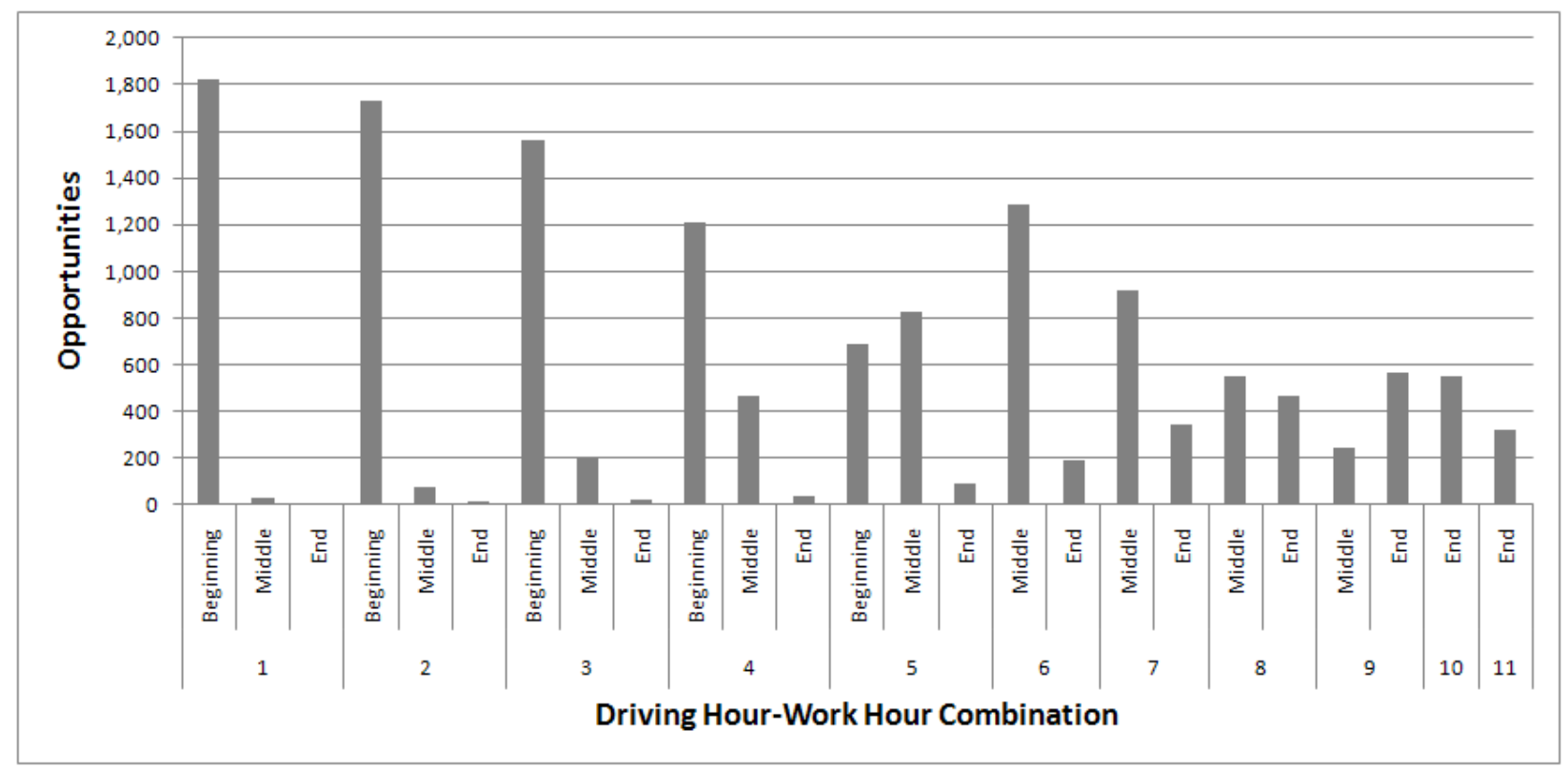

Figure 25. Bar Graph. Total Opportunities as a Function of Driving Hour and Work Hour

The following graphs present a breakdown of the rate of SCE occurrence by driving hour and work hour category for each type of SCE. It includes crashes, curb strikes, near-crashes, crashrelevant conflicts, unintentional lane deviations, and all SCEs. Similar to the analyses on driving hour, the frequencies of crashes, curb strikes, and near-crashes were too small to conduct any meaningful analyses independent of the crash-relevant conflict and unintentional lane deviation data. Figure 26, Figure 27, and Figure 28 present the rate of SCE occurence as a function of driving hours divided by the time during the work hours in which they happened (Beginning, Middle, and End of the work hours). Not all of the combinations are possible; for example, the 10th and 11th hour of driving can only happen to the End of the work hours of a shift per work hour grouping definition. There are several exceptions, but a visual inspection suggests that as driving hours move towards the End of the shift, the corresponding rate of SCE occurrence increases (analysis presented later examined this further). 


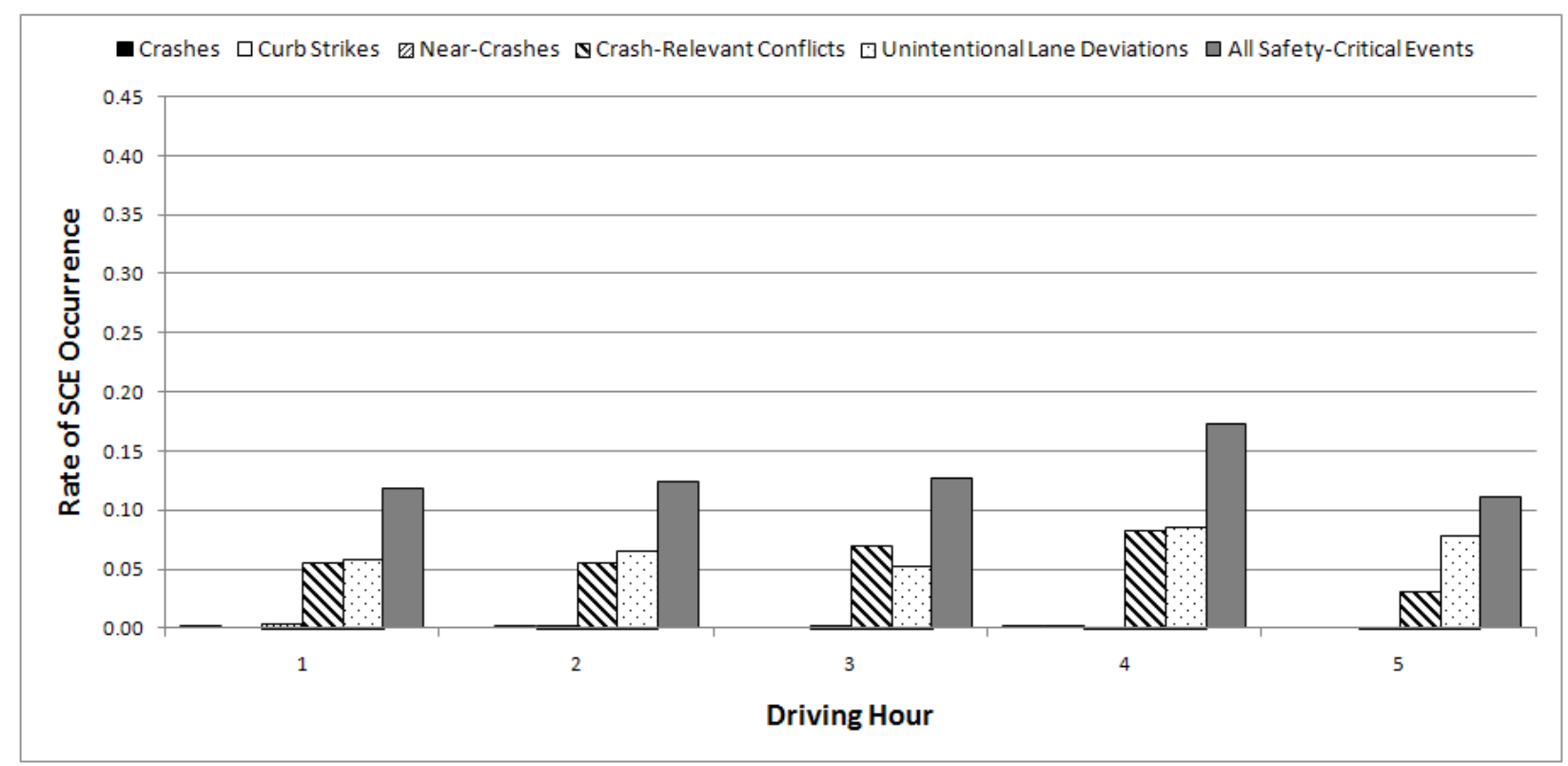

Figure 26. Bar Graph. Rate of SCE Occurrence as a Function of Driving Hour and Beginning Work Hours (Hours 1-5)

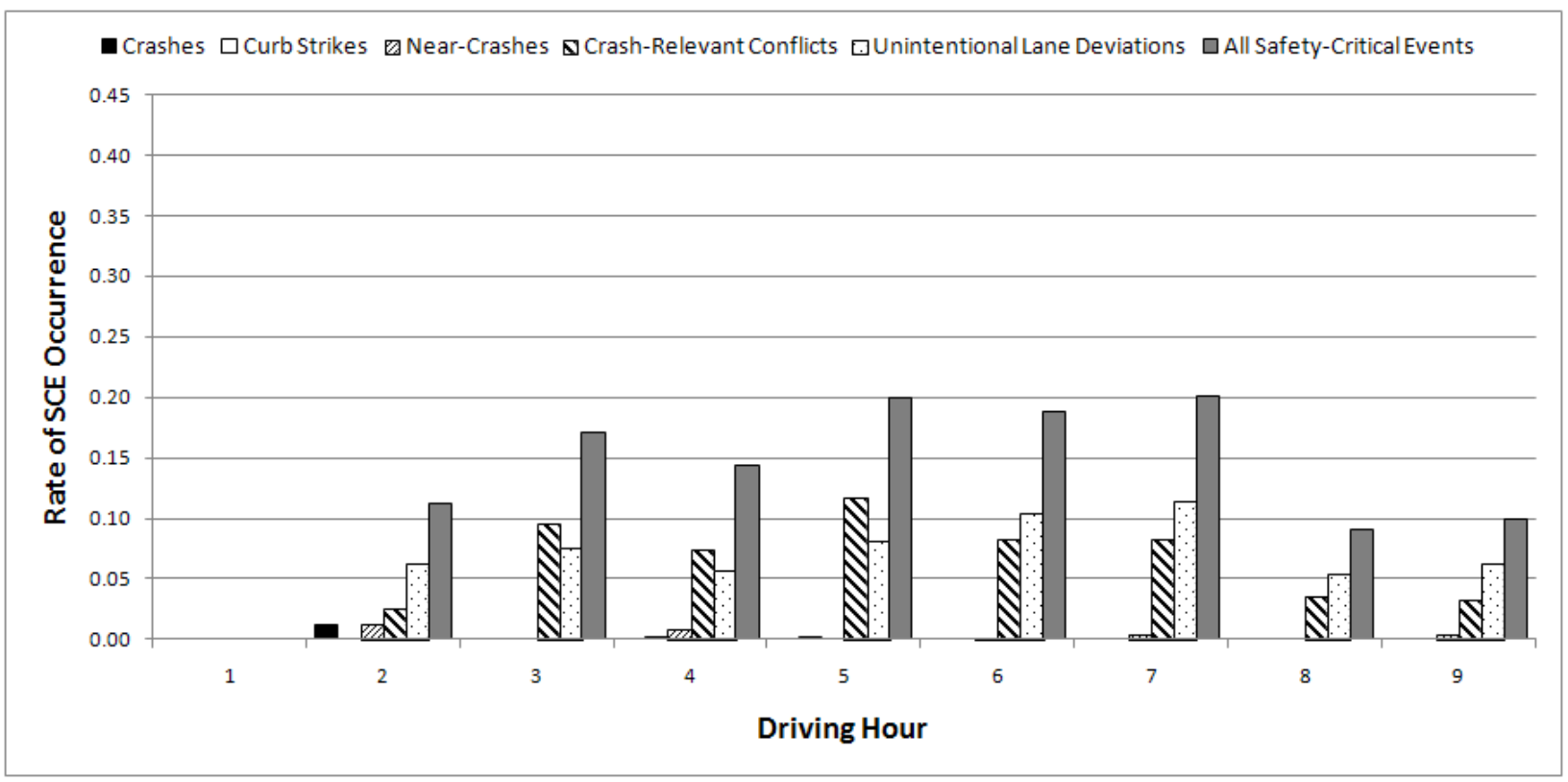

Figure 27. Bar Graph. Rate of SCE Occurrence as a Function of Driving Hour and Middle Work Hours (Hours 6-9) 


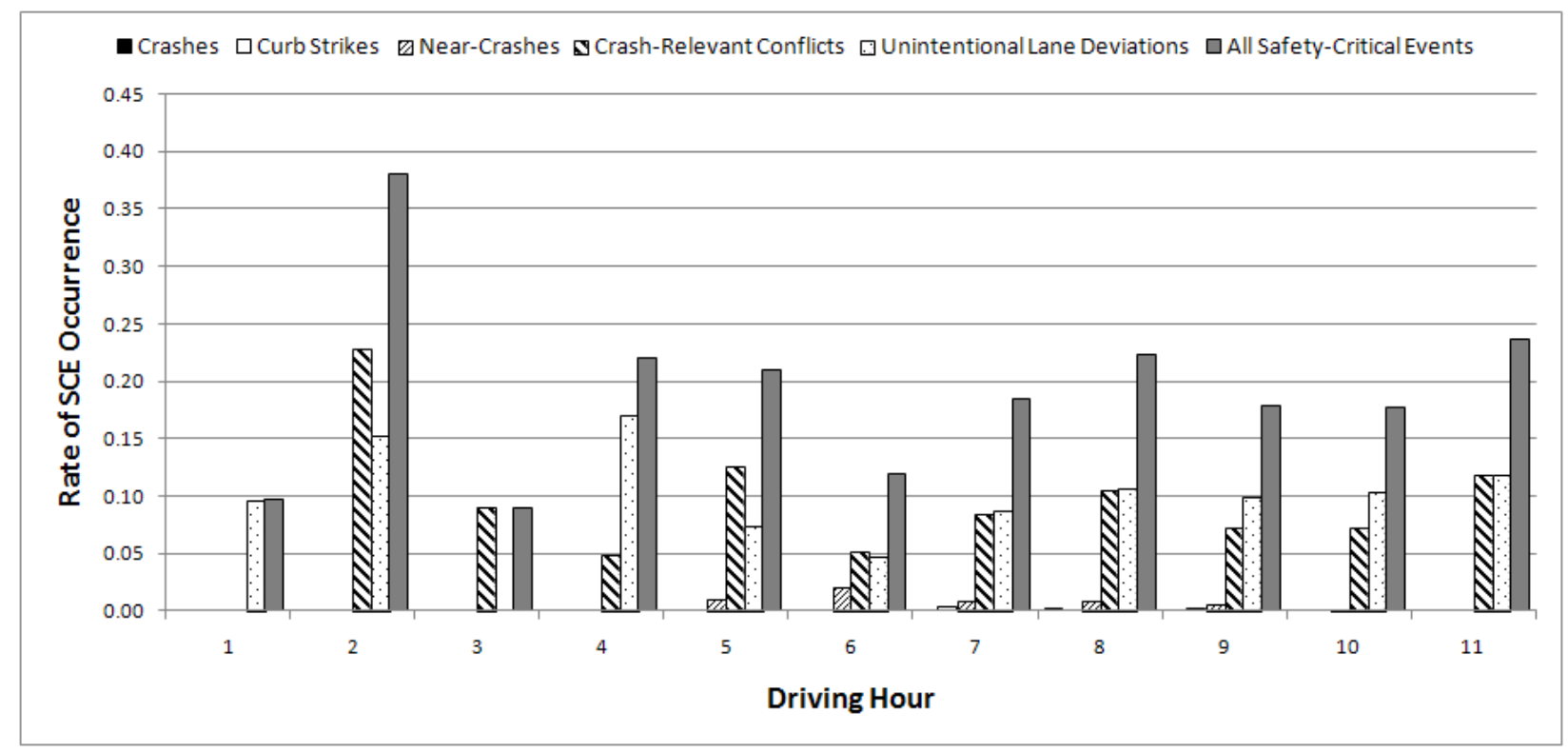

Figure 28. Bar Graph. Rate of SCE Occurrence as a Function of Driving Hour and End Work Hours (Hours 10-14)

Figure 29 is a summary graph of the three previous figures and shows the rate of SCE occurrence when the driving hour-work hour combinations were grouped into Beginning, Middle, and End of the shift. To walk through an example, consider the 5th driving-hour shown in Figure 29. In the 5 th hour, the rate of SCE occurrence was 0.11 when drivers spent their 5 th hour of driving during the Beginning (within work hours 1-5) of their workday. In order for this to occur, a driver would have had to start driving in the 1st hour of the workday that is, if a driver began driving in the 1st hour of his workday, then the 5th driving hour would have occurred during the 5 th working hour. It can also be seen that the rate of SCE occurrence was 0.20 when the 5 th driving hour occurred during the Middle (work hours 6-9) of the driver's workday. In order for this to occur, a driver would have had to start driving no earlier than the 2 nd hour of his shift (causing the 5th driving hour to occur in the 6th working hour) and no later than the 5th hour of his shift (causing the 5th driving hour to occur in the 9th working hour). Finally, it can be seen that the rate of SCE occurrence was 0.21 when the 5th driving hour occurred during the End (work hours 10-14) of the driver's workday. In order for this to occur, a driver would have had to start driving no earlier than the 6th hour of his shift (causing the 5th driving hour to occur in the 10th working hour) and no later than the 10th hour of his shift (causing the 5th driving hour to occur in the 14th working hour). This example for the 5th driving hour is one possible scenario of how the 5th driving hour may occur during different times of the workday. Another aspect to consider is the use of breaks from driving throughout the day; that is, a driver may start the workday by driving for 3 hours, then take a 7-hour rest break. This would cause his 5 th hour of driving to again fall in the $12^{\text {th }}$ working hour or at the End of his shift. 


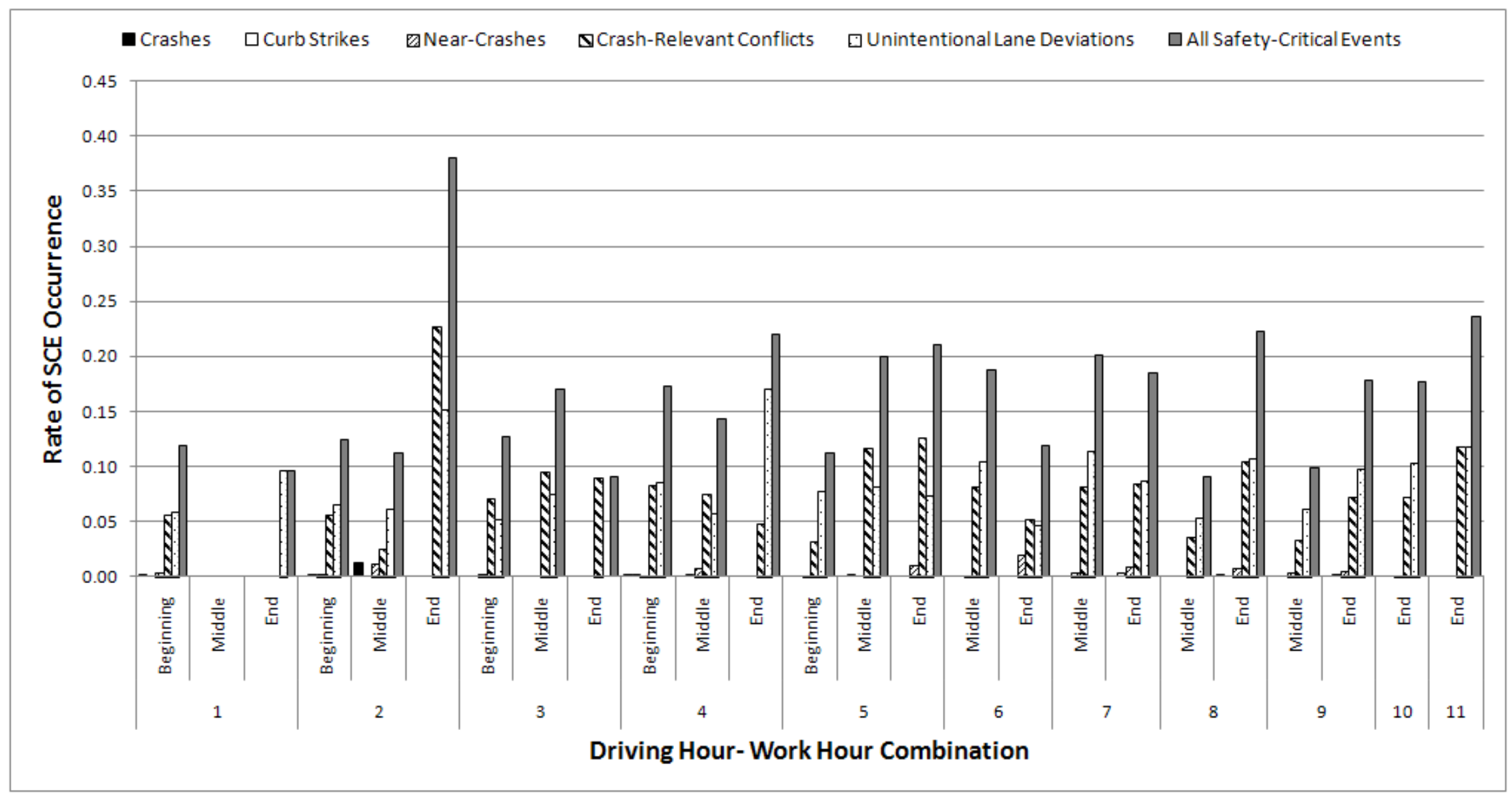

Figure 29. Bar Graph. Rate of SCE Occurrence as a Function of Driving Hour and Work Hour 


\subsubsection{Evaluation of All Shifts with Multiple Within-Hour SCE Collapsed}

As noted, the larger data set included multiple SCEs that may have been recorded in the same hour of the same shift. Table 27 shows the data set for the second analysis where these multiple SCEs (same hour, during the same shift), were removed from all the driving hour-work hour combinations, resulting in a dichotomous variable, either "yes, at least one SCE occurred" or "no SCE occurred." In addition, all driving opportunities that occurred in the 1st through 11th driving hours are shown as well as the work hours divided as Beginning, Middle, or End of the shift.

Table 27. SCEs and Total Opportunities for Driving Hours 1-11 and Work Hours 1-14, with Multiple Within-Hour SCEs Collapsed

\begin{tabular}{|c|c|r|r|r|}
\hline $\begin{array}{c}\text { Driving } \\
\text { Hour }\end{array}$ & $\begin{array}{c}\text { Work Hour } \\
\text { Category }\end{array}$ & $\begin{array}{c}\text { SCEs Per Driving } \\
\text { Hour-Work Hour }\end{array}$ & $\begin{array}{c}\text { Total } \\
\text { Opportunities Per } \\
\text { Driving Hour-Work } \\
\text { Hour }\end{array}$ & $\begin{array}{c}\text { Rate of SCE/Total } \\
\text { Opportunities }\end{array}$ \\
\hline 1 & Beginning & 157 & $1,824.97$ & 0.086 \\
\hline 1 & Middle & 0 & 29.26 & 0.000 \\
\hline 1 & End & 1 & 10.37 & 0.096 \\
\hline 2 & Beginning & 144 & $1,733.69$ & 0.083 \\
\hline 2 & Middle & 8 & 80.12 & 0.100 \\
\hline 2 & End & 1 & 13.16 & 0.076 \\
\hline 3 & Beginning & 140 & $1,565.25$ & 0.089 \\
\hline 3 & Middle & 24 & 199.49 & 0.120 \\
\hline 3 & End & 1 & 22.17 & 0.045 \\
\hline 4 & Beginning & 108 & $1,206.41$ & 0.090 \\
\hline 4 & Middle & 50 & 468.20 & 0.107 \\
\hline 4 & End & 6 & 40.96 & 0.146 \\
\hline 5 & Beginning & 33 & 688.87 & 0.048 \\
\hline 5 & Middle & 113 & 828.99 & 0.136 \\
\hline 5 & End & 13 & 95.08 & 0.137 \\
\hline 6 & Middle & 134 & $1,285.18$ & 0.104 \\
\hline 6 & End & 18 & 192.47 & 0.094 \\
\hline 7 & Middle & 100 & 920.65 & 0.109 \\
\hline 7 & End & 42 & 340.76 & 0.123 \\
\hline 8 & Middle & 33 & 553.96 & 0.060 \\
\hline 8 & End & 75 & 467.10 & 0.161 \\
\hline 9 & Middle & 13 & 241.29 & 0.054 \\
\hline 9 & End & 65 & 567.49 & 0.115 \\
\hline 10 & End & 59 & 553.16 & 0.107 \\
\hline 11 & End & 37 & 321.48 & 0.115 \\
\hline & & & & \\
\hline
\end{tabular}

Figure 30-Figure 33 show plots of the rate of SCE occurence for each driving hour-work hour combination. Figure 30 displays the SCE rate, by SCE type, for the Beginning work hour category (work hours 1-5); Figure 31 provides the SCE rate, by SCE type, for the Middle work hour category (hours 6-9); and Figure 32 provides the SCE rate, by SCE type, for the End work hour category (hours 10-14). Finally, Figure 33 provides an overview of SCE rate, by SCE type, 
for all working hours (i.e., a summary figure that includes the graphs from the three individual figures that break out into Beginning, Middle, and End).

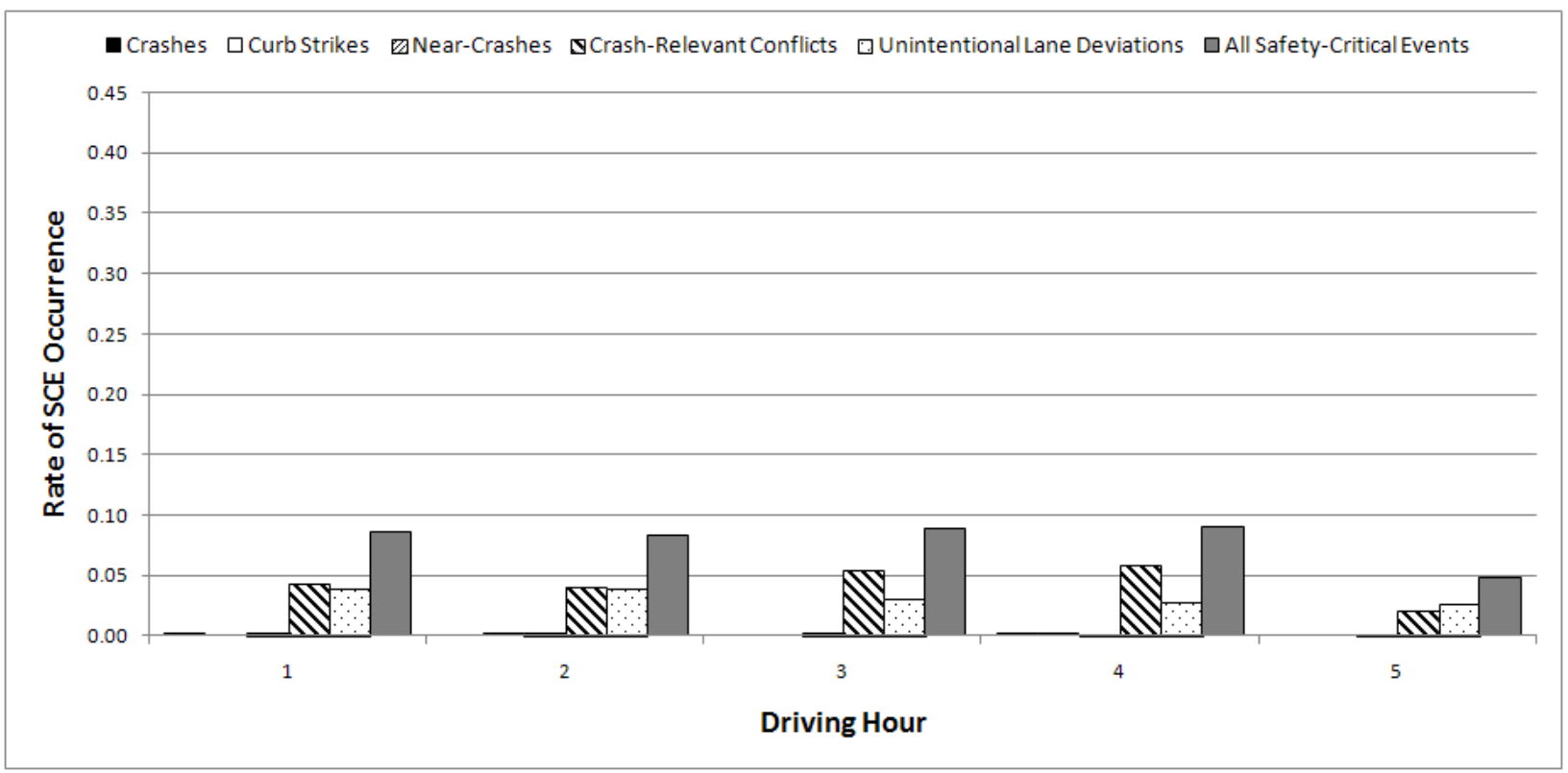

Figure 30. Bar Graph. Rate of SCE Occurrence as a Function of Driving Hour and Beginning Work Hours (Hours 1-5), with Multiple Within-Hour SCEs Collapsed

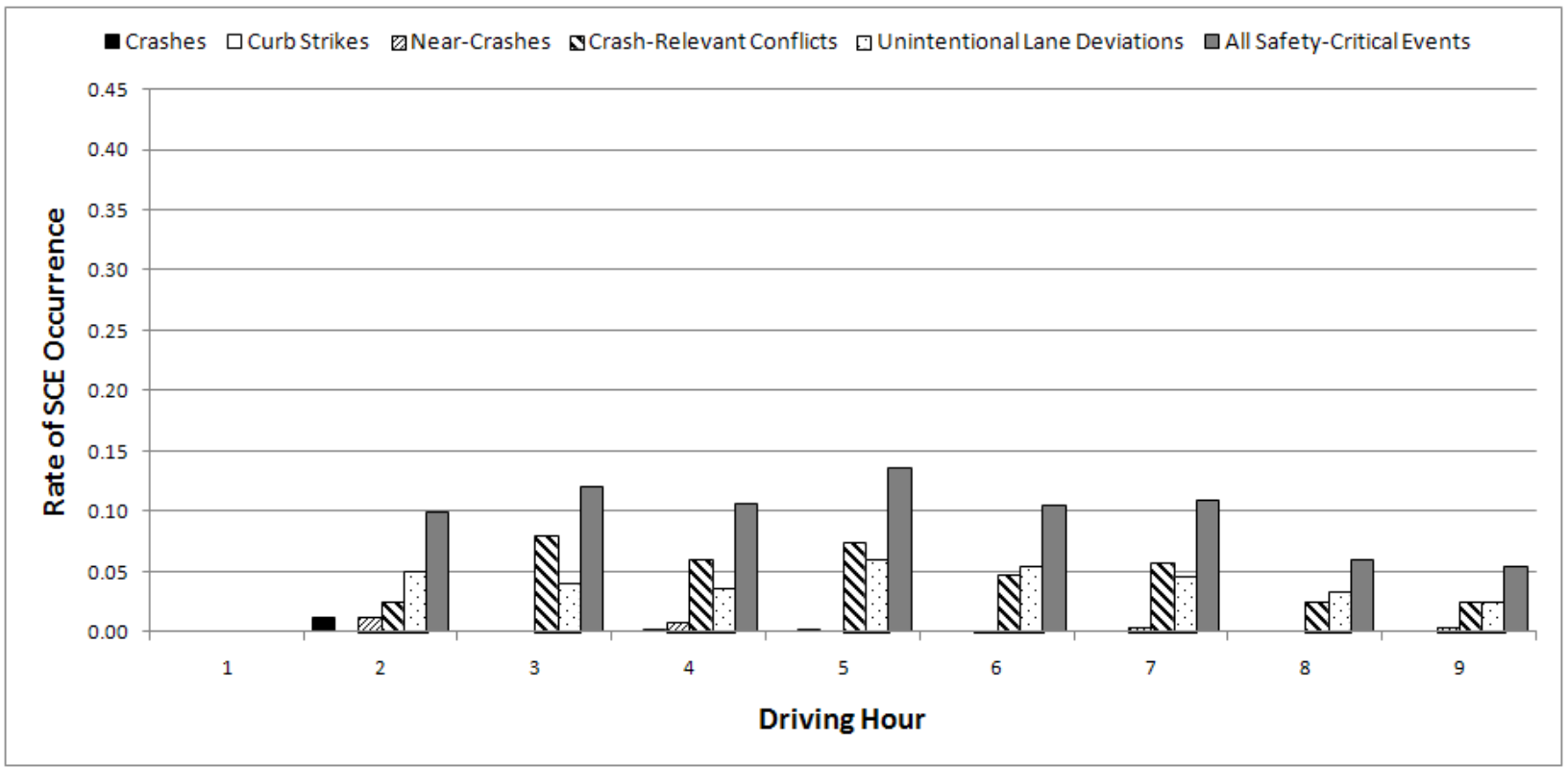

Figure 31. Bar Graph. Rate of SCE Occurrence as a Function of Driving Hour and Middle Work Hours (Hours 6-9), with Multiple Within-Hour SCEs Collapsed 


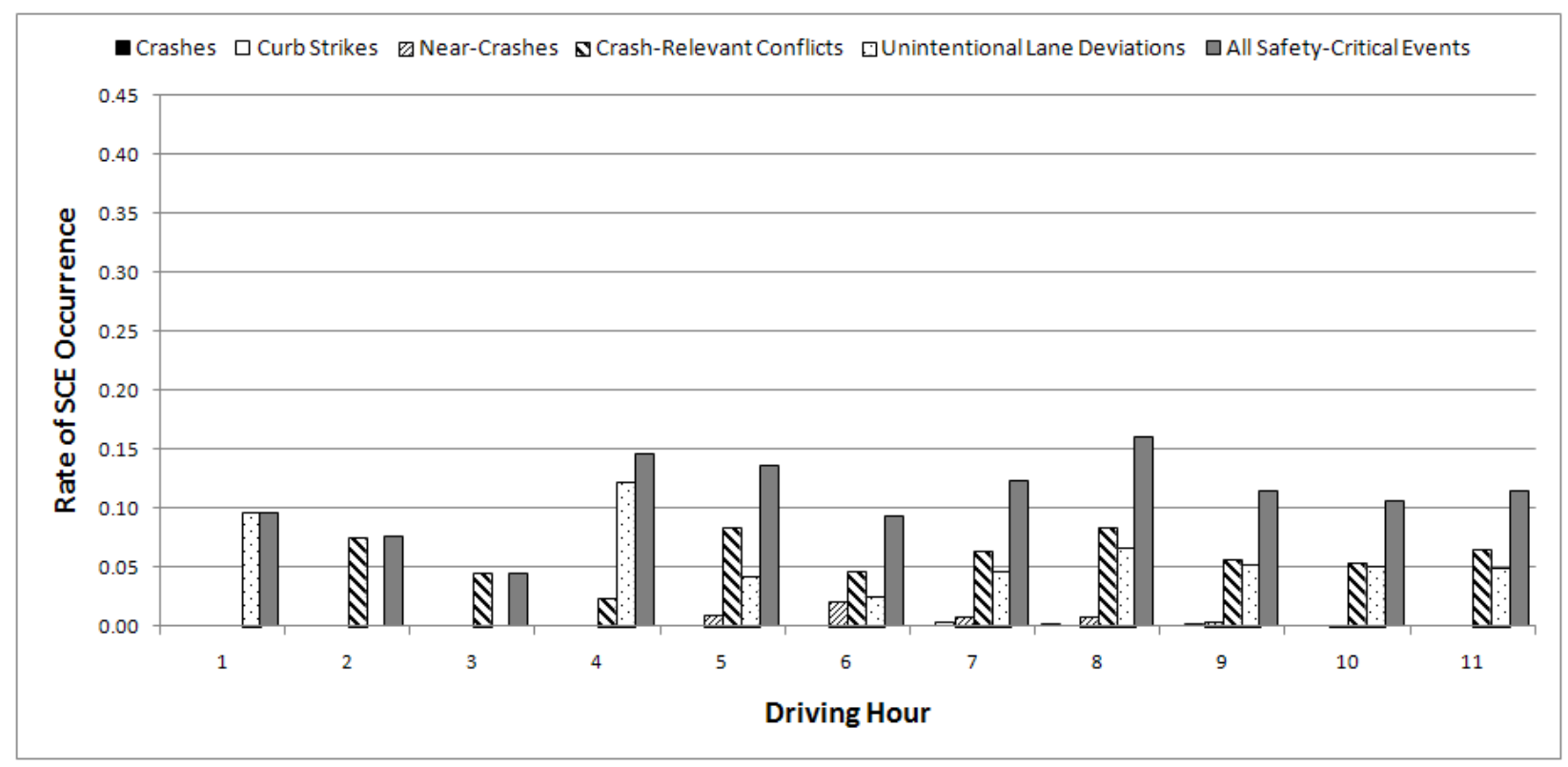

Figure 32. Bar Graph. Rate of SCE Occurrence as a Function of Driving Hour and End Work Hours (Hours 10-14), with Multiple Within-Hour SCEs Collapsed 


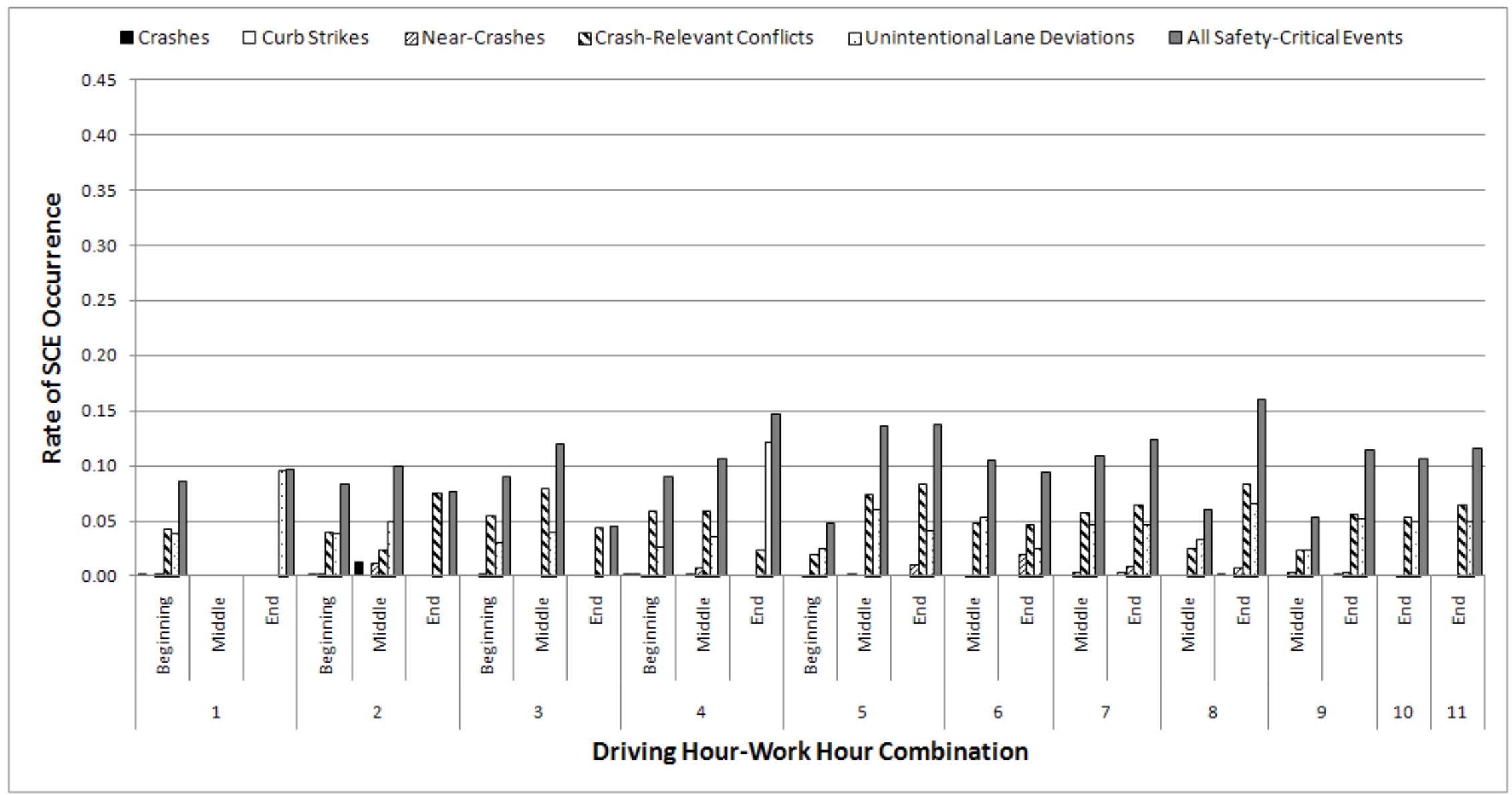

Figure 33. Bar Graph. Rate of SCE Occurrence as a Function of Driving Hour and Work Hour, with Multiple Within-Hour SCEs Collapsed 
Odds ratios were calculated and analyzed using the data shown in Table 28.

Table 28. SCEs and Total Shifts for Driving Hours 1-11 and Work Hours 1-14, with Multiple WithinHour SCEs Collapsed-Data Used to Calculate Odds Ratios

\begin{tabular}{|c|c|c|c|c|}
\hline $\begin{array}{l}\text { Driving } \\
\text { Hour }\end{array}$ & $\begin{array}{l}\text { Work Hour } \\
\text { Category }\end{array}$ & $\begin{array}{l}\text { SCEs Per Driving } \\
\text { Hour-Work Hour }\end{array}$ & $\begin{array}{l}\text { Total Shifts Per } \\
\text { Driving Hour-Work } \\
\text { Hour }\end{array}$ & $\begin{array}{c}\text { Rate of SCE/Total } \\
\text { Shifts }\end{array}$ \\
\hline 1 & Beginning & 157 & 1,839 & 0.085 \\
\hline 1 & Middle & 0 & 31 & 0.000 \\
\hline 1 & End & 1 & 11 & 0.091 \\
\hline 2 & Beginning & 144 & 1,747 & 0.082 \\
\hline 2 & Middle & 8 & 82 & 0.098 \\
\hline 2 & End & 1 & 16 & 0.063 \\
\hline 3 & Beginning & 140 & 1,576 & 0.089 \\
\hline 3 & Middle & 24 & 208 & 0.115 \\
\hline 3 & End & 1 & 25 & 0.040 \\
\hline 4 & Beginning & 108 & 1,253 & 0.086 \\
\hline 4 & Middle & 50 & 463 & 0.108 \\
\hline 4 & End & 6 & 45 & 0.133 \\
\hline 5 & Beginning & 33 & 707 & 0.047 \\
\hline 5 & Middle & 113 & 856 & 0.132 \\
\hline 5 & End & 13 & 106 & 0.123 \\
\hline 6 & Middle & 134 & 1,336 & 0.100 \\
\hline 6 & End & 18 & 221 & 0.081 \\
\hline 7 & Middle & 100 & 993 & 0.101 \\
\hline 7 & End & 42 & 402 & 0.104 \\
\hline 8 & Middle & 33 & 592 & 0.056 \\
\hline 8 & End & 75 & 536 & 0.140 \\
\hline 9 & Middle & 13 & 253 & 0.051 \\
\hline 9 & End & 65 & 670 & 0.097 \\
\hline 10 & End & 59 & 698 & 0.085 \\
\hline 11 & End & 37 & 429 & 0.086 \\
\hline
\end{tabular}

Table 29 displays all significant odds ratios. For example, the 9th hour showed a significantly higher risk than did the 5th hour when it was at the Beginning of the shift and the 8th and 9th hours when they were at the Middle of the shift. Also, the 10th hour demonstrated a statistically significant higher risk than the 5th hour at the Beginning of the shift and the 8th hour at the Middle of a shift. All odds ratios, including both significant and non-significant results, can be found in appendix B.

It is important to point out that there were no statistically significant differences when the 10th and 11th driving hours were compared. The 11th driving hour only showed a significantly higher odds ratio when compared to the 5th driving hour at the Beginning of the shift. No statistically significant results were obtained when the 10th and 11th hours were compared to other hours at the End of the shift (work hours 10-14). 
Table 29. Significant Results from the Odds Ratio Analysis with Multiple Within-Hour SCEs Collapsed

\begin{tabular}{|c|c|c|c|c|c|c|}
\hline $\begin{array}{l}\text { Driving } \\
\text { Hour }\end{array}$ & $\begin{array}{l}\text { Work Hour } \\
\text { Category }\end{array}$ & $\begin{array}{l}\text { Driving } \\
\text { Hour }\end{array}$ & $\begin{array}{l}\text { Work Hour } \\
\text { Category }\end{array}$ & Odds Ratio & LCL & UCL \\
\hline 1 & Beginning & 5 & Beginning & 1.91 & 1.30 & 2.80 \\
\hline 1 & Beginning & 8 & Middle & 1.58 & 1.07 & 2.33 \\
\hline 2 & Beginning & 5 & Beginning & 1.83 & 1.24 & 2.71 \\
\hline 2 & Beginning & 8 & Middle & 1.52 & 1.03 & 2.25 \\
\hline 3 & Beginning & 5 & Beginning & 1.99 & 1.35 & 2.94 \\
\hline 3 & Beginning & 8 & Middle & 1.65 & 1.12 & 2.44 \\
\hline 3 & Beginning & 9 & Middle & 1.80 & 1.00 & 3.23 \\
\hline 3 & Middle & 5 & Beginning & 2.66 & 1.54 & 4.62 \\
\hline 3 & Middle & 8 & Middle & 2.21 & 1.27 & 3.84 \\
\hline 3 & Middle & 9 & Middle & 2.41 & 1.19 & 4.86 \\
\hline 4 & Beginning & 5 & Beginning & 1.93 & 1.29 & 2.88 \\
\hline 4 & Beginning & 8 & Middle & 1.60 & 1.07 & 2.39 \\
\hline 4 & Middle & 5 & Beginning & 2.47 & 1.57 & 3.90 \\
\hline 4 & Middle & 8 & Middle & 2.05 & 1.30 & 3.24 \\
\hline 4 & Middle & 9 & Middle & 2.24 & 1.19 & 4.20 \\
\hline 4 & End & 5 & Beginning & 3.14 & 1.24 & 7.95 \\
\hline 4 & End & 8 & Middle & 2.61 & 1.03 & 6.59 \\
\hline 4 & End & 9 & Middle & 2.84 & 1.02 & 7.91 \\
\hline 5 & Middle & 1 & Beginning & 1.63 & 1.26 & 2.11 \\
\hline 5 & Middle & 2 & Beginning & 1.69 & 1.30 & 2.20 \\
\hline 5 & Middle & 3 & Beginning & 1.56 & 1.20 & 2.03 \\
\hline 5 & Middle & 4 & Beginning & 1.61 & 1.22 & 2.13 \\
\hline 5 & Middle & 5 & Beginning & 3.11 & 2.08 & 4.64 \\
\hline 5 & Middle & 6 & Middle & 1.36 & 1.05 & 1.78 \\
\hline 5 & Middle & 6 & End & 1.72 & 1.02 & 2.89 \\
\hline 5 & Middle & 7 & Middle & 1.36 & 1.02 & 1.81 \\
\hline 5 & Middle & 8 & Middle & 2.58 & 1.72 & 3.86 \\
\hline 5 & Middle & 9 & Middle & 2.81 & 1.55 & 5.08 \\
\hline 5 & Middle & 9 & End & 1.42 & 1.02 & 1.96 \\
\hline 5 & Middle & 10 & End & 1.65 & 1.18 & 2.30 \\
\hline 5 & Middle & 11 & End & 1.61 & 1.09 & 2.39 \\
\hline 5 & End & 5 & Beginning & 2.86 & 1.45 & 5.62 \\
\hline 5 & End & 8 & Middle & 2.37 & 1.20 & 4.67 \\
\hline 5 & End & 9 & Middle & 2.58 & 1.15 & 5.77 \\
\hline 6 & Middle & 5 & Beginning & 2.28 & 1.54 & 3.37 \\
\hline 6 & Middle & 8 & Middle & 1.89 & 1.27 & 2.80 \\
\hline 6 & Middle & 9 & Middle & 2.06 & 1.15 & 3.70 \\
\hline 6 & End & 5 & Beginning & 1.81 & 1.00 & 3.28 \\
\hline 7 & Middle & 5 & Beginning & 2.29 & 1.52 & 3.43 \\
\hline 7 & Middle & 8 & Middle & 1.90 & 1.26 & 2.85 \\
\hline 7 & Middle & 9 & Middle & 2.07 & 1.14 & 3.75 \\
\hline
\end{tabular}




\begin{tabular}{|c|c|c|c|c|c|c|}
\hline $\begin{array}{c}\text { Driving } \\
\text { Hour }\end{array}$ & $\begin{array}{c}\text { Work Hour } \\
\text { Category }\end{array}$ & $\begin{array}{c}\text { Driving } \\
\text { Hour }\end{array}$ & $\begin{array}{c}\text { Work Hour } \\
\text { Category }\end{array}$ & Odds Ratio & LCL & UCL \\
\hline 7 & End & 5 & Beginning & 2.38 & 1.48 & 3.83 \\
\hline 7 & End & 8 & Middle & 1.92 & 1.23 & 3.18 \\
\hline 7 & End & 9 & Middle & 2.15 & 1.13 & 4.10 \\
\hline 8 & End & 1 & Beginning & 1.74 & 1.30 & 2.34 \\
\hline 8 & End & 2 & Beginning & 1.81 & 1.34 & 2.44 \\
\hline 8 & End & 3 & Beginning & 1.67 & 1.24 & 2.25 \\
\hline 8 & End & 4 & Beginning & 1.72 & 1.26 & 2.36 \\
\hline 8 & End & 5 & Beginning & 3.32 & 2.17 & 5.09 \\
\hline 8 & End & 6 & Middle & 1.46 & 1.08 & 1.97 \\
\hline 8 & End & 6 & End & 1.83 & 1.07 & 3.15 \\
\hline 8 & End & 7 & Middle & 1.45 & 1.06 & 2.00 \\
\hline 8 & End & 8 & Middle & 2.76 & 1.80 & 4.23 \\
\hline 8 & End & 9 & Middle & 3.00 & 1.63 & 5.52 \\
\hline 8 & End & 9 & End & 1.51 & 1.06 & 2.16 \\
\hline 8 & End & 10 & End & 1.76 & 1.23 & 2.53 \\
\hline 8 & End & 11 & End & 1.72 & 1.14 & 2.61 \\
\hline 9 & End & 5 & Beginning & 2.19 & 1.42 & 3.38 \\
\hline 9 & End & 8 & Middle & 1.82 & 1.18 & 2.81 \\
\hline 9 & End & 9 & Middle & 1.98 & 1.07 & 3.66 \\
\hline 10 & End & 5 & Beginning & 1.89 & 1.22 & 2.93 \\
\hline 10 & End & 8 & Middle & 1.56 & 1.01 & 2.43 \\
\hline 11 & End & 5 & Beginning & 1.93 & 1.19 & 3.13 \\
\hline & & & & & \\
\hline
\end{tabular}

\subsubsection{Evaluation of Only Shifts with 14 Working Hours}

To be able to investigate the relative impact of driving hour-work hour combinations, the data set included shifts where the driver drove 11 hours or less, but only included shifts where the driver worked into the 14th hour. Table 30 shows the data set used for this analysis. The table demonstrates that not all driving hour-work hour combinations occurred in the data set. 
Table 30. SCEs and Total Opportunities for Driving Hours 1-11 and Work Hour Categories Beginning, Middle, and End, for Shifts That Went Into the 14th Work Hour

\begin{tabular}{|c|c|c|c|c|}
\hline $\begin{array}{l}\text { Driving } \\
\text { Hour }\end{array}$ & $\begin{array}{l}\text { Work Hour } \\
\text { Category }\end{array}$ & $\begin{array}{l}\text { SCEs Per Driving } \\
\text { Hour-Work Hour }\end{array}$ & $\begin{array}{c}\text { Total } \\
\text { Opportunities Per } \\
\text { Driving Hour-Work } \\
\text { Hour }\end{array}$ & $\begin{array}{c}\text { Rate of SCE/Total } \\
\text { Opportunities }\end{array}$ \\
\hline 1 & Beginning & 51 & 505.00 & 0.101 \\
\hline 1 & Middle & 0 & 22.50 & 0.000 \\
\hline 1 & End & 1 & 9.37 & 0.107 \\
\hline 2 & Beginning & 76 & 474.25 & 0.160 \\
\hline 2 & Middle & 4 & 46.00 & 0.087 \\
\hline 2 & End & 5 & 12.25 & 0.408 \\
\hline 3 & Beginning & 60 & 410.85 & 0.146 \\
\hline 3 & Middle & 20 & 97.27 & 0.206 \\
\hline 3 & End & 2 & 19.00 & 0.105 \\
\hline 4 & Beginning & 33 & 293.89 & 0.112 \\
\hline 4 & Middle & 28 & 192.64 & 0.145 \\
\hline 4 & End & 8 & 29.27 & 0.273 \\
\hline 5 & Beginning & 18 & 134.00 & 0.134 \\
\hline 5 & Middle & 51 & 307.45 & 0.166 \\
\hline 5 & End & 7 & 63.50 & 0.110 \\
\hline 6 & Middle & 52 & 371.56 & 0.140 \\
\hline 6 & End & 17 & 116.27 & 0.146 \\
\hline 7 & Middle & 39 & 231.28 & 0.169 \\
\hline 7 & End & 53 & 220.24 & 0.241 \\
\hline 8 & Middle & 2 & 101.79 & 0.020 \\
\hline 8 & End & 39 & 300.16 & 0.130 \\
\hline 9 & Middle & 2 & 28.75 & 0.070 \\
\hline 9 & End & 57 & 298.11 & 0.191 \\
\hline 10 & End & 37 & 221.29 & 0.167 \\
\hline 11 & End & 39 & 109.32 & 0.357 \\
\hline
\end{tabular}

Figure 34-Figure 37 show plots of the rate of SCE occurence for each driving hour-work hour combination. Figure 34 displays the SCE rate, by SCE type, for the Beginning work hour category (work hours 1-5); Figure 35 provides the SCE rate, by SCE type, for the Middle work hour category (hours 6-9); and Figure 36 provides the SCE rate, by SCE type, for the End work hour category (hours 10-14). Finally, Figure 37 provides an overview of SCE rate, by SCE type, for all working hours. 


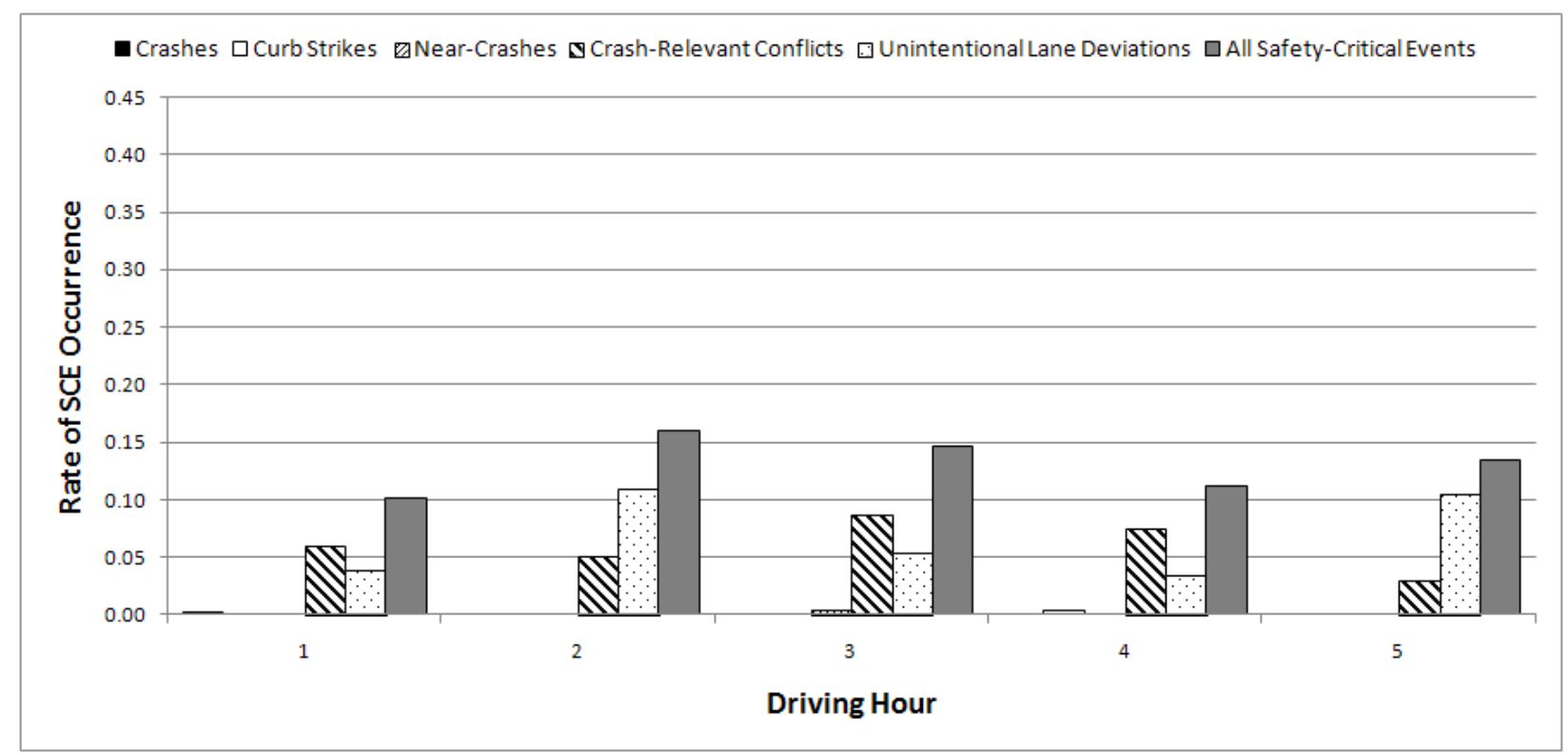

Figure 34. Bar Graph. Rate of SCE Occurrence as a Function of Driving Hour and Beginning Work Hours (Hours 1-5), for Shifts That Went Into the 14th Work Hour

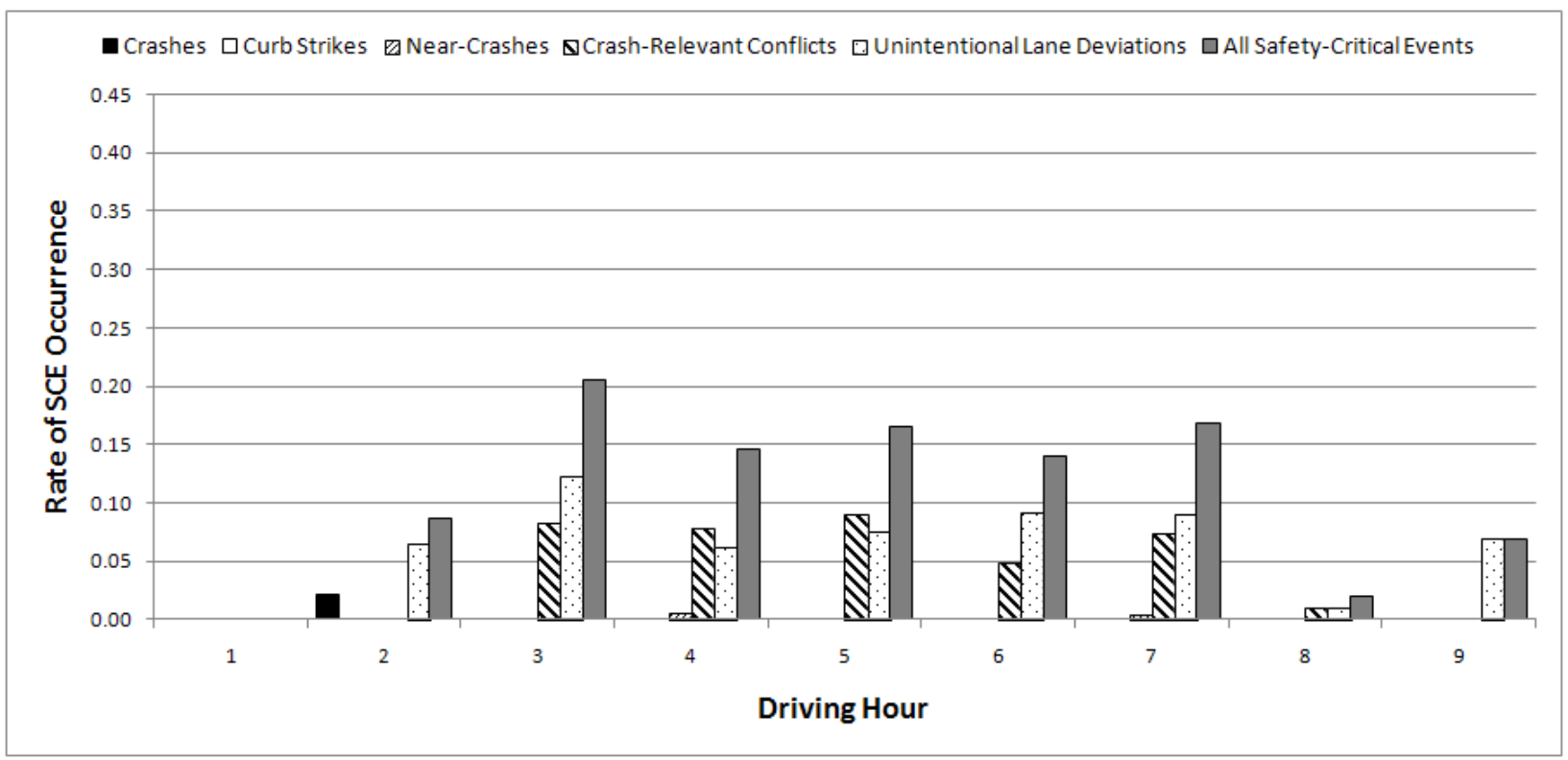

Figure 35. Bar Graph. Rate of SCE Occurrence as a Function of Driving Hour and Middle Work Hours (Hours 6-9), for Shifts That Went Into the 14th Work Hour 


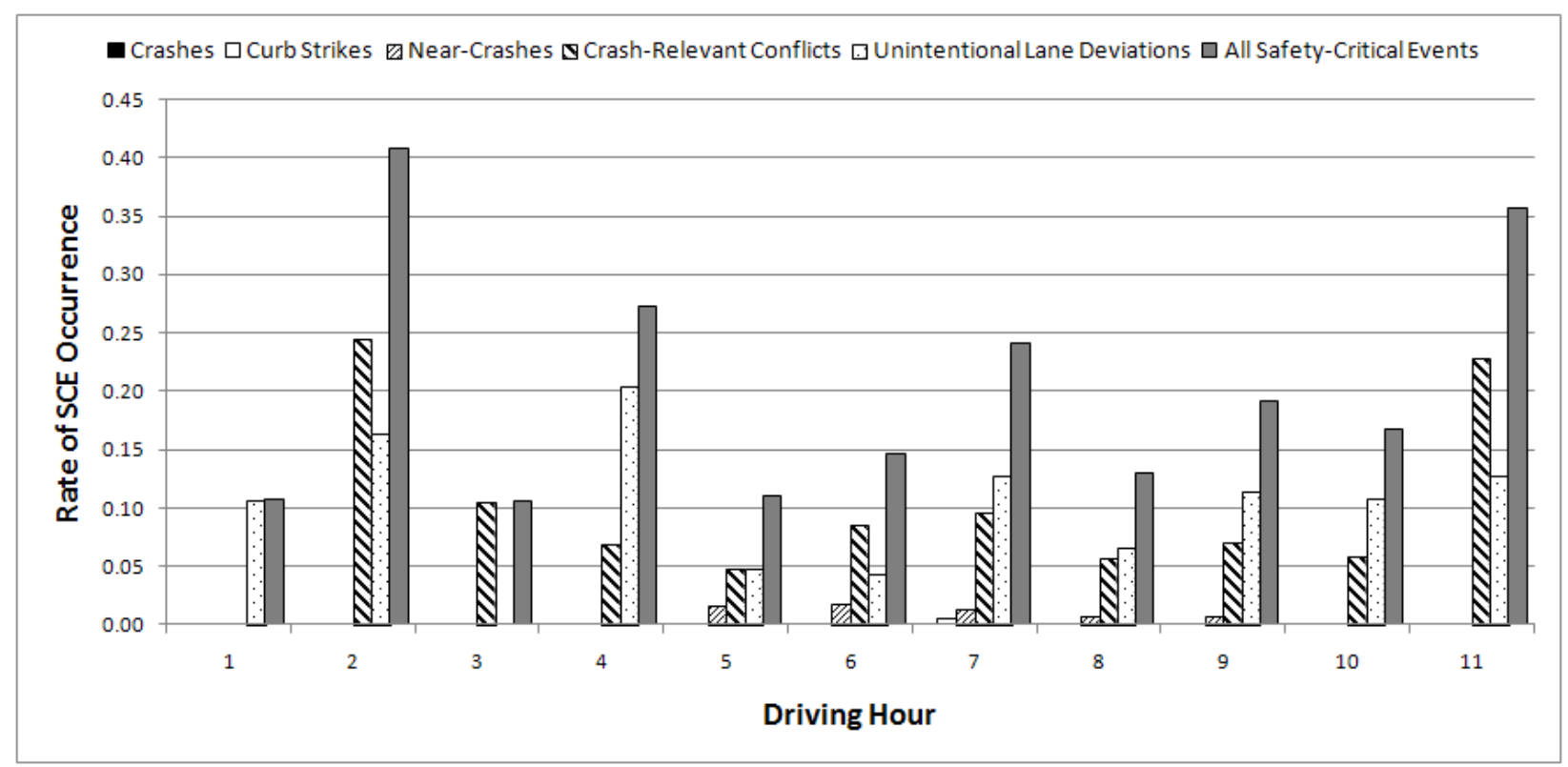

Figure 36. Bar Graph. Rate of SCE Occurrence as a Function of Driving Hour and End Work Hours (Hours 10-14), for Shifts That Went Into the 14th Work Hour 


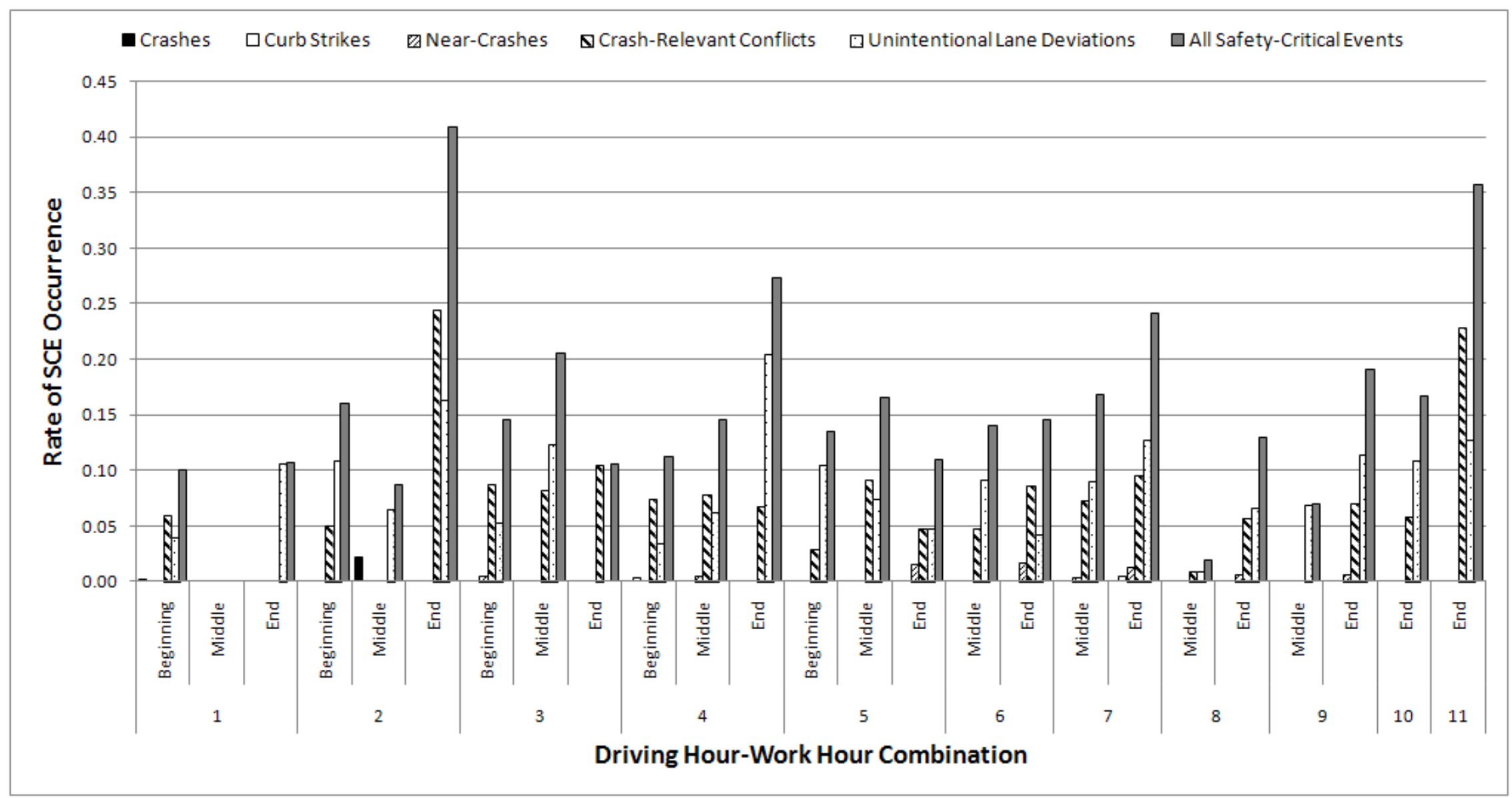

Figure 37. Bar Graph. Rate of SCE Occurrence as a Function of Driving Hour and Work Hour, for Shifts That Went Into the 14th Work Hour 


\subsubsection{Evaluation of All Shifts with Multiple Within-Hour SCE Collapsed}

Following a similar method to the one used to analyze driving hours, a dichotomous approach was used to analyze work hours where the driver worked into the 14th working hour. As in the driving-hour analysis, the SCE data along with the exposure data were used to calculate a rate of SCE occurrence as a function of the driving hour and work hour combination. To be able to investigate the relative impact of driving hour-work hour combinations, this data set included shifts where the driver drove 11 hours or less, but only included shifts where the driver worked into the 14th hour. Table 31 shows the dichotomous variable (either "yes, at least one SCE occurred" or "no SCE occurred") data set that was used for this analysis, and Figure 38-Figure 41 show a plot of the rate of SCE occurrence for each driving hour by work hour category (Beginning, Middle, and End of shift).

Table 31. SCEs and Total Opportunities for Driving Hours 1-11 and Work Hours 1-14, with Multiple Within-Hour SCEs Collapsed (Dichotomous Approach), for Shifts That Went Into the 14th Work Hour

\begin{tabular}{|c|c|c|c|c|}
\hline $\begin{array}{l}\text { Driving } \\
\text { Hour }\end{array}$ & $\begin{array}{l}\text { Work Hour } \\
\text { Category }\end{array}$ & $\begin{array}{l}\text { SCEs Per Driving } \\
\text { Hour-Work Hour }\end{array}$ & $\begin{array}{c}\text { Total } \\
\text { Opportunities Per } \\
\text { Driving Hour-Work } \\
\text { Hour }\end{array}$ & $\begin{array}{l}\text { Rate of SCE/Total } \\
\text { Opportunities }\end{array}$ \\
\hline 1 & Beginning & 40 & 505.00 & 0.079 \\
\hline 1 & Middle & 0 & 22.50 & 0.000 \\
\hline 1 & End & 1 & 9.37 & 0.107 \\
\hline 2 & Beginning & 41 & 474.25 & 0.086 \\
\hline 2 & Middle & 3 & 46.00 & 0.065 \\
\hline 2 & End & 1 & 12.25 & 0.082 \\
\hline 3 & Beginning & 42 & 410.85 & 0.102 \\
\hline 3 & Middle & 10 & 97.27 & 0.103 \\
\hline 3 & End & 1 & 19.00 & 0.053 \\
\hline 4 & Beginning & 23 & 293.89 & 0.078 \\
\hline 4 & Middle & 19 & 192.64 & 0.099 \\
\hline 4 & End & 5 & 29.27 & 0.171 \\
\hline 5 & Beginning & 7 & 134.00 & 0.052 \\
\hline 5 & Middle & 34 & 307.45 & 0.111 \\
\hline 5 & End & 6 & 63.50 & 0.094 \\
\hline 6 & Middle & 28 & 371.56 & 0.075 \\
\hline 6 & End & 13 & 116.27 & 0.112 \\
\hline 7 & Middle & 20 & 231.28 & 0.086 \\
\hline 7 & End & 35 & 220.24 & 0.159 \\
\hline 8 & Middle & 2 & 101.79 & 0.020 \\
\hline 8 & End & 31 & 300.16 & 0.103 \\
\hline 9 & Middle & 1 & 28.75 & 0.035 \\
\hline 9 & End & 33 & 298.11 & 0.111 \\
\hline 10 & End & 20 & 221.29 & 0.090 \\
\hline 11 & End & 16 & 109.32 & 0.146 \\
\hline
\end{tabular}


Figure 38 displays the SCE rate, by SCE type, for the Beginning work hour category (hours 15); Figure 39 provides the SCE rate, by SCE type, for the Middle work hour category (hours 69); and Figure 40 provides the SCE rate, by SCE type, for the End work hour category (hours 10-14). Finally, Figure 41 provides an overview of SCE rate, by SCE type, for all working hours.

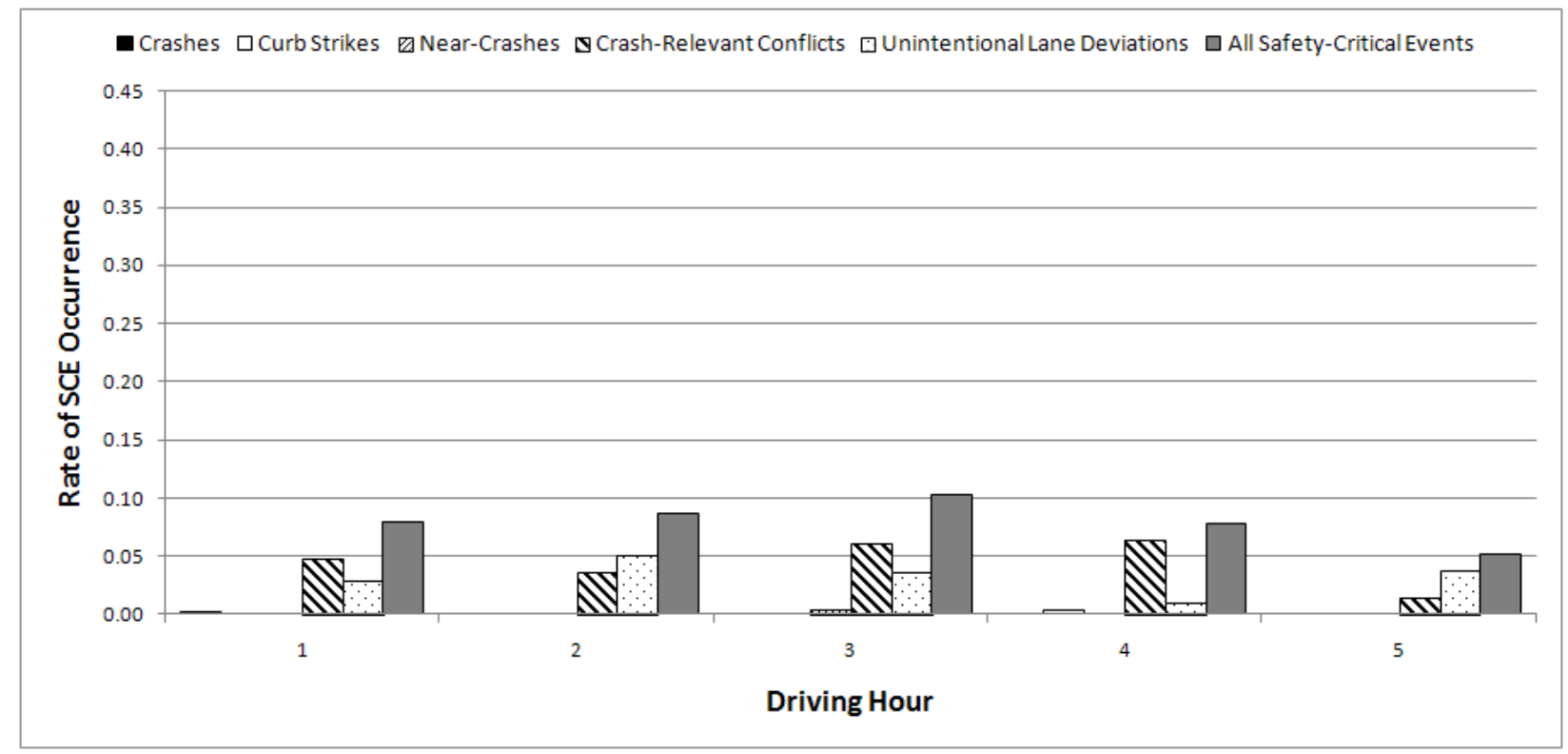

Figure 38. Bar Graph. Rate of SCE Occurrence as a Function of Driving Hour and Beginning Work Hours (Hours 1-5) (Dichotomous Approach), with Multiple Within-Hour SCEs Collapsed, for Shifts That Went Into the 14th Work Hour

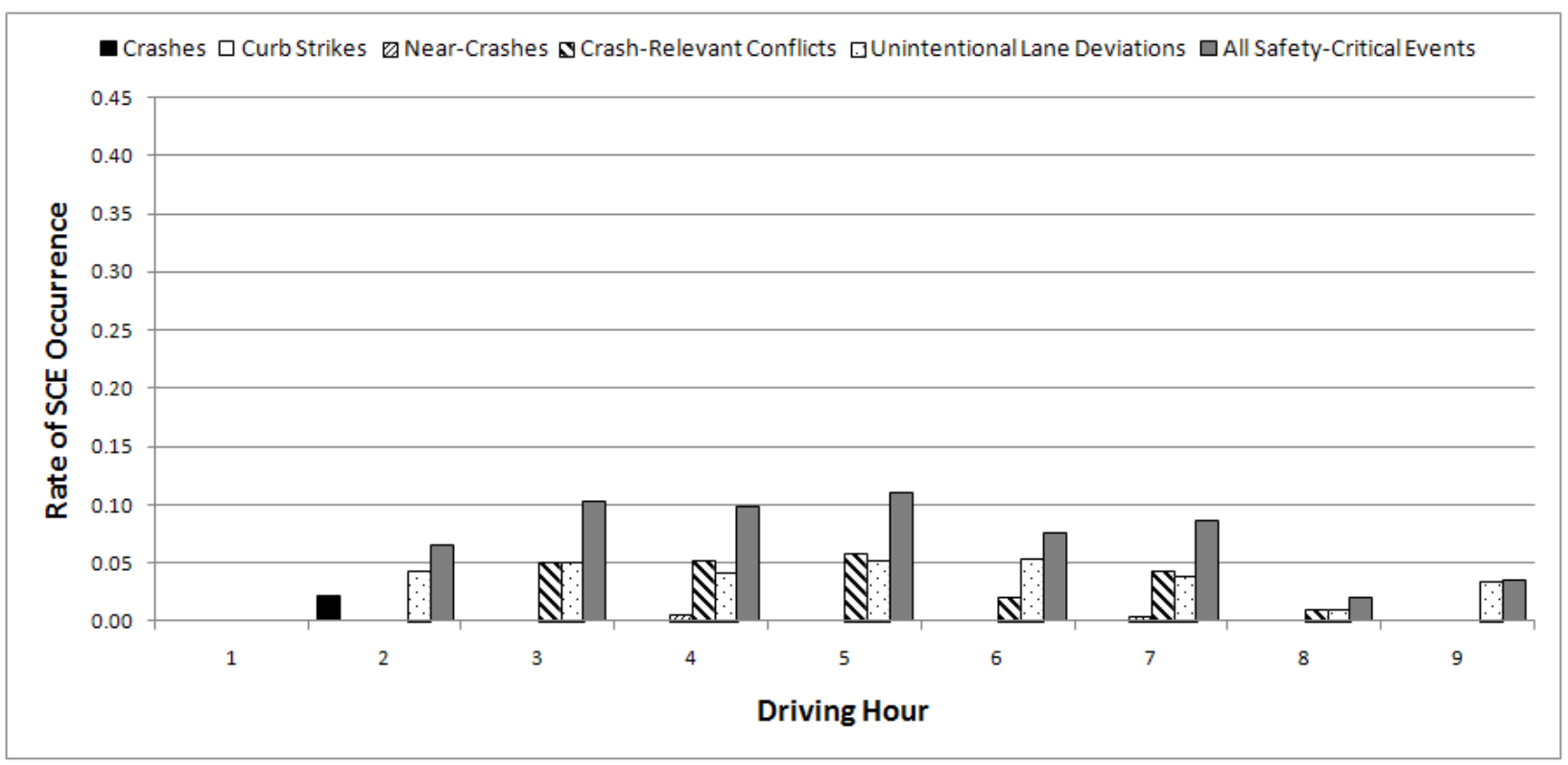

Figure 39. Bar Graph. Rate of SCE Occurrence as a function of Driving Hour and Middle Work Hours (Hours 6-9) (Dichotomous Approach), with Multiple Within-Hour SCEs Collapsed, for Shifts That Went Into the 14th Work Hour 


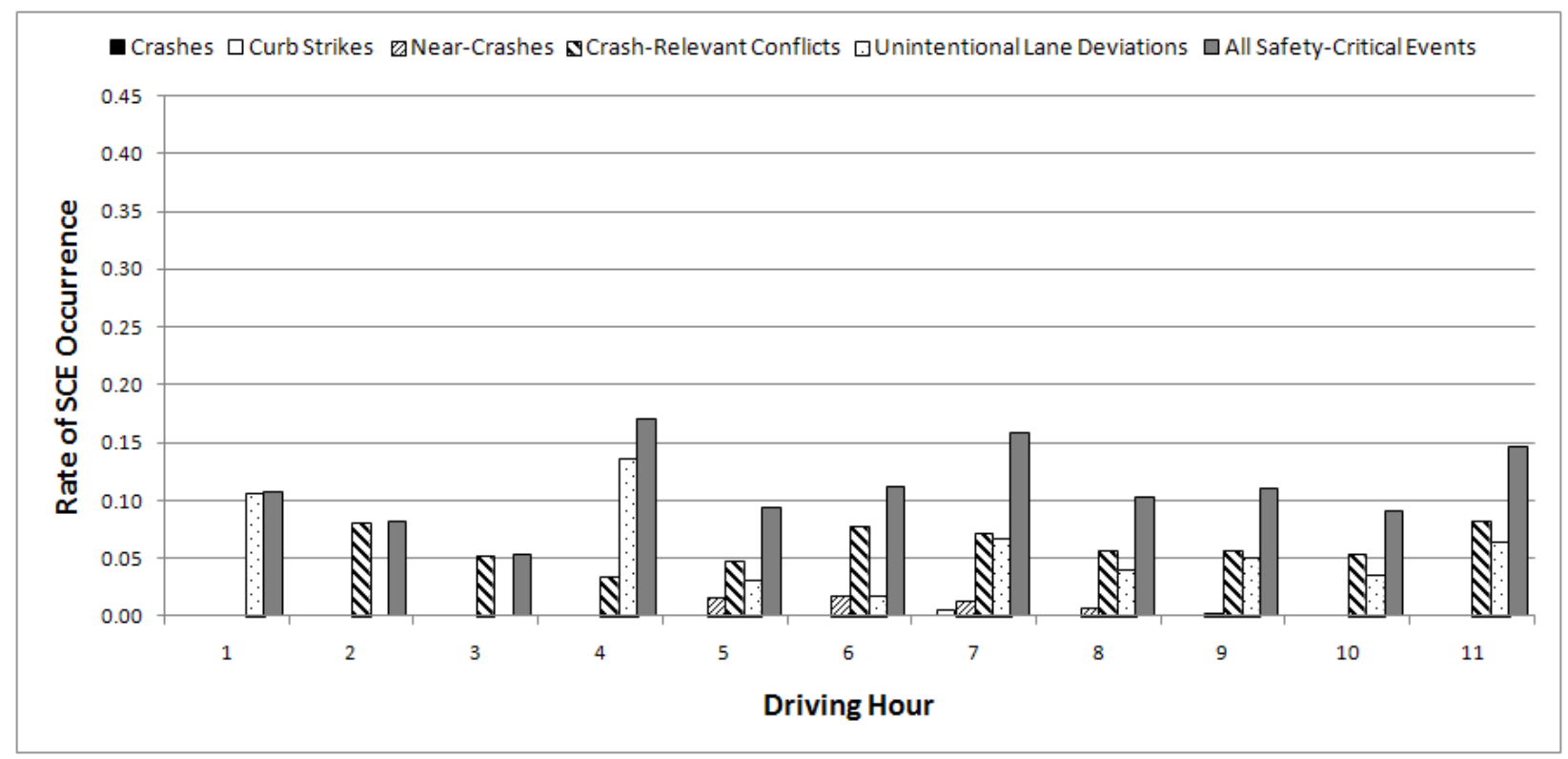

Figure 40. Bar Graph. Rate of SCE Occurrence as a Function of Driving Hour and End Work Hours (Hours 10-14) (Dichotomous Approach), with Multiple Within-Hour SCEs Collapsed, for Shifts That Went Into the 14th Work Hour 


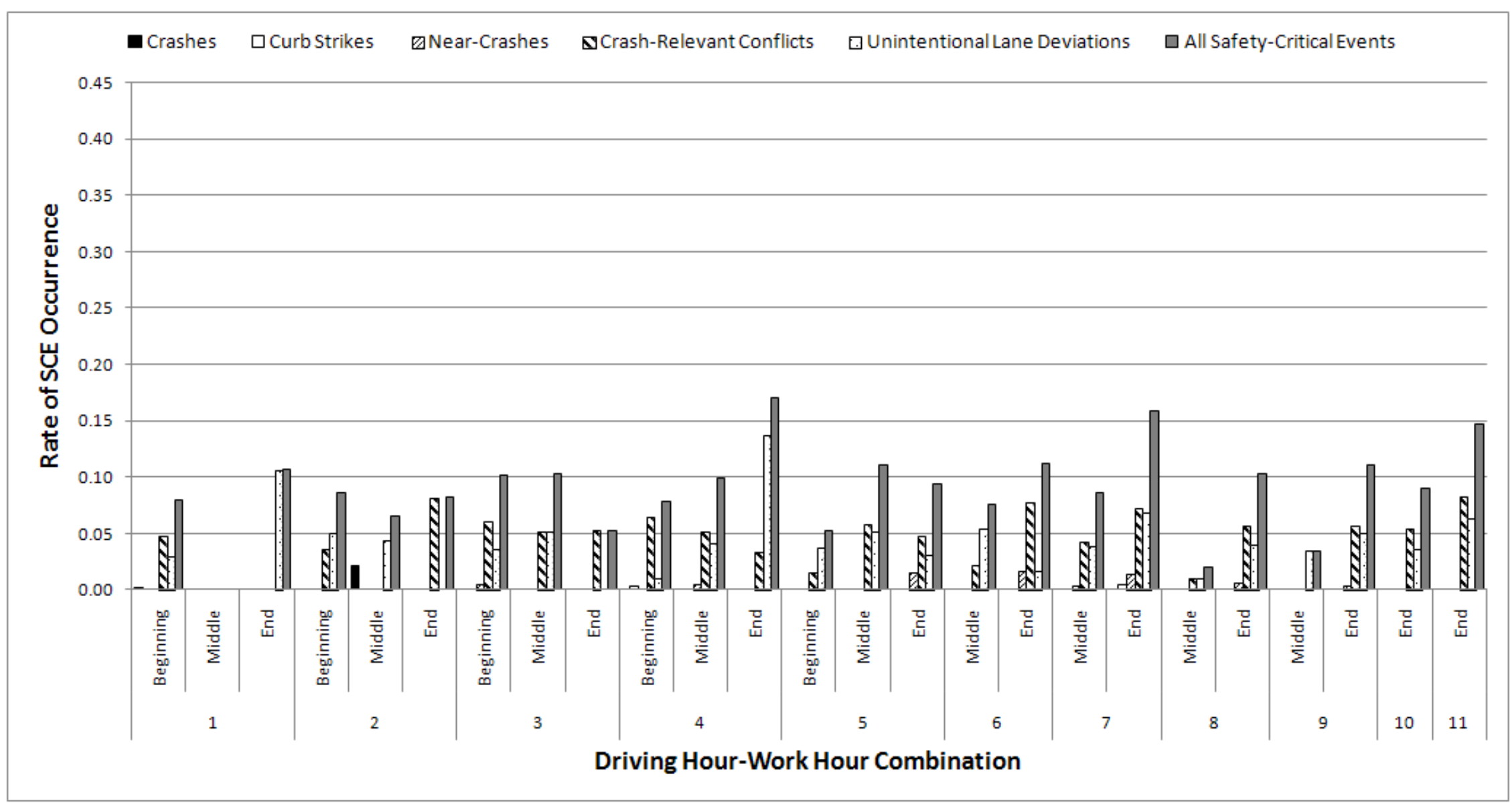

Figure 41. Bar Graph. Rate of SCE Occurrence as a Function of Driving Hour and Work Hour (Dichotomous Approach), with Multiple Within-Hour SCEs Collapsed, for Shifts That Went Into the 14th Work Hour 
A follow-up analysis focusing on comparing the three work-hour categories, independent of driving hour, was conducted to examine these findings further. Using the data from Figure 41, the rate of SCE occurrence is plotted in Figure 42 solely as a function of the work hour category (collapsing over driving hour from Figure 41).

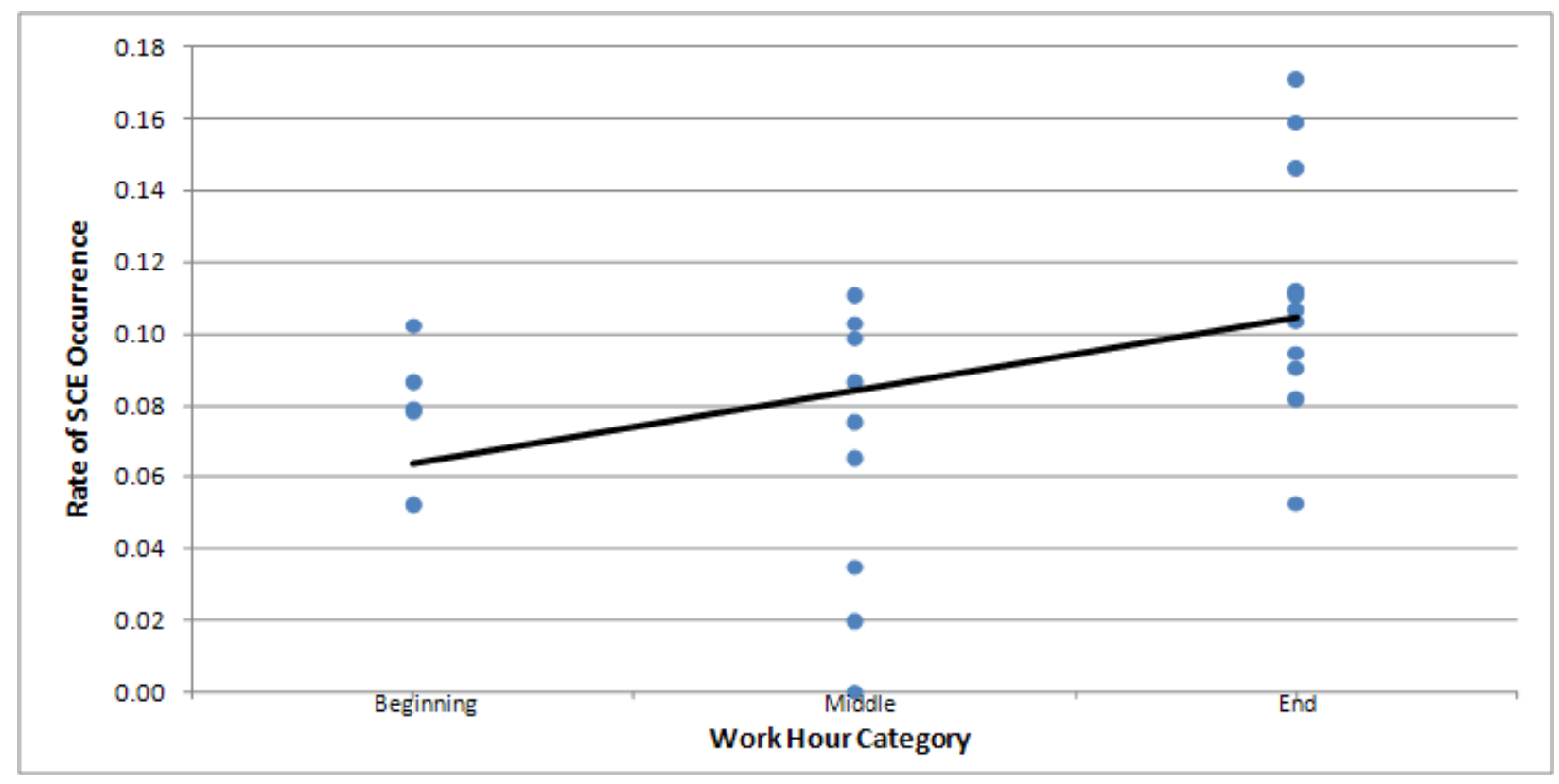

Figure 42. Data Plot. Rate of SCE Occurrence as a Function of Work Hour Category for Shifts That Went Into the 14th Work Hour

Each point on the plot represents a driving hour-work hour SCE rate (as calculated in Table 31). To measure if a trend existed between rate of SCE occurrence and work hour category, different models (simple linear regression, exponential regression, as well as regression with variable transformation, among others) were fitted to the data with similar results. A simple linear regression analysis indicated that as the work hour increases from Beginning to End, the SCE rate increases, demonstrated by the trend line shown in Figure 42 (Pearson correlation coefficient of 0.16). A positive Pearson correlation coefficient indicates that the $\mathrm{x}$-axis and $\mathrm{y}$-axis variables grow together. Note that each model tested drew the same conclusion. Odds ratios were examined on the rate of SCE occurrence across the driving hour-work hour combinations to evaluate if the increase was statistically significant.

Table 32 displays the significant odds ratios from this analysis. The results show that the risk of an SCE statistically increases as work hour increases. The key points of comparison are when a driving hour of interest is compared against that same driving hour at two different points of work hours. For example, when the 7th driving hour is performed during the End of the shift (between 10 and 14 hours from when the shift started) a driver is two times more likely to be involved in an SCE than when the 7th hour of driving is performed in the Middle of the shift. 
Table 32. Significant Results from the Odds Ratio Analysis with Multiple Within-Hour SCEs Collapsed (Dichotomous Approach), for Shifts That Went Into the 14th Working Hour

\begin{tabular}{|c|c|c|c|c|c|c|}
\hline $\begin{array}{c}\text { Driving } \\
\text { Hour }\end{array}$ & $\begin{array}{c}\text { Work Hour } \\
\text { Category }\end{array}$ & $\begin{array}{c}\text { Driving } \\
\text { Hour }\end{array}$ & $\begin{array}{c}\text { Work Hour } \\
\text { Category }\end{array}$ & Odds Ratio & LCL & UCL \\
\hline 1 & Beginning & 8 & Middle & 4.29 & 1.02 & 18.05 \\
\hline 2 & Beginning & 8 & Middle & 4.72 & 1.12 & 19.85 \\
\hline 3 & Beginning & 8 & Middle & 5.68 & 1.35 & 23.88 \\
\hline 3 & Middle & 8 & Middle & 5.72 & 1.22 & 26.81 \\
\hline 4 & Middle & 8 & Middle & 5.46 & 1.25 & 23.93 \\
\hline 5 & Middle & 8 & Middle & 6.20 & 1.46 & 26.30 \\
\hline 7 & Middle & 8 & Middle & 4.72 & 1.08 & 20.60 \\
\hline 4 & End & 5 & Beginning & 3.74 & 1.10 & 12.75 \\
\hline 4 & End & 8 & Middle & 10.28 & 1.88 & 56.20 \\
\hline 5 & End & 8 & Middle & 5.21 & 1.02 & 26.65 \\
\hline 6 & End & 8 & Middle & 6.28 & 1.38 & 28.54 \\
\hline 7 & End & 1 & Beginning & 2.20 & 1.35 & 3.57 \\
\hline 7 & End & 2 & Beginning & 2.00 & 1.23 & 3.24 \\
\hline 7 & End & 3 & Beginning & 1.66 & 1.02 & 2.69 \\
\hline 7 & End & 4 & Beginning & 2.23 & 1.27 & 3.89 \\
\hline 7 & End & 5 & Beginning & 3.43 & 1.48 & 7.96 \\
\hline 7 & End & 6 & Middle & 2.32 & 1.37 & 3.93 \\
\hline 7 & End & 7 & Middle & 2.00 & 1.11 & 3.58 \\
\hline 7 & End & 8 & Middle & 9.43 & 2.22 & 40.01 \\
\hline 7 & End & 10 & End & 1.90 & 1.06 & 3.41 \\
\hline 8 & End & 8 & Middle & 5.75 & 1.35 & 24.46 \\
\hline 9 & End & 8 & Middle & 6.21 & 1.46 & 26.37 \\
\hline 10 & End & 8 & Middle & 4.96 & 1.14 & 21.63 \\
\hline 11 & End & 1 & Beginning & 1.99 & 1.07 & 3.71 \\
\hline 11 & End & 4 & Beginning & 2.02 & 1.02 & 3.99 \\
\hline 11 & End & 5 & Beginning & 3.11 & 1.23 & 7.86 \\
\hline 11 & End & 6 & Middle & 2.10 & 1.09 & 4.05 \\
\hline & End & 8 & Middle & 8.55 & 1.91 & 38.22 \\
\hline
\end{tabular}

A key take-away from the above analyses on work hour is that the risk of being involved in an SCE generally increased as work hour increased that is, driving time that occurred later in the driver's workday, due to performing non-driving tasks earlier in the workday, had a negative safety effect. Therefore, though driving hour, in and of itself, may not have shown an increase in risk when comparing the 10th and 11th driving hours, the combination of driving hour-work hour did show a negative time-on-task effect for driving hours that occurred late in the 14 hour workday.

\subsection{SAFETY IMPACTS OF BREAKS FROM DRIVING}

The results from the work-hour analysis suggest that performing non-driving tasks prior to the start of driving (at the Beginning of a driver's shift), which leads to driving late into the 14-hour 
workday, may have an adverse effect on safety. However, not all breaks from driving are similar. As noted in the workday characterization, drivers performed other tasks in addition to the driving task (light/heavy work, rest). In this study, a break was operationally defined as a break from driving of at least 30 minutes. Breaks were grouped into four categories: rest during duty period, work during duty period, rest during duty period/off duty, and off duty. Neither a break of 10 hours or longer, nor a break that qualified as part of the Sleeper Berth provision-either of which could restart a driver's shift-were not included in this analysis. These are further described in Table 33, below.

Table 33. Taxonomy of Break-From-Driving Types

\begin{tabular}{|l|l|}
\hline \multicolumn{1}{|c|}{ Break Type } & \multicolumn{1}{c|}{ Description } \\
\hline Type 1/Rest During Duty Period. & $\begin{array}{l}\text { Any consecutive duration of rest activities during the duty period } \\
\text { (sleep, eat, rest). }\end{array}$ \\
\hline Type 2/Work During Duty Period. & Any consecutive duration of work (light work, heavy work). \\
\hline $\begin{array}{l}\text { Type 3/Off Duty Rest During } \\
\text { Duty Period. }\end{array}$ & $\begin{array}{l}\text { Any combination of consecutive duration of rest activities during a } \\
\text { duty period (Type 1) and off-duty activity (Type 4). }\end{array}$ \\
\hline Type 4/Off Duty. & $\begin{array}{l}\text { Any consecutive duration of off-duty activity (rest, eat, light house } \\
\text { work, heavy house work, light leisure activity, heavy leisure activity, } \\
\text { driving other vehicle, other). }\end{array}$ \\
\hline
\end{tabular}

This analysis focuses on the safety effects of breaks from the driving task. The purpose of this analysis was to examine the safety impacts of the number of breaks to a shift and the SCE rate before and after a break.

\subsubsection{Total Breaks Taken from Driving During a Shift}

As noted in Section 2, a break was operationally defined as a break from driving that lasted at least 30 minutes but less than the time needed to start a new shift (a 10-hour or longer break or sleeper berth provision breaks that are not counted against the work hours). The mean SCE rate and number of breaks are shown in Table 34. The SCE rate was defined as the number of SCEs divided by the total driving time of a shift. Twenty-two percent of the shifts had no breaks from driving, 30 percent of shifts had one break from driving, 23 percent had two breaks from driving, and 25 percent of the shifts had three or more breaks.

Table 34. Mean SCE Rate by Number of Breaks from Driving

\begin{tabular}{|c|c|c|c|}
\hline $\begin{array}{c}\text { Number of Breaks } \\
\text { from Driving }\end{array}$ & Shift Frequency & $\begin{array}{c}\text { Percentage of } \\
\text { Total Shift }\end{array}$ & Mean SCE Rate \\
\hline 0 & 405 & $22 \%$ & 0.134 \\
\hline 1 & 562 & $30 \%$ & 0.173 \\
\hline 2 & 437 & $23 \%$ & 0.126 \\
\hline 3 & 269 & $14 \%$ & 0.121 \\
\hline 4 & 144 & $8 \%$ & 0.118 \\
\hline 5 & 43 & $2 \%$ & 0.211 \\
\hline$\geq 6$ & 21 & $1 \%$ & 0.060 \\
\hline
\end{tabular}


The rate of SCE occurrence for a shift was statistically related to the total driving hour, the type of break, and the number of breaks using an NB regression model with logarithm link function, which was used to model the relationship between the SCE occurrence rate and other factors of interest. The NB regression model assumes that the number of SCEs for a shift was generated from a stochastic process and that the expected event rate was a function of the type and number of breaks. This approach accords with the random nature of the safety event and has been the state-of-practice approach in traffic safety modeling. ${ }^{(43)}$

Total driving hours for a shift serves a dual role in this analysis. It is both the exposure measure and potentially a risk factor. Longer trips are associated with greater levels of exposures. Thus more SCEs are expected over a greater number of driving hours if the event rate is constant. The standard practice in handling this relationship is to use a power transformation of driving hour as the exposure, where $a$ is a coefficient estimated from the data ${ }^{(44)}\left(\right.$ Exposure $=$ Driving Hour $\left.^{a}\right)$.

This exposure measure takes into account the non-linear relationship between the event frequency and driving hours. There are multiple SCEs for each driver. In order to account for this, a random effect term was added to the model. The final model used in the analysis was a random effect NB model. The original model, seen in Table 35, included working hours, number of breaks from driving, and exposure. However, this inclusive model failed to reach significance for two of the variables - namely, the number of breaks from driving and working hours. This may be due to multicollinearity (i.e., an instance where two or more variables in a model are highly correlated) between the number of breaks from driving and working hours

(Pearson's $r=0.35$ ). The number of breaks from driving and working hours measures a similar factor: time during the day to do non-driving activities. If a driver had many breaks from driving, then the driver had many 30-minute periods of non-driving activities counted as work. Therefore, the high degree of correlation between these variables may prevent them from being practically useful in a model. A technique used to address this is discussed below.

Table 35. Safety Impact of Number of Breaks from Driving, Working Hours, and Driving Hours

\begin{tabular}{|l|r|r|r|r|r|}
\hline \multicolumn{1}{|c|}{ Effect } & Estimate & \multicolumn{1}{c|}{ SE } & \multicolumn{1}{c|}{ df } & \multicolumn{1}{c|}{$\boldsymbol{t}$} & \multicolumn{1}{c|}{$\boldsymbol{p}$} \\
\hline Intercept & -3.1540 & 0.3039 & 96 & -10.38 & $<0.0001$ \\
\hline Number of Breaks from Driving & 0.06042 & 0.03791 & 1781 & 1.59 & 0.1111 \\
\hline Working Hours & -0.02587 & 0.01631 & 1781 & -1.59 & 0.1129 \\
\hline Exposure $(a)$ & 1.2281 & 0.1240 & 1781 & 9.90 & $<0.0001$ \\
\hline
\end{tabular}

A backwards modeling technique was applied, where the variable with the largest $p$-value was removed from the analysis. The resultant model was then recalculated, and this strategy of removing the variable with the largest $p$-value was repeated until only significant variables remained. For this analysis, the variable for working hours $(p=0.1129)$ was removed. When working hours were excluded from the model, the resultant model included only the number of breaks from driving and exposure. The output of this resultant model is shown in Table 36. The overall number of breaks from driving during a shift had no significant effects on the SCE rate $(p$ $=0.2569)$. However, the exposure coefficient was significant $(p<0.001)$, which indicates a nonlinear relationship between driving hours and SCE frequencies. 
Table 36. Safety Impact of Total Number of Breaks from Driving: NB Model Results

\begin{tabular}{|l|r|r|r|r|r|}
\hline \multicolumn{1}{|c|}{ Effect } & Estimate & \multicolumn{1}{c|}{ SE } & \multicolumn{1}{c|}{ df } & \multicolumn{1}{c|}{$\boldsymbol{t}$} & \multicolumn{1}{c|}{$\boldsymbol{p}$} \\
\hline Intercept & -3.3222 & 0.2872 & 96 & -11.57 & $<0.0001$ \\
\hline Number of Breaks from Driving & 0.04099 & 0.03586 & 1,782 & 1.14 & 0.2533 \\
\hline Exposure $(a)$ & 1.2827 & 0.1201 & 1,782 & 10.68 & $<0.0001$ \\
\hline
\end{tabular}

One possible explanation for the failure of the work hours and number of breaks from driving variables to reach statistical significance may result from their correlation with exposure, in turn resulting in multicollinearity. For this model, the Pearson correlation coefficient between work hours and exposure was $r=-0.18$, and the Pearson correlation coefficient between number of breaks from driving and exposure was $r=0.11$. The correlation coefficients were tested for significance, using the same formula above, and found to be significant with $t$-statistics of 7.93 and 4.67, respectively. Each of these three variables is related to each other, as driving hours were needed to have breaks from driving, and driving hours can only happen during the 14-hour window when working hours were not also happening. Therefore, it is likely that the multicollinearity present prevented some aspects of the model from reaching significance.

It is clear from these models that further investigation is needed into the relationships between breaks, working hours, and exposure. The next set of analyses looked in more detail at breaks from driving. The above model takes an overall approach (number of breaks during a shift and total SCEs during the shift) regardless of when the SCE happened with respect to a break from driving. Thus, a higher-level analysis was conducted, evaluating SCEs before and after breaks from driving. In order to accomplish this, however, it was necessary to characterize the breaks from driving more precisely. Just because there is a break from driving, the driver is not necessarily resting; i.e., the driver could be performing other non-driving work-related tasks.

\subsubsection{Type of Break Taken from Driving During a Shift}

The second model used for this analysis evaluated the effects of the four different types of breaks: rest during duty period, work during duty period, rest during duty period/off duty, and off duty (see Table 33). Figure 43-Figure 45 present an overview of the frequency of breaks across shifts, the driving hour when each type of break was taken, and a characterization of each break type. Figure 43 presents the number of breaks a driver takes during a shift. Each break from driving may be made up of one or more of the four break types. Combination breaks are represented in Figure 43 using fractions to calculate how a single break was split. In order to correctly represent the frequency of breaks by break type, the total count of each break type was divided by the number of breaks per shift. Figure 43 shows that the most common number of breaks taken over a shift is one break and that drivers took between zero and nine breaks over a shift. Note that not all shifts included each break type; that is, there were: 1,465 shifts without a Break 1; 752 shifts without a Break 2; 1,876 shifts without a Break 3; and 1,792 shifts without a Break 4. Break 2 (work during duty period) was the most common break type across all numbers of breaks during shifts. It also illustrates that the proportion of each break type is similar even if multiple breaks are taken.

As an example, a driver could take two breaks during a shift, one of which is a Break 1 and the other is a combination of Break 2 and Break 4. In Figure 43, this is shown in the " 2 " column for two breaks taken over the shift. Break 2 and Break 4 would each be marked as having one-half 
of a break, since a single break was split into two break types. Break 1 would be marked as onehalf of the break, while Break 2 and Break 4 would each be marked as one-fourth of the break. The sum of these numbers is 1 , meaning that a set of two breaks happened in a shift.

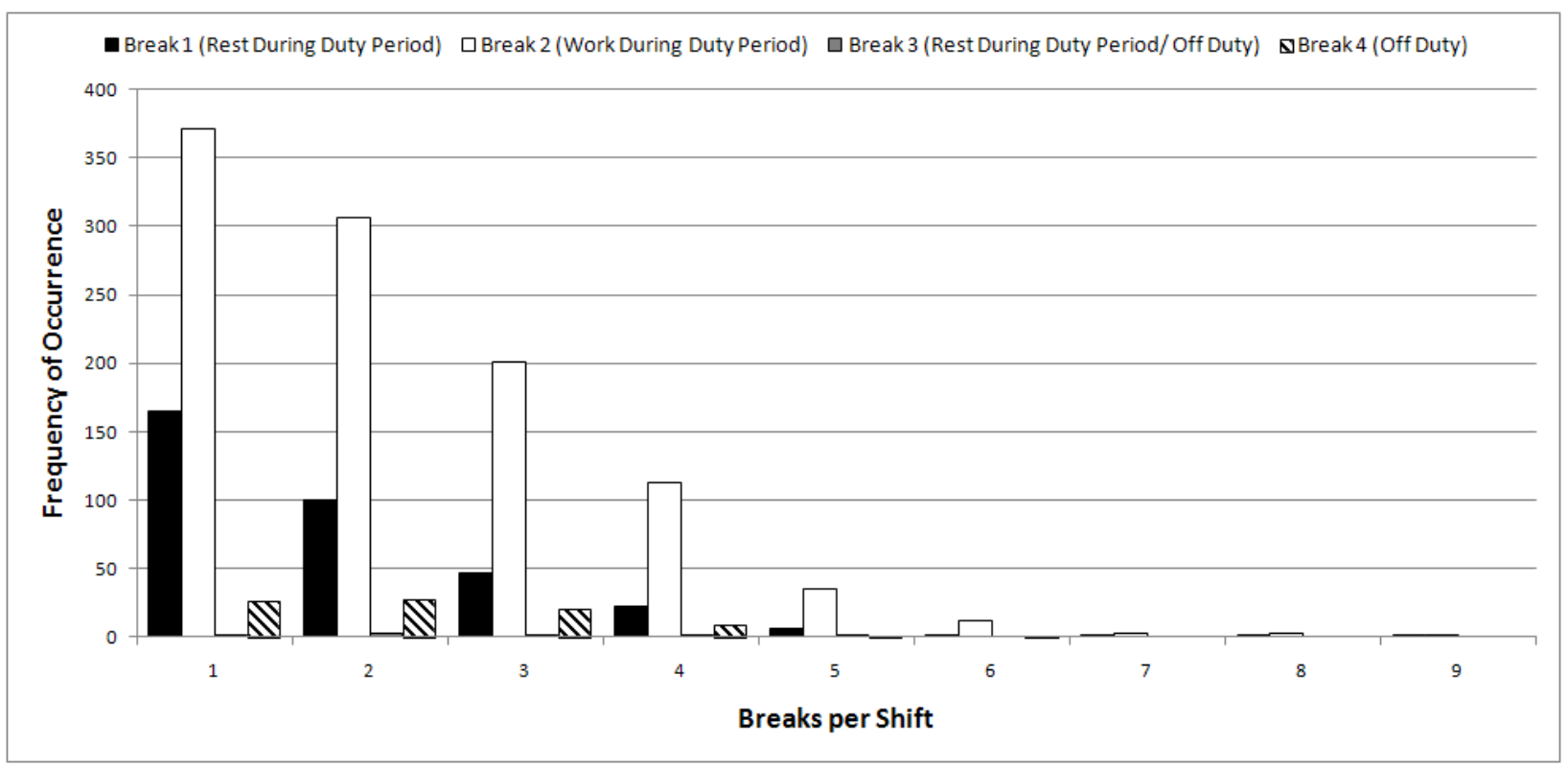

Figure 43. Bar Graph. Number of Shifts That Included Breaks From Driving

Figure 44 shows the driving hour in which the breaks begin. Breaks were taken most frequently in driving hours $1-4$, with the 4 th driving hour being the most common hour for breaks. There is a steep decline in frequency of breaks taken in driving hours 5-11. Each break type follows this same general pattern.

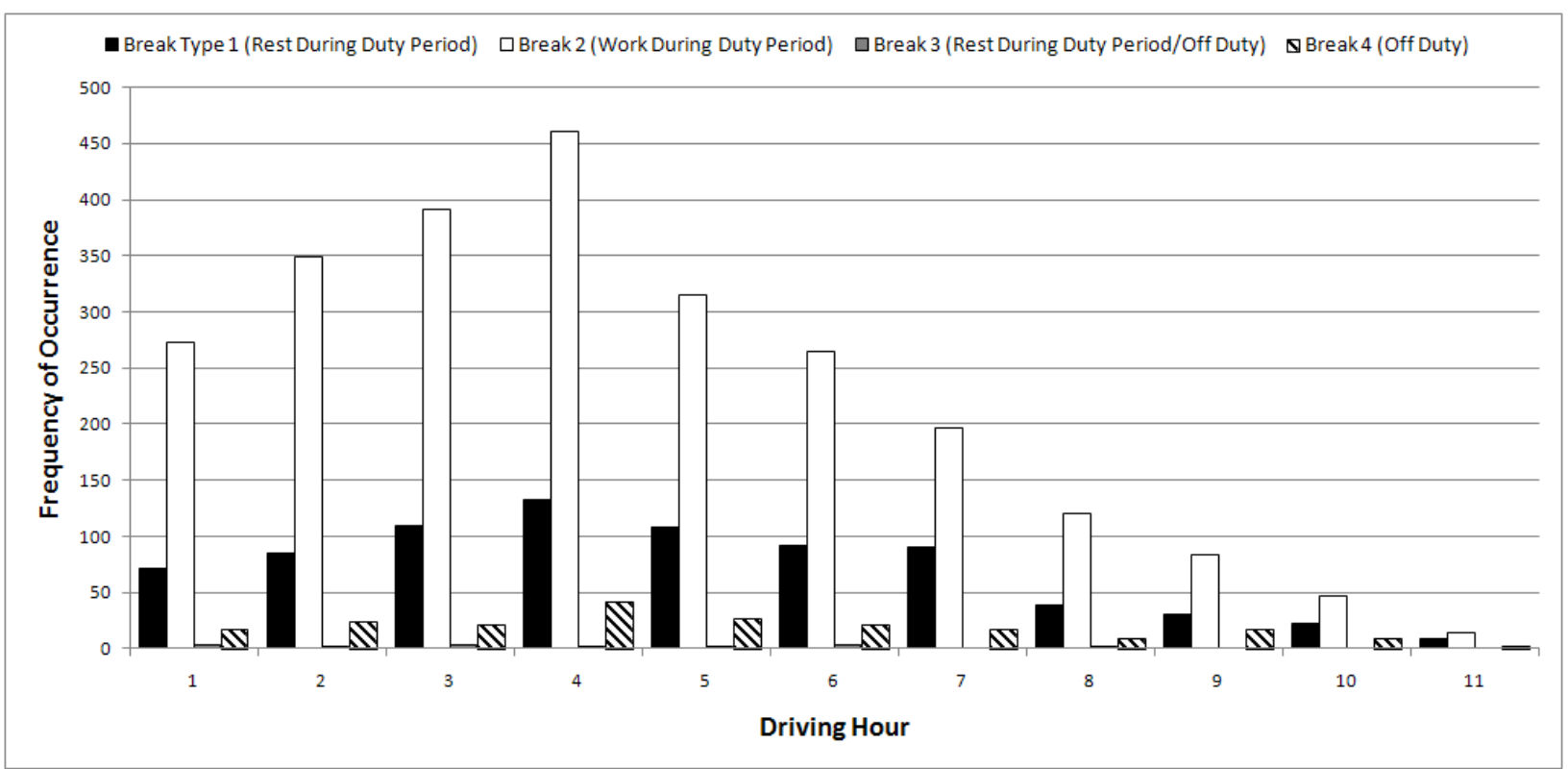

Figure 44. Bar Graph. Driving Hour in Which Break Begins 
In Figure 45 below, the distribution of break length was explored using box plots for each break type. The box plots indicate the median value for each break type, as well as the quartile, minimum, and maximum values. The median, represented by the horizontal bar in the box for each break type, was not affected by extreme values. The upper and lower quartiles are represented by the top and bottom borders of the gray/black box. The whiskers of the plot indicate minimum and maximum break duration for each break type.

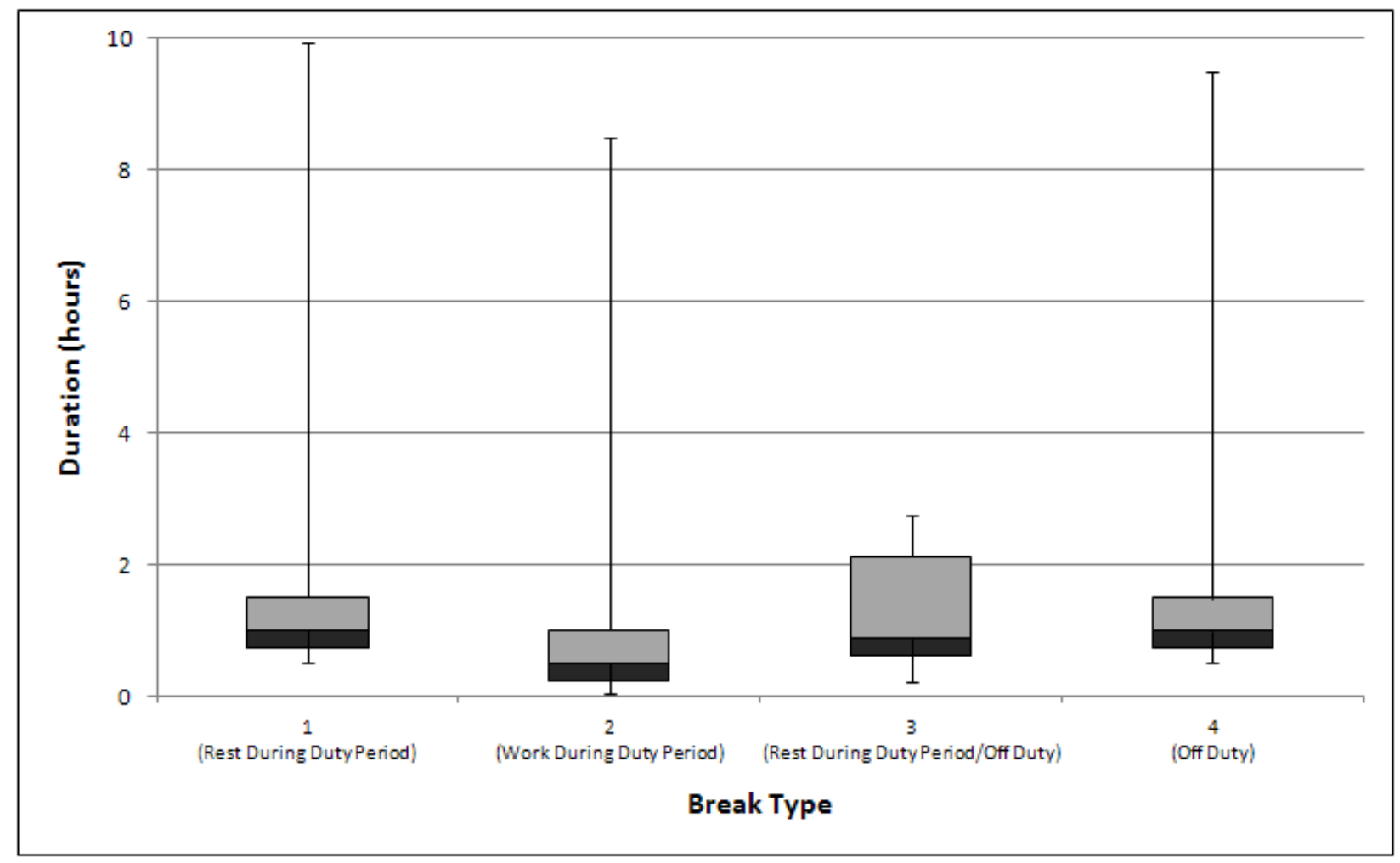

Figure 45. Box Plot. Total Duration of Breaks by Break Type

The median break length is more likely than the other measures to be an accurate description of break length because it will not be affected by few extreme values. Breaks tend to be less than 2hours long, with Breaks 1, 2, and 4 having median values of approximately 1 hour. Twenty-five percent of the data are greater than the upper quartile; 25 percent of the data are less than the lower quartile. Break 3 has the greatest upper quartile value (2.1 hours). Breaks 1, 2, and 4 have upper quartile values of 1.5 hours or less. A similar pattern is seen for lower quartile values. Break 3 has the greatest value (1.25 hours), while Breaks 1, 2, and 4 have lower quartile values of 0.5 hours. Minimum values of less than half an hour come from single breaks made up of multiple break types, each with a short duration. The long whiskers of the plot for each break type extending towards 10 hours display an issue seen often in the data (i.e., drivers taking breaks not quite long enough to start a new shift and then continuing to drive after completion of the break). According to HOS regulations ${ }^{(11)}$ drivers must take a break of at least 10 hours to start a new driving duty period (unless they are using the sleeper berth provision).

Table 37 further details the distribution of drivers and shifts across various break durations. Although a break was defined as being at least 30 minutes in length (and that was what was used in the analyses), to further examine the drivers' workday, breaks of shorter durations are 
included in this table. In this table, "All Breaks" refers to any of the four break types, while "Rest Breaks" refers to break types 1, 3, and 4. This table describes how many and what percentage of drivers and shifts fell into four different break durations (less than 30 minutes, 3059 minutes, 60-89 minutes, and 60-119 minutes). Of the 1,881 shifts with driving data, 612 shifts had at least one break of less than 30 minutes, 1,065 had at least one break of 30 minutes-1 hour, 474 had at least one break of 1-1.5 hours, and 686 had at least one break of 1-2 hours in duration.

Table 37. Distribution of Drivers and Shifts by Break Duration

\begin{tabular}{|l|c|c|c|c|}
\hline \multicolumn{1}{|c|}{ Break Duration } & $\begin{array}{c}\text { All Breaks, } \\
\text { Drivers }(\boldsymbol{n}, \boldsymbol{\%})\end{array}$ & $\begin{array}{c}\text { All Breaks, } \\
\text { Shifts }(\boldsymbol{n}, \boldsymbol{\%})\end{array}$ & $\begin{array}{c}\text { Rest Breaks, } \\
\text { Drivers }(\boldsymbol{n}, \boldsymbol{\%})\end{array}$ & $\begin{array}{c}\text { Rest Breaks, } \\
\text { Shifts }(\boldsymbol{n}, \%)\end{array}$ \\
\hline Less than 30 min & $92(94.8)$ & $612(32.5)$ & $73(75.3)$ & $213(11.3)$ \\
\hline $30 \mathrm{~min}-59$ min & $97(100)$ & $1,065(56.6)$ & $73(75.3)$ & $310(16.5)$ \\
\hline 60 min-89 $\min$ & $89(91.8)$ & $474(25.2)$ & $60(61.9)$ & $184(9.8)$ \\
\hline 60 min-119 $\min$ & $91(93.8)$ & $686(36.5)$ & $70(72.2)$ & $257(13.7)$ \\
\hline
\end{tabular}

These data may also be analyzed using different bin sizes for breaks. For instance, breaks were also examined as 5 minutes or longer, 30 minutes or longer, and 1 hour or longer (Table 38). As in the prior table, "All Breaks" refers to any of the four break types, while "Rest Breaks" refers to break types 1, 3, and 4. Each driver had at least one break of 5 minutes or longer, with nearly 85 percent of shifts including a break of 5 minutes or longer. Although this very brief break duration was not further analyzed, it does demonstrate that many drivers were pulling off the road for non-driving breaks at some point during their workday. Every driver also took a break of 30 minutes or longer at some point while participating in this study, with 80 percent of shifts including a 30-minute or longer break. In general, rest breaks were far less common. Most drivers took rest breaks as part of the sleeper berth provision or in a 10-hour rest period in order to be able to start a new working window.

Table 38. Distribution of Drivers and Shifts by Break Duration, Alternative Bin Sizes

\begin{tabular}{|l|c|c|c|c|}
\hline \multicolumn{1}{|c|}{ Break Duration } & $\begin{array}{c}\text { All Breaks, } \\
\text { Drivers }(\boldsymbol{n}, \boldsymbol{\%})\end{array}$ & $\begin{array}{c}\text { All Breaks, } \\
\text { Shifts }(\boldsymbol{n}, \boldsymbol{\%})\end{array}$ & $\begin{array}{c}\text { Rest Breaks, } \\
\text { Drivers }(\boldsymbol{n}, \%)\end{array}$ & $\begin{array}{c}\text { Rest Breaks, } \\
\text { Shifts }(\boldsymbol{n}, \boldsymbol{\%})\end{array}$ \\
\hline 5 min or Longer & $97(100)$ & $1,594(84.7)$ & $89(91.8)$ & $801(42.6)$ \\
\hline 30 min or Longer & $97(100)$ & $1,476(78.5)$ & $84(86.6)$ & $699(37.2)$ \\
\hline 1 hour or Longer & $96(99)$ & $984(52.3)$ & $76(78.4)$ & $406(21.6)$ \\
\hline
\end{tabular}

To follow up the analysis of number of breaks, working hours, and exposure, an additional mixed-effect NB regression model with logarithm link was conducted using the frequencies of the four types of breaks (of at least 30 minutes) included in a single model. The output of this model is shown in Table 39 and suggests that none of the break types have a significant impact on the SCE risk as the $p$-values for each break type are greater than 0.05 . 
Table 39. Safety Impacts of Number of Breaks by Type: NB Model Results

\begin{tabular}{|l|r|r|r|r|r|}
\hline \multicolumn{1}{|c|}{ Effect } & \multicolumn{1}{c|}{ Estimate } & \multicolumn{1}{c|}{ SE } & \multicolumn{1}{c|}{ df } & \multicolumn{1}{c|}{$\boldsymbol{t}$} & \multicolumn{1}{c|}{$\boldsymbol{p}$} \\
\hline Intercept & -3.3468 & 0.2875 & 96 & -11.64 & $<0.0001$ \\
\hline $\begin{array}{l}\text { Break Type 1: } \\
\text { Rest During Duty Period }\end{array}$ & -0.05466 & 0.06712 & 1,779 & -0.81 & 0.4155 \\
\hline $\begin{array}{l}\text { Break Type 2: } \\
\text { Work During Duty Period }\end{array}$ & 0.05333 & 0.03848 & 1,779 & 1.39 & 0.1659 \\
\hline $\begin{array}{l}\text { Break Type 3: } \\
\text { Rest During Duty Period /Off Duty }\end{array}$ & 0.4862 & 0.3911 & 1,779 & 1.24 & 0.2140 \\
\hline $\begin{array}{l}\text { Break Type 4: } \\
\text { Off Duty }\end{array}$ & 0.1392 & 0.1066 & 1,779 & 1.31 & 0.1919 \\
\hline Exposure $(\alpha)$ & 1.2932 & 0.1205 & 1,779 & 10.73 & $<0.0001$ \\
\hline
\end{tabular}

Although this model failed to reach significance, there are numerous factors that could affect the occurrence of SCEs (e.g., trip purpose, physical and psychological health of the driver for the trip, weather condition for the trip). The impacts of breaks can be masked by those factors. Therefore, a break-level analysis was conducted in order to better control for the confounding factor and isolate the effect of breaks.

\subsubsection{SCE Rate One Hour Before/After Breaks}

This analysis examined the rate of SCE occurrence during the time period of 1 hour before and 1 hour after a break from driving. The safety benefit of breaks was evaluated by comparing the $\mathrm{SCE}$ rate between these two time periods. The relationships between various break types and the SCE rates were thus explored in this analysis. Because the before period was used as a baseline, potential confounding factors associated with driver or shift characteristics-including environmental factors such as road type and weather, and driver factors such as the previous night's sleep and previous shift work - were somewhat controlled. Therefore, while not a direct cause-and-effect examination, the effects from this analysis could be attributed more directly to driving breaks. The analysis was performed considering all breaks as well as individual break types.

There were 3,171 breaks in the data used for this analysis (only breaks of 30 minutes or more were included). Table 40 presents a comparison of SCE rates during the 1-hour window before and after a break. It should be noted that because multiple break types could make up a single break, the summation of break frequency by types can be more than the total number of breaks. As shown in Table 40, the SCE rate for the 1-hour window after a break is consistently lower than the before period, regardless of the break type.

To calculate the magnitude of the decrease in rate before to rate after, the following equation was used: Magnitude equals [(SCE Rate $_{\text {before }}$ minus SCE Rate after $)$ divided by SCE Rate before $_{\text {times }}$ 100.

The magnitude of the decrease in SCE rate ranges from 30 percent to more than 50 percent. The break-level analysis indicates a 29-percent reduction in SCE rate in the 1-hour window after a break compared to the 1-hour window before a break for all break types. The largest reduction in SCE rate was observed after Break Type 4 (off duty). The SCE rate after the break is half that of 
before the break (a reduction of more than 51 percent). Break Type 2 (work during duty period) shows the smallest reduction in SCE rate, where a 28-percent reduction was observed.

Table 40. SCE Rate Before/After: All Break Types

\begin{tabular}{|l|c|c|c|c|c|}
\hline \multicolumn{1}{|c|}{ Break Type } & Metric & $\begin{array}{c}\text { Before } \\
\text { Break }\end{array}$ & $\begin{array}{c}\text { After } \\
\text { Break }\end{array}$ & $\begin{array}{c}\text { SCE Ratio } \\
\text { (Before/After) }\end{array}$ & $\begin{array}{c}\text { Magnitude of } \\
\text { Reduction }\end{array}$ \\
\hline All Break Types & SCE Frequency & 429 & 305 & - & - \\
\hline All Break Types & Opportunities & 3171 & 3171 & - & - \\
\hline All Break Types & SCE Rate & 0.135 & 0.096 & 1.406 & 28.889 \\
\hline $\begin{array}{l}\text { Break Type 1: } \\
\text { Rest During Duty Period }\end{array}$ & SCE Frequency & 118 & 85 & - & - \\
\hline $\begin{array}{l}\text { Break Type 1: } \\
\text { Rest During Duty Period }\end{array}$ & Opportunities & 789 & 789 & - & - \\
\hline $\begin{array}{l}\text { Break Type 1: } \\
\text { Rest During Duty Period }\end{array}$ & SCE Rate & 0.150 & 0.108 & 1.389 & 28.000 \\
\hline $\begin{array}{l}\text { Break Type 2: } \\
\text { Work During Duty Period }\end{array}$ & SCE Frequency & 339 & 237 & - & - \\
\hline $\begin{array}{l}\text { Break Type 2: } \\
\text { Work During Duty Period }\end{array}$ & Opportunities & 2,518 & 2,518 & - & - \\
\hline $\begin{array}{l}\text { Break Type 2: } \\
\text { Work During Duty Period }\end{array}$ & SCE Rate & 0.135 & 0.094 & 1.436 & 30.370 \\
\hline $\begin{array}{l}\text { Break Type 3: } \\
\text { Rest During Duty/ Off Duty }\end{array}$ & SCE Frequency & 3 & 2 & - & - \\
\hline $\begin{array}{l}\text { Break Type 3: } \\
\text { Rest During Duty/ Off Duty }\end{array}$ & Opportunities & 15 & 15 & - & - \\
\hline $\begin{array}{l}\text { Break Type 3: } \\
\text { Rest During Duty/ Off Duty }\end{array}$ & SCE Rate & 0.200 & 0.133 & 1.504 & 33.500 \\
\hline $\begin{array}{l}\text { Break Type 4: } \\
\text { Off Duty }\end{array}$ & SCE Frequency & 35 & 17 & - & - \\
\hline $\begin{array}{l}\text { Break Type 4: } \\
\text { Off Duty }\end{array}$ & Opportunities & 211 & 211 & - & - \\
\hline $\begin{array}{l}\text { Break Type 4: } \\
\text { Off Duty }\end{array}$ & SCE Rate & 0.166 & 0.081 & 2.049 & 51.205 \\
\hline
\end{tabular}

A mixed-effect NB regression model with logarithm link function was used to evaluate the safety impacts of breaks based on the before/after break SCE counts. As described earlier, the NB model is widely used to examine SCE frequency, since it assumes that the number of SCEs for a shift was generated from a stochastic process. Each break was assigned a random effect as the intercept. Thus, the before and after time periods share the same intercept, and the estimated break is analogous to a pair-wise comparison between the before and after periods. This model allows the period before a break to be used as a baseline and provides maximum control over driver- and shift-related confounding factors.

The NB models for the difference between the 1-hour window before and after a break (expressed as Before-After) are shown in Table 41. When examining all break types, the SCE rate in the 1-hour window before a break is significantly higher than the SCE rate in the 1-hour window after a break $\left(p\right.$-value $\left._{(\text {Change Before-After) }}<0.0001\right)$. For Break Type 2, the SCE rate during the before period is significantly higher than the SCE rate during the after period $(p=0.0002)$. 
Due to small sample sizes, Break Types 1, 3, and 4 were analyzed as one group of restful breaks. For restful breaks, the SCE rate in the 1-hour window before the break was significantly higher than the SCE rate in the 1-hour window after the break $(p=0.0099)$. This analysis suggests that there was a reduction in SCE rate after breaks were taken, whether the break consisted of nondriving work activities or rest.

Table 41. NB Model: Change (Before-After) by Break Types

\begin{tabular}{|l|l|l|l|c|}
\hline \multicolumn{1}{|c|}{ Break Type } & \multicolumn{1}{c|}{ Effect } & \multicolumn{1}{c|}{ Estimate } & \multicolumn{1}{c|}{ SE } & \multicolumn{1}{c|}{$\boldsymbol{p}$} \\
\hline All Break Types & Intercept & -3.3637 & 0.1814 & $<0.0001$ \\
\hline All Break Types & Before-After & 0.4448 & 0.1108 & $<0.0001$ \\
\hline Type 2: Work During Duty Period & Intercept & -3.3450 & 0.1925 & $<0.0001$ \\
\hline Type 2: Work During Duty Period & Before-After & 0.4525 & 0.1234 & 0.0002 \\
\hline Type 1, 3, 4: Rest During Duty Period/ Off Duty & Intercept & -3.6422 & 0.3525 & $<0.0001$ \\
\hline Type 1, 3, 4: Rest During Duty Period/ Off Duty & Before-After & 0.5186 & 0.2006 & 0.0099 \\
\hline
\end{tabular}

A key take-away from these break analyses is that the 1-hour window following a break from driving is associated with a significant reduction in SCE rate as compared to the 1-hour window preceding a break. The magnitude of this reduction in risk ranges between approximately 30 and 50 percent, with the greatest reductions in risk observed for break types classified as Type 4 (off duty; SCE rate reduction of 51 percent).

Analysis using the NB model reached similar conclusions, with the SCE rate in the 1-hour window before a break being significantly higher than the SCE rate in the 1-hour window after a break. These results suggest that there was a reduction in SCE rate after breaks were taken, whether the break consisted of work activities or restful activities. Put another way, any break was better than no break, though an off-duty break provided the most benefit. 
[This page intentionally left blank.] 


\section{SUMMARY AND CONCLUSIONS}

This study provides data on many aspects of the drivers' daily operations, including driving hours, work hours, and breaks. The data for this study were extracted from a naturalistic driving study of 97 long-haul and line-haul drivers, each with a valid Class A commercial driver's license. These 97 drivers, each driving for 4 weeks, drove approximately 735,000 miles. A total of 1,881 shifts were taken into consideration for these analyses. For 429 of those shifts the drivers drove into the 11th hour (with a total of 321.48 hours of driving in the 11th hour).

The key findings from this research include:

- Workday Characterization: Most of the drivers' workday (66 percent) was spent driving or performing other work-related activities (23 percent), while 11 percent of the workday was classified as "Rest."

- Driving Hour: One of the analyses conducted identified a significant time-on-task effect across all driving hours. However, follow-up hour-by-hour comparison analyses did not find a statistically significant difference between the 10th and 11th driving hours.

- Work Hours: The risk of SCE involvement increased when non-driving activities pushed driving hours towards the end of the shift. This significant time-on-task effect may be the result of the inclusion of the non-driving work (in addition to the driving work), which represented a considerable portion of the CMV drivers' workday (i.e., 23 percent).

- Breaks from Driving: When non-driving activities (both work- and rest-related) were introduced during the drivers' shift, creating a break from the driving task, they significantly reduced the risk of being involved in an SCE during the 1-hour window after the break.

This research effort provides information not available from past research. By combining driving data (from the NTDS) with an activity register of non-driving tasks (off-duty and during-duty period activities), a more complete picture of the driver's workday was obtained. In addition, several key findings relevant to HOS were revealed from this study. These results include information on the potential for an increase in risk in the 11th driving hour, the impact of work hour on SCEs, and the positive impact that breaks can have on safety.

As suggested in the current analysis, some of the higher SCE rates for the 11th hour observed in the present study were an artifact of a few drivers with uncharacteristically high rates of SCE occurrence and a low occurrence of opportunities for driving in the 11th hour. This has been demonstrated in other research, whereby a few drivers account for a large proportion of safety events. ${ }^{(41)}$ Despite including the outliers identified in the current study in the analyses (whereby approximately 4 percent of the drivers accounted for approximately 36 percent of the identified SCEs), when pair-wise comparisons and an NB model were used to analyze the data, the 11th driving hour was not statistically significant in rates of SCE occurrence when compared to the preceding hour. This further reinforces the hypothesis that there is not an increase in risk associated with the 11th driving hour as compared to the 10th driving hour. This largely concurs with the findings of Hanowski et al., ${ }^{(3)}$ who also used naturalistic data and found that there was no statistically significant increase in risk when comparing the 11th driving hour to the 10th 
driving hour. One difference, however, from the previous Hanowski et al., study was with regard to the 1st driving hour. Though Hanowski et al., found that the 1st driving hour had a significantly higher SCE rate than driving hours 2-11, this result was not replicated with the current data set.

However, when a second analysis was conducted, which treated driving hour as a continuous variable using a mixed-effect NB regression model to assess the impact of driving hour on SCE rate, the results did show a statistically significant effect for driving hour ( $p_{\text {Driving Hour }}=0.0014$ ). Follow-up pair-wise analyses, showed a statistically significant increase in SCE rate comparing the 11 th driving hour to the 1 st $(p=0.020)$ and 2 nd $(p=0.016)$ driving hour but not when comparing the 11th driving hour to the 10th driving hour $(p=0.300)$.

It must be noted that the algorithm used to assess the risk of driving hour in the Hanowski et al., ${ }^{(3)}$ study was based solely on driving hours and, because the data were not available, could not account for the impact of non-driving work on driving risk. The results from the current study regarding work hour indicate that time-on-task, across 14 hours of work, impacts risk. When drivers drove deep into their 14-hour shift, due to non-driving work conducted prior to late-shift driving, there was an increase in the rate of SCEs; that is, the risk of being involved in an SCE generally increased as work hour increased. When controlling for driving hour, the results found that the risk of an SCE was reduced when driving was completed earlier in the shift as compared to late in the shift. This suggests that time-on-task effects may not be related to driving hours alone, but implies that there may be an interaction between driving hours and work hours; that is, when a driver drives deep into the 14-hour workday, SCE risk may increase. The presence of an interaction makes intuitive sense based on the results of the breakdown of the drivers' workday. Recall, though driving comprised the bulk of the workday at 66 percent, non-driving work was also a factor at 23 percent. Therefore, focusing solely on driving hours (unless it represents 100 percent of a driver's workday) does not account for the entirety of work that drivers actually perform. This finding may raise other issues beyond the scope of this research, including pay approaches (i.e., pay-per-mile) that do not account for the substantial amount of daily, nondriving work that truck drivers routinely perform. This is the first study of which the authors are aware that has investigated work hours in combination with — and independent of — driving hours and, therefore, additional research is needed to further evaluate this issue. However, the significant time-on-task results from this study are consistent with findings from time-on-task research in other domains. ${ }^{(4,5,6)}$

Breaks can be used to counteract the negative effects of time-on-task. The results from the break analyses indicated that significant safety benefits can be afforded when drivers take breaks from driving. This was a key finding in the current study and clearly shows that breaks can ameliorate the negative impacts associated with time-on-task. The benefits from breaks from driving ranged from a 30-50-percent reduction of rate of SCE occurrence in the hour following a break, depending on the type of break from driving, with the most benefit occurring for off-duty (nonworking) breaks.

While the focus areas that were investigated in the current study (i.e., workday characterization, driving, non-driving work, and breaks from driving) have provided important information to explain some of the parameters that may impact SCEs due to time-on-task, there are other factors, not investigated in the current effort, that must also be considered. Although outside the 
scope of this study, other factors that may impact SCE occurrence include, but are not limited to, sleep hygiene and off-duty activities. It must be noted that activities in which a driver is involved during off-duty time cannot be controlled in a naturalistic study such as this. Previous research by Hanowski et al. ${ }^{(43)}$ suggested that providing more time to rest under the current HOS regulations allowed drivers to increase the amount of sleep they obtained, and that drivers usually received less than their own average amount of sleep in the time prior to an SCE. Therefore, there are key issues that must be addressed in addition to those investigated in this study. For example, educating drivers on the importance of sleep hygiene, company policies that allow drivers to rest when needed, and the implementation of a safety culture within fleets, along with other countermeasures to address behind-the-wheel drowsiness, are additional critical components that must be considered for reducing risk in CMV operations. 
[This page intentionally left blank.] 


\section{ACKNOWLEDGMENTS}

The research team wishes to thank the individuals who acted as peer reviewers for this project: Mike Perel, Jerry Robin, and Simon Washington. 
[This page intentionally left blank.] 


\section{APPENDIX A-DRIVING HOUR ODDS RATIO TABLES}

Table 42. Results from the Odds Ratio Analysis with Multiple Within-Hour SCEs Collapsed (Dichotomous Approach), for All Shifts

\begin{tabular}{|c|c|c|c|c|}
\hline Driving Hour & Driving Hour & Odds Ratio & LCL & UCL \\
\hline 1 & 2 & 1.03 & 0.81 & 1.31 \\
\hline 1 & 9 & 1.00 & 0.75 & 1.34 \\
\hline 1 & 10 & 1.02 & 0.74 & 1.41 \\
\hline 1 & 11 & 1.12 & 0.75 & 1.67 \\
\hline 2 & 11 & 1.09 & 0.73 & 1.63 \\
\hline 3 & 1 & 1.10 & 0.87 & 1.39 \\
\hline 3 & 2 & 1.14 & 0.90 & 1.44 \\
\hline 3 & 4 & 1.07 & 0.84 & 1.35 \\
\hline 3 & 6 & 1.03 & 0.81 & 1.31 \\
\hline 3 & 8 & 1.00 & 0.77 & 1.30 \\
\hline 3 & 9 & 1.11 & 0.83 & 1.47 \\
\hline 3 & 10 & 1.13 & 0.82 & 1.55 \\
\hline 3 & 11 & 1.24 & 0.83 & 1.85 \\
\hline 4 & 1 & 1.04 & 0.82 & 1.31 \\
\hline 4 & 2 & 1.07 & 0.84 & 1.36 \\
\hline 4 & 9 & 1.04 & 0.77 & 1.39 \\
\hline 4 & 10 & 1.06 & 0.76 & 1.46 \\
\hline 4 & 11 & 1.16 & 0.78 & 1.74 \\
\hline 5 & 1 & 1.11 & 0.87 & 1.40 \\
\hline 5 & 2 & 1.14 & 0.90 & 1.45 \\
\hline 5 & 3 & 1.00 & 0.79 & 1.27 \\
\hline 5 & 4 & 1.07 & 0.84 & 1.36 \\
\hline 5 & 6 & 1.03 & 0.81 & 1.32 \\
\hline 5 & 8 & 1.00 & 0.77 & 1.31 \\
\hline 5 & 9 & 1.11 & 0.83 & 1.48 \\
\hline 5 & 10 & 1.13 & 0.82 & 1.56 \\
\hline 5 & 11 & 1.24 & 0.83 & 1.86 \\
\hline 6 & 1 & 1.07 & 0.84 & 1.36 \\
\hline 6 & 2 & 1.10 & 0.86 & 1.41 \\
\hline 6 & 4 & 1.03 & 0.81 & 1.32 \\
\hline 6 & 9 & 1.07 & 0.80 & 1.44 \\
\hline 6 & 10 & 1.09 & 0.79 & 1.52 \\
\hline 6 & 11 & 1.20 & 0.80 & 1.80 \\
\hline 7 & 1 & 1.18 & 0.92 & 1.50 \\
\hline 7 & 2 & 1.21 & 0.95 & 1.56 \\
\hline 7 & 3 & 1.07 & 0.84 & 1.36 \\
\hline 7 & 4 & 1.14 & 0.89 & 1.46 \\
\hline 7 & 5 & 1.06 & 0.83 & 1.36 \\
\hline 7 & 6 & 1.10 & 0.85 & 1.42 \\
\hline 7 & 8 & 1.07 & 0.81 & 1.40 \\
\hline
\end{tabular}




\begin{tabular}{|c|c|c|c|c|}
\hline Driving Hour & Driving Hour & Odds Ratio & LCL & UCL \\
\hline 7 & 9 & 1.18 & 0.87 & 1.59 \\
\hline 7 & 10 & 1.20 & 0.86 & 1.67 \\
\hline 7 & 11 & 1.32 & 0.88 & 1.98 \\
\hline 8 & 1 & 1.10 & 0.85 & 1.44 \\
\hline 8 & 2 & 1.14 & 0.87 & 1.48 \\
\hline 8 & 4 & 1.06 & 0.81 & 1.39 \\
\hline 8 & 6 & 1.03 & 0.78 & 1.35 \\
\hline 8 & 9 & 1.10 & 0.81 & 1.51 \\
\hline 8 & 10 & 1.12 & 0.80 & 1.59 \\
\hline 8 & 11 & 1.24 & 0.81 & 1.88 \\
\hline 9 & 2 & 1.03 & 0.77 & 1.38 \\
\hline 9 & 10 & 1.02 & 0.71 & 1.47 \\
\hline 9 & 11 & 1.12 & 0.72 & 1.73 \\
\hline 10 & 2 & 1.01 & 0.73 & 1.40 \\
\hline 10 & 11 & 1.10 & 0.69 & 1.74 \\
\hline
\end{tabular}

Table 43. Results from the Odds Ratio Analysis with Multiple Within-Hour SCEs Collapsed (Dichotomous Approach), for Shifts That Went Into the 11th Driving Hour

\begin{tabular}{|c|c|c|c|c|}
\hline Driving Hour & Driving Hour & Odds Ratio & LCL & UCL \\
\hline 1 & 2 & 1.03 & 0.64 & 1.64 \\
\hline 1 & 3 & 1.03 & 0.64 & 1.64 \\
\hline 1 & 9 & 1.09 & 0.68 & 1.75 \\
\hline 1 & 10 & 1.03 & 0.64 & 1.64 \\
\hline 1 & 11 & 1.28 & 0.79 & 2.1 \\
\hline 2 & 3 & 1.00 & 0.62 & 1.60 \\
\hline 2 & 9 & 1.06 & 0.66 & 1.71 \\
\hline 2 & 10 & 1.00 & 0.62 & 1.60 \\
\hline 2 & 11 & 1.25 & 0.76 & 2.05 \\
\hline 3 & 9 & 1.06 & 0.66 & 1.71 \\
\hline 3 & 10 & 1.00 & 0.62 & 1.60 \\
\hline 3 & 11 & 1.25 & 0.76 & 2.05 \\
\hline 5 & 1 & 1.03 & 0.65 & 1.63 \\
\hline 5 & 2 & 1.06 & 0.66 & 1.69 \\
\hline 5 & 3 & 1.06 & 0.66 & 1.69 \\
\hline 5 & 9 & 1.12 & 0.70 & 1.80 \\
\hline 5 & 10 & 1.06 & 0.66 & 1.69 \\
\hline 5 & 11 & 1.32 & 0.81 & 2.15 \\
\hline 6 & 1 & 1.20 & 0.77 & 1.88 \\
\hline 6 & 2 & 1.24 & 0.79 & 1.94 \\
\hline 6 & 3 & 1.24 & 0.79 & 1.94 \\
\hline 6 & 4 & 1.17 & 0.75 & 1.83 \\
\hline 6 & 5 & 1.17 & 0.75 & 1.83 \\
\hline 6 & 8 & 1.08 & 0.69 & 1.67 \\
\hline 6 & 9 & 1.31 & 0.83 & 2.07 \\
\hline
\end{tabular}




\begin{tabular}{|c|c|c|c|c|}
\hline Driving Hour & Driving Hour & Odds Ratio & LCL & UCL \\
\hline 6 & 10 & 1.24 & 0.79 & 1.94 \\
\hline 6 & 11 & 1.54 & 0.96 & 2.48 \\
\hline 7 & 1 & 1.32 & 0.85 & 2.05 \\
\hline 7 & 2 & 1.36 & 0.87 & 2.12 \\
\hline 7 & 3 & 1.36 & 0.87 & 2.12 \\
\hline 7 & 4 & 1.28 & 0.83 & 1.99 \\
\hline 7 & 5 & 1.28 & 0.83 & 1.99 \\
\hline 7 & 6 & 1.10 & 0.72 & 1.68 \\
\hline 7 & 8 & 1.18 & 0.77 & 1.82 \\
\hline 7 & 9 & 1.44 & 0.92 & 2.26 \\
\hline 7 & 10 & 1.36 & 0.87 & 2.12 \\
\hline 7 & 11 & 1.69 & 1.06 & 2.71 \\
\hline 8 & 1 & 1.11 & 0.71 & 1.76 \\
\hline 8 & 2 & 1.15 & 0.72 & 1.81 \\
\hline 8 & 3 & 1.15 & 0.72 & 1.81 \\
\hline 8 & 4 & 1.08 & 0.69 & 1.70 \\
\hline 8 & 5 & 1.08 & 0.69 & 1.70 \\
\hline 8 & 9 & 1.22 & 0.76 & 1.94 \\
\hline 8 & 10 & 1.15 & 0.72 & 1.81 \\
\hline 8 & 11 & 1.43 & 0.88 & 2.32 \\
\hline 9 & 11 & 1.18 & 0.71 & 1.94 \\
\hline 10 & 9 & 1.06 & 0.66 & 1.71 \\
\hline 10 & 11 & 1.25 & 0.76 & 2.05 \\
\hline
\end{tabular}


[This page intentionally left blank.] 


\section{APPENDIX B-DRIVING HOUR-WORK HOUR COMBINATION ODDS RATIOS TABLES}

Table 44. Results from the Odds Ratio Analysis for the Beginning Work Hours (Hours 1-5) with Multiple Within-Hour SCEs Collapsed (Dichotomous Approach), for All Shifts

\begin{tabular}{|c|c|c|c|c|c|c|}
\hline $\begin{array}{l}\text { Driving } \\
\text { Hour }\end{array}$ & $\begin{array}{l}\text { Work Hour } \\
\text { Category }\end{array}$ & $\begin{array}{c}\text { Driving } \\
\text { Hour }\end{array}$ & $\begin{array}{l}\text { Work Hour } \\
\text { Category }\end{array}$ & Odds Ratio & LCL & UCL \\
\hline 1 & Beginning & 2 & Beginning & 1.04 & 0.82 & 1.32 \\
\hline 1 & Beginning & 2 & End & 1.40 & 0.18 & 10.67 \\
\hline 1 & Beginning & 3 & End & 2.24 & 0.30 & 16.67 \\
\hline 1 & Beginning & 5 & Beginning & 1.91 & 1.30 & 2.80 \\
\hline 1 & Beginning & 6 & End & 1.05 & 0.63 & 1.75 \\
\hline 1 & Beginning & 8 & Middle & 1.58 & 1.07 & 2.33 \\
\hline 1 & Beginning & 9 & Middle & 1.72 & 0.96 & 3.08 \\
\hline 1 & Beginning & 10 & End & 1.01 & 0.74 & 1.38 \\
\hline 2 & Beginning & 2 & End & 1.25 & 0.18 & 10.27 \\
\hline 2 & Beginning & 3 & End & 2.16 & 0.29 & 16.05 \\
\hline 2 & Beginning & 5 & Beginning & 1.83 & 1.24 & 2.71 \\
\hline 2 & Beginning & 6 & End & 1.01 & 0.61 & 1.69 \\
\hline 2 & Beginning & 8 & Middle & 1.52 & 1.03 & 2.25 \\
\hline 2 & Beginning & 9 & Middle & 1.66 & 0.93 & 2.97 \\
\hline 3 & Beginning & 1 & Beginning & 1.04 & 0.82 & 1.33 \\
\hline 3 & Beginning & 2 & Beginning & 1.09 & 0.85 & 1.38 \\
\hline 3 & Beginning & 2 & End & 1.46 & 0.19 & 11.15 \\
\hline 3 & Beginning & 3 & End & 2.34 & 0.31 & 17.43 \\
\hline 3 & Beginning & 4 & Beginning & 1.03 & 0.79 & 1.34 \\
\hline 3 & Beginning & 5 & Beginning & 1.99 & 1.35 & 2.94 \\
\hline 3 & Beginning & 6 & End & 1.10 & 0.66 & 1.84 \\
\hline 3 & Beginning & 8 & Middle & 1.65 & 1.12 & 2.44 \\
\hline 3 & Beginning & 9 & Middle & 1.80 & 1.00 & 3.23 \\
\hline 3 & Beginning & 10 & End & 1.06 & 0.77 & 1.45 \\
\hline 3 & Beginning & 11 & End & 1.03 & 0.71 & 1.51 \\
\hline 4 & Beginning & 1 & Beginning & 1.01 & 0.78 & 1.31 \\
\hline 4 & Beginning & 2 & Beginning & 1.05 & 0.81 & 1.36 \\
\hline 4 & Beginning & 2 & End & 1.41 & 0.19 & 10.81 \\
\hline 4 & Beginning & 3 & End & 2.26 & 0.30 & 16.90 \\
\hline 4 & Beginning & 5 & Beginning & 1.93 & 1.29 & 2.88 \\
\hline 4 & Beginning & 6 & End & 1.06 & 0.63 & 1.79 \\
\hline 4 & Beginning & 8 & Middle & 1.60 & 1.07 & 2.39 \\
\hline 4 & Beginning & 9 & Middle & 1.74 & 0.96 & 3.15 \\
\hline 4 & Beginning & 10 & End & 1.02 & 0.73 & 1.42 \\
\hline 5 & Beginning & 3 & End & 1.18 & 0.15 & 8.95 \\
\hline
\end{tabular}


Table 45. Results from the Odds Ratio Analysis for the Middle Work Hours (Hours 6-9) with Multiple Within-Hour SCEs Collapsed (Dichotomous Approach), for All Shifts

\begin{tabular}{|c|c|c|c|c|c|c|}
\hline $\begin{array}{l}\text { Driving } \\
\text { Hour }\end{array}$ & $\begin{array}{l}\text { Work Hour } \\
\text { Category }\end{array}$ & $\begin{array}{c}\text { Driving } \\
\text { Hour }\end{array}$ & $\begin{array}{l}\text { Work Hour } \\
\text { Category }\end{array}$ & Odds Ratio & LCL & UCL \\
\hline 2 & Middle & 1 & Beginning & 1.16 & 0.55 & 2.45 \\
\hline 2 & Middle & 1 & End & 1.08 & 0.12 & 9.58 \\
\hline 2 & Middle & 2 & Beginning & 1.20 & 0.57 & 2.55 \\
\hline 2 & Middle & 2 & End & 1.62 & 0.19 & 13.95 \\
\hline 2 & Middle & 3 & Beginning & 1.11 & 0.52 & 2.35 \\
\hline 2 & Middle & 3 & End & 2.59 & 0.31 & 21.82 \\
\hline 2 & Middle & 4 & Beginning & 1.15 & 0.54 & 2.44 \\
\hline 2 & Middle & 5 & Beginning & 2.21 & 0.98 & 4.96 \\
\hline 2 & Middle & 6 & End & 1.22 & 0.51 & 2.92 \\
\hline 2 & Middle & 8 & Middle & 1.83 & 0.82 & 4.11 \\
\hline 2 & Middle & 9 & Middle & 2.00 & 0.80 & 5.00 \\
\hline 2 & Middle & 9 & End & 1.01 & 0.46 & 2.18 \\
\hline 2 & Middle & 10 & End & 1.17 & 0.54 & 2.55 \\
\hline 2 & Middle & 11 & End & 1.15 & 0.51 & 2.56 \\
\hline 3 & Middle & 1 & Beginning & 1.40 & 0.89 & 2.20 \\
\hline 3 & Middle & 1 & End & 1.30 & 0.16 & 10.64 \\
\hline 3 & Middle & 2 & Beginning & 1.45 & 0.92 & 2.30 \\
\hline 3 & Middle & 2 & Middle & 1.21 & 0.52 & 2.81 \\
\hline 3 & Middle & 2 & End & 1.96 & 0.25 & 15.48 \\
\hline 3 & Middle & 3 & Beginning & 1.34 & 0.85 & 2.12 \\
\hline 3 & Middle & 3 & End & 3.13 & 0.40 & 24.20 \\
\hline 3 & Middle & 4 & Beginning & 1.38 & 0.87 & 2.21 \\
\hline 3 & Middle & 4 & Middle & 1.08 & 0.64 & 1.81 \\
\hline 3 & Middle & 5 & Beginning & 2.66 & 1.54 & 4.62 \\
\hline 3 & Middle & 6 & Middle & 1.17 & 0.74 & 1.86 \\
\hline 3 & Middle & 6 & End & 1.47 & 0.77 & 2.80 \\
\hline 3 & Middle & 7 & Middle & 1.16 & 0.73 & 1.87 \\
\hline 3 & Middle & 7 & End & 1.12 & 0.66 & 1.90 \\
\hline 3 & Middle & 8 & Middle & 2.21 & 1.27 & 3.84 \\
\hline 3 & Middle & 9 & Middle & 2.41 & 1.19 & 4.86 \\
\hline 3 & Middle & 9 & End & 1.21 & 0.74 & 1.99 \\
\hline 3 & Middle & 10 & End & 1.41 & 0.86 & 2.33 \\
\hline 3 & Middle & 11 & End & 1.38 & 0.80 & 2.38 \\
\hline 4 & Middle & 1 & Beginning & 1.30 & 0.93 & 1.81 \\
\hline 4 & Middle & 1 & End & 1.21 & 0.15 & 9.66 \\
\hline 4 & Middle & 2 & Beginning & 1.35 & 0.96 & 1.89 \\
\hline 4 & Middle & 2 & Middle & 1.12 & 0.51 & 2.46 \\
\hline 4 & Middle & 2 & End & 1.82 & 0.23 & 14.04 \\
\hline 4 & Middle & 3 & Beginning & 1.24 & 0.88 & 1.75 \\
\hline 4 & Middle & 3 & End & 2.91 & 0.38 & 21.94 \\
\hline 4 & Middle & 4 & Beginning & 1.28 & 0.90 & 1.83 \\
\hline
\end{tabular}




\begin{tabular}{|c|c|c|c|c|c|c|}
\hline $\begin{array}{l}\text { Driving } \\
\text { Hour }\end{array}$ & $\begin{array}{c}\text { Work Hour } \\
\text { Category }\end{array}$ & $\begin{array}{c}\text { Driving } \\
\text { Hour }\end{array}$ & $\begin{array}{l}\text { Work Hour } \\
\text { Category }\end{array}$ & Odds Ratio & LCL & UCL \\
\hline 4 & Middle & 5 & Beginning & 2.47 & 1.57 & 3.90 \\
\hline 4 & Middle & 6 & Middle & 1.09 & 0.77 & 1.53 \\
\hline 4 & Middle & 6 & End & 1.37 & 0.78 & 2.40 \\
\hline 4 & Middle & 7 & Middle & 1.08 & 0.76 & 1.55 \\
\hline 4 & Middle & 7 & End & 1.04 & 0.67 & 1.60 \\
\hline 4 & Middle & 8 & Middle & 2.05 & 1.30 & 3.24 \\
\hline 4 & Middle & 9 & Middle & 2.24 & 1.19 & 4.20 \\
\hline 4 & Middle & 9 & End & 1.13 & 0.76 & 1.66 \\
\hline 4 & Middle & 10 & End & 1.31 & 0.88 & 1.95 \\
\hline 4 & Middle & 11 & End & 1.28 & 0.82 & 2.01 \\
\hline 5 & Middle & 1 & Beginning & 1.63 & 1.26 & 2.11 \\
\hline 5 & Middle & 1 & End & 1.52 & 0.19 & 11.99 \\
\hline 5 & Middle & 2 & Beginning & 1.69 & 1.30 & 2.20 \\
\hline 5 & Middle & 2 & Middle & 1.41 & 0.66 & 3.00 \\
\hline 5 & Middle & 2 & End & 2.28 & 0.30 & 17.44 \\
\hline 5 & Middle & 3 & Beginning & 1.56 & 1.20 & 2.03 \\
\hline 5 & Middle & 3 & Middle & 1.17 & 0.73 & 1.86 \\
\hline 5 & Middle & 3 & End & 3.65 & 0.49 & 27.25 \\
\hline 5 & Middle & 4 & Beginning & 1.61 & 1.22 & 2.13 \\
\hline 5 & Middle & 4 & Middle & 1.26 & 0.88 & 1.79 \\
\hline 5 & Middle & 5 & Beginning & 3.11 & 2.08 & 4.64 \\
\hline 5 & Middle & 5 & End & 1.09 & 0.59 & 2.01 \\
\hline 5 & Middle & 6 & Middle & 1.36 & 1.05 & 1.78 \\
\hline 5 & Middle & 6 & End & 1.72 & 1.02 & 2.89 \\
\hline 5 & Middle & 7 & Middle & 1.36 & 1.02 & 1.81 \\
\hline 5 & Middle & 7 & End & 1.30 & 0.90 & 1.90 \\
\hline 5 & Middle & 8 & Middle & 2.58 & 1.72 & 3.86 \\
\hline 5 & Middle & 9 & Middle & 2.81 & 1.55 & 5.08 \\
\hline 5 & Middle & 9 & End & 1.42 & 1.02 & 1.96 \\
\hline 5 & Middle & 10 & End & 1.65 & 1.18 & 2.30 \\
\hline 5 & Middle & 11 & End & 1.61 & 1.09 & 2.39 \\
\hline 6 & Middle & 1 & Beginning & 1.19 & 0.94 & 1.52 \\
\hline 6 & Middle & 1 & End & 1.11 & 0.14 & 8.78 \\
\hline 6 & Middle & 2 & Beginning & 1.24 & 0.97 & 1.59 \\
\hline 6 & Middle & 2 & Middle & 1.03 & 0.49 & 2.19 \\
\hline 6 & Middle & 2 & End & 1.67 & 0.22 & 12.76 \\
\hline 6 & Middle & 3 & Beginning & 1.14 & 0.89 & 1.47 \\
\hline 6 & Middle & 3 & End & 2.68 & 0.36 & 19.94 \\
\hline 6 & Middle & 4 & Beginning & 1.18 & 0.91 & 1.54 \\
\hline 6 & Middle & 5 & Beginning & 2.28 & 1.54 & 3.37 \\
\hline 6 & Middle & 6 & End & 1.26 & 0.75 & 2.10 \\
\hline 6 & Middle & 8 & Middle & 1.89 & 1.27 & 2.80 \\
\hline 6 & Middle & 9 & Middle & 2.06 & 1.15 & 3.70 \\
\hline
\end{tabular}




\begin{tabular}{|c|c|c|c|c|c|c|}
\hline $\begin{array}{c}\text { Driving } \\
\text { Hour }\end{array}$ & $\begin{array}{c}\text { Work Hour } \\
\text { Category }\end{array}$ & $\begin{array}{c}\text { Driving } \\
\text { Hour }\end{array}$ & $\begin{array}{c}\text { Work Hour } \\
\text { Category }\end{array}$ & Odds Ratio & LCL & UCL \\
\hline 6 & Middle & 9 & End & 1.04 & 0.76 & 1.42 \\
\hline 6 & Middle & 10 & End & 1.21 & 0.88 & 1.66 \\
\hline 6 & Middle & 11 & End & 1.18 & 0.81 & 1.73 \\
\hline 7 & Middle & 1 & Beginning & 1.20 & 0.92 & 1.56 \\
\hline 7 & Middle & 1 & End & 1.12 & 0.14 & 8.84 \\
\hline 7 & Middle & 2 & Beginning & 1.25 & 0.95 & 1.63 \\
\hline 7 & Middle & 2 & Middle & 1.04 & 0.49 & 2.21 \\
\hline 7 & Middle & 2 & End & 1.68 & 0.22 & 12.85 \\
\hline 7 & Middle & 3 & Beginning & 1.15 & 0.88 & 1.50 \\
\hline 7 & Middle & 3 & End & 2.69 & 0.36 & 20.08 \\
\hline 7 & Middle & 4 & Beginning & 1.19 & 0.89 & 1.58 \\
\hline 7 & Middle & 5 & Beginning & 2.29 & 1.52 & 3.43 \\
\hline 7 & Middle & 6 & Middle & 1.00 & 0.76 & 1.32 \\
\hline 7 & Middle & 6 & End & 1.26 & 0.75 & 2.13 \\
\hline 7 & Middle & 8 & Middle & 1.90 & 1.26 & 2.85 \\
\hline 7 & Middle & 9 & Middle & 2.07 & 1.14 & 3.75 \\
\hline 7 & Middle & 9 & End & 1.04 & 0.75 & 1.45 \\
\hline 7 & Middle & 10 & End & 1.21 & 0.87 & 1.70 \\
\hline 7 & Middle & 11 & End & 1.19 & 0.80 & 1.76 \\
\hline 8 & Middle & 3 & End & 1.42 & 0.19 & 10.80 \\
\hline 8 & Middle & 5 & Beginning & 1.21 & 0.73 & 1.98 \\
\hline 8 & Middle & 9 & Middle & 1.09 & 0.56 & 2.11 \\
\hline 9 & Middle & 3 & End & 1.30 & 0.16 & 10.37 \\
\hline 9 & Middle & 5 & Beginning & 1.11 & 0.57 & 2.14 \\
\hline
\end{tabular}

Table 46. Results from the Odds Ratio Analysis for the End Work Hours (Hours 10-14) with Multiple Within-Hour SCEs Collapsed (Dichotomous Approach), for All Shifts

\begin{tabular}{|c|c|c|c|c|c|c|}
\hline $\begin{array}{c}\text { Driving } \\
\text { Hour }\end{array}$ & $\begin{array}{c}\text { Work Hour } \\
\text { Category }\end{array}$ & $\begin{array}{c}\text { Driving } \\
\text { Hour }\end{array}$ & $\begin{array}{c}\text { Work Hour } \\
\text { Category }\end{array}$ & Odds Ratio & LCL & UCL \\
\hline 1 & End & 1 & Beginning & 1.07 & 0.14 & 8.42 \\
\hline 1 & End & 2 & Beginning & 1.11 & 0.14 & 8.76 \\
\hline 1 & End & 2 & End & 1.50 & 0.08 & 26.86 \\
\hline 1 & End & 3 & Beginning & 1.03 & 0.13 & 8.07 \\
\hline 1 & End & 3 & End & 2.40 & 0.14 & 42.26 \\
\hline 1 & End & 4 & Beginning & 1.06 & 0.13 & 8.36 \\
\hline 1 & End & 5 & Beginning & 2.04 & 0.25 & 16.43 \\
\hline 1 & End & 6 & End & 1.13 & 0.14 & 9.32 \\
\hline 1 & End & 8 & Middle & 1.69 & 0.21 & 13.63 \\
\hline 1 & End & 9 & Middle & 1.85 & 0.22 & 15.54 \\
\hline 1 & End & 10 & End & 1.08 & 0.14 & 8.61 \\
\hline 1 & End & 11 & End & 1.06 & 0.13 & 8.51 \\
\hline 2 & End & 3 & End & 1.60 & 0.09 & 27.55 \\
\hline 2 & End & 5 & Beginning & 1.36 & 0.17 & 10.62 \\
\hline 2 & End & 8 & Middle & 1.13 & 0.14 & 8.81 \\
\hline
\end{tabular}




\begin{tabular}{|c|c|c|c|c|c|c|}
\hline $\begin{array}{c}\text { Driving } \\
\text { Hour }\end{array}$ & $\begin{array}{l}\text { Work Hour } \\
\text { Category }\end{array}$ & $\begin{array}{l}\text { Driving } \\
\text { Hour }\end{array}$ & $\begin{array}{l}\text { Work Hour } \\
\text { Category }\end{array}$ & Odds Ratio & LCL & UCL \\
\hline 2 & End & 9 & Middle & 1.23 & 0.15 & 10.05 \\
\hline 2 & End & 3 & End & 1.60 & 0.09 & 27.55 \\
\hline 2 & End & 5 & Beginning & 1.36 & 0.17 & 10.62 \\
\hline 2 & End & 8 & Middle & 1.13 & 0.14 & 8.81 \\
\hline 2 & End & 9 & Middle & 1.23 & 0.15 & 10.05 \\
\hline 4 & End & 1 & Beginning & 1.65 & 0.69 & 3.95 \\
\hline 4 & End & 1 & End & 1.54 & 0.17 & 14.28 \\
\hline 4 & End & 2 & Beginning & 1.71 & 0.71 & 4.11 \\
\hline 4 & End & 2 & Middle & 1.42 & 0.46 & 4.39 \\
\hline 4 & End & 2 & End & 2.31 & 0.26 & 20.81 \\
\hline 4 & End & 3 & Beginning & 1.58 & 0.66 & 3.79 \\
\hline 4 & End & 3 & Middle & 1.18 & 0.45 & 3.08 \\
\hline 4 & End & 3 & End & 3.69 & 0.42 & 32.57 \\
\hline 4 & End & 4 & Beginning & 1.63 & 0.68 & 3.94 \\
\hline 4 & End & 4 & Middle & 1.27 & 0.51 & 1.15 \\
\hline 4 & End & 5 & Beginning & 3.14 & 1.24 & 7.95 \\
\hline 4 & End & 5 & Middle & 1.01 & 0.42 & 2.44 \\
\hline 4 & End & 5 & End & 1.10 & 0.39 & 3.10 \\
\hline 4 & End & 6 & Middle & 1.38 & 0.57 & 3.32 \\
\hline 4 & End & 6 & End & 1.74 & 0.65 & 1.54 \\
\hline 4 & End & 7 & Middle & 1.37 & 0.57 & 3.33 \\
\hline 4 & End & 7 & End & 1.32 & 0.53 & 3.30 \\
\hline 4 & End & 8 & Middle & 2.61 & 1.03 & 6.59 \\
\hline 4 & End & 9 & Middle & 2.84 & 1.02 & 7.91 \\
\hline 4 & End & 9 & End & 1.43 & 0.58 & 3.51 \\
\hline 4 & End & 10 & End & 1.67 & 0.68 & 4.10 \\
\hline 4 & End & 11 & End & 1.63 & 0.65 & 4.10 \\
\hline 5 & End & 1 & Beginning & 1.50 & 0.82 & 2.74 \\
\hline 5 & End & 1 & End & 1.40 & 0.17 & 11.83 \\
\hline 5 & End & 2 & Beginning & 1.56 & 0.85 & 2.85 \\
\hline 5 & End & 2 & Middle & 1.29 & 0.51 & 3.28 \\
\hline 5 & End & 2 & End & 2.10 & 0.26 & 17.22 \\
\hline 5 & End & 3 & Beginning & 1.43 & 0.78 & 2.63 \\
\hline 5 & End & 3 & Middle & 1.07 & 0.52 & 2.20 \\
\hline 5 & End & 3 & End & 3.35 & 0.42 & 26.93 \\
\hline 5 & End & 4 & Beginning & 1.48 & 0.80 & 2.74 \\
\hline 5 & End & 4 & Middle & 1.15 & 0.60 & 2.21 \\
\hline 5 & End & 5 & Beginning & 2.86 & 1.45 & 5.62 \\
\hline 5 & End & 6 & Middle & 1.25 & 0.68 & 2.30 \\
\hline 5 & End & 6 & End & 1.58 & 0.74 & 3.35 \\
\hline 5 & End & 7 & Middle & 1.25 & 0.67 & 2.31 \\
\hline 5 & End & 7 & End & 1.20 & 0.62 & 2.32 \\
\hline
\end{tabular}




\begin{tabular}{|c|c|c|c|c|c|c|}
\hline $\begin{array}{c}\text { Driving } \\
\text { Hour }\end{array}$ & $\begin{array}{l}\text { Work Hour } \\
\text { Category }\end{array}$ & $\begin{array}{l}\text { Driving } \\
\text { Hour }\end{array}$ & $\begin{array}{l}\text { Work Hour } \\
\text { Category }\end{array}$ & Odds Ratio & LCL & UCL \\
\hline 5 & End & 8 & Middle & 2.37 & 1.20 & 4.67 \\
\hline 5 & End & 9 & Middle & 2.58 & 1.15 & 5.77 \\
\hline 5 & End & 9 & End & 1.30 & 0.69 & 2.45 \\
\hline 5 & End & 10 & End & 1.51 & 0.80 & 2.87 \\
\hline 5 & End & 11 & End & 1.48 & 0.76 & 2.90 \\
\hline 6 & End & 2 & End & 1.33 & 0.17 & 10.66 \\
\hline 6 & End & 3 & End & 2.13 & 0.27 & 16.66 \\
\hline 6 & End & 5 & Beginning & 1.81 & 1.00 & 3.28 \\
\hline 6 & End & 8 & Middle & 1.50 & 0.83 & 2.73 \\
\hline 6 & End & 9 & Middle & 1.64 & 0.78 & 3.42 \\
\hline 6 & End & 2 & End & 1.33 & 0.17 & 10.66 \\
\hline 6 & End & 3 & End & 2.13 & 0.27 & 16.66 \\
\hline 6 & End & 5 & Beginning & 1.81 & 1.00 & 3.28 \\
\hline 6 & End & 8 & Middle & 1.50 & 0.83 & 2.73 \\
\hline 6 & End & 9 & Middle & 1.64 & 0.78 & 3.42 \\
\hline 7 & End & 1 & Beginning & 1.25 & 0.87 & 1.79 \\
\hline 7 & End & 1 & End & 1.17 & 0.15 & 9.34 \\
\hline 7 & End & 2 & Beginning & 1.30 & 0.90 & 1.87 \\
\hline 7 & End & 2 & Middle & 1.08 & 0.49 & 2.39 \\
\hline 7 & End & 2 & End & 1.75 & 0.23 & 13.59 \\
\hline 7 & End & 3 & Beginning & 1.20 & 0.81 & 1.72 \\
\hline 7 & End & 3 & End & 2.80 & 0.37 & 21.23 \\
\hline 7 & End & 4 & Beginning & 1.24 & 0.85 & 1.80 \\
\hline 7 & End & 5 & Beginning & 2.38 & 1.48 & 3.83 \\
\hline 7 & End & 6 & Middle & 1.05 & 0.73 & 1.51 \\
\hline 7 & End & 6 & End & 1.32 & 0.74 & 2.35 \\
\hline 7 & End & 7 & Middle & 1.04 & 0.71 & 1.52 \\
\hline 7 & End & 8 & Middle & 1.92 & 1.23 & 3.18 \\
\hline 7 & End & 9 & Middle & 2.15 & 1.13 & 4.10 \\
\hline 7 & End & 9 & End & 1.09 & 0.72 & 1.64 \\
\hline 7 & End & 10 & End & 1.26 & 0.83 & 1.92 \\
\hline 7 & End & 11 & End & 1.24 & 0.78 & 1.97 \\
\hline 8 & End & 1 & Beginning & 1.74 & 1.30 & 2.34 \\
\hline 8 & End & 1 & End & 1.63 & 0.21 & 12.89 \\
\hline 8 & End & 2 & Beginning & 1.81 & 1.34 & 2.44 \\
\hline 8 & End & 2 & Middle & 1.50 & 0.70 & 3.25 \\
\hline 8 & End & 2 & End & 2.44 & 0.32 & 18.75 \\
\hline 8 & End & 3 & Beginning & 1.67 & 1.24 & 2.25 \\
\hline 8 & End & 3 & Middle & 1.25 & 0.76 & 2.04 \\
\hline 8 & End & 3 & End & 3.90 & 0.52 & 29.29 \\
\hline 8 & End & 4 & Beginning & 1.72 & 1.26 & 2.36 \\
\hline 8 & End & 4 & Middle & 1.34 & 0.92 & 1.97 \\
\hline
\end{tabular}




\begin{tabular}{|c|c|c|c|c|c|c|}
\hline $\begin{array}{l}\text { Driving } \\
\text { Hour }\end{array}$ & $\begin{array}{l}\text { Work Hour } \\
\text { Category }\end{array}$ & $\begin{array}{l}\text { Driving } \\
\text { Hour }\end{array}$ & $\begin{array}{l}\text { Work Hour } \\
\text { Category }\end{array}$ & Odds Ratio & LCL & UCL \\
\hline 8 & End & 4 & End & 1.06 & 0.43 & 2.58 \\
\hline 8 & End & 5 & Beginning & 3.32 & 2.17 & 5.09 \\
\hline 8 & End & 5 & Middle & 1.07 & 0.78 & 1.46 \\
\hline 8 & End & 5 & End & 1.16 & 0.62 & 2.18 \\
\hline 8 & End & 6 & Middle & 1.46 & 1.08 & 1.97 \\
\hline 8 & End & 6 & End & 1.83 & 1.07 & 3.15 \\
\hline 8 & End & 7 & Middle & 1.45 & 1.06 & 2.00 \\
\hline 8 & End & 7 & End & 1.39 & 0.93 & 2.08 \\
\hline 8 & End & 8 & Middle & 2.76 & 1.80 & 4.23 \\
\hline 8 & End & 9 & Middle & 3.00 & 1.63 & 5.52 \\
\hline 8 & End & 9 & End & 1.51 & 1.06 & 2.16 \\
\hline 8 & End & 10 & End & 1.76 & 1.23 & 2.53 \\
\hline 8 & End & 11 & End & 1.72 & 1.14 & 2.61 \\
\hline 9 & End & 1 & Beginning & 1.15 & 0.85 & 1.56 \\
\hline 9 & End & 1 & End & 1.07 & 0.14 & 8.53 \\
\hline 9 & End & 2 & Beginning & 1.20 & 0.88 & 1.63 \\
\hline 9 & End & 2 & End & 1.61 & 0.21 & 12.40 \\
\hline 9 & End & 3 & Beginning & 1.10 & 0.81 & 1.50 \\
\hline 9 & End & 3 & End & 2.58 & 0.34 & 19.37 \\
\hline 9 & End & 4 & Beginning & 1.14 & 0.82 & 1.57 \\
\hline 9 & End & 5 & Beginning & 2.19 & 1.42 & 3.38 \\
\hline 9 & End & 6 & End & 1.21 & 0.70 & 2.09 \\
\hline 9 & End & 8 & Middle & 1.82 & 1.18 & 2.81 \\
\hline 9 & End & 9 & Middle & 1.98 & 1.07 & 3.66 \\
\hline 9 & End & 10 & End & 1.16 & 0.80 & 1.68 \\
\hline 9 & End & 11 & End & 1.14 & 0.75 & 1.74 \\
\hline 10 & End & 2 & Beginning & 1.03 & 0.75 & 1.41 \\
\hline 10 & End & 2 & End & 1.38 & 0.18 & 10.67 \\
\hline 10 & End & 3 & End & 2.22 & 0.29 & 16.67 \\
\hline 10 & End & 5 & Beginning & 1.89 & 1.22 & 2.93 \\
\hline 10 & End & 6 & End & 1.04 & 0.60 & 1.81 \\
\hline 10 & End & 8 & Middle & 1.56 & 1.01 & 2.43 \\
\hline 10 & End & 9 & Middle & 1.70 & 0.92 & 3.16 \\
\hline 11 & End & 1 & Beginning & 1.01 & 0.70 & 1.47 \\
\hline 11 & End & 2 & Beginning & 1.05 & 0.72 & 1.53 \\
\hline 11 & End & 2 & End & 1.42 & 0.18 & 11.02 \\
\hline 11 & End & 3 & End & 2.27 & 0.30 & 17.22 \\
\hline 11 & End & 4 & Beginning & 1.00 & 0.68 & 1.48 \\
\hline 11 & End & 5 & Beginning & 1.93 & 1.19 & 3.13 \\
\hline 11 & End & 6 & End & 1.06 & 0.59 & 1.92 \\
\hline 11 & End & 8 & Middle & 1.60 & 0.98 & 2.60 \\
\hline 11 & End & 9 & Middle & 1.74 & 0.91 & 3.34 \\
\hline
\end{tabular}




\begin{tabular}{|c|c|c|c|c|c|c|}
\hline $\begin{array}{c}\text { Driving } \\
\text { Hour }\end{array}$ & $\begin{array}{c}\text { Work Hour } \\
\text { Category }\end{array}$ & $\begin{array}{c}\text { Driving } \\
\text { Hour }\end{array}$ & $\begin{array}{c}\text { Work Hour } \\
\text { Category }\end{array}$ & Odds Ratio & LCL & UCL \\
\hline 11 & End & 10 & End & 1.02 & 0.67 & 1.57 \\
\hline
\end{tabular}

Table 47. Results from the Odds Ratio Analysis for the Beginning Work Hours (Hours 1-5) with Multiple Within-Hour SCEs Collapsed (Dichotomous Approach), for Shifts That Went Into the 14th

\begin{tabular}{|c|c|c|c|c|c|c|}
\hline \multicolumn{7}{|c|}{ Working Hour } \\
\hline $\begin{array}{c}\text { Driving } \\
\text { Hour }\end{array}$ & $\begin{array}{c}\text { Work Hour } \\
\text { Category }\end{array}$ & $\begin{array}{l}\text { Driving } \\
\text { Hour }\end{array}$ & $\begin{array}{l}\text { Work Hour } \\
\text { Category }\end{array}$ & Odds Ratio & LCL & UCL \\
\hline 1 & Beginning & 4 & Beginning & 1.01 & 0.59 & 1.73 \\
\hline 1 & Beginning & 5 & Beginning & 1.56 & 0.68 & 3.57 \\
\hline 1 & Beginning & 2 & Middle & 1.23 & 0.37 & 4.15 \\
\hline 1 & Beginning & 6 & Middle & 1.06 & 0.64 & 1.74 \\
\hline 1 & Beginning & 8 & Middle & 4.29 & 1.02 & 18.05 \\
\hline 1 & Beginning & 9 & Middle & 2.39 & 0.32 & 18.01 \\
\hline 1 & Beginning & 3 & End & 1.55 & 0.20 & 11.90 \\
\hline 2 & Beginning & 1 & Beginning & 1.10 & 0.70 & 1.73 \\
\hline 2 & Beginning & 4 & Beginning & 1.11 & 0.65 & 1.90 \\
\hline 2 & Beginning & 5 & Beginning & 1.72 & 0.75 & 3.92 \\
\hline 2 & Beginning & 2 & Middle & 1.36 & 0.40 & 4.56 \\
\hline 2 & Beginning & 6 & Middle & 1.16 & 0.70 & 1.92 \\
\hline 2 & Beginning & 8 & Middle & 4.72 & 1.12 & 19.85 \\
\hline 2 & Beginning & 9 & Middle & 2.63 & 0.35 & 19.81 \\
\hline 2 & Beginning & 2 & End & 1.06 & 0.13 & 8.44 \\
\hline 2 & Beginning & 3 & End & 1.70 & 0.22 & 13.09 \\
\hline 3 & Beginning & 1 & Beginning & 1.32 & 0.84 & 2.08 \\
\hline 3 & Beginning & 2 & Beginning & 1.20 & 0.77 & 1.89 \\
\hline 3 & Beginning & 4 & Beginning & 1.34 & 0.79 & 2.28 \\
\hline 3 & Beginning & 5 & Beginning & 2.07 & 0.91 & 4.71 \\
\hline 3 & Beginning & 2 & Middle & 1.63 & 0.49 & 5.49 \\
\hline 3 & Beginning & 4 & Middle & 1.04 & 0.59 & 1.84 \\
\hline 3 & Beginning & 6 & Middle & 1.40 & 0.85 & 2.30 \\
\hline 3 & Beginning & 7 & Middle & 1.20 & 0.69 & 2.10 \\
\hline 3 & Beginning & 8 & Middle & 5.68 & 1.35 & 23.88 \\
\hline 3 & Beginning & 9 & Middle & 3.16 & 0.42 & 23.83 \\
\hline 3 & Beginning & 2 & End & 1.28 & 0.16 & 10.15 \\
\hline 3 & Beginning & 3 & End & 2.05 & 0.27 & 15.74 \\
\hline 3 & Beginning & 5 & End & 1.09 & 0.44 & 2.68 \\
\hline 3 & Beginning & 10 & End & 1.15 & 0.65 & 2.02 \\
\hline 4 & Beginning & 5 & Beginning & 1.54 & 0.64 & 3.68 \\
\hline 4 & Beginning & 2 & Middle & 1.22 & 0.35 & 4.23 \\
\hline 4 & Beginning & 6 & Middle & 1.04 & 0.59 & 1.85 \\
\hline 4 & Beginning & 8 & Middle & 4.24 & 0.98 & 18.30 \\
\hline 4 & Beginning & 9 & Middle & 2.36 & 0.31 & 18.12 \\
\hline 4 & Beginning & 3 & End & 1.53 & 0.20 & 11.97 \\
\hline 5 & Beginning & 8 & Middle & 2.75 & 0.56 & 13.53 \\
\hline
\end{tabular}




\begin{tabular}{|c|c|c|c|c|c|c|}
\hline $\begin{array}{c}\text { Driving } \\
\text { Hour }\end{array}$ & $\begin{array}{c}\text { Work Hour } \\
\text { Category }\end{array}$ & $\begin{array}{c}\text { Driving } \\
\text { Hour }\end{array}$ & $\begin{array}{c}\text { Work Hour } \\
\text { Category }\end{array}$ & Odds Ratio & LCL & UCL \\
\hline 5 & Beginning & 9 & Middle & 1.53 & 0.18 & 12.94 \\
\hline
\end{tabular}

Table 48. Results from the Odds Ratio Analysis for the Middle Work Hours (Hours 6-9) with Multiple Within-Hour SCEs Collapsed (Dichotomous Approach), for Shifts That Went Into the 14th Working Hour

\begin{tabular}{|c|c|c|c|c|c|c|}
\hline $\begin{array}{c}\text { Driving } \\
\text { Hour }\end{array}$ & $\begin{array}{l}\text { Work Hour } \\
\text { Category }\end{array}$ & $\begin{array}{c}\text { Driving } \\
\text { Hour }\end{array}$ & $\begin{array}{c}\text { Work Hour } \\
\text { Category }\end{array}$ & Odds Ratio & LCL & UCL \\
\hline 2 & Middle & 5 & Beginning & 1.27 & 0.31 & 5.11 \\
\hline 2 & Middle & 8 & Middle & 3.48 & 0.59 & 21.58 \\
\hline 2 & Middle & 9 & Middle & 1.94 & 0.19 & 19.56 \\
\hline 2 & Middle & 3 & End & 1.26 & 0.12 & 12.90 \\
\hline 3 & Middle & 1 & Beginning & 1.33 & 0.64 & 2.76 \\
\hline 3 & Middle & 2 & Beginning & 1.21 & 0.58 & 2.51 \\
\hline 3 & Middle & 3 & Beginning & 1.01 & 0.49 & 2.08 \\
\hline 3 & Middle & 4 & Beginning & 1.35 & 0.62 & 2.95 \\
\hline 3 & Middle & 5 & Beginning & 2.08 & 0.76 & 5.67 \\
\hline 3 & Middle & 2 & Middle & 1.64 & 0.43 & 6.28 \\
\hline 3 & Middle & 4 & Middle & 1.05 & 0.47 & 2.35 \\
\hline 3 & Middle & 6 & Middle & 1.41 & 0.66 & 3.00 \\
\hline 3 & Middle & 7 & Middle & 1.21 & 0.54 & 2.69 \\
\hline 3 & Middle & 8 & Middle & 5.72 & 1.22 & 26.81 \\
\hline 3 & Middle & 9 & Middle & 3.18 & 0.39 & 25.96 \\
\hline 3 & Middle & 2 & End & 1.29 & 0.15 & 11.04 \\
\hline 3 & Middle & 3 & End & 2.06 & 0.25 & 17.14 \\
\hline 3 & Middle & 5 & End & 1.10 & 0.38 & 3.19 \\
\hline 3 & Middle & 10 & End & 1.15 & 0.52 & 2.57 \\
\hline 4 & Middle & 1 & Beginning & 1.27 & 0.72 & 2.26 \\
\hline 4 & Middle & 2 & Beginning & 1.16 & 0.65 & 2.05 \\
\hline 4 & Middle & 4 & Beginning & 1.29 & 0.68 & 2.44 \\
\hline 4 & Middle & 5 & Beginning & 1.99 & 0.81 & 4.86 \\
\hline 4 & Middle & 2 & Middle & 1.57 & 0.44 & 5.54 \\
\hline 4 & Middle & 6 & Middle & 1.34 & 0.73 & 2.47 \\
\hline 4 & Middle & 7 & Middle & 1.16 & 0.60 & 2.23 \\
\hline 4 & Middle & 8 & Middle & 5.46 & 1.25 & 23.93 \\
\hline 4 & Middle & 9 & Middle & 3.04 & 0.39 & 23.60 \\
\hline 4 & Middle & 2 & End & 1.23 & 0.15 & 10.05 \\
\hline 4 & Middle & 3 & End & 1.97 & 0.25 & 15.59 \\
\hline 4 & Middle & 5 & End & 1.05 & 0.40 & 2.75 \\
\hline 4 & Middle & 10 & End & 1.10 & 0.57 & 2.13 \\
\hline 5 & Middle & 1 & Beginning & 1.45 & 0.89 & 2.34 \\
\hline 5 & Middle & 2 & Beginning & 1.31 & 0.81 & 2.12 \\
\hline 5 & Middle & 3 & Beginning & 1.09 & 0.68 & 1.76 \\
\hline 5 & Middle & 4 & Beginning & 1.46 & 0.84 & 2.55 \\
\hline
\end{tabular}




\begin{tabular}{|c|c|c|c|c|c|c|}
\hline $\begin{array}{c}\text { Driving } \\
\text { Hour }\end{array}$ & $\begin{array}{c}\text { Work Hour } \\
\text { Category }\end{array}$ & $\begin{array}{c}\text { Driving } \\
\text { Hour }\end{array}$ & $\begin{array}{c}\text { Work Hour } \\
\text { Category }\end{array}$ & Odds Ratio & LCL & UCL \\
\hline 5 & Middle & 5 & Beginning & 2.26 & 0.97 & 5.23 \\
\hline 5 & Middle & 2 & Middle & 1.78 & 0.52 & 6.06 \\
\hline 5 & Middle & 3 & Middle & 1.09 & 0.52 & 2.29 \\
\hline 5 & Middle & 4 & Middle & 1.14 & 0.63 & 2.06 \\
\hline 5 & Middle & 6 & Middle & 1.53 & 0.90 & 2.58 \\
\hline 5 & Middle & 7 & Middle & 1.31 & 0.73 & 2.35 \\
\hline 5 & Middle & 8 & Middle & 6.20 & 1.46 & 26.30 \\
\hline 5 & Middle & 9 & Middle & 3.45 & 0.45 & 26.18 \\
\hline 5 & Middle & 1 & End & 1.04 & 0.13 & 8.54 \\
\hline 5 & Middle & 2 & End & 1.40 & 0.18 & 11.15 \\
\hline 5 & Middle & 3 & End & 2.24 & 0.29 & 17.30 \\
\hline 5 & Middle & 5 & End & 1.19 & 0.48 & 2.97 \\
\hline 5 & Middle & 8 & End & 1.08 & 0.65 & 1.81 \\
\hline 5 & Middle & 10 & End & 1.25 & 0.70 & 2.24 \\
\hline 6 & Middle & 5 & Beginning & 1.48 & 0.63 & 3.47 \\
\hline 6 & Middle & 2 & Middle & 1.17 & 0.34 & 4.01 \\
\hline 6 & Middle & 8 & Middle & 4.07 & 0.95 & 17.37 \\
\hline 6 & Middle & 9 & Middle & 2.26 & 0.30 & 17.25 \\
\hline 6 & Middle & 3 & End & 1.47 & 0.19 & 11.40 \\
\hline 7 & Middle & 1 & Beginning & 1.10 & 0.63 & 1.96 \\
\hline 7 & Middle & 2 & Beginning & 1.00 & 0.57 & 1.75 \\
\hline 7 & Middle & 4 & Beginning & 1.11 & 0.60 & 2.08 \\
\hline 7 & Middle & 5 & Beginning & 1.72 & 0.71 & 4.18 \\
\hline 7 & Middle & 2 & Middle & 1.36 & 0.39 & 4.77 \\
\hline 7 & Middle & 6 & Middle & 1.16 & 0.64 & 2.11 \\
\hline 7 & Middle & 8 & Middle & 4.72 & 1.08 & 20.60 \\
\hline 7 & Middle & 9 & Middle & 2.63 & 0.34 & 20.34 \\
\hline 7 & Middle & 2 & End & 1.06 & 0.13 & 8.66 \\
\hline 9 & Middle & 3 & End & 1.70 & 0.22 & 13.44 \\
\hline 5 & 8 & Middle & 1.80 & 0.16 & 20.57 \\
\hline
\end{tabular}

Table 49. Results from the Odds Ratio Analysis for the End Work Hours (Hours 10-14) with Multiple Within-Hour SCEs (Dichotomous Approach), for Shifts That Went Into the 14th Working Hour

\begin{tabular}{|c|c|c|c|c|c|c|}
\hline $\begin{array}{c}\text { Driving } \\
\text { Hour }\end{array}$ & $\begin{array}{c}\text { Work Hour } \\
\text { Category }\end{array}$ & $\begin{array}{c}\text { Driving } \\
\text { Hour }\end{array}$ & $\begin{array}{c}\text { Work Hour } \\
\text { Category }\end{array}$ & Odds Ratio & LCL & UCL \\
\hline 1 & End & 1 & Beginning & 1.39 & 0.17 & 11.32 \\
\hline 1 & End & 2 & Beginning & 1.26 & 0.15 & 10.29 \\
\hline 1 & End & 3 & Beginning & 1.05 & 0.13 & 8.55 \\
\hline 1 & End & 4 & Beginning & 1.41 & 0.17 & 11.68 \\
\hline 1 & End & 5 & Beginning & 2.17 & 0.24 & 19.73 \\
\hline 1 & End & 2 & Middle & 1.71 & 0.16 & 18.52 \\
\hline 1 & End & 3 & Middle & 1.04 & 0.12 & 9.17 \\
\hline 1 & End & 4 & Middle & 1.09 & 0.13 & 9.16 \\
\hline
\end{tabular}




\begin{tabular}{|c|c|c|c|c|c|c|}
\hline $\begin{array}{c}\text { Driving } \\
\text { Hour }\end{array}$ & $\begin{array}{l}\text { Work Hour } \\
\text { Category }\end{array}$ & $\begin{array}{l}\text { Driving } \\
\text { Hour }\end{array}$ & $\begin{array}{c}\text { Work Hour } \\
\text { Category }\end{array}$ & Odds Ratio & LCL & UCL \\
\hline 1 & End & 6 & Middle & 1.47 & 0.18 & 12.08 \\
\hline 1 & End & 7 & Middle & 1.26 & 0.15 & 10.55 \\
\hline 1 & End & 8 & Middle & 5.96 & 0.49 & 72.73 \\
\hline 1 & End & 9 & Middle & 3.31 & 0.19 & 58.90 \\
\hline 1 & End & 2 & End & 1.34 & 0.07 & 24.73 \\
\hline 1 & End & 3 & End & 2.15 & 0.12 & 38.70 \\
\hline 1 & End & 5 & End & 1.14 & 0.12 & 10.73 \\
\hline 1 & End & 8 & End & 1.04 & 0.13 & 8.53 \\
\hline 1 & End & 10 & End & 1.20 & 0.14 & 10.05 \\
\hline 2 & End & 1 & Beginning & 1.03 & 0.13 & 8.19 \\
\hline 2 & End & 4 & Beginning & 1.05 & 0.13 & 8.46 \\
\hline 2 & End & 5 & Beginning & 1.61 & 0.18 & 14.30 \\
\hline 2 & End & 2 & Middle & 1.27 & 0.12 & 13.45 \\
\hline 2 & End & 6 & Middle & 1.09 & 0.14 & 8.74 \\
\hline 2 & End & 8 & Middle & 4.44 & 0.37 & 52.87 \\
\hline 2 & End & 9 & Middle & 2.47 & 0.14 & 42.95 \\
\hline 2 & End & 3 & End & 1.60 & 0.09 & 28.23 \\
\hline 3 & End & 5 & Beginning & 1.01 & 0.12 & 8.68 \\
\hline 3 & End & 8 & Middle & 2.77 & 0.24 & 32.20 \\
\hline 3 & End & 9 & Middle & 1.54 & 0.09 & 26.25 \\
\hline 4 & End & 1 & Beginning & 2.40 & 0.87 & 6.61 \\
\hline 4 & End & 2 & Beginning & 2.18 & 0.79 & 6.00 \\
\hline 4 & End & 3 & Beginning & 1.81 & 0.66 & 4.99 \\
\hline 4 & End & 4 & Beginning & 2.43 & 0.85 & 6.95 \\
\hline 4 & End & 5 & Beginning & 3.74 & 1.10 & 12.75 \\
\hline 4 & End & 2 & Middle & 2.95 & 0.65 & 13.44 \\
\hline 4 & End & 3 & Middle & 1.80 & 0.56 & 5.76 \\
\hline 4 & End & 4 & Middle & 1.88 & 0.64 & 5.50 \\
\hline 4 & End & 5 & Middle & 1.66 & 0.59 & 4.63 \\
\hline 4 & End & 6 & Middle & 2.53 & 0.90 & 7.13 \\
\hline 4 & End & 7 & Middle & 2.18 & 0.75 & 6.32 \\
\hline 4 & End & 8 & Middle & 10.28 & 1.88 & 56.20 \\
\hline 4 & End & 9 & Middle & 5.72 & 0.62 & 52.38 \\
\hline 4 & End & 1 & End & 1.73 & 0.18 & 16.97 \\
\hline 4 & End & 2 & End & 2.32 & 0.24 & 22.22 \\
\hline 4 & End & 3 & End & 3.71 & 0.40 & 34.56 \\
\hline 4 & End & 4 & End & 1.09 & 0.39 & 3.05 \\
\hline 4 & End & 5 & End & 1.97 & 0.55 & 7.09 \\
\hline 4 & End & 6 & End & 1.64 & 0.53 & 5.03 \\
\hline 4 & End & 7 & End & 1.09 & 0.39 & 3.05 \\
\hline 4 & End & 8 & End & 1.79 & 0.64 & 5.02 \\
\hline 4 & End & 9 & End & 1.66 & 0.59 & 4.63 \\
\hline 4 & End & 10 & End & 2.07 & 0.71 & 6.02 \\
\hline
\end{tabular}




\begin{tabular}{|c|c|c|c|c|c|c|}
\hline $\begin{array}{l}\text { Driving } \\
\text { Hour }\end{array}$ & $\begin{array}{l}\text { Work Hour } \\
\text { Category }\end{array}$ & $\begin{array}{c}\text { Driving } \\
\text { Hour }\end{array}$ & $\begin{array}{l}\text { Work Hour } \\
\text { Category }\end{array}$ & Odds Ratio & LCL & UCL \\
\hline 4 & End & 11 & End & 1.20 & 0.40 & 3.61 \\
\hline 5 & End & 1 & Beginning & 1.21 & 0.49 & 2.99 \\
\hline 5 & End & 2 & Beginning & 1.10 & 0.45 & 2.71 \\
\hline 5 & End & 4 & Beginning & 1.23 & 0.48 & 3.15 \\
\hline 5 & End & 5 & Beginning & 1.89 & 0.61 & 5.88 \\
\hline 5 & End & 2 & Middle & 1.50 & 0.35 & 6.32 \\
\hline 5 & End & 6 & Middle & 1.28 & 0.51 & 3.23 \\
\hline 5 & End & 7 & Middle & 1.10 & 0.42 & 2.87 \\
\hline 5 & End & 8 & Middle & 5.21 & 1.02 & 26.65 \\
\hline 5 & End & 9 & Middle & 2.90 & 0.33 & 25.23 \\
\hline 5 & End & 2 & End & 1.17 & 0.13 & 10.72 \\
\hline 5 & End & 3 & End & 1.88 & 0.21 & 16.65 \\
\hline 5 & End & 10 & End & 1.05 & 0.40 & 2.74 \\
\hline 6 & End & 1 & Beginning & 1.46 & 0.76 & 2.83 \\
\hline 6 & End & 2 & Beginning & 1.33 & 0.69 & 2.57 \\
\hline 6 & End & 3 & Beginning & 1.11 & 0.57 & 2.14 \\
\hline 6 & End & 4 & Beginning & 1.48 & 0.72 & 3.04 \\
\hline 6 & End & 5 & Beginning & 2.28 & 0.88 & 5.93 \\
\hline 6 & End & 2 & Middle & 1.80 & 0.49 & 6.65 \\
\hline 6 & End & 3 & Middle & 1.10 & 0.46 & 2.63 \\
\hline 6 & End & 4 & Middle & 1.15 & 0.55 & 2.43 \\
\hline 6 & End & 5 & Middle & 1.01 & 0.51 & 1.99 \\
\hline 6 & End & 6 & Middle & 1.54 & 0.77 & 3.09 \\
\hline 6 & End & 7 & Middle & 1.33 & 0.64 & 2.78 \\
\hline 6 & End & 8 & Middle & 6.28 & 1.38 & 28.54 \\
\hline 6 & End & 9 & Middle & 3.49 & 0.44 & 27.87 \\
\hline 6 & End & 1 & End & 1.05 & 0.12 & 9.07 \\
\hline 6 & End & 2 & End & 1.42 & 0.17 & 11.86 \\
\hline 6 & End & 3 & End & 2.27 & 0.28 & 18.41 \\
\hline 6 & End & 5 & End & 1.21 & 0.44 & 3.34 \\
\hline 6 & End & 8 & End & 1.09 & 0.55 & 2.17 \\
\hline 6 & End & 9 & End & 1.01 & 0.51 & 2.00 \\
\hline 6 & End & 10 & End & 1.27 & 0.61 & 2.65 \\
\hline 7 & End & 1 & Beginning & 2.20 & 1.35 & 3.57 \\
\hline 7 & End & 2 & Beginning & 2.00 & 1.23 & 3.24 \\
\hline 7 & End & 3 & Beginning & 1.66 & 1.02 & 2.69 \\
\hline 7 & End & 4 & Beginning & 2.23 & 1.27 & 3.89 \\
\hline 7 & End & 5 & Beginning & 3.43 & 1.48 & 7.96 \\
\hline 7 & End & 2 & Middle & 2.71 & 0.80 & 9.22 \\
\hline 7 & End & 3 & Middle & 1.65 & 0.78 & 3.48 \\
\hline 7 & End & 4 & Middle & 1.73 & 0.95 & 3.13 \\
\hline 7 & End & 5 & Middle & 1.52 & 0.91 & 2.52 \\
\hline 7 & End & 6 & Middle & 2.32 & 1.37 & 3.93 \\
\hline
\end{tabular}




\begin{tabular}{|c|c|c|c|c|c|c|}
\hline $\begin{array}{l}\text { Driving } \\
\text { Hour }\end{array}$ & $\begin{array}{l}\text { Work Hour } \\
\text { Category }\end{array}$ & $\begin{array}{c}\text { Driving } \\
\text { Hour }\end{array}$ & $\begin{array}{l}\text { Work Hour } \\
\text { Category }\end{array}$ & Odds Ratio & LCL & UCL \\
\hline 7 & End & 7 & Middle & 2.00 & 1.11 & 3.58 \\
\hline 7 & End & 8 & Middle & 9.43 & 2.22 & 40.01 \\
\hline 7 & End & 9 & Middle & 5.24 & 0.69 & 39.82 \\
\hline 7 & End & 1 & End & 1.58 & 0.19 & 12.98 \\
\hline 7 & End & 2 & End & 2.13 & 0.27 & 16.96 \\
\hline 7 & End & 3 & End & 3.40 & 0.44 & 26.31 \\
\hline 7 & End & 5 & End & 1.81 & 0.73 & 4.52 \\
\hline 7 & End & 6 & End & 1.50 & 0.76 & 2.96 \\
\hline 7 & End & 8 & End & 1.64 & 0.98 & 2.75 \\
\hline 7 & End & 9 & End & 1.52 & 0.91 & 2.53 \\
\hline 7 & End & 10 & End & 1.90 & 1.06 & 3.41 \\
\hline 7 & End & 11 & End & 1.10 & 0.58 & 2.09 \\
\hline 8 & End & 1 & Beginning & 1.34 & 0.82 & 2.19 \\
\hline 8 & End & 2 & Beginning & 1.22 & 0.75 & 1.99 \\
\hline 8 & End & 3 & Beginning & 1.01 & 0.62 & 1.65 \\
\hline 8 & End & 4 & Beginning & 1.36 & 0.77 & 2.39 \\
\hline 8 & End & 5 & Beginning & 2.09 & 0.90 & 4.87 \\
\hline 8 & End & 2 & Middle & 1.65 & 0.48 & 5.64 \\
\hline 8 & End & 3 & Middle & 1.01 & 0.47 & 2.13 \\
\hline 8 & End & 4 & Middle & 1.05 & 0.58 & 1.92 \\
\hline 8 & End & 6 & Middle & 1.41 & 0.83 & 2.41 \\
\hline 8 & End & 7 & Middle & 1.22 & 0.67 & 2.20 \\
\hline 8 & End & 8 & Middle & 5.75 & 1.35 & 24.46 \\
\hline 8 & End & 9 & Middle & 3.20 & 0.42 & 24.32 \\
\hline 8 & End & 2 & End & 1.30 & 0.16 & 10.36 \\
\hline 8 & End & 3 & End & 2.07 & 0.27 & 16.07 \\
\hline 8 & End & 5 & End & 1.10 & 0.44 & 2.77 \\
\hline 8 & End & 10 & End & 1.16 & 0.64 & 2.09 \\
\hline 9 & End & 1 & Beginning & 1.45 & 0.89 & 2.35 \\
\hline 9 & End & 2 & Beginning & 1.32 & 0.81 & 2.13 \\
\hline 9 & End & 3 & Beginning & 1.09 & 0.67 & 1.77 \\
\hline 9 & End & 4 & Beginning & 1.47 & 0.84 & 2.56 \\
\hline 9 & End & 5 & Beginning & 2.26 & 0.97 & 5.24 \\
\hline 9 & End & 2 & Middle & 1.78 & 0.52 & 6.07 \\
\hline 9 & End & 3 & Middle & 1.09 & 0.51 & 2.29 \\
\hline 9 & End & 4 & Middle & 1.14 & 0.63 & 2.06 \\
\hline 9 & End & 5 & Middle & 1.00 & 0.60 & 1.66 \\
\hline 9 & End & 6 & Middle & 1.53 & 0.90 & 2.59 \\
\hline 9 & End & 7 & Middle & 1.31 & 0.73 & 2.36 \\
\hline 9 & End & 8 & Middle & 6.21 & 1.46 & 26.37 \\
\hline 9 & End & 9 & Middle & 3.45 & 0.45 & 26.24 \\
\hline 9 & End & 1 & End & 1.04 & 0.13 & 8.55 \\
\hline 9 & End & 2 & End & 1.40 & 0.18 & 11.18 \\
\hline
\end{tabular}




\begin{tabular}{|c|c|c|c|c|c|c|}
\hline $\begin{array}{c}\text { Driving } \\
\text { Hour }\end{array}$ & $\begin{array}{l}\text { Work Hour } \\
\text { Category }\end{array}$ & $\begin{array}{c}\text { Driving } \\
\text { Hour }\end{array}$ & $\begin{array}{c}\text { Work Hour } \\
\text { Category }\end{array}$ & Odds Ratio & LCL & UCL \\
\hline 9 & End & 3 & End & 2.24 & 0.29 & 17.33 \\
\hline 9 & End & 5 & End & 1.19 & 0.48 & 2.98 \\
\hline 9 & End & 8 & End & 1.08 & 0.64 & 1.82 \\
\hline 9 & End & 10 & End & 1.25 & 0.70 & 2.25 \\
\hline 10 & End & 1 & Beginning & 1.16 & 0.66 & 2.03 \\
\hline 10 & End & 2 & Beginning & 1.05 & 0.60 & 1.84 \\
\hline 10 & End & 4 & Beginning & 1.17 & 0.63 & 2.19 \\
\hline 10 & End & 5 & Beginning & 1.80 & 0.74 & 4.39 \\
\hline 10 & End & 2 & Middle & 1.42 & 0.41 & 5.02 \\
\hline 10 & End & 6 & Middle & 1.22 & 0.67 & 2.22 \\
\hline 10 & End & 7 & Middle & 1.05 & 0.55 & 2.01 \\
\hline 10 & End & 8 & Middle & 4.96 & 1.14 & 21.63 \\
\hline 10 & End & 9 & Middle & 2.76 & 0.36 & 21.36 \\
\hline 10 & End & 2 & End & 1.12 & 0.14 & 9.09 \\
\hline 10 & End & 3 & End & 1.79 & 0.23 & 14.11 \\
\hline 11 & End & 1 & Beginning & 1.99 & 1.07 & 3.71 \\
\hline 11 & End & 2 & Beginning & 1.81 & 0.98 & 3.37 \\
\hline 11 & End & 3 & Beginning & 1.51 & 0.81 & 2.80 \\
\hline 11 & End & 4 & Beginning & 2.02 & 1.02 & 3.99 \\
\hline 11 & End & 5 & Beginning & 3.11 & 1.23 & 7.86 \\
\hline 11 & End & 2 & Middle & 2.46 & 0.68 & 8.88 \\
\hline 11 & End & 3 & Middle & 1.50 & 0.64 & 3.47 \\
\hline 11 & End & 4 & Middle & 1.57 & 0.77 & 3.19 \\
\hline 11 & End & 5 & Middle & 1.38 & 0.73 & 2.61 \\
\hline 11 & End & 6 & Middle & 2.10 & 1.09 & 4.05 \\
\hline 11 & End & 7 & Middle & 1.81 & 0.90 & 3.65 \\
\hline 11 & End & 8 & Middle & 8.55 & 1.91 & 38.22 \\
\hline 11 & End & 9 & Middle & 4.76 & 0.60 & 37.49 \\
\hline 11 & End & 1 & End & 1.44 & 0.17 & 12.21 \\
\hline 11 & End & 2 & End & 1.93 & 0.23 & 15.96 \\
\hline 11 & End & 3 & End & 3.09 & 0.38 & 24.76 \\
\hline 11 & End & 5 & End & 1.64 & 0.61 & 4.44 \\
\hline 11 & End & 6 & End & 1.36 & 0.62 & 2.98 \\
\hline 11 & End & 8 & End & 1.49 & 0.78 & 2.84 \\
\hline 11 & End & 9 & End & 1.38 & 0.72 & 2.62 \\
\hline 11 & End & 10 & End & 1.73 & 0.86 & 3.48 \\
\hline
\end{tabular}




\section{REFERENCES}

1. Transport Topics 100: 2006 Top For-Hire Carriers. (2006, July 24). Transport Topics, 3700, 4-21.

2 Van Dongen, H., Jackson, M.L., and Belenky, G. (2010). Duration of restart period needed to recycle with optimal performance: Phase II. (Report No. FMCSA-MC-RRR-10-062). Washington, DC: Federal Motor Carrier Safety Administration, USDOT.

3 Olds, D.M., and Clarke, S.P. (2010). The effect of work hours on adverse events and errors in health care. Journal of Safety Research, 41, 153-162.

4 Rogers, A.E., Hwang, W.T., Scott, L.D., Aiken, L.H., and Dinges, D.F. (2004). The working hours of hospital staff nurses and patient safety. Health Affairs, 23(4), 202-212.

5 Dembe, A.E., Erickson, J.B., Delbos, R.G., and Banks, S.M. (2005). The impact of overtime and long work hours on occupational injuries and illnesses: New evidence from the United States. Occupational and Environmental Medicine, 62, 588-597.

6 Wylie, C. D., Shultz, T., Miller, J. C., Mitler, M. M., and Mackie, R. R. (1996). Commercial motor vehicle driver fatigue and alertness study: Technical summary. (FHWA report no. FHWA-MC-97-001.) Washington, DC: Federal Highway Administration, USDOT.

7 Mitler, M., Miller, J., Lipsitz, J., Walsh, J., and Wylie, D. (1997). The sleep of long-haul truck drivers. The New England Journal of Medicine, 337(11), 755-761.

8 Federal Highway Administration. (March 1999). Effects of operating practices on commercial driver alertness. TechBrief.

9 US DOT FMCSA. (2010) Notice of proposed rulemaking: Hours of Service of Drivers. Federal Register, 75(249), 82170-82198. http://www.fmcsa.dot.gov/rulesregulations/TOPICS/hos-proposed/HOS\%20NPRM.pdf

10 Federal Motor Carrier Safety Administration. (2008). Hours-of-Service of Drivers: Final Rule. 49 CFR Parts 385 and 395. Docket No. FMCSA-2004-19608.

11 Jensen, A., and Dahl, S. (2009). Truck drivers hours-of-service regulations and occupational health. Work, 32(3), 363-368.

12 Stutts, J.C., Wilkins, J.W., and Vaughn, B.V. (1999). Why do people have drowsy driving crashes? Input from drivers who just did. Washington, DC: AAA Foundation for Traffic Safety.

13 Dingus, T., Neale, V., Garness, S., Hanowski, R., Keisler, A., Lee, S., Perez, M., Robinson, G., Belz, S., Casali, J., Pace-Schott, E., Stickgold, R., and Hobson, J. (2001). Impact of sleeper berth usage on driver fatigue, final project report (Report No. FMCSA-RT-02-050). Washington, DC: Federal Motor Carrier Safety Administration, USDOT. 
14 Williamson, A., Feyer, A., and Friswell, R. (1996). The impact of work practices on fatigue in long distance truck drivers. Accident Analysis and Prevention, 28(6), 709-719.

15 American Transportation Research Institute. (2006). Safety and health impacts of the new hours-of-service rules (Technical Report). Arlington, VA: American Transportation Research Institute.

16 Dick, V., Hendrix, J., and Knipling, R. R. (2006). New hours-of-service rules: Trucking industry reactions and safety outcomes. Proceedings of the 85th Annual Meeting of the Transportation Research Board (pp. 103-109). Washington, DC: Transportation Research Board.

17 American Transportation Research Institute. (2010). Hours-of-service rules safety impacts: 2010 Analysis (Technical Report). Arlington, VA: American Transportation Research Institute.

18 Hanowski, R.J., Olson, R., Bocanegra, J., Hickman, J., Dingus, T.A., and Sudweeks, J.D. (in press). Safety-critical events that occur in the 10th and 11th hour of driving in commercial vehicle operations: Does risk increase in the 11th hour? (Technical Report). Washington DC: Federal Motor Carrier Safety Administration, USDOT.

19 Blanco, M., Hickman, J., Olson, R., Bocanegra, J., Hanowski, R. J., Nakata, A., et al. (in press). Investigating critical incidents, driver restart period, sleep quantity, and crash countermeasures in commercial vehicle operations using naturalistic data collection. Washington DC: Federal Motor Carrier Safety Administration, USDOT.

20 Hanowski, R.J., Hickman, J.S., Olson, R.L., and Bocanegra, J. (2009). Evaluating the 2003 revised hours-of-service regulations for truck drivers: The impact of time-on-task on safetycritical event risk. Accident Analysis and Prevention, 41, 268-275.

21 Knipling, R.R. (2009). Three large truck crash categories: What they tell us about crash causation. Paper presented at the International Driving Symposium on Human Factors in Driver Assessment, Training and Vehicle Design, Big Sky, Montana.

22 Williamson, A., Lombardi, D.A., Folkard, S., Stutts, J., Coutney, T.K., and Connor, J.L. (2011). The link between fatigue and safety. Accident Analysis and Prevention, 43, 498-515.

23 Lockley, S.W., Cronin, J.W., Evans, E.E., Cade, B.E., Lee, C.J., Landrigan, C.P., et al. (2004). Effect of reducing interns' weekly work hours on sleep and attentional failures. New England Journal of Medicine, 351, 1829-1837.

24 Budnick, L.D., Lerman, S.E., Baker, T.L., Jones, H., and Czeisler, C.A. (1994). Sleep and alertness in a 12-hour rotating shift work environment. Journal of Occupational Medicine, $36,1295$. 
25 Carter, N., Ulfberg, J., Nystrom, B., and Edling, C. (2003). Sleep debt, sleepiness and accidents among males in the general population and male professional drivers. Accident Analysis and Prevention, 35, 613-617.

26 Philip, P., and Akerstedt, T. (2006). Transport and industrial safety, how are they affected by sleepiness and sleep restriction? Sleep Medicine Review, 10, 347-356.

27 Trinkoff, A., Geiger-Brown, J., Brady, B., Lipscomb, J., and Lang, G. (2006). How long and how much are nurses now working? American Journal of Nursing, 106(4), 60-71.

28 Jovanis, P.P., Park, S-W, Gross, F., and Chen, K-Y. (2005). Crash risk and hours driving: Interim report II. University Park, PA: Pennsylvania Transportation Institute.

Hanowski, R.J., Wierwille, W.W., and Dingus, T.A. (2003). An on-road study to investigate fatigue in local/short haul trucking. Accident Analysis \& Prevention, 35(2), 153-160.

30 Henning, R.A., Sauter, S.L., Salvendy, G., and Krieg, E.F. (1989). Microbreak length, performance, and stress in a data entry task. Ergonomics, 32, 855-864.

31 Jett, Q.R., and George, J.M. (2003). Work interrupted: A closer look at the role of interruptions in organizational life. Academy of Management Review, 28(3), 494-507.

32 Society of Automotive Engineers, Inc. (2002). SAE J1587- Electronic data interchange between microcomputer systems in heavy-duty vehicle applications. Warrendale, PA: SAE, Inc.

33 Society of Automotive Engineers, Inc. (1993). SAE J1708- Serial data communications between microcomputer systems in heavy-duty vehicle applications. Warrendale, PA: SAE, Inc.

34 Society of Automotive Engineers, Inc. (2001). SAE HS-1939- Truck and bus control and communications network standards manual. Warrendale, PA: SAE, Inc.

35 Agresti, A. (1996). An introduction to categorical data analysis. Hoboken, NJ: John Wiley \& Sons.

36 Skipper, J.H. and Wierwille, W.W. (1986). Drowsy driver detection using discriminant analysis. Human Factors, 28(5), 527-540.

37 O'Hanlon, J.F. and Kelly, G.R. (1974). A psycho-physiological evaluation of devices for preventing lane drift and run-off-road accidents (Technical Report 1736-F). Goleta, CA: Human Factors Research Inc., Santa Barbara Research Park.

38 O'Hanlon, J.F. and Kelley, G.R. (1977). Comparison of performance and physiological changes between drivers who perform well and poorly during prolonged vehicular operation. In R.R. Mackie (Ed.), Vigilance (pp. 189-202). New York, NY: Plenum Press. 
39 Wylie, C.D., Schultz, T., Miller, J.C., Mitler, M.M., and Mackie, R.R. (1996). Commercial motor vehicle driver fatigue and alertness study: Technical summary (Rep. No. FHWAMC97-001). Washington, DC: Federal Highway Administration, USDOT.

40 Hickman, J.S., Knipling, R.R., Olson, R.L., and Hanowski, R.J. (in press). Commercial vehicle data collection \& countermeasure assessment project. Phase I: Preliminary analysis of data collected in the drowsy driver warning system field operational test-Task 3: Preliminary analysis of partial countermeasure data. Contract No. DTNH22-00-C-07007, Task Order 21. Washington, DC: Federal Motor Carrier Safety Administration, USDOT.

41 Knipling, R. J. (2009). Safety for the long-haul: Large truck crash risk, causation and prevention. Arlington, VA: American Trucking Associations.

42 Hanowski, R.J., Hickman, J., Fumero, M.C., Olson, R.L., and Dingus, T.A. (2007). The sleep of commercial vehicle drivers under the 2003 hours-of-service regulations. Accident Analysis and Prevention, 39(6), 1140-1145.

43 Lord, D., and Mannering, F. (2010). The statistical analysis of crash-frequency data: A review and assessment of methodological alternatives. Transportation Research Part A: Policy and Practice; 44(5):291-305.

44 Qin, X. and Ivan, J.N. (2001). Estimating Pedestrian Exposure Prediction Model in Rural Areas. Transportation Research Record, 1773: 89-96. 